UNIVERSIDADE DE SÃO PAULO FACULDADE DE CIÊNCIAS FARMACÊUTICAS PROGRAMA DE PÓS-GRADUAÇÃO EM FÁRMACO E MEDICAMENTOS ÁREA DE INSUMOS FARMACÊUTICOS

Departamento de Farmácia

\title{
PRÓ-FÁRMACOS DENDRIMÉRICOS POTENCIALMENTE ATIVOS EM MALÁRIA E TUBERCULOSE: SÍNTESE E AVALIAÇÃO DA ATIVIDADE BIOLÓGICA
}

\author{
DIEGO CAMPOS PRIETO \\ Dissertação para obtenção do título de Mestre \\ Orientadora: Profa. Dra. JEANINE GIAROLLA VARGAS
}


UNIVERSIDADE DE SÃO PAULO FACULDADE DE CIÊNCIAS FARMACÊUTICAS PROGRAMA DE PÓS-GRADUAÇÃO EM FÁRMACO E MEDICAMENTOS ÁREA DE INSUMOS FARMACÊUTICOS

Departamento de Farmácia

PRÓ-FÁRMACOS DENDRIMÉRICOS POTENCIALMENTE ATIVOS EM MALÁRIA E TUBERCULOSE: SÍNTESE E AVALIAÇÃO DA ATIVIDADE BIOLÓGICA

\author{
DIEGO CAMPOS PRIETO \\ Versão Original \\ Dissertação para obtenção do título de Mestre \\ Orientadora: Profa. Dra. JEANINE GIAROLLA VARGAS
}

São Paulo

2020 


\section{DIEGO CAMPOS PRIETO}

\section{PRÓ-FÁRMACOS DENDRIMÉRICOS POTENCIALMENTE ATIVOS EM MALÁRIA E TUBERCULOSE: SÍNTESE E AVALIAÇÃO DA ATIVIDADE BIOLÓGICA}

Comissão Julgadora da Dissertação para obtenção do Título de Mestre

\begin{tabular}{c} 
Profa. Dra. Jeanine Giarolla \\
orientadora/presidente \\
\hline 10. examinador \\
\\
20. examinador \\
\hline
\end{tabular}

3o. examinador

São Paulo, de de 2020. 
Ficha Catalográfica elaborada eletronicamente pelo autor, utilizando o programa desenvolvido pela Seção Técnica de Informática do ICMC/USP e adaptado para a Divisão de Biblioteca e Documentação do Conjunto das Químicas da USP

Bibliotecária responsável pela orientação de catalogação da publicação: Marlene Aparecida Vieira - CRB - 8/5562

P949p Prieto, Diego contra malária e tuberculose: Sintese e avaliação da atividade biológica / Diego Prieto. - São Paulo, 2020 .

$134 \mathrm{p}$.

Dissertação (mestrado) - Faculdade de Ciências Farmacêuticas da Universidade de Săo Paulo. Departamento de Farmácia.

orientador: Giarolla, Jeanine

1. Dendrimeros. 2. Doenças Negligneciadas. 3. Malária. 4. Tuberculose. 5. Pró-fármacos. I. T. II. Giarolla, Jeanine, orientador. 
"I wish it need not have happened in my time," said Frodo.

"So do I," said Gandalf, "and so do all who live to see such times. But that is not for them to decide. All we have to decide is what to do with the time that is given us." J.R.R. Tolkien The Fellowship of The Ring

Aos colegas cientistas e a todos que, por mais obscuros que sejam os tempos, tentam levar a luz do conhecimento. 


\section{AGRADECIMENTOS}

Agradeço, primeiramente, aos que vieram antes. Conhecimento não é pontual, é uma construção, logo esse trabalho só foi possível devido a conhecimentos criados e sedimentados por mulheres e homens que dedicaram a sua vida a ciência.

Agradeço também a minha família: Meus pais, Rosana e Carlos por todo o apoio e dedicação a minha educação e a minha formação como homem e cidadão. As minhas avós que me ensinam que conhecimento não vem só da academia. $A$ minha madrasta Mirla pelos debates, ao meu padrasto Danilo pelas longas conversas sobre qualquer (qualquer mesmo) assunto. Aos meus tios, Angélica e Betinho e aos meus primos Victor, Vini e Laís. E ao meu irmão Gubs, por me ensinar que carinho e afeto independem de frases.

Á Natassja, a pessoa mais responsável e atenciosa que eu conheço. Obrigado pela companhia em todos os momentos, das viagens mais incríveis ao momentos de ansidedade. E por acreditar em mim, mesmo quando eu não acredito.

Á Professora Jeanine, como exemplo de orientadora, por me deixar criar, ter ideias e principalmente por apoiá-las e incentivá-las. Tenho muita sorte de ser seu orientado. Á professora Beth, pelo imenso conhecimento e por todos os ensinamentos.

Aos colegas de LAPEN recentes e passados: Rodrigo, João, Bruna, Soraya, Luccas, Fi, Lucas, Débora, Charles, Gabriel, Mônica, Ricardo, Marina e tantos outros que estão e que passaram por lá e dividiram não só o espaço, mas seus conhecimentos, vivências e compartilharam a angústia da vida de pósgraduação.

Aos colegas de outros laboratórios, começando pelo Professor Roberto Parise, meu primeiro orientador de IC e que teve uma contriuição enorme por ajudar a despertar em mim o amor pela ciência. A Rose com quem eu trabalhei na minha primeira IC, a Thais, Maurício, Fernando, Alfredo, Gustavo e vários outros.

To all the colleagues in the University of Groningen, starting with Professor Matthew Groves for receiving me so kindly on his lab. To Rick Oerlemans, not only for the friendship, but also for teaching of his incredible knowledge about most everything. I also would like to thank Juliana, Fernando, Maiara, Kai and Fabiola for receiving me and making me feel at home in Groningen.

Aos professores que de alguma forma contribuíram com esse projeto: Professor Scott Grayson pelos dendrímeros, Professor Jonas Gruber pelas dicas e contatos na central analítica.

Aos alunos de IC que estiveram comigo ajudando a fazer desse trabalho o mais completo possível: Helena, Sophia, Célia, José Carlos e Sara. Um agradecimento especial ao Renan (Guaru) pelos conhecimentos, discussões e compartilhamento de memes. 
Ao Farma Roots, meus amigos queridos desde os tempos de graduação: Laila, Thamy, Nina, Zé, Raul, Dragunas, Chinelo e Erika pelos anos de amizade, bares do Tutu, cervejas, churrascos, festas e viagens. Agradecer por aguentarem a minha chatice nesses últimos 9 anos.

Em especial, gostaria de agradecer ao Nuno, um também farma roots, mas que esteve ao meu lado durante a pós. Obrigado de coração pelas conversas, desabafos, idéias mirabolantes de síntese, por colocar fogo nas coisas e fazer desses dois anos e meio de mestrado MUITO mais divertidos.

Aos amigos da Farmatuque, do Pharmaceltics, a Thaina, o Witor, o Arthur, e aos amigos de longa data de Escola da Vila: Mari, Isa, Fê, Eric e outros.

Aos funcionários Kelma, David, Alexandre. E a Dora pelo seu papel fundamental em manter a produtividade do departamento com o seus cafés.

Por último, gostaria de agradecer a CNPq pela bolsa de mestrado e a Erasmus pela bolsa de intercâmbio. 


\section{RESUMO}

PRIETO, D.C. Pró-fármacos dendriméricos potencialmente ativos em malária e tuberculose: síntese e avaliação da atividade biológica. 2020. 134p. Tese (Mestrado) Faculdade de ciências farmacêuticas, Universidade de São Paulo, São Paulo, 2020.

HIV/AIDS, tuberculose, malária e as doenças tropicais negligenciadas representam uma grande preocupação em Saúde em muitas regiões do mundo. Os fármacos disponíveis para o tratamento apresentam diversos problemas, tais como toxicidade e resistência ao parasita. Mesmo com esse triste panorama, o investimento em pesquisa nessa área é, ainda, pouco significativo. Assim, dentre os métodos de modificação molecular para melhorar propriedades farmacêuticas, farmacocinéticas e/ou farmacodinâmica de compostos bioativos destaca-se a latenciação. Já os dendrímeros vêm despertando interesse em aplicações biológicas, principalmente como transportadores de fármacos, além de atuarem como transportadores de genes, imagem em diagnóstico e compostos com ação per se. Face ao exposto e tendo em vista o caráter promissor dos dendrímeros como sistemas de drug delivery, o objetivo deste trabalho foi a síntese de pró-fármacos dendriméricos potencialmente ativos em malária e tuberculose. Os dendrímeros de Bis-MPA (gerações 0,1 e 2) foram sintetizados pelo grupo do Professor Scott Grayson, da Tulane University (EUA). No Brasil, foram feitas as funcionalizações destes compostos, através do acoplamento do ácido succínico (que funciona como espaçante) e as moléculas ativas. Selecionaram-se as seguintes substâncias: (1) primaquina, com ação antimalárica e (2) isoniazida, de ação nos primeiros estágios da tuberculose. Foram sintetizados os pró-fármacos dendriméricos de isoniazida nas gerações 0 e 1 (G0-Iso e G1-Iso), e primaquina nas gerações 0, 1 e 2 (G0-Pq, G1-Pq e G2Pq). Importante mencionar que os resultados de Ressonância Magnética e Nuclear de ${ }^{1} \mathrm{H}$ e de ${ }^{13} \mathrm{C}$ demostraram as obtenções dos respectivos produtos, porém contendo impurezas. Já a análise do resultado proveniente da espectrometria de massas do composto G0-Iso revelou a presença de um subproduto ciclizado da isonizaida succinoilada (Clso-Suc), o qual pode ser um potencial pró-fármaco ou apresentar atividade per se. Como não se conhece este composto, o laboratório coordenado pela Profas Elizabeth Igne Ferreira e Jeanine Giarolla manifestou interesse em pesquisa-lo, principalmente quanto suas propriedades físico- químicas, bem como quanto à atividade biológica. 
Assim, utilizando metodologia analítica previamente estabelecida para o G0-Iso, os estudos de estabilidade química da Clso-Suc, em diferentes valores de $\mathrm{pH}$, demonstraram a capacidade da forma ciclizada em se converter no protótipo IsoSuc, majoritariamente em pH 7,4 e 8,5. Como perspectivas, destaca-se a avaliação da estabilidade enzimática deste potencial derivado. Ressalta-se, ainda, a a avaliação da respectiva atividade antimicobacteriana. Em relação aos pró-fármacos, as necessidades de aprimoramentos das sínteses são, também, evidenciadas. Uma vez sintetizados e caracterizados, estes últimos derivados serão avaliados quanto à atividade biológica. Ademais, estudos computacionais, sobretudo simulações de docking molecular, foram desenvolvidos com intuito de se entender o modo de interação de alguns compostos com alvos biológicos prédeterminados.

Palavras-chave: pró-fármacos, dendrímeros de Bis-MPA, malária, tuberculose. 


\section{ABSTRACT}

PRIETO, D.C. Dendrimeric prodrugs potentially active in malaria and tuberculosis: Synthesis and evaluation of biological activity. 2020. 134p. Tese (Mestrado) Faculdade de ciências farmacêuticas, Universidade de São Paulo, São Paulo, 2020.

HIV/AIDS, tuberculosis, malaria and neglected diseases are a major health concern in many regions of the world. The drugs available present various problems, such as toxicity and parasite resistance. Even with this sad outlook, research investment in this area is still insignificant. Among the molecular modification methods to improve the pharmaceutical, pharmacokinetic and/or pharmacodynamic properties we stands out prodrug design. On the other hand, dendrimers are arousing interest in biological applications, mainly as drug carriers, besides gene delivery, diagnostic imaging, as well as acting as compounds with activity per se. Considering that, added to the promising dendrimer drug delivery features, the aim of this study was to synthesize potentially active dendrimer prodrugs in malaria and tuberculosis. Bis-MPA dendrimers (generations 0, 1 and 2) were synthesized by the group of Professor Scott Grayson of Tulane University (USA). Herein in Brazil, the compounds were functionalized by coupling succinic acid (spacer group), as well as the active molecules. We selected the following substances: (1) primaquine, with antimalarial action and (2) isoniazid, acting in the early stages of tuberculosis. Isoniazid dendrimer prodrugs were synthesized generations 0 and 1 (G0-Iso and G1-Iso), and primaquine in generations 0, 1 and 2 (G0-Pq, G1-Pq and G2-Pq). It is important to mention that the results related to Nuclear and Magnetic Resonance ${ }^{1} \mathrm{H}$ and ${ }^{13} \mathrm{C}$ showed chemical structures features, however with impurities. Analysis of the mass spectrometry regarding G0-Iso has revealed the presence of a cyclized by-product of succinylated isonized (Clso-Suc), which may be a potential prodrug or may presentactivity itself. Using the analytical methodology performed for G0-Iso, ICso-Suc demonstrated its ability to convert the Iso-Suc prototype at different $\mathrm{pH}$ values, especially at $\mathrm{pH} 7.4$ and 8.5. As perspectives, we highlight the determinations of the chemical stability of ICsoSuc at $\mathrm{pH} 1.5$ and 6.0, as well as the evaluation of the enzymatic stability. We will also investigate the respective antimicobacterial activities. Regarding prodrugs, the needs for synthesis enhancements are also necessary. Once synthesized and characterized, these latter derivatives will be evaluated for biological activity. Moreover, computational studies, especially molecular docking simulations, were developed in order to understand the mode of interaction of some compounds with predetermined biological targets. 
Key-words: Prodrug design, Bis-MPA dendrimers, malaria, tuberculosis. 


\section{SUMÁRIO GERAL}

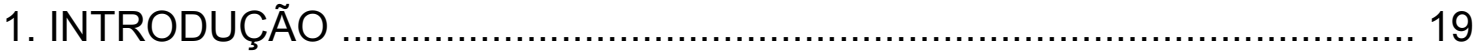

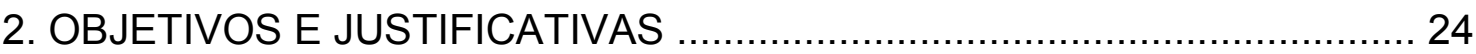

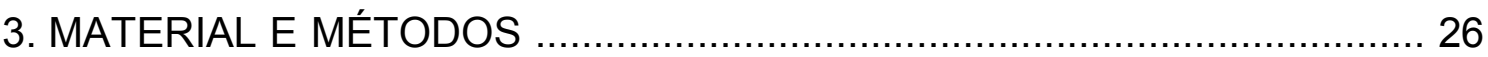

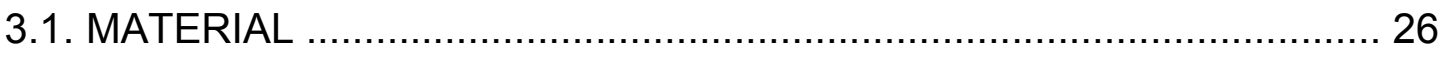

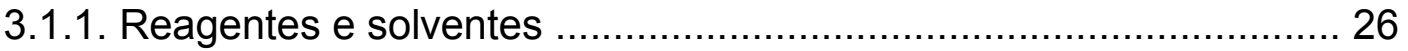

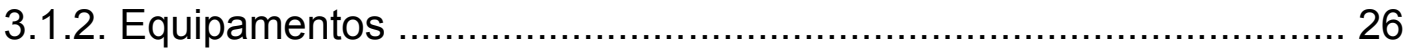

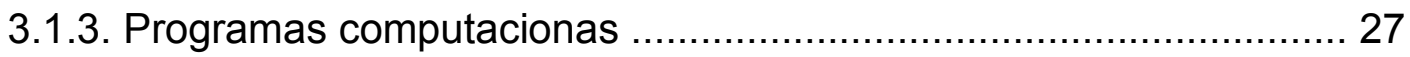

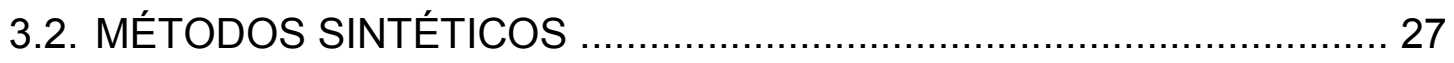

3.2.1. Síntese do pró-fármaco succinoilado de isoniazida (Iso-Suc) ....... 27

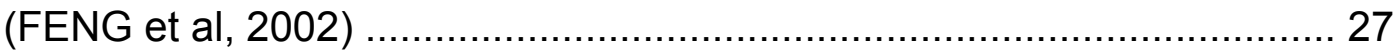

3.2.2. Síntese do pró-fármaco succinoilado de primaquina (Pq-Suc) ...... 27

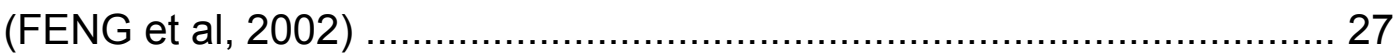

3.2.3. Formação de cloreto de ácido de isoniazida in situ e posterior reação com dendrímero geração 0 (G0-Iso) (CHAUDHARI, AKAMANCHI, 28 28

3.2.4. Síntese do pró-fármaco dendrimérico de G0 contendo isoniazida 29 (G0-Iso) (MOONEY et al, 2010) 29

3.2.5. Síntese do pró-fármaco dendrimérico de $\mathrm{G} 0$ contendo primaquina 29

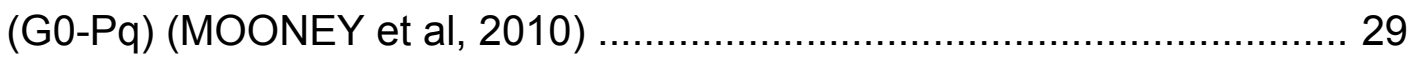

3.2.6. Síntese do pró-fármaco dendrimérico de $\mathrm{G} 1$ contendo isoniazida 30

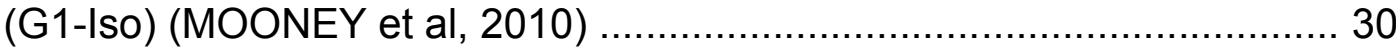

3.2.7. Síntese do pró-fármaco dendrimérico de $\mathrm{G} 1$ contendo primaquina 31

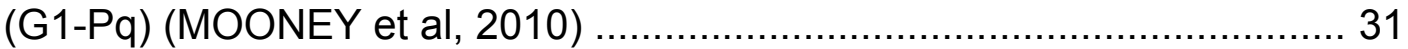

3.2.8. Síntese do pró-fármaco Clso-Suc................................................ 32

3.3. ESTUDOS DE ESTABILIDADE QUÍMICA DE Clso-Suc (NAJLAH et al,

3.3.1. Desenvolvimento do método analítico 33 
3.3.2. Estudo de estabilidade química 33

3.4. Estudos in silico

3.4.1. Simulações de docking molecular entre os pró-fármacos dendriméricos e esterase inespecífica

35 3.4.2. Simulações de docking molecular entre a Clso-Suc e a catalase- .37 peroxidase

4. RESULTADOS E DISCUSSÃO 38

4.1. METODOLOGIA SINTÉTICA 38

4.1.1. Sintese dos derivados succinoilados de isoniazida e de primaquina 38

(Iso-Suc e Iso-Pq) 38

4.1.2. Síntese dos pró-fármacos dendriméricos de geração 0 (G0-Iso e G0$\mathrm{Pq})$ 43

4.1.3. Síntese dos pró-fármacos dendriméricos de geração 1 (G1-Iso e G1$\mathrm{Pq})$ 59

4.2. ESTUDOS IN SILICO 66

4.2.1. Simulações de docking molecular entre os pró-fármacos 66 dendriméricos e esterase inespecífica 66

4.2.2. Re-docking no programa GOLD (Verdonk et al, 2003) 67

4.2.3. Resultados de docking no programa GOLD (Verdonk et al, 2003)69 69

4.2.4. G0-Iso 71

4.2.5. G1-Iso 73

4.2.6. $\mathrm{G} 0-\mathrm{Pq}$ 75

4.2.7. $\mathrm{G} 1-\mathrm{Pq}$ 76

4.2.8. Resultados AutoDock (Trott et al., 2010) 78

4.2.9. Simulações de docking molecular entre a Clso-Suc e a catalase- .79 peroxidase

4.3. ESTUDOS DE ESTABILIDADE QUÍMICA DA Clso-Suc (NAJLAH et al, 2006) 
4.3.1. Desenvolvimento do método analítico

4.3.2. Estudos de estabilidade química

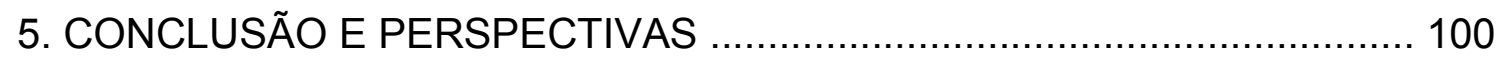

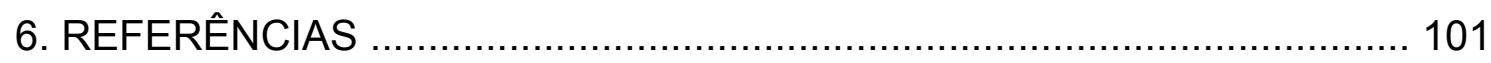

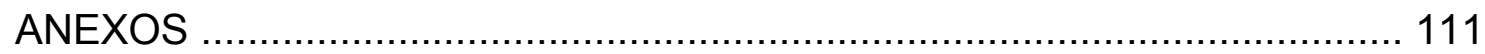

\section{SUMÁRIO DE FIGURAS}

Figura 1. Incidência global de tuberculose para cada 100 mil habitantes em 2018 (WHO, 2019).

Figura 2. Incidência global de malária em 2017 (WHO, 2018).

Figura 3. Principais métodos de síntese dos dendrímeros: convergente e divergente (traduzido de SATIJA et al., 2011).

Figura 4. Pró-fármaco dendrimérico potencialmente ativo em tuberculose contendo isoniazida. Fez-se esta representação esquemática com o dendrímero de geração 0 .

Figura 5. Representação esquemática do Clso-Suc. ................................ 25

Figura 6. Síntese da Iso-suc. ........................................................ 26

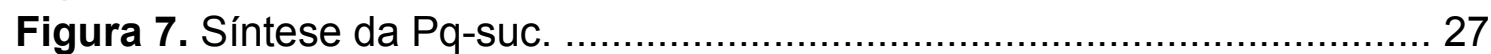

Figura 8. Esquema 1. Formação do cloreto de ácido de Iso-Suc. Esquema 2. reação de acoplamento do derivado cloreto de ácido da Iso-Suc com o G0. .. 27 Figura 9. Síntese do pró-fármaco dendrimérico de isoniazida geração 0 (G0-

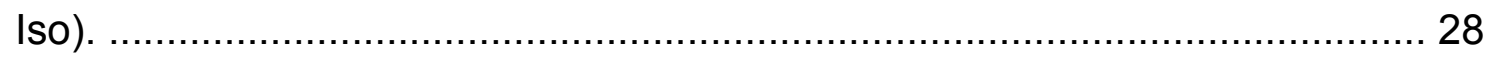

Figura 10. Síntese do pró-fármaco dendrimérico de primaquina geração 0 (G0$\mathrm{Pq}$ ).

Figura 11. Síntese do pró-fármaco dendrimérico de isoniazida geração 1 (G1-

Iso).

Figura 12. Síntese do pró-fármaco dendrimérico de primaquina geração 1 (G1$\mathrm{Pq})$. 31

Figura 13. Síntese do pró-fármaco ciclizado de isoniazida (Clso-Suc). .......... 31

Figura 14. Mecanismo de reação das reações com o agente condensante DCC (NEISES et al, 1979).

Figura 15. Mecanismo de reação de formação de cloreto de ácido utilizando cloreto de oxalila (CHAUDHARI, AKAMANCHI, 1999)

45 Figura 16. Esquema simplificado da transformação de EDC em EDU nas reações de esterificação.

Figura 17. LC-MS de G0-Iso impuro. Condições de análise: Condições de análise no LC: solvente A (0,1\% Ácido Fórmico/Tampão fosfato pH 6,9, v/v); solvente B (Metanol). Proporção de solvente $95 \%$ de A e $5 \%$ de B. Gradiente de fluxo de 0,6 a 1,3 mL/min por 10 minutos. Condições de análise no MS: voltagem no capilar ( $4500 \mathrm{~V}$ ) e temperatura $\left(325^{\circ} \mathrm{C}\right), 20$ 口de amostra. 53 Figura 18. Composto do pico majoritário do LC-MS .Condições de análise: Condições de análise no LC: solvente A (0,1\% Ácido Fórmico/Tampão fosfato $\mathrm{pH} 6,9, \mathrm{v} / \mathrm{v}$ ); solvente B (Metanol). Proporção de solvente 95\% de A e 5\% de B. 
Gradiente de fluxo de 0,6 a 1,3 mL/min por 10 minutos. Condições de análise no MS: voltagem no capilar (4500 V) e temperatura $\left(325^{\circ} \mathrm{C}\right), 20 \mathrm{~L}$ de amostra.

Figura 19. Estruturas químicas e algumas das propriedades da Clso-Suc de 6 e 5 membros.

Figura 20. LogP da Clso-Suc de 6 membros (esqueda) e 5 membros (direita).

Figura 21. Mecanismo proposto de formação da Clso-Suc. ........................... 55

Figura 22. Dendrímero de Bis-MPA de geração 1................................... 59

Figura 23. Pró-fármacos dendriméricos potencialmente ativos em malária ou tuberculose. Representaram-se as gerações 0 (esquema 1) e 1 (esquema 2). Destacaram-se nos quadrados: a) isoniazida succinoilada e b) primaquina succinoilada. As carbonilas de interesse estão realçadas em vermelho e verde na figura. 66

Figura 24. Confôrmero 4 do re-docking do ligante na enzima $2 \mathrm{H} 7 \mathrm{C}$. 67

Figura 25. Mecanismo geral da catálise da serinoprotease (HEDSTROM, 2002).

Figura 26. Confôrmeros 24 (esquerda) e 10 (direita) resultantes das simulações de docking da G0-Iso na enzima 2H7C. As distâncias entre a

Serina 221 e as carbonilas C2 estão destacadas em vermelho.

71 Figura 27. Confôrmero 17 resultante das simulações de docking da G1-Iso na enzima 2H7C.A distância entre a Serina 221 e C1 está destacada em vermelho.

Figura 28. Confôrmeros 7 (esquerda) e 2 resultantes das simulações de docking da G1-Iso na enzima 2H7C. As distâncias entre a Serina 221 e C1 estão destacadas em vermelho. 73

Figura 29. Dock (número 2) da isoniazida na enzima PDB 1SJ2. ................. 82

Figura 31. Dock (número 17) da Iso_Cic5 na enzima 1SJ2. .......................... 83

Figura 30. Dock (número 17) da Iso_Cic6 na enzima 1SJ2. ....................... 83

Figura 32. Gráfico da variação da área do pró-fármaco ao longo de 24 horas em solução tampão pH 1,2.

Figura 33. Gráfico da variação da área do pró-fármaco ao longo de 24 horas em solução tampão pH 6,0.

Figura 34. Gráfico da variação da área do pró-fármaco ao longo de 24 horas em solução tampão pH 7,4. 95

Figura 35. Gráfico da variação da área do pró-fármaco ao longo de 24 horas em solução tampão $\mathrm{pH} 8,5$. 96

Figura 36. Estruturas da Clso-Suc (esquerda) e Iso-Suc (direita). 99

\section{SUMÁRIO DE TABELAS}

Tabela 1. Metodologia farmacopeica e System Suitability para análise 
cromatográfica de isoniazida

Tabela 2. Parâmetros analíticos para o ensaio de liberação ............................ 33

Tabela 3. Relação entre o número da amostra e o tempo de coleta. ............... 34

Tabela 5. Resultados obtidos no re-docking realizados programa GOLD

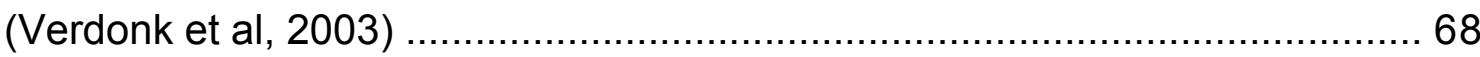

Tabela 6. Melhor pose obtida no re-docking com o programa GOLD e confirmação do RMSd

Tabela 7. Resultados dos 30 confôrmeros obtidos pelo docking da G0-Iso, G1Iso, G0-Pq e G1-Pq no programa GOLD (Verdonk et al, 2003). ................... 70

Tabela 8. Melhores resultados de docking da G0-Iso na enzima 2H7C. C1 e C2 estão destacadas em vermelho na estrutura. 71

Tabela 9. Resultados obtidos pelo docking da G1-Iso no programa GOLD (Verdonk et al, 2003). As carbonilas C1 e C2 estão destacadas em vermelho.73 Tabela 10. Resultados obtidos pelo docking da G0-primaquina no programa GOLD (Verdonk et al, 2003)

Tabela 11. Resultados obtidos pelo docking da G1-Pq no programa GOLD (Verdonk et al, 2003)

Tabela 12. Resultados das simulações de docking resultantes do programa AutoDock (Trott et al., 2010).

Tabela 13. Resultados obtidos no programa Gold (Verdonk et al, 2003) para as funções de scores ChemScore e ASP e as distâncias médias (em $\AA$ ) entre os ligantes e o ferro do grupo heme.

Tabela 14. Distância média das estruturas em relação ao ferro do grupo heme $(\mathrm{em} \AA)$. 78

Tabela 15. Principais aminoácidos envolvidos nas interação de Iso_Cic5 e Iso_Cic6 com o alvo molecular, comparados com a isoniazida. 80 Tabela 16. Comparação entre quantidade de interações das estruturas com os aminoácidos.

Tabela 17. Colunas cromatográficas testadas.

Tabela 18. Determinação da proporção entre os solventes tampão fosfato e metanol.

Tabela 19. Gradiente de fluxo escolhido.

Tabela 20. Comparação entre o fluxo constante e o gradiente de fluxo.

Tabela 21. Média das áreas de Clso-suc e Iso-suc ao longo do ensaio em solução tampão pH 1,2.

Tabela 22. Média das áreas de Clso-suc e Iso-suc ao longo do ensaio em solução tampão pH 6,0.

Tabela 23. Média das áreas de Clso-suc e Iso-Suc ao longo do ensaio em pH

7,4 .

Tabela 24. Média das áreas de Clso-suc e Iso-Suc ao longo do ensaio em pH 8,5 . 


\section{SUMÁRIO DE ESPECTROS}

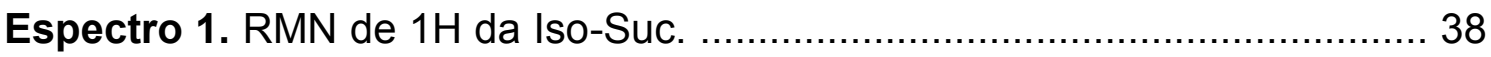

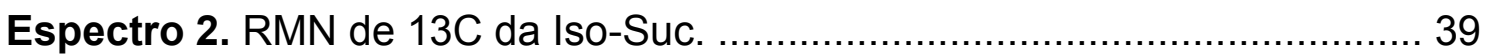

Espectro 3. Espectro no IV $(\lambda, \mathrm{KBr}, \mathrm{cm}-1)$ da Iso-Suc. …............................. 40

Espectro 4. RMN de 1H do produto Pq-Suc............................................... 41

Espectro 5. RMN de 13C do produto Pq-Suc. .......................................... 42

Espectro 6. RMN de $1 \mathrm{H}$ do produto G0-Pq. Observam-se os sinais característicos do DCU na região entre 1-1,5 ppm. ..................................... 44

Espectro 7. Espectro de RMN de 1H do produto G0-Pq. ............................ 47

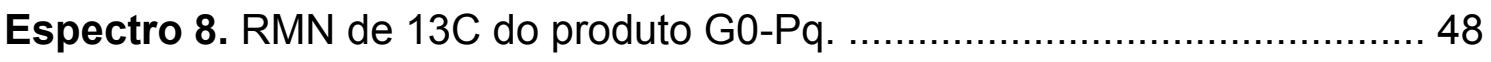

Espectro 9. Espectro no infravermelho do produto G0-Pq. .......................... 49

Espectro 10. RMN de 1H do produto G0-Iso............................................... 50

Espectro 11. RMN de 13C do produto G0-Iso. .......................................... 51

Espectro 12. Espectro no infravermelho do produto G0-Iso.......................... 52

Espectro 13. Espectro de 1H RMN do produto Clso-Suc .............................. 57

Espectro 14. Espetro de 13C RMN do produto Clso-Suc. ............................. 58

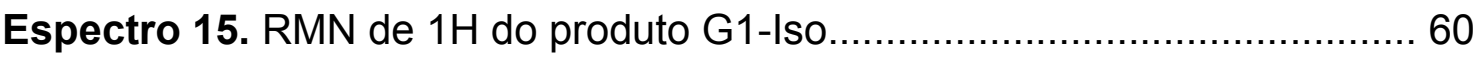

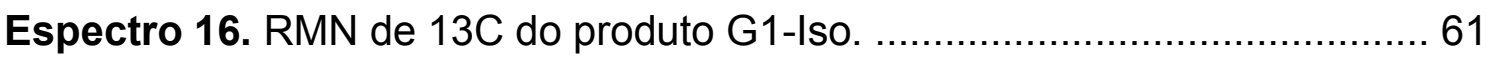

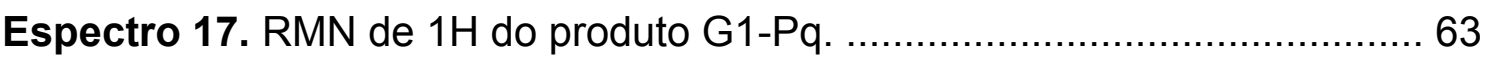

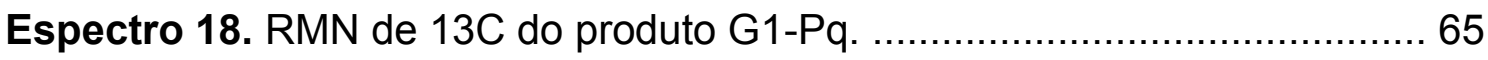

\section{SUMÁRIO DE CROMATOGRAMAS}

Cromatograma 1. Cromatograma resultante do estudo de estabilidade em $\mathrm{pH}$ 1,2 (T0). Condições cromatográficas: Solvente A ( $0,1 \%$ TFA/Tampão fosfato $\mathrm{pH}$ $6,9, \mathrm{v} / \mathrm{v})$; solvente B (Metanol). Proporção de solvente $95 \%$ de A e $5 \%$ de B. Gradiente de fluxo de 0,6 a $1,3 \mathrm{~mL} / \mathrm{min}$ por 10 minutos. Comprimento de onda: $261 \mathrm{~nm}$.

Cromatograma 3. Cromatograma resultante do estudo de estabilidade em $\mathrm{pH}$ 6,0 (T0). Condições cromatográficas: Solvente A ( $0,1 \%$ TFA/Tampão fosfato $\mathrm{pH}$ $6,9, \mathrm{v} / \mathrm{v})$; solvente B (Metanol). Proporção de solvente $95 \%$ de A e $5 \%$ de B. Gradiente de fluxo de 0,6 a $1,3 \mathrm{~mL} / \mathrm{min}$ por 10 minutos. Comprimento de onda: $261 \mathrm{~nm}$.

Cromatograma 2. Cromatograma resultante do estudo de estabilidade em $\mathrm{pH}$ 1,2 (T13). Condições cromatográficas: Solvente A (0,1\% TFA/Tampão fosfato $\mathrm{pH} 6,9, \mathrm{v} / \mathrm{v}$ ); solvente B (Metanol). Proporção de solvente $95 \%$ de A e $5 \%$ de B. Gradiente de fluxo de 0,6 a $1,3 \mathrm{~mL} / \mathrm{min}$ por 10 minutos. Comprimento de onda: $261 \mathrm{~nm}$.

Cromatograma 4. Cromatograma resultante do estudo de estabilidade em $\mathrm{pH}$ 6,0 (T13). Condições cromatográficas: Solvente A (0,1\% TFA/Tampão fosfato $\mathrm{pH} 6,9, \mathrm{v} / \mathrm{v}$ ); solvente B (Metanol). Proporção de solvente $95 \%$ de A e $5 \%$ de B. Gradiente de fluxo de 0,6 a $1,3 \mathrm{~mL} / \mathrm{min}$ por 10 minutos. Comprimento de onda: $261 \mathrm{~nm}$.

Cromatograma 5. Cromatograma resultante do estudo de estabilidade em $\mathrm{pH}$ 
7,4 (T0). Condições cromatográficas: Solvente A (0,1\% TFA/Tampão fosfato $\mathrm{pH}$ $6,9, \mathrm{v} / \mathrm{v})$; solvente B (Metanol). Proporção de solvente $95 \%$ de A e $5 \%$ de B. Gradiente de fluxo de 0,6 a 1,3 mL/min por 10 minutos. Comprimento de onda: $261 \mathrm{~nm}$. 97

Cromatograma 7. Cromatograma resultante do estudo de estabilidade em $\mathrm{pH}$ 8,5 (T0). Condições cromatográficas: Solvente A (0,1\% TFA/Tampão fosfato $\mathrm{pH}$ $6,9, \mathrm{v} / \mathrm{v})$; solvente B (Metanol). Proporção de solvente $95 \%$ de A e $5 \%$ de B. Gradiente de fluxo de 0,6 a 1,3 mL/min por 10 minutos. Comprimento de onda: $261 \mathrm{~nm}$. 98

Cromatograma 6. Cromatograma resultante do estudo de estabilidade em $\mathrm{pH}$ 7,4 (T13). Condições cromatográficas: Solvente A (0,1\% TFA/Tampão fosfato $\mathrm{pH}$ $6,9, \mathrm{v} / \mathrm{v})$; solvente B (Metanol). Proporção de solvente $95 \%$ de A e $5 \%$ de B. Gradiente de fluxo de 0,6 a 1,3 mL/min por 10 minutos. Comprimento de onda: $261 \mathrm{~nm}$. 97

Cromatograma 8. Cromatograma resultante do estudo de estabilidade em $\mathrm{pH}$ 8,5 (T13). Condições cromatográficas: Solvente A (0,1\% TFA/Tampão fosfato pH 6,9, v/v); solvente B (Metanol). Proporção de solvente $95 \%$ de A e $5 \%$ de B. Gradiente de fluxo de 0,6 a 1,3 mL/min por 10 minutos. Comprimento de onda: $261 \mathrm{~nm}$. 98 


\section{INTRODUÇÃO}

Malária, HIVIAIDS e tuberculose fazem parte do grupo conhecido como "três grandes" doenças por causarem efeitos devastadores em países pobres, especialmente na África. Juntas foram responsáveis por mais de cinco milhões de mortes em 2007, o equivalente a $39 \%$ das mortes por doenças infecciosas (KEALEY, SMITH, 2010). Apesar de terem números de mortalidades extremamente elevados, as "três grandes" não são consideradas negligenciadas. Estas infecções contam com fundos humanitários de doação de investimentos, captando a maioria do aporte financeiro em pesquisas (MORAN et al., 2009; GREENALL et al., 2017). Assim, possuem maiores incentivos monetários em relação às outras classificadas como negligenciadas, por exemplo, a esquistossomose e a doença de Chagas (MORAN et al., 2009).

Segundo dados dos relatórios anuais da Organização Mundial da Saúde (OMS) a prevalência de tuberculose em 2018 foi entre 9,9 e 11,1 milhões de pessoas no mundo, com uma incidência média de 132/100 mil habitantes. Apesar de ter casos relatados na Europa e na América do Norte, a maioria foi reportada no sudeste asiático (44\%) e África (24\%), aproximando, epidemiologicamente, a tuberculose das doenças negligenciadas. A Figura 1 ilustra a incidência global de tuberculose no ano de 2018. No mesmo ano, a OMS registrou uma mortalidade estimada de 1,2 milhões de pessoas por tuberculose em pacientes HIV-negativo (intervalo entre 1,1 e 1,3 milhões). Desse número de mortes, 82\% aconteceram nas mesmas regiões onde a incidência é maior, ou seja, o sudeste asiático e a África (WHO, 2019), locais que, também, concentram as maires taxas de tuberculose entre pacientes HIV-positivo. 


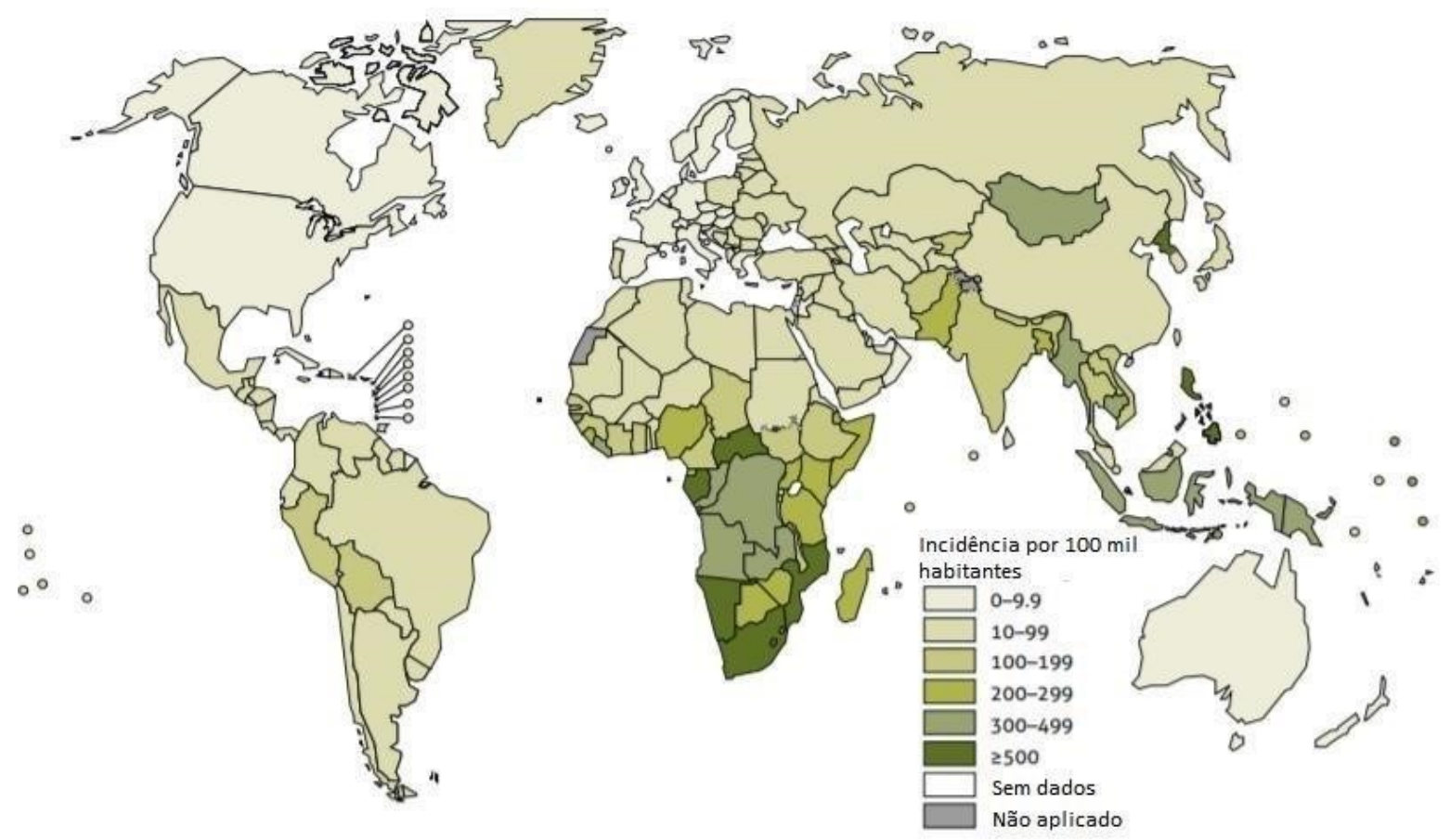

Figura 1. Incidência global de tuberculose para cada 100 mil habitantes em 2018 (WHO, 2019).

Já para a malária, foi registrado uma incidência de 219 milhões de casos em 2017, com mortalidade de 435 mil pessoas (WHO, 2017). As regiões endêmicas incluem parte da América do Sul, da América Central, grande parte da África, da Ásia e da Oceania (WHO, 2017). Como mostra a Figura 2, a doença acomete, principalmente, regiões tropicais, onde o vetor, o mosquito Anopheles, é mais frequentemente encontrado.

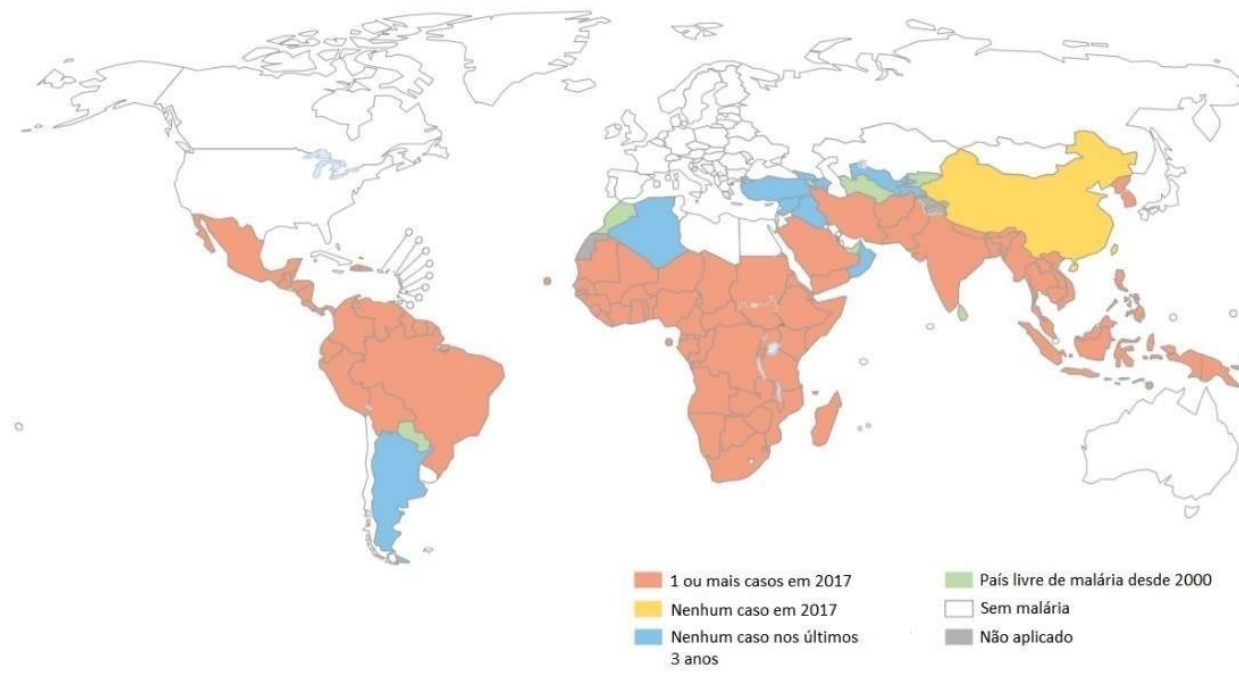

Figura 2. Incidência global de malária em 2017 (WHO, 2018). 
Os poucos compostos disponíveis da terapêutica para estas infecções apresentam problemas farmacocinéticos, são tóxicos, pouco atrativos para a aderência pelo paciente e existem relatos de resistência (RENSLO; MCKERROW, 2006; ABDULLA et al., 2009; CROFT, 2016).

O desenvolvimento de novos fármacos, por sua vez, é um processo extremamente complexo e caro. A busca de um líder, ou seja, uma molécula com potencialidade para se tornar um fármaco, é demorada. Primeiramente, é necessário determinar o tipo de estratégia de planejamento a ser utilizada, a baseada no alvo, chamada de Structure Based Drug Design (SBDD), ou no ligante Ligand Based Drug Design (LBDD) (GUIDO; ANDRICOPULO; OLIVA, 2010). Aproximadamente $70 \%$ de compostos líderes falham nas primeiras etapas de ensaios pré-clínicos, devido, principalmente, a toxicidade e problemas farmacocinéticos (FAKUNLE; LORING, 2012). Neste sentido, métodos de modificações moleculares podem úteis. Dentre estes métodos, destaca-se a latenciação, que foi proposta por Harpper em 1959 (CHUNG et al., 2005). Neste processo, a molécula é transformada em sua forma inativa de transporte, denominada pró-fármaco que, in vivo, é biotransformada em sua forma ativa. Simplificadamente, os pró-fármacos podem ser divididos em duas classes, os que estão ligados a transportadores e os bioprecursores. Na primeira classificação, a síntese pode ser feita reagindo o composto ativo com um transportador, através de uma ligação lábil. $O$ ideal é que os experimentos sejam fáceis e baratos. Éster é o grupo funcional mais utilizado na obtenção de prófármacos, por ser facilmente hidrolisado por esterases plasmáticas. Dentre as características importantes do transportador têm-se: não ser imunogênico, deve ser estável e, quando desligado da forma ativa, não deve gerar metabólitos tóxicos. Já os bioprecursores necessitam ser metabolizados para terem ação biológica (CHUNG et al, 2005; SILVA et al., 2005; ZAWILSKA, WOJCIESZAK, OLEJNICZAK, 2013, HAMADA, 2017).

Como mecionado anteriormente, para que o fármaco/compostos ativo tenha ação é necessário que haja a liberação do transportador. Assim, a predição deste comportamento farmacocinético é de suma importância no desenvolvimento pré-clínico da forma latente. A hidrólise ácida ou básica, a qual pode acontecer durante o trânsito no trato gastro-intestinal, pode ser responsável pela desmontagem do pró-fármaco. Já a liberação do componente ativo por ação 
enzimática pode ocorrer pela ação de esterases e fosfatases plasmáticas. Assim, em estudos de estabilidades químicas, é importante que se escolha $\mathrm{opH}$ apropriado, o qual simula a condição fisiológica (RAUTIO et al, 2008).

O planejamento de pró-fármacos almeja três objetivos principais, os quais estão relacionados: (1) na fase farmacêutica, a forma latente pode melhorar solubilidade, estabilidade química, propriedades organolépticas, entre outras; (2) na fase farmacocinética, pode interferir, por exemplo, na absorção, meia-vida e metabolismo de primeira passagem e (3) na fase farmacodinâmica o pró-fármaco pode aprimorar, de modo indireto, a interação do composto ativo com o alvo molecular (MORI et al., 2017).

Na última década, os dendrímeros vêm despertando interesse em diversas aplicações biológicas, por exemplo, como transportadores de fármacos, transportadores de genes, imagem em diagnóstico e compostos com ação por se (DIAS, A.P et al, 2020; ARAUJO, R.V et al, 2018). Segundo definição de Cheng e colaboradores (2008), dendrimeros são macromoléculas artificiais parecidas com árvores, com muitas ramificações, tamanho nanoscópico, as quais ocupam o mesmo espaço nas três dimensões, já que são sintetizadas a partir do mesmo monômero (TOMALIA et al., 1985; CHENG et al., 2008). A estrutura da molécula é dividida em três regiões distintas: um foco central, camada de ligações repetidas partindo do centro e grupos funcionais na camada externa das unidades repetidas (GRAYSON, FRÉCHET, 2001). A cada adição de monômero, o dendrímero aumenta uma geração e esse crescimento pode acontecer de 2 até 32 gerações. É possível se ter precisão de algumas de suas propriedades, tais como tamanho, densidade, polaridade e flexibilidade. Além disso, podem possuir uma cavidade interna, que possibilita o encapsulamento de fármacos hidrofóbicos (KESHARWANI; JAIN; JAIN, 2014).

O tamanho definido e a uniformidade estrutural garantem, de um modo geral, que estes compostos tenham a habilidade de atravessar membranas biológicas, escapando do metabolismo. Ao mesmo tempo, em drug delivery, são considerados transportadores relativamente seguros, com baixa citotoxicidade, a qual está relacionada com os grupos terminais. O dendrímero de poliamidoamina (PAMAM), por exemplo, por ter superfície carregada positivamente, pode provocar lise celular com dose dependente. Por outro lado, compostos neutros tem esse efeito menos pronunciado. O mascaramento das 
aminas terminais com PEG, acetilações, carboidratos, aminoácidos, podem, portanto, reduzir este efeito indesejável (SADEKAR et al., 2013). Importante mencionar que a adição de grupos espaçantes, como por exemplo ácido succínico e ácido maleico, podem ser úteis no planejamento deste último propósito. Tratam-se de diácidos com 4 carbonos, os quais, quando acoplados aos dendrímeros, são passíveis de sofrerem a ação de um nucleofilo, originado, principalmente, ésteres ou amidas. Outra vantagem do uso dos espaçantes é diminuir o efeito estérico negativo que o dendrímero tem nas reações de formação dos pró-fármacos e no acesso que as enzimas plasmáticas tem aos pró-fármacos.

As sínteses de dendrímeros acontecem com reagentes que tenham dois ou mais grupos eletrófilos e dois ou mais grupos nucleófilos. Essas reações, como apresentado na Figura 3, são classificadas, principalmente, como: (1) convergentes, quando a síntese acontece da periferia em direção ao núcleo ou (2) divergentes quando a reação acontece do foco central em direção ao grupo terminal. As metodologias, muitas vezes, demandam a proteção e desproteção de grupos funcionais para que seja controlada, garantindo, assim, que as gerações dos dendrímeros cresçam como o esperado. Isso faz com que os experimentos sejam, muitas vezes, trabalhosos e custosos, justificando, então, a pouca disponibilidade de compostos comerciais (CHENG et al, 2008;

KESHARWANI, JAIN, JAIN, 2014; TWIBANIRE, GRINDLEY, 2014; SELIN et al., 2016).

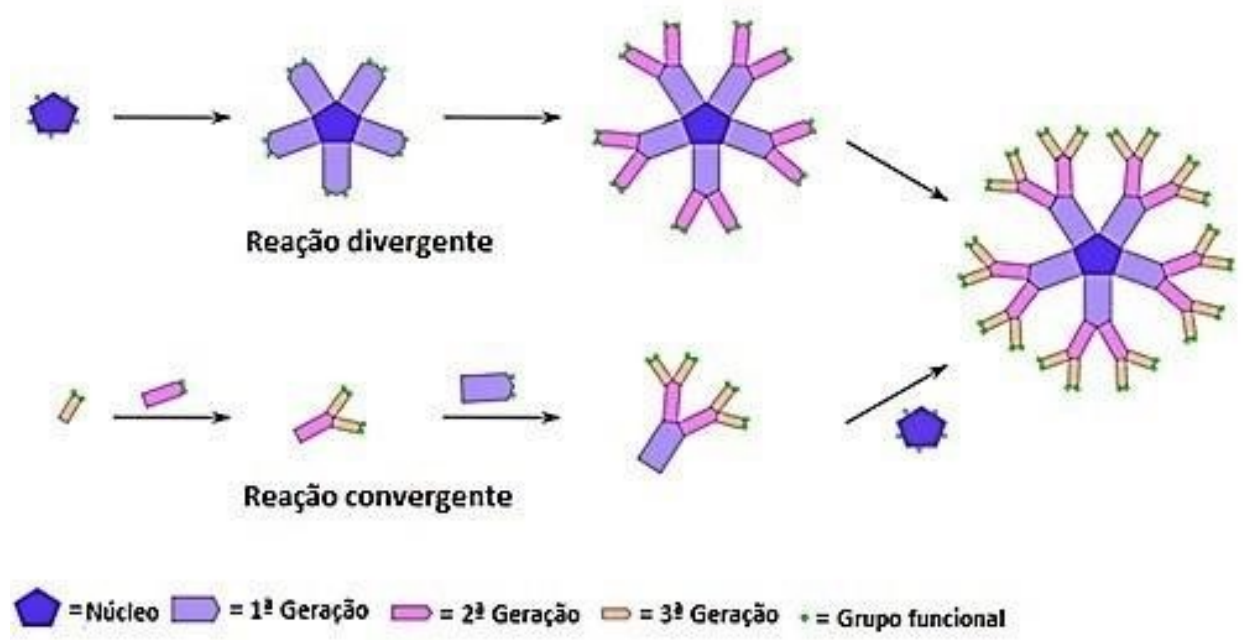

Figura 3. Principais métodos de síntese dos dendrímeros: convergente e divergente (traduzido de SATIJA et al., 2011). 


\section{OBJETIVOS E JUSTIFICATIVAS}

Malária e tuberculose representam problemas emergentes em saúde pública, com índices epidemiológicos desastrosos em todo mundo, especialmente em regiões tropicias. Os fármacos disponíveis na terapêutica, por sua vez, mostram-se tóxicos e com eficácia bastante discutida. Já os dendrímeros têm sido amplamente estudados como potenciais transportadores de fármacos. Assim, tendo em vista a necessidade de descobertas de novos compostos para o tratamento destas enfermidades, o objetivo deste trabalho foi a síntese de pró-fármaco dendriméricos potencialmente ativos em malária e tuberculose, utilizando dendrímero de bis-MPA (Figura 4). Vale ressaltar que o projeto teve a colaboração do Professor Scott Grayson, da Tulane University (USA), responsável por sintetizar os dendrímeros (gerações 0, 1 e 2). No Brasil, fizeram-se as funcionalizações dos dendrímeros com os compostos bioativos. Utilizou-se o ácido succínico como espaçante e as ligações ésteres ou amidas obtidas são passíveis de serem hidrolisadas no organismo.

Os fármacos escolhidos para a produção das formas latentes foram: (1) primaquina, com ação antimalárica (BAIRD et al., 2001) e (2) isoniazida que, segundo dados publicados por Cattamanchi e colaboradores (2009), apresenta ação nos primeiros estágios da tuberculose (CATTAMANCHI et al., 2009).

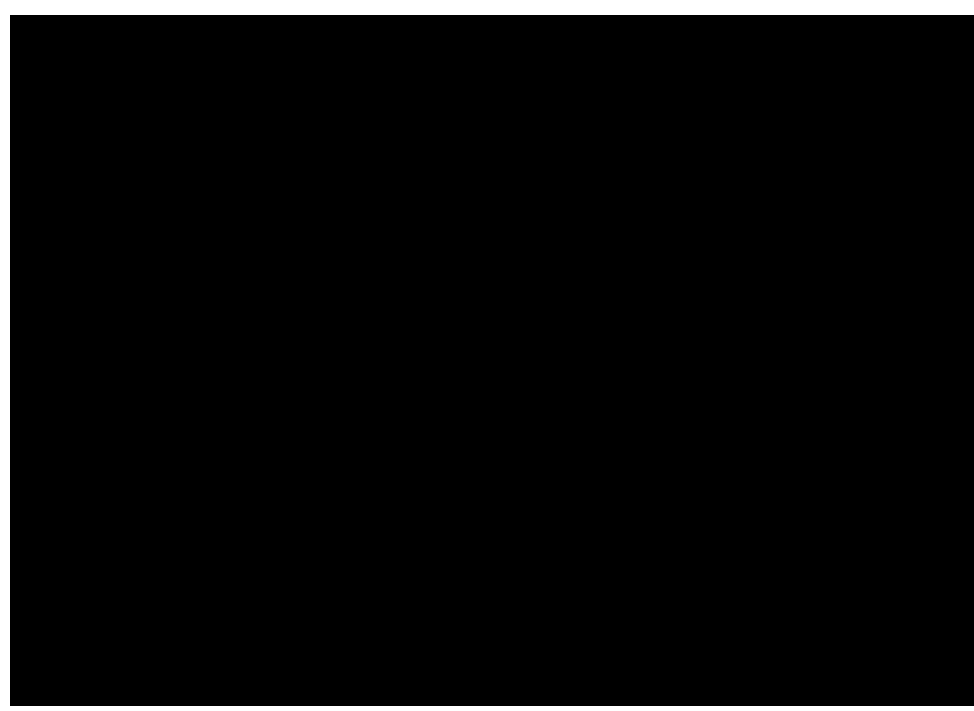

Figura 4. Pró-fármaco dendrimérico potencialmente ativo em tuberculose contendo isoniazida. Fez-se esta representação esquemática com o dendrímero de geração 0 .

Caracterizaram-se o composto G0-Iso por Ressonância Magnética e 
Nuclear $\left({ }^{1} \mathrm{H} \mathrm{e}{ }^{13} \mathrm{C}\right)$ e por espectrometria de massas. Por este último método de caracterização estrutura, descobriu-se um intermediário de síntese, a isoniazida succinoilada ciclizada (Clso-Suc) (Figura 5). Importante mencionar que este composto já foi descrito pelo grupo (RANDO, D.G et al, 2004), em um trabalho com objetivo principal de sintetizar pró-fármacos de isoniazida usando quitosana como transportador. Ressalta-se, entretanto, que a atividade biológica deste intermediário cíclico, bem como estudos de estabilidades química e enzimática não foram investigadas, até o momento. Como são poucas as informações relacionadas com esta molécula, o laboratório coordenado pela Profas Elizabeth Igne Ferreira e Jeanine Giarolla manifestou interesse em pesquisa-lo, principalmente quanto suas propriedades físico-químicas, bem como quanto à atividade biológica. Por esta razão, diante do insucesso de obtenção de prófármacos dendriméricos puros, investiu-se na compreensão do mecanismo de hidrólise da Clso-Suc. Desta maneira, , realizaram-se experimentos empH 1,2, 6,0, 7,4 e 8,5, mimetizando os fisiológicos. Na tentativa de se avançar na compreensão das propriedades deste intermediário, fizeram-se estudos in sílico para entender a sua interação com a catalase-peroxidase Katg. Em relação aos estudos computacionais, avaliaram-se, também, os modos de interações dos pró-fármacos dendriméricos G0-Iso, G0-Pq, G1-Iso e G1-Pq com uma esterase inespecífica utilizando a abordagem de docking molecular. O principal objetivo destas simulações foi compreender a desmontagem da forma latente diante a ação enzimática no organismo.

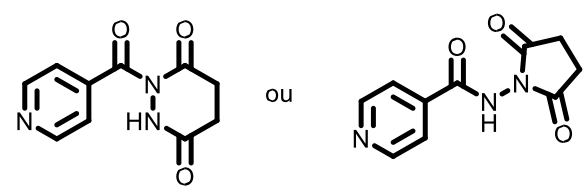

Figura 5. Representação esquemática do Clso-Suc.

\section{MATERIAL E MÉTODOS}

\subsection{MATERIAL}




\subsubsection{Reagentes e solventes}

- Acetato de etila, água, anidrido succínico, clorofórmio, dendrímeros de BISMPA de gerações 1 e 2, diciloexilcarbodiimida (DCC), 1-etil-

3,3(dimetilaminopropil)carbodiimida (EDC), dimetilaminopiridina (DMAP), dimetilfromamida (DMF), etanol, isoniazida, metanol, piridina, pentaeritritol, primaquina, tretraidrofurano (THF), trietilamina (TEA).

\subsubsection{Equipamentos}

- Agitadores magnéticos

- Aparelho digital Buchi M-565 para determinar faixa de fusão

- Câmara de fotoestabilidade Farma 424 CF Nova Ética

- Cromatografia em Isolera Biotage

- Espectrofotômetro FTIR Bomem MB 100

- Espectrômetro de Ressonância Magnética Nuclear 300 MHz BRUKER, modelo Advanced DPX-300

- Espectrofotômetro UV Beckam DU-70

- Rotaevaporador Büchi

\subsubsection{Programas computacionas}

Utilizaram-se para desenho das estruturas, visualização, tratamento de macromoléculas e simulações de docking molecular, os seguintes programas:

- ChemBioDraw 17.0 (PerkinElmer)

- ChemBio 3D 17.0 (PerkinElmer)

- Chimera (Pettersen et al., 2004)

- Spartan (WaveFunction Inc)

- Discovery Studio 2019 (Accelrys Software Inc)

- Sybyl-X 2.0 (Tripos Inc)

- GOLD 4.1.2 (Verdonk et al., 2003)

\subsection{MÉTODOS SINTÉTICOS}

\subsubsection{Síntese do pró-fármaco succinoilado de isoniazida (Iso-Suc)}




\section{(FENG et al, 2002)}

Em um balão de reação, adicionaram-se 1,6 mmol de anidrido succínico $(0,160 \mathrm{~g}), 0,16 \mathrm{mmol}$ de DMAP $(0,020 \mathrm{~g}), 1 \mathrm{mmol}$ de isoniazida $(0,137 \mathrm{~g})$ e 70 $\mathrm{mL}$ de acetato de etila. Manteve-se a a reação em temperatura ambiente e agitação constante por 18 horas. Após esse período, rotaevaporou-se o solvente e o produto foi purificado por precipitação em etanol. O esquema de reação está ilustrado na Figura 4.

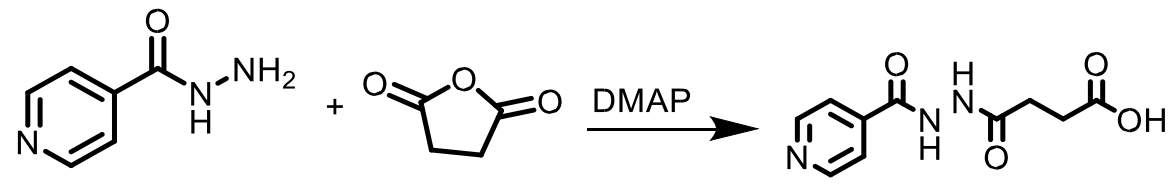

Figura 6. Síntese da Iso-suc.

\subsubsection{Síntese do pró-fármaco succinoilado de primaquina ( $\mathrm{Pq}-\mathrm{Suc})$} (FENG et al, 2002)

Em um balão de reação, adicionaram-se 1,2 mmol de anidrido succínico $(0,120 \mathrm{~g}), 1 \mathrm{mmol}$ de primaquina $(0,259 \mathrm{~g})$ e $70 \mathrm{~mL}$ de clorofórmio. Manteve-se a reação em temperatura ambiente e agitação constante por 5 horas. Após esse período, rotaevaporou-se o solvente e o produto foi purificado por coluna cromatográfica automática, com sistema eluente acetado de etila:metanol (7:3 v/v). O esquema de reação está ilustrado na Figura 5.

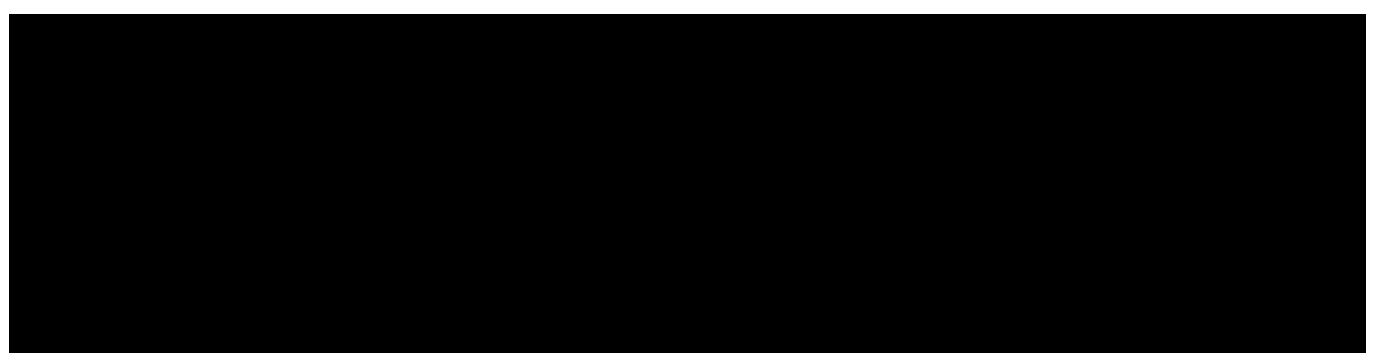

3.2.3. Formação de cloreto de ácido de isoniazida in situ e posterior reação com dendrímero geração 0 (G0-Iso) (CHAUDHARI, AKAMANCHI, 1999)

Em um balão de reação, adicionaram-se, primeiramente, 4,5 mmol de succinil-isoniazida $(1,060 \mathrm{~g}), 4,2 \mathrm{mmol}$ de cloreto de oxalila $(0,357 \mathrm{~mL})$ e uma gota de dimetilformamida (DMF) em $50 \mathrm{~mL}$ de acetonitrila. Após o término da 
formação de bolhas, colocou-se $1 \mathrm{mmol}$ de pentaeritritiol (G0) e $5 \mathrm{mmol}$ de trietilamina (TEA) $(0,7 \mathrm{~mL})$. Manteve-se a reação em refluxo de $65^{\circ} \mathrm{C}$ e agitação constante por 24 horas. Após esse período, rotaevaporou-se o conteúdo do balão e a purificação foi feita por coluna cromatográfica automática com sistema eluente acetado de etila:metanol (7:3 v/v). O esquema de reação está ilustrado na Figura 6.

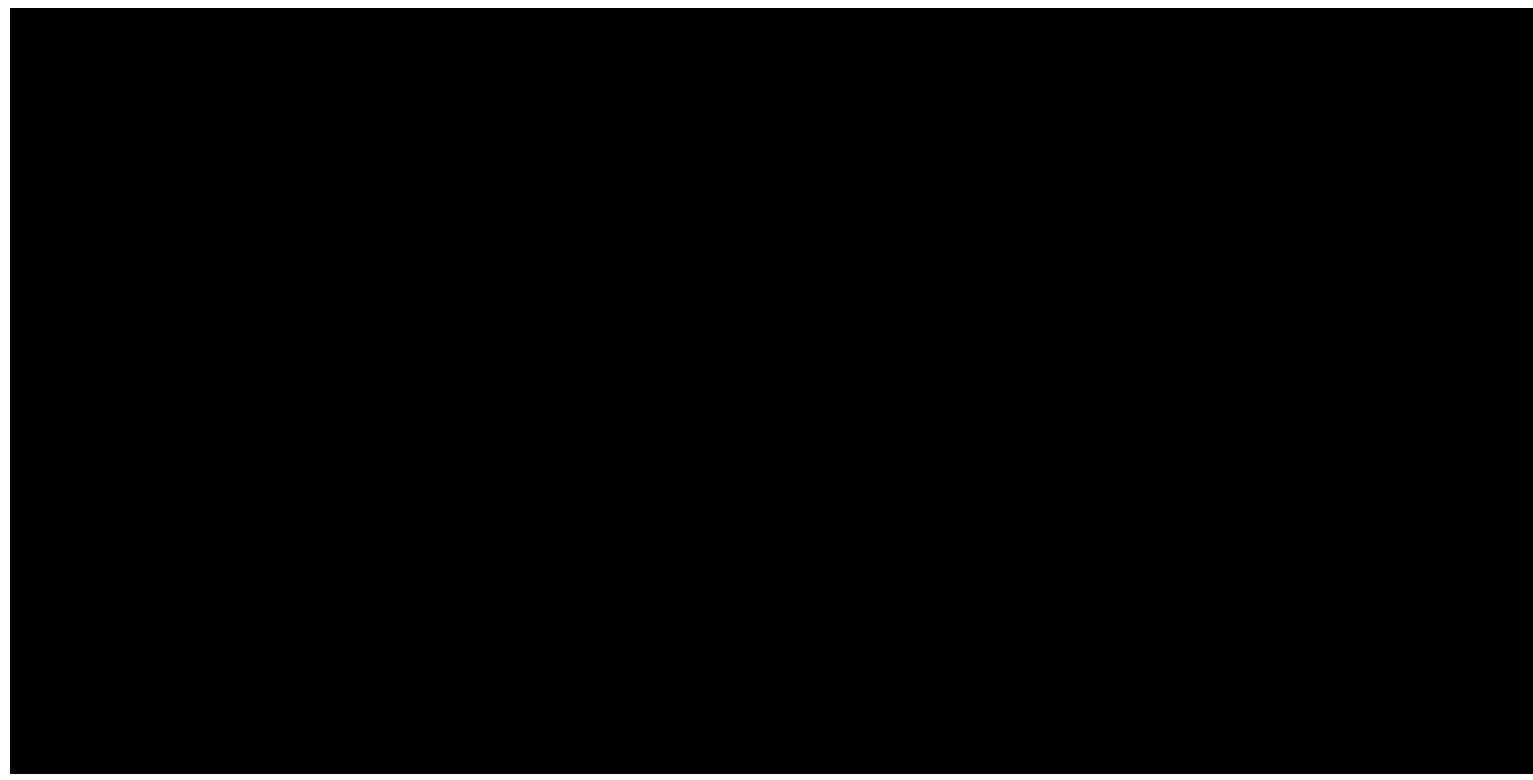

Figura 8. Esquema 1. Formação do cloreto de ácido de Iso-Suc. Esquema 2. reação de acoplamento do derivado cloreto de ácido da Iso-Suc com o G0.

\subsubsection{Síntese do pró-fármaco dendrimérico de G0 contendo isoniazida (G0-Iso) (MOONEY et al, 2010)}

Em um balão de reação, adicionaram-se 1,5 mmol de Iso-suc $(0,350 \mathrm{~g})$, $1,5 \mathrm{mmol}$ de $\operatorname{EDC}(0,287 \mathrm{~g})$ e $75 \mathrm{~mL}$ de acetato de etila. Após 5 minutos, colocaram-se $0,15 \mathrm{mmol}$ de $\operatorname{DMAP}(0,018 \mathrm{~g})$. Depois de mais 30 minutos, adicionou-se $0,5 \mathrm{mmol}$ de pentaeritritol $(0,068 \mathrm{~g})$. Manteve-se a reação sob agitação constante e temperatura ambiente por 3 dias, a qual foi acompanhada por Cromatografia de Camada Delgada (CCD). Após o término da reação, reotaevaporou-se o conteúdo do balão e a purificação do produto foi feita por coluna cromatográfica automatizada usando o sistema eluente acetato de etila:metanol (7:3 v/v). A reação está ilustrada na Figura 7. 
Figura 9. Síntese do pró-fármaco dendrimérico de isoniazida geração 0 (G0-Iso).

\subsubsection{Síntese do pró-fármaco dendrimérico de $\mathbf{G 0}$ contendo primaquina (G0-Pq) (MOONEY et al, 2010)}

Em um balão de reação, adicionaram-se 2,5 mmol de Pq-suc (0,538 g), 1,5 $\mathrm{mmol}$ de $\operatorname{EDC}(0,287 \mathrm{~g})$ e $75 \mathrm{~mL}$ de clorofórmio. Após 5 minutos, adicionaramse $0,15 \mathrm{mmol}$ de DMAP $(0,018 \mathrm{~g})$. Depois de mais 30 minutos, colocou-se $0,5 \mathrm{mmol}$ de pentaeritritol $(0,068 \mathrm{~g})$. Manteve-se a reação sob agitação constante e temperatura ambiente por 3 dias, a qual foi acompanhada por CCD. Após o término da reação, rotaevaporou-se o conteúdo do balão e a purificação do produto foi feita por coluna cromatográfica automatizada usando o sistema eluente acetato de etila:metanol (7:3 v/v). A reação está ilustrada na Figura 10. 
Figura 10. Síntese do pró-fármaco dendrimérico de primaquina geração 0 (G0-Pq).

\subsubsection{Síntese do pró-fármaco dendrimérico de $\mathbf{G} 1$ contendo isoniazida (G1-Iso) (MOONEY et al, 2010)}

Em um balão de reação, adicionaram-se 2,5 mmol de Iso-suc $(0,350 \mathrm{~g})$, 1,5 mmol de $\operatorname{EDC}(0,287 \mathrm{~g})$ e $75 \mathrm{~mL}$ de acetato de etila. Após 5 minutos, colocouse 0,15 mmol de DMAP $(0,018 \mathrm{~g})$. Depois de mais 30 minutos, adicionaram-se 0,25 mmol do dendrímero de Bis-MPA geração 1 (0,150 g). Manteve-se a reação sob agitação constante e temperatura ambiente por 3 dias, a qual foi acompanhada por CCD. Após o término da reação, rotaevaporou-se o conteúdo do balão e a purificação do produto foi feita por coluna cromatográfica automatizada usando o sistema eluente acetato de etila:metanol (7:3 v/v). A reação é ilustrada na Figura 11. 
Figura 11. Síntese do pró-fármaco dendrimérico de isoniazida geração 1 (G1-Iso).

\subsubsection{Síntese do pró-fármaco dendrimérico de G1 contendo primaquina (G1-Pq) (MOONEY et al, 2010)}

Em um balão de reação, adicionaram-se 2,5 mmol de Pq-suc (0,538 g), 1,5 mmol de $\operatorname{EDC}(0,287 \mathrm{~g})$ e $75 \mathrm{~mL}$ de clorofórmio. Após 5 minutos, adicionaramse 0,15 mmol de DMAP (0,018 g). Depois de mais 30 minutos, colocou-se 0,25 mmol de dendrímero de Bis-MPA geração 1 (0,150 g). Manteve-se a reação sob agitação constante e temperatura ambiente por 3 dias, a qual foi acompanhada por CCD. Após o término da reação, rotaevaporou-se o conteúdo do balão e a purificação do produto foi feita por coluna cromatográfica automatizada usando o sistema eluente acetato de etila:metanol (7:3 v/v). A reação está ilustrada na 
Figura 12

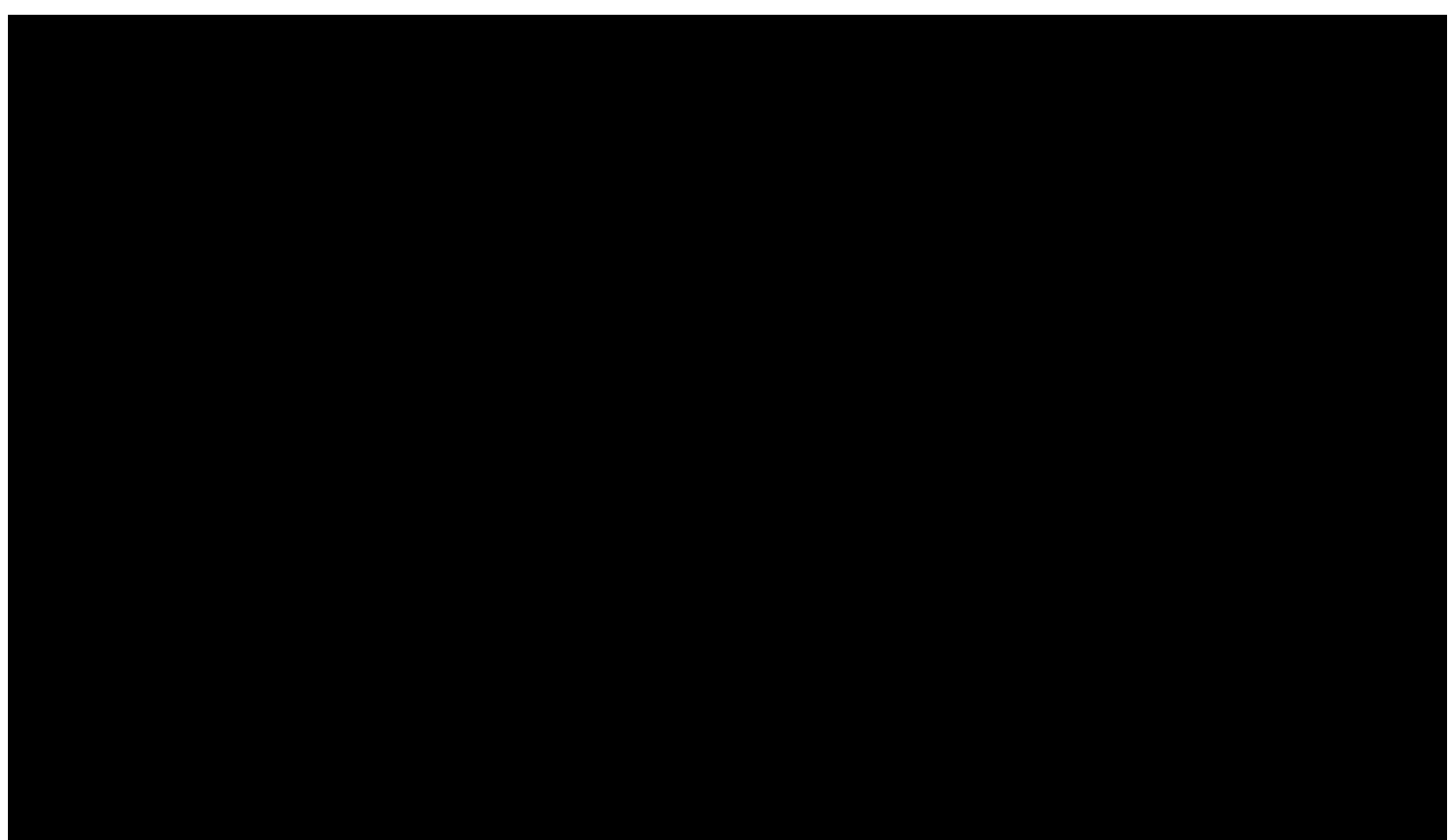

Figura 12. Síntese do pró-fármaco dendrimérico de primaquina geração 1 (G1-Pq).

\subsubsection{Síntese do pró-fármaco Clso-Suc}

Em um balão de reação, adicionaram-se 1,0 mmol de Iso-Suc $(0,237 \mathrm{~g})$, 0,16 mmol de DMAP (0,020 g), $1 \mathrm{mmol}$ de $\operatorname{EDC}(0,192 \mathrm{~g})$ e $70 \mathrm{~mL}$ de acetato de etila. Manteve-se a a reação em temperatura ambiente e agitação constante por 2 dias. Após esse período, rotaevaporou-se o solvente e a purificação do produto foi feita por coluna cromatográfica automatizada usando o sistema eluente acetato de etila:metanol (7:3 v/v). A reação está ilustrada na Figura 13.

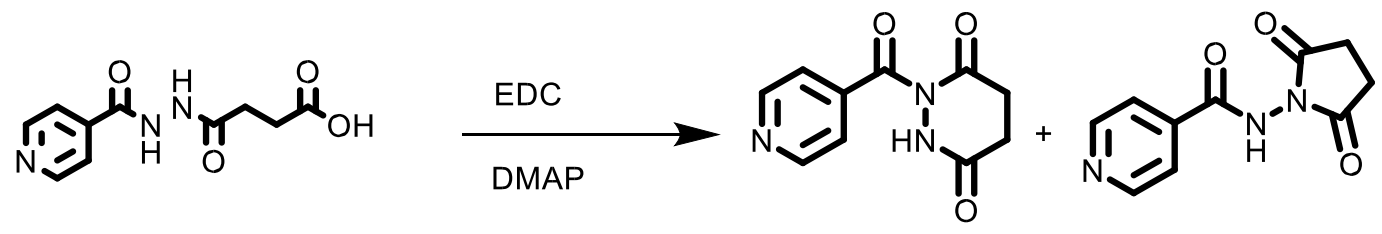

Figura 13. Síntese do pró-fármaco ciclizado de isoniazida (Clso-Suc).

\subsection{ESTUDOS DE ESTABILIDADE QUÍMICA DE Clso-Suc (NAJLAH et al, 2006)}




\subsubsection{Desenvolvimento do método analítico}

Como ponto de partida para o desenvolvimento do método de identificação e quantificação dos compostos com a técnica de Cromatografia Líquida de Alta Eficiência (CLAE), foi utilizada, como referência, a metodologia descrita para a isoniazida na Farmacopeia Brasileira - 5a Edição - Volume 2 (ANVISA, 2010), conforme apresentado na Tabela 1.

Tabela 1. Metodologia farmacopeica e System Suitability para análise cromatográfica de isoniazida

\begin{tabular}{|c|c|}
\hline Parâmetro & Condição \\
\hline Detector & UV-Vis \\
\hline Coluna & Octadecilsilano $(5 \mu \mathrm{m})-250 \mathrm{~mm} \times 4,6 \mathrm{~mm}$ \\
\hline Temperatura forno & $1,5 \mathrm{~mL} /$ minuto \\
\hline Fluxo de Fase Móvel & Tampão fosfato $(\mathrm{pH} 6,9)$ e metanol $-95: 5$ \\
$(\mathrm{v}, \mathrm{v})$
\end{tabular}

A partir dos resultados obtidos nestas análises, ajustaram-se os métodos afim de otimizá-los, adequando-os aos compostos descritos na Figura 5, conforme descrito na seção "Resultados e Discussão".

\subsubsection{Estudo de estabilidade química}

Os estudos de estabilidade química foram realizados com base na metodologia empregada por Najlah e colaboradores (2006), onde a hidrólise dos derivados succinoilados foram feitas em $\mathrm{pH} 7,4$ (tampão fosfato $0,02 \mathrm{M}$ ), $\mathrm{pH} \mathrm{1,2}$ 
(tampão de ácido clorídrico 0,06 M), pH 6 (tampão acetato 0,26 M) e pH 8,5 (tampão borato $0,05 \mathrm{M}$ ). A reação iniciou com a adição de quantidade adequada do composto a $5 \mathrm{~mL}$ de solução tampão pré-aquecida para chegar a concentração final de $2 \times 10^{-6} \mathrm{M}$. As soluções foram mantidas a $37^{\circ} \mathrm{C}$. Em intervalos de tempos mostrados na Tabela 2 , amostras $(50 \mu \mathrm{L})$ foram retiradas e foram adicionandos $200 \mathrm{~mL}$ de solução metanólica de salicilato de sódio $(1,25$ $\mathrm{mM}$ ). As amostras foram armazenadas a $-20^{\circ} \mathrm{C}$ até que fossem feitas as análises em CLAE. Os parâmetros analíticos utilizados podem ser vistos na Tabela 1.

Tabela 2. Parâmetros analíticos para o ensaio de liberação

\begin{tabular}{|c|c|c|}
\hline Parâmetro & \multicolumn{2}{|c|}{ Condição } \\
\hline Detector & \multicolumn{2}{|c|}{ UV-Vis a $261 \mathrm{~nm}$} \\
\hline Coluna & \multicolumn{2}{|c|}{ Octadecilsilano $(5 \mu \mathrm{m})-150 \mathrm{~mm} \times 4,6 \mathrm{~mm}$} \\
\hline Temperatura forno & \multicolumn{2}{|c|}{$35^{\circ} \mathrm{C}$} \\
\hline Fluxo de Fase Móvel & $\begin{array}{l}\text { Tempo } \\
(\min )\end{array}$ & $\begin{array}{l}\text { Fluxo } \\
(\mathrm{mL} / \mathrm{min} \\
)\end{array}$ \\
\hline \multirow[t]{2}{*}{ Fase Móvel } & \multirow{2}{*}{\multicolumn{2}{|c|}{$\begin{array}{l}\text { Tampão fosfato }(\mathrm{pH} 6,9) \text { e metanol } \\
\qquad(97,5: 2,5, \mathrm{v} / \mathrm{v})\end{array}$}} \\
\hline & & \\
\hline Volume de Injeção & \multicolumn{2}{|c|}{$60 \mu \mathrm{L}$} \\
\hline Pratos Teóricos & \multicolumn{2}{|c|}{$>1800$} \\
\hline Fator de Cauda & \multicolumn{2}{|c|}{$<2,0$} \\
\hline Fator de Retenção & \multicolumn{2}{|c|}{$>2,35$} \\
\hline Tempo de Corrida & \multicolumn{2}{|c|}{10 minutos } \\
\hline
\end{tabular}


Tabela 3. Relação entre o número da amostra e o tempo de coleta.

\begin{tabular}{|c|c|}
\hline Número da Amostra & $\begin{array}{c}\text { Tempo de coleta } \\
\text { (horas) }\end{array}$ \\
\hline T0 & 0 \\
\hline T1 & 0,2 \\
\hline $\mathrm{T} 2$ & 0,3 \\
\hline T3 & 0,5 \\
\hline $\mathrm{T} 4$ & 0,7 \\
\hline T5 & 0,8 \\
\hline T6 & 1 \\
\hline T7 & 1,5 \\
\hline T8 & 2 \\
\hline T9 & 2,5 \\
\hline T10 & 3 \\
\hline T11 & 21 \\
\hline T12 & 24 \\
\hline
\end{tabular}

\subsection{Estudos in silico}

\subsubsection{Simulações de docking molecular entre os pró-fármacos}

\section{dendriméricos e esterase inespecífica}

Os modelos tridimensionais foram construídos no software ChemDraw 17.0 (PerkinElmer). Realizou-se a análise conformacional no programa Chem3D 17.0 (PerkinElmer), utilizando campo de força MMFF94. Adicionou-se a carga parcial AMBER no programa UCSF Chimera (PETTERSEN et al., 2004). Em seguida, a otimização da geometria das estruturas, assim como a adição de carga por mecânica molecular (MMFF94) foram realizadas no programa Spartan (WaveFunction Inc).

A esterase humana inespecífica selecionada foi a estrutura cristalizada de carboxilesterase humana (complexada com coenzima A) disponível no Protein Data Bank (PDB) com código 2H7C e resolução de 2 A (YOUNG et al., 2018). 
Sabe-se que é uma serino-protease, cujo mecanismo se inicia pelo ataque nucleofílico do oxigênio da hidroxila da Serina 221 a grupos passíveis desta ação, como exemplo, carbonila de éster/amida presentes no dendrímero. Utilizou-se o sítio ativo formado com a tríade catalitica Serina 221, Histidina 468 e Ácido Glutâmico 354 tanto para o re-docking, quanto para o docking (BENCHARIT et al., 2006).

Tratou-se a enzima selecionada no programa Sybyl-X 2.0 (Tripos Inc). Utilizando-se a ferramenta de preparação da estrutura polimérica, realizou-se a minimização da energia pelo método conjugate gradient. Utilizou-se o mesmo programa para verificar e corrigir problemas nas estruturas dos dendrímeros, como ausência de átomos ou ligações, antes de iniciar o docking.

Primeiramente, realizou-se o re-docking no programa Gold 4.1.2 (Verdonk et al., 2003) para definir a melhor função de score a ser aplicada. Utilizaram-se as funções Astex Statistical Potential (ASP), cujo melhor resultado dá-se pelo menor valor, e ChemScore (função que estima a mudança de energia livre total que ocorre durante a interação do ligante e do receptor, então, quanto maior seu valor melhor é o resultado). Analisaram-se os dados no programa Discovery Studio 2019 (Accelrys Software Inc), comparando as poses obtidas através de diagrama 2D de interações entre o ligante e a enzima. A função cuja pose obteve o maior número médio de interações foi selecionada para a realização do docking com os compostos.

Realizaram-se as simulações de docking molecular, também, no Gold 4.1.2 (Verdonk et al, 2003), bem como no Autodock (Trott, Olson, 2010), ambos em triplicata, totalizando 240 simulações. Foram mantidos os aminoácidos Histidina 468, Serina 221 e Ácido Glutâmico 354 e as moléculas de água com distância inferior a $4 \AA$ em relação ao oxigênio da hidroxila da Serina 221 , as quais participam do processo de catálise (BENCHARIT et al., 2006).

Analisaram-se os resultados de docking molecular do Gold (Verdonk et al, 2003) com base nos complexos enzima-pró-fármacos dendriméricos de melhor Root Mean Square deviation (RMSd), score e de distância igual ou inferior a $3 \AA$ entre a carbonila dos ésteres e amidas das estruturas, distância esta considerada favorável para ligação de hidrogênio (JIANG, LAI, 2002).

Já no AutoDock (Trott, Olson, 2010), foram gerados os arquivos para input no AutoDockVina (Trott et al., 2010) utilizando: (1) as configurações padrões do 
programa; (2) o arquivo com o ligante e o com a proteína; (3) o arquivo dos parâmetros contendo informações sobre a proteína e o ligante; (4) as dimensões da grid box e (5) sua localização na enzima (coordenadas do gridcenter). O AutoDock (Trott, Olson, 2010) utiliza Affinity como score e gera o próprio valor de RMSd para possibilitar a análise dos resultados. Por fim, selecionaram-se os melhores resultados com o auxílio do programa AutoDockVina (Trott et al., 2010), utilizando como base os menores valores de energia no cluster. Para a visualização dos complexos enzima-ligante e para a determinação das distâncias das interações, utilizou-se o programa Discovery Studio 2019 (Accelrys Software $\operatorname{lnc})$.

\subsubsection{Simulações de docking molecular entre a Clso-Suc e a catalase- peroxidase}

Do mesmo modo que o item anterior, os modelos tridimensionais foram construídos no software ChemDraw 17.0 (PerkinElmer). A análise conformacional foi realizada no programa Chem3D 17.0 (PerkinElmer), utilizando campo de força MMFF94. A carga parcial AMBER foi adicionada no programa UCSF Chimera (PETTERSEN et al., 2004). Em seguida, a otimização da geometria das estruturas assim como a adição de carga por método quântico (Hartree-fock 6-31+G*) foram realizadas no programa Spartan (WaveFunction Inc).

O cristal da catalase-peroxidase do Micobacterium tuberculosis com o grupo heme como cofator selecionado foi o da enzima selvagem disponível no PDB com código 1SJ2, com resolução 2,4 A (BERTRAND et al, 2004). Tratouse a enzima selecionada no programa Sybyl-X 2.0 (Tripos Inc). Utilizando-se a ferramenta de preparação da estrutura polimérica, realizou-se a minimização da energia pelo método conjugate gradient. Utilizou-se o mesmo programa para verificar e corrigir problemas nas estruturas dos ligantes, como ausência de átomos ou ligações, antes de iniciar as simulações de docking molecular.

Realizaram-se os cálculos no Gold 4.1.2 (Verdonk et al, 2003). Nesse programa, o docking foi feito após a adição de hidrogênio, em configurações padrões e foi calculado em triplicata. Selecionou-se o átomo de ferro como binding site por sua relevância no mecanismo de ação da enzima. Utilizaram-se 
as funções ASP e ChemScore (função que estima a mudança de energia livre total que ocorre durante a interação do ligante e do receptor).

Analisaram-se os resultados resultantes do Gold (Verdonk et al, 2003) com base nas interações dos ligantes com os aminoácidos, a) distância média (em $\AA$ ) em relação ao átomo de ferro do grupo heme e b) valores obtidos para os scores. Para a visualização dos complexos enzima-ligante e para a determinação das distâncias das interações, utilizou-se o programa Discovery Studio 2019 (Accelrys Software Inc).

\section{RESULTADOS E DISCUSSÃO}

\subsection{METODOLOGIA SINTÉTICA}

\subsubsection{Sintese dos derivados succinoilados de isoniazida e de primaquina (Iso-Suc e Iso-Pq)}

Nos resultados de Ressonância Magnética e Nuclear (RMN) da Iso-Suc, observaram-se deslocamentos químicos nos espectros de ${ }^{1} \mathrm{H}$ (Espectro 1) e de

${ }^{13} \mathrm{C}$ (Espectro 2), quando comparados com os dados encontrados literatura sobre a isoniazida (de ASSIS et al, 2012), os quais serão discutidos a seguir. O primeiro deles foi o do sinal dos dois hidrogênios da amina primária da hidrazida (H4), o qual foi de 4,5 ppm (isoniazida) para 10,61 ppm (produto). Já o segundo, verificado no RMN de ${ }^{13} \mathrm{C}$, está relacionado com o carbono da carbonila (C6), o qual passou de 167,2 ppm (isoniazida) para 163,88 ppm (produto). Os sinais do ácido succínico também estão presentes no RMN de ${ }^{1} \mathrm{H}$, com deslocamento químicos em 2,69 ppm (H2). Importante mencionar que as integrais estão ligeiramente diferentes do esperado, pois o sinal do solvente deuterado (DMSO) também aparece nessa região. Houve, também, alteração deste último sinal, o qual deveria aparecer como dois tripletos, no entando, verifica-se um multipleto. Observa-se a água de DMSO em 3,30 ppm. Já os carbonos do espaçante succínico também estão no RMN de ${ }^{13} \mathrm{C}$. Os carbonos carbonílicos $\mathrm{C} 1$ e C3 estão, respectivamente, em 170,41 e 173,45 ppm. A diferença se dá pelo fato do ácido carboxílico estar mais blindado que a cetohidrazida, cuja ressonância deslocaliza seus elétrons. Observaram-se os carbonos centrais do ácido succínico (C2) em 28,12 e 28,34 ppm. 


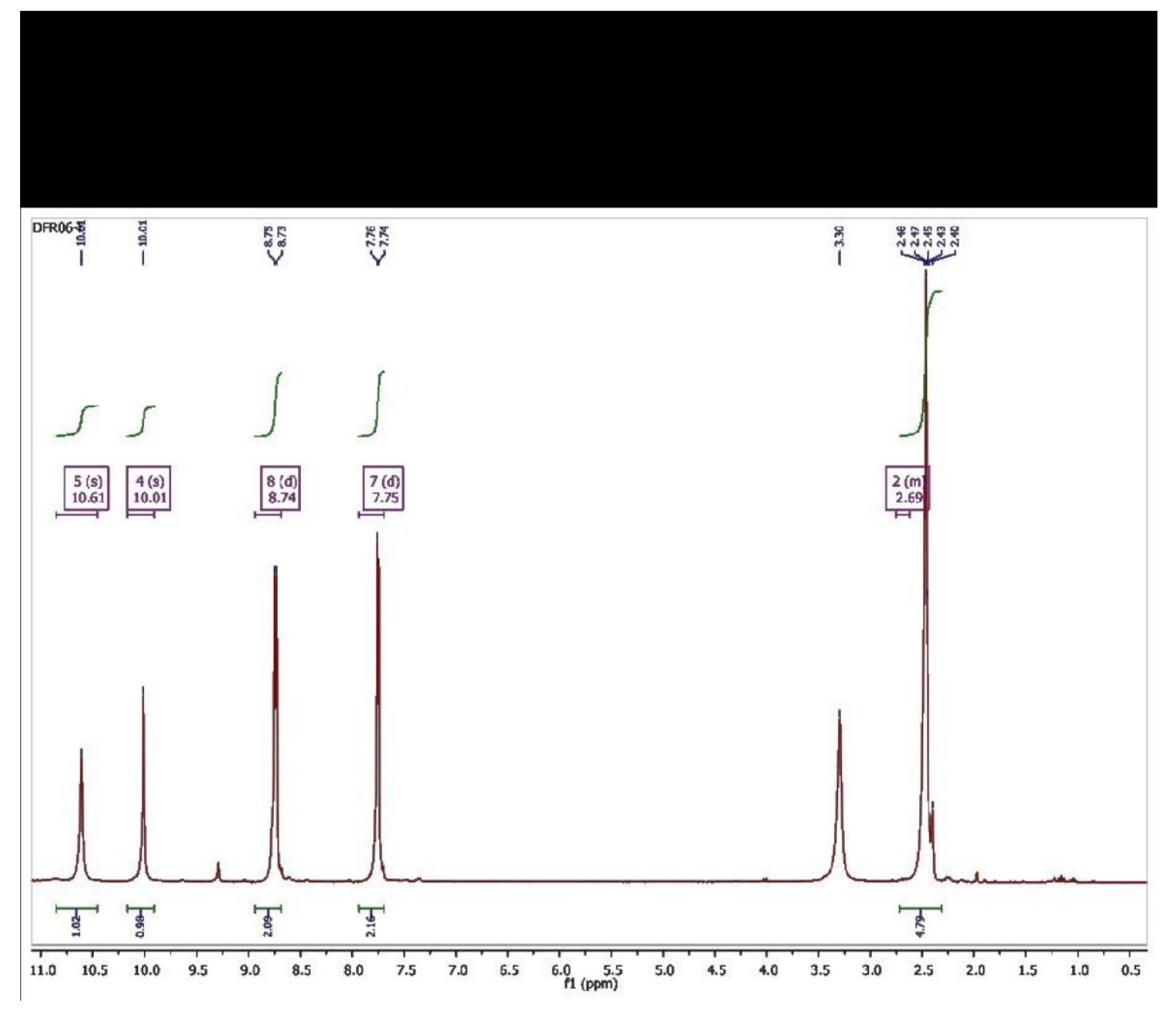

Espectro 1. RMN de $1 \mathrm{H}$ da Iso-Suc.

$$
{ }^{1} \mathrm{H}-\mathrm{RMN} \text { (DMSO), } 300 \mathrm{MHz}, \mathrm{Q}=\mathrm{ppm}
$$

H5: 10.61 (s, 1H), H4: 10.01 (s, 1H), H8: 8.74 (d, J = 5.6 Hz, 2H), H7: 7.75 (d, J = 5.7 Hz, $2 \mathrm{H}), \mathrm{H} 2: 2.76-2.62(\mathrm{~m}, 4 \mathrm{H})$. 


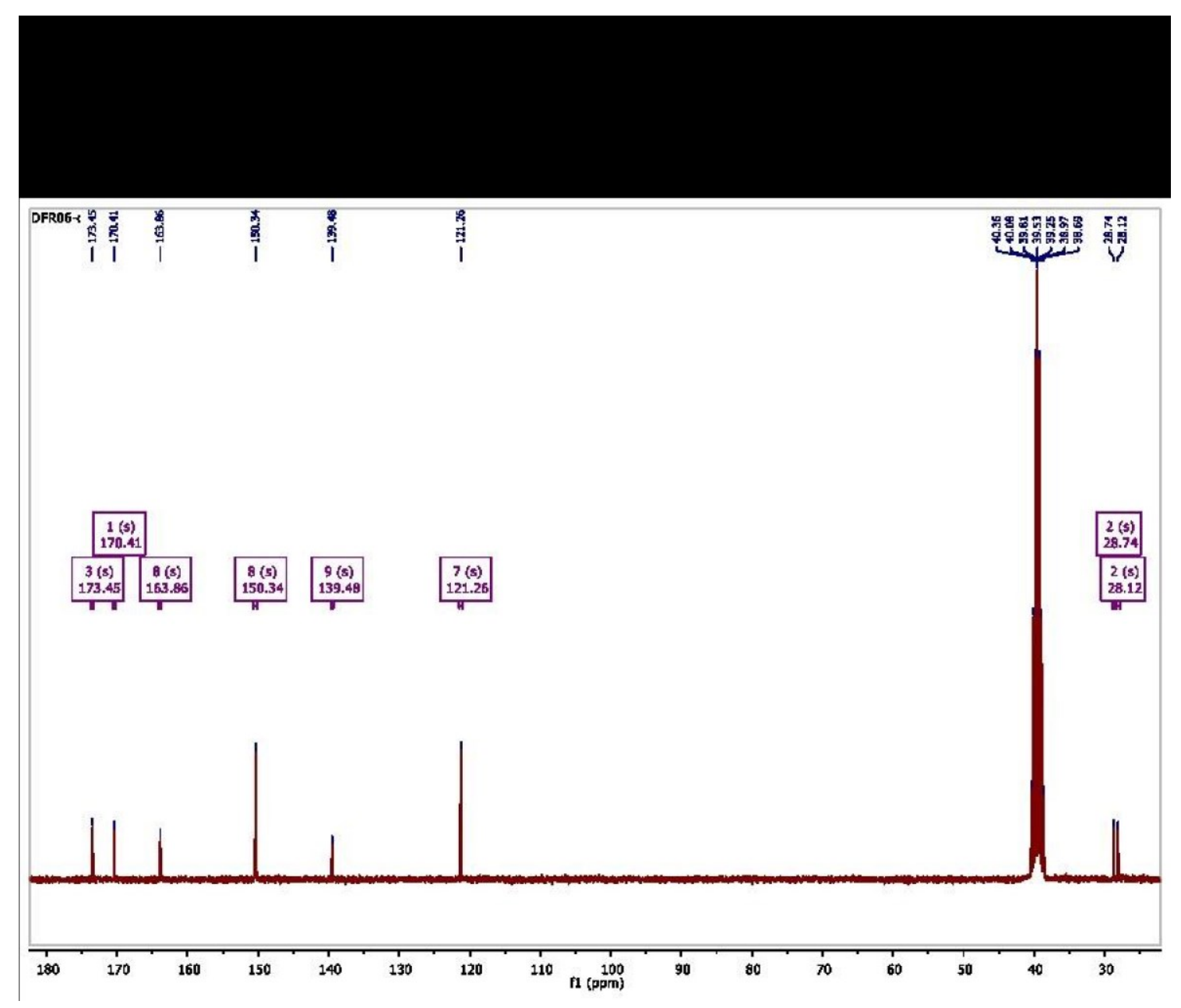

Espectro 2. RMN de $13 \mathrm{C}$ da Iso-Suc.

${ }^{13} \mathrm{C}-\mathrm{RMN}$ (DMSO), $75 \mathrm{MHz}, \mathrm{Q}=\mathrm{ppm}$

C3: 173.45, C1 - 170.41, C6: 163.86, C8: 150.34, C9: 139.48, C7: 121.26, C2: 28.74, C2: 28.12 .

Os espectros no infravermelho (IV) ajudam a caracterizar compostos, uma vez que demonstram estiramentos e deformações de grupos funcionais característicos de cada molécula (SILVERSTEIN, 2006). A análise do espectro no IV indicou, igualmente, a formação do produto Iso-suc, com as bandas características em $1705 \mathrm{~cm}^{-1}$ ( $\lambda_{\mathrm{C}=\mathrm{O}}$ axial de ácido carboxílico) e em $1604 \mathrm{~cm}^{-1}$ relacionado com $\lambda_{\mathrm{c}=\mathrm{O}}$ da hidrazida (Espectro 3 ). 


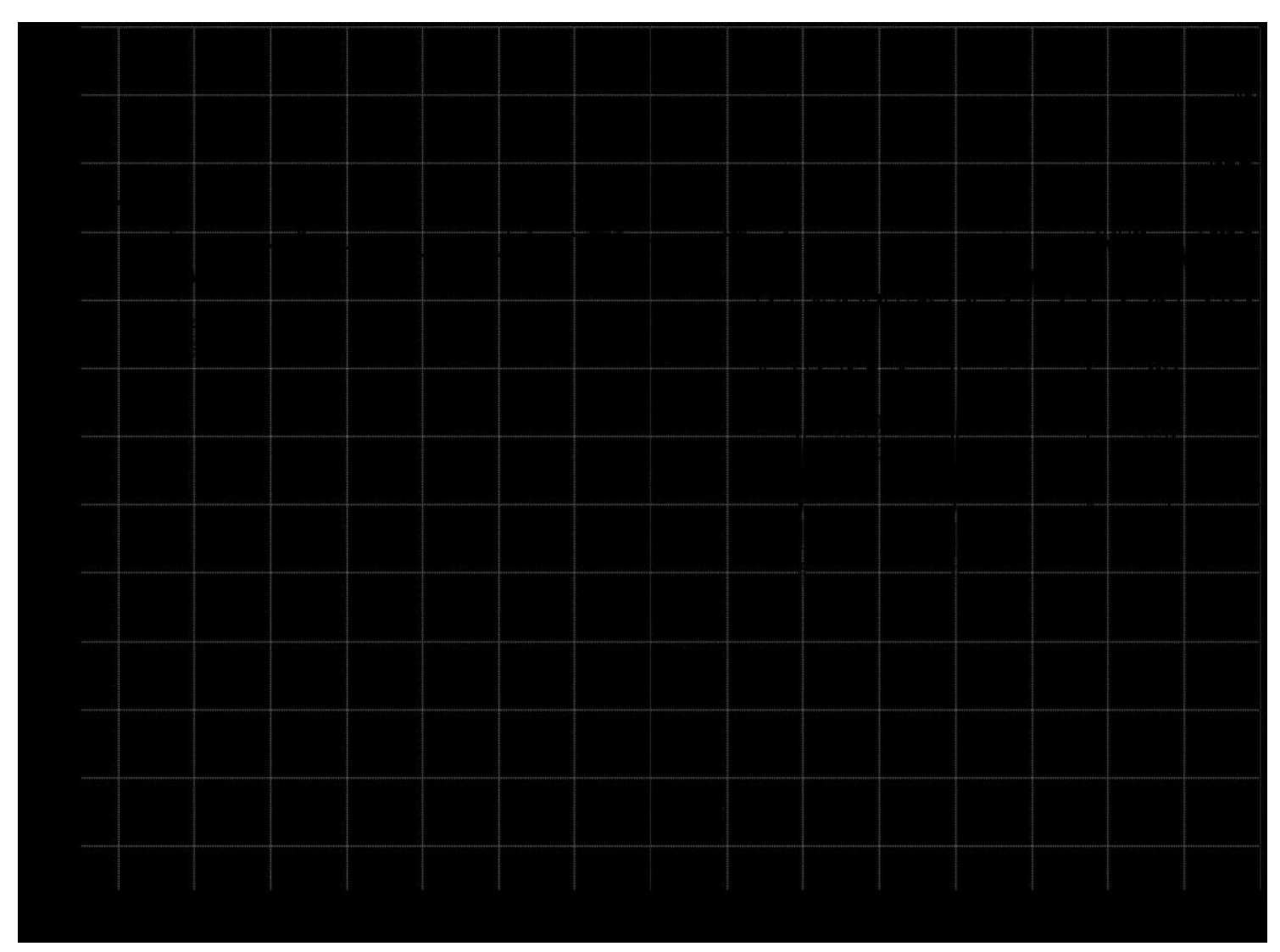

Espectro 3. Espectro no IV $(\lambda, \mathrm{KBr}, \mathrm{cm}-1)$ da Iso-Suc.

$\mathrm{Na}$ síntese do derivado succinoilado de primaquina, não houve a necessidade de utilizar catalisador, uma vez que a amina primária da primaquina é um bom nucleófilo para atacar diretamente uma das carbonilas do anidrido succínico para formar o produto em até 5 horas Assim, alguns deslocamentos químicos no RMN de ${ }^{1} \mathrm{H}$ e ${ }^{13} \mathrm{C}$ (Espectro 4 e Espectro 5), quando comparados com o padrão primaquina (Espectro I, Anexo I), indicaram a formação do produto de interesse. No RMN de ${ }^{1} \mathrm{H}$, por exemplo, os sinais dos hidrogênios da amina primária (H16) deslocam de 1,50 ppm (primaquina) para 7,30 ppm (produto). Os hidrogênios do carbono ligado à amina primária (H11), por sua vez, deslocam de 2,6 ppm (primaquina) para 3,16 ppm (produto). No ${ }^{13} \mathrm{C}$ RMN, o sinal do carbono ligado à amina primária (C11) deslocou de 42 ppm (primaquina) para 39 ppm após a formação da amida. Os sinais do ácido succínico também sugeriram a formação do derivado. No RMN de ${ }^{1} \mathrm{H}$, há o sinal em 2,66 ppm referente aos hidrogênios $\mathrm{H} 21$ e $\mathrm{H} 22$, porém, como na mesma região há o sinal do $H 1$, as integrais, quando somadas, resultaram em 5 hidrogênios. O resíduo do solvente deuterado $\left(\mathrm{CDCl}_{3}\right)$ apareceu em 7,30 ppm junto com o $\mathrm{H} 16$, o que modificou a 
respectiva integral e distorceu a multiplicidade deste sinal. No $\mathrm{RMN}$ de ${ }^{13} \mathrm{C}$, os sinais em 174,95 ppm, referente ao C22, e o em 172,58 ppm, do C19, sugerem o acoplamento do ácido succínco, com formação do ácido carboxílico e da amida. Ademais, os sinais em 29,67 e 31,75 ppm (C20 e C21) também reforçam a possível obtenção deste pró-fármaco. Vale ressaltar que os sinais em 4,09 ppm e 1,97 ppm (espectro de $1 \mathrm{H}$ ) são resíduos de acetato de etila utilizado no processo de purificação.

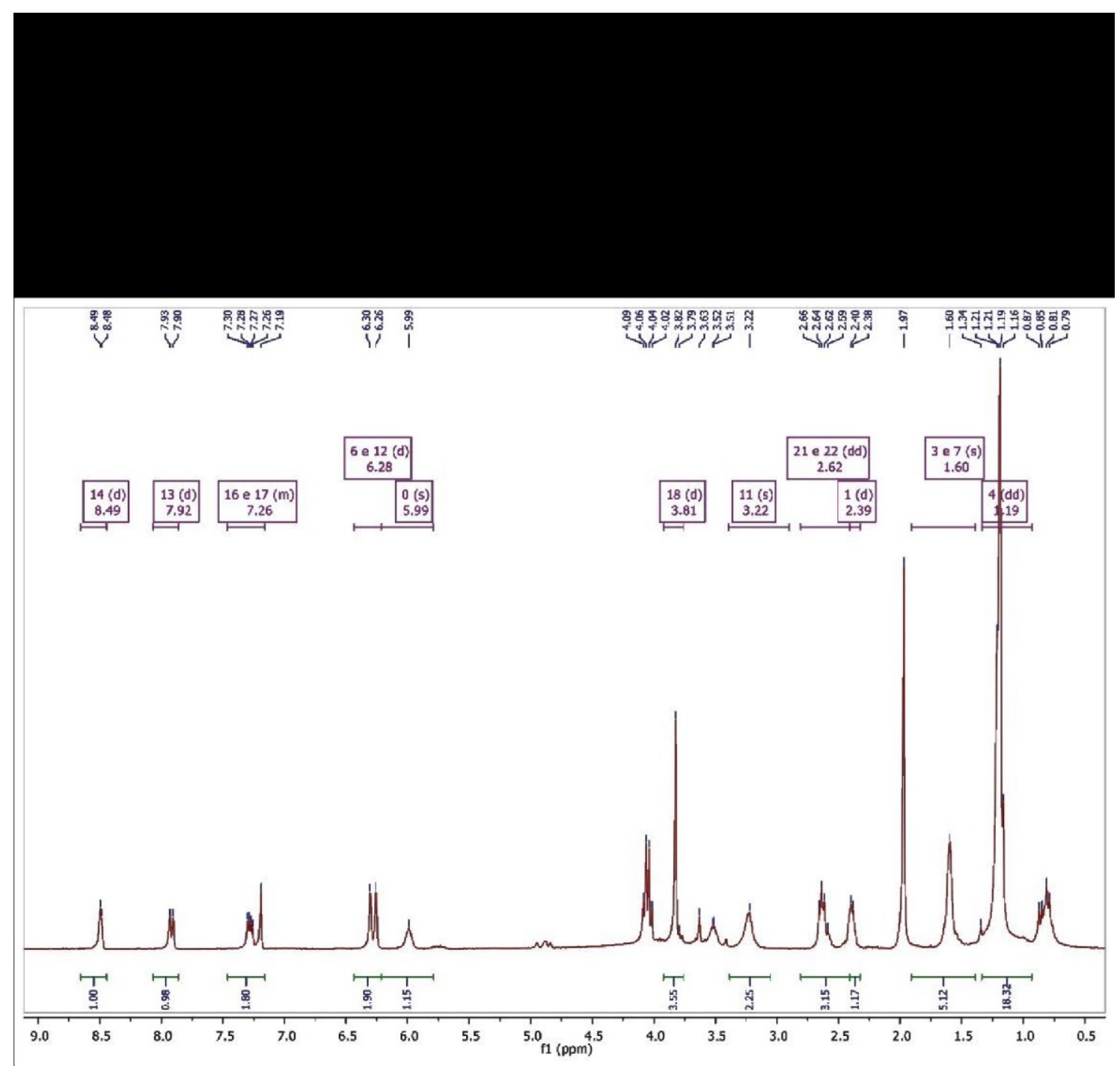

Espectro 4. RMN de $1 \mathrm{H}$ do produto Pq-Suc.

${ }^{1} \mathrm{H}-\mathrm{RMN}\left(\mathrm{CDCl}_{3}\right), 300 \mathrm{MHz}, \mathrm{Q}=\mathrm{ppm}$

$\mathrm{H} 14: 8.49(\mathrm{~d}, J=3.0 \mathrm{~Hz}, 1 \mathrm{H}), \mathrm{H} 13: 7.92(\mathrm{~d}, J=8.1 \mathrm{~Hz}, 1 \mathrm{H}), \mathrm{H} 16$ e H17: $7.46-7.16$ (m, 2H), H6 e H12: 6.28 (d, $J=14.3 \mathrm{~Hz}, 2 \mathrm{H}$ ), H0: 5.99 (s, 1H), H18: 3.81 (d, $J=9.3 \mathrm{~Hz}, 3 \mathrm{H}$ ), H11: 3.22 (s, 2H), H21 e H22: 2.62 (dd, $J=13.4,7.0 \mathrm{~Hz}, 4 \mathrm{H}$ ), H1: 2.39 (d, $J=6.0 \mathrm{~Hz}$, 1H), H3 e H7: 1.60 (s, 4H), H4: 1.19 (dd, $J=10.0,4.3 \mathrm{~Hz}, 3 \mathrm{H}$ ). 


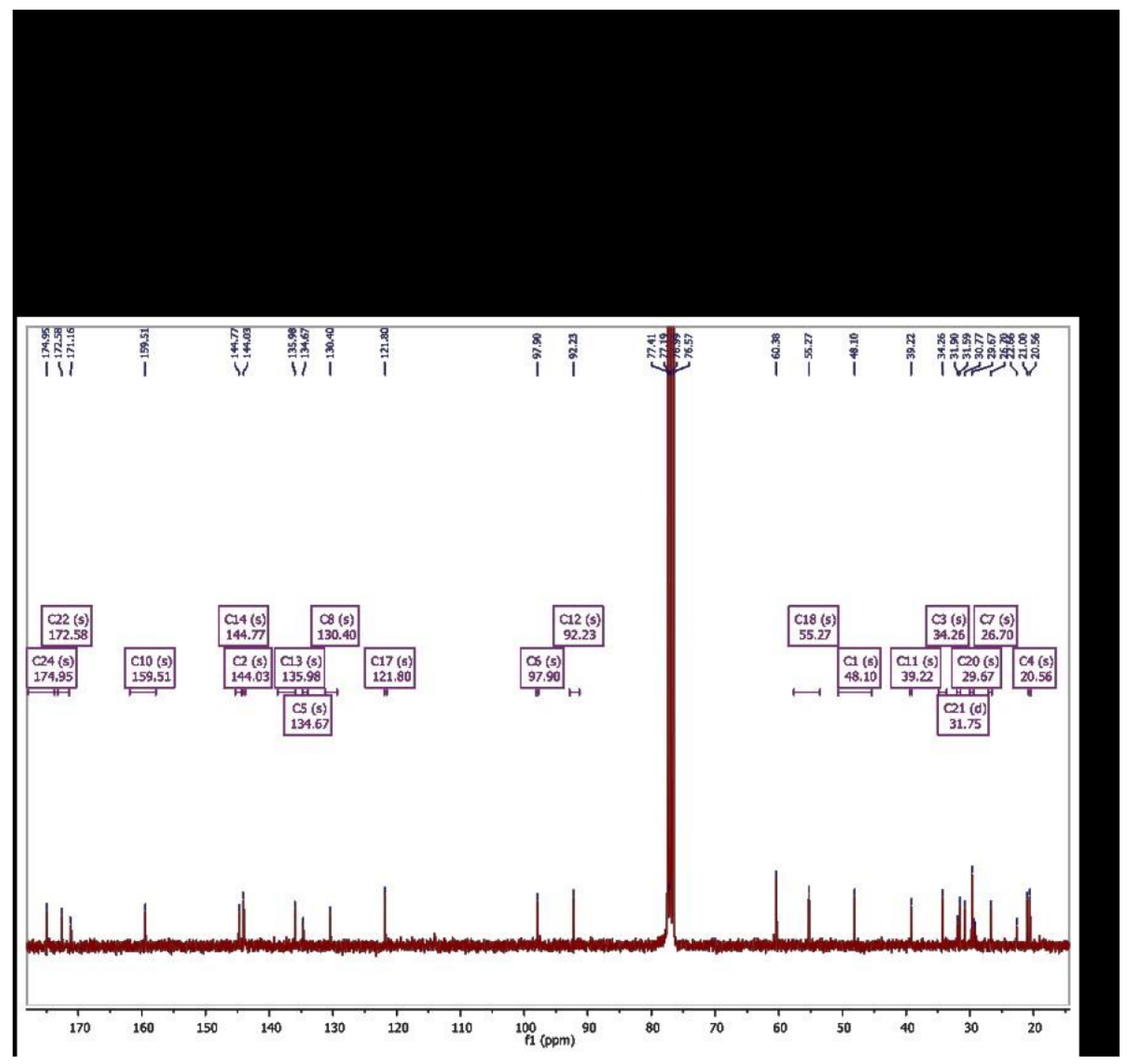

Espectro 5. RMN de $13 \mathrm{C}$ do produto Pq-Suc.

${ }^{13} \mathrm{C}-\mathrm{RMN}\left(\mathrm{CDCl}_{3}\right), 75 \mathrm{MHz}, \mathrm{Q}=\mathrm{ppm}$

C24: 174.95, C22: 172.58, C10: 159.51, C14: 144.77, C2: 144.03, C13: 135.98, C5: 134.67, C8: 130.40, C13: 121.80, C6: 97.90, C12: 92.23, C18: 55.27, C1: 48.10, C11: 39.22, C3: 34.26, C21: 31.75, C20: 29.67, C7: 26.70, C4: 20.56.

\subsubsection{Síntese dos pró-fármacos dendriméricos de geração 0 (G0lso e G0-Pq)}

Para a síntese dos dendrímeros de geração 0 (G0-Iso e G0-Pq), utilizouse a esterificação de Steglich, a qual contém um agente condensante, geralmente dicicloexilcarbodiimida (DCC), além de um catalisador básico, o 
4dimetilaminopiridina (DMAP), por exemplo. Nas reações com DCC e DMAP, há um primeiro ataque no DCC pela carbonila do ácido (previamente desprotonada pelo nitrogênio do DCC), que é, então, substituído, em um segundo ataque, pelo DMAP. Após o acoplamento com o DMAP, há a liberação de dicicloexilureia (DCU) , subproduto característico da reação. Assim, forma-se um intermediário com carga positiva e excelente grupo de saída, facilitando o ataque nucleofílico do álcool. Este mecanismo de reação é ilustrado na Figura 17 (NEISES et al, 1979).

Figura 14. Mecanismo de reação das reações com o agente condensante DCC (NEISES et al, 1979).

A remoção do DCU não é uma tarefa simples. Não se conseguiu retirar esse subproduto em nenhum dos compostos sintetizados por este método. $O$ Espectro 6, por exemplo, demonstra este resultado. Neste, é possível verificar os sinais característicos desta impureza na região entre 1 e 1,5 ppm.

Tentaramse, assim, outros métodos para a síntese dos produtos aqui planejados. 


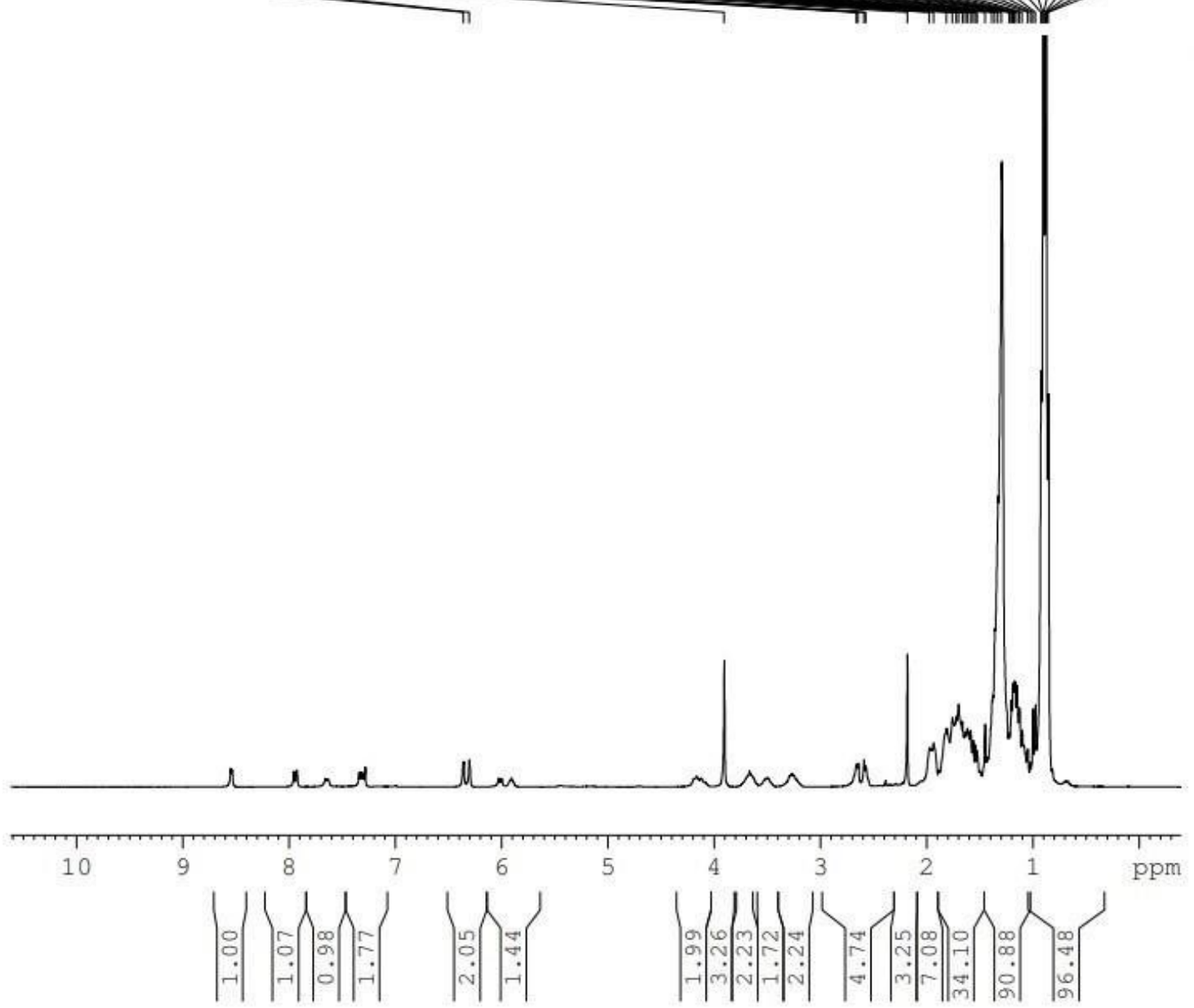

Espectro 6. RMN de $1 \mathrm{H}$ do produto G0-Pq. Observam-se os sinais característicos do DCU na região entre 1-1,5 ppm.

Uma tentativa de formação de G0-Iso, sem a utilização de DCC, foi a formação de cloreto de ácido in situ a partir da Iso-suc para, posteriormente, reagir com o G0. Essa reação aconteceu usando cloreto de oxalila, que é, inicialmente, atacado pelo oxigênio da carbonila do DMF e, após uma série de rearranjos, há um ataque de um ânion $\mathrm{Cl}^{-}$e a liberação de $\mathrm{HCl}$ e $\mathrm{CO}_{2}$. A Figura 18 ilustra o mecanismo (CHAUDHARI, AKAMANCHI, 1999). 


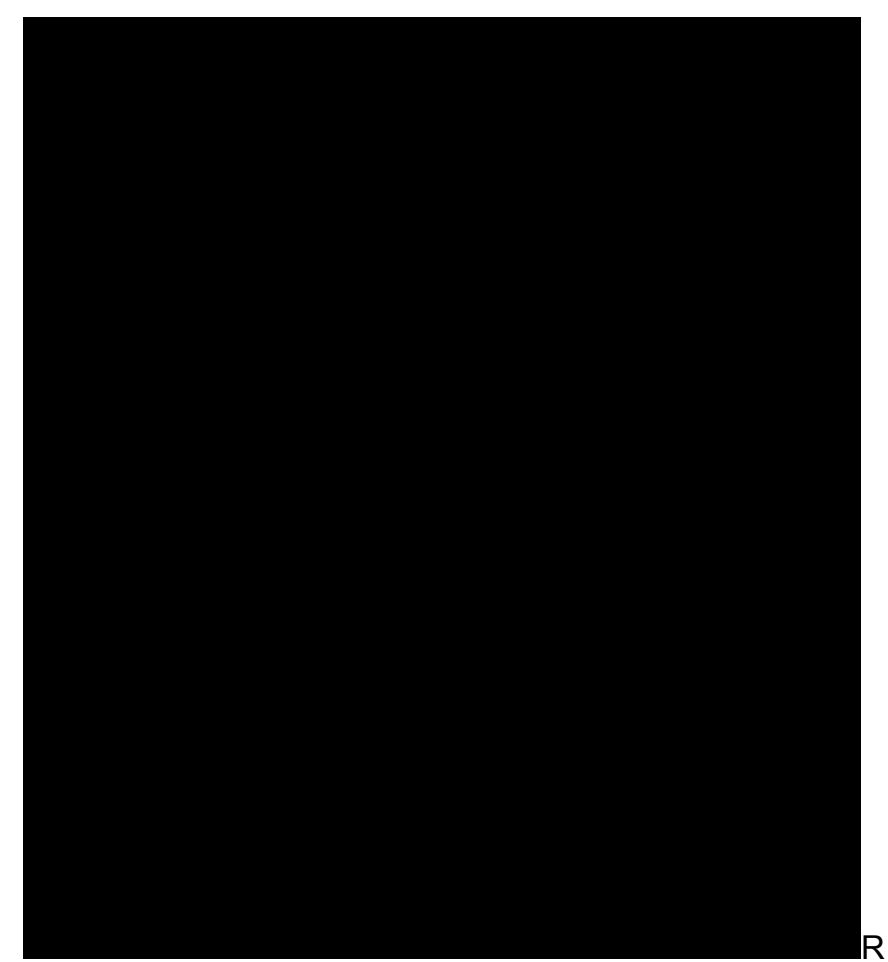

Figura 15. Mecanismo de reação de formação de cloreto de ácido utilizando cloreto de oxalila (CHAUDHARI, AKAMANCHI, 1999)

A reação não foi bem-sucedida. Após o procedimento de purificação em coluna cromatográfica, não houve o aparecimento de algum sinal na CCD. Isso possivelmente aconteceu devido a presença de água no solvente e/ou na base utilizada na reação. Haveria, portanto, a necessidade de destilações e processos de secagem de todos os reagentes para se alcançar sucesso por este método.

Na tentativa de evitar a formação de DCU, substituiu-se o DCC por outro agente condensante, o 1-etil-3,3-(dimetiaminopropil)carbodiimida (EDC). O mecanismo da reação é o mesmo, porém, o subproduto formado é o 1(3(dimetilamino)-propil-3-metilureia (EDU), como ilutrado na Figura 19. Este composto é retirado de modo mais fácil, uma vez que, na sílica da coluna cromatográfica, a amina terciária é protonada e fica retida na fase estacionária (MOONEY et al, 2010).<smiles>CN=C=NCCCN(C)CCCCCCC(=O)NCCCN(C)C</smiles>

Figura 16. Esquema simplificado da transformação de EDC em EDU nas reações de esterificação. 
Nos espectros de RMN de ${ }^{1} \mathrm{H}$ (Espectro 10) e ${ }^{13} \mathrm{C}$ (Espectro 11) do GOPq, há os sinais característicos já discutidos da Pq-Suc em 3,18 ppm (H13), 2,55 ppm (H16) e 2,33 ppm (H17). Já no RMN de ${ }^{13} \mathrm{C}$, observaram-se 28,69 ppm (C17), 30,10 ppm (C16) e 38,55 (C13). Os sinais a mais característicos deste prófármaco são os dos hidrogênios e carbonos do pentaeritritol. No RMN de ${ }^{1} \mathrm{H}$, há os sinais em 3,93 ppm ( $\mathrm{H} 19)$ para os grupos substituídos e 3,54 $\left(\mathrm{H} 19^{*}\right)$ para os não substituídos. No RMN de ${ }^{13} \mathrm{C}$, há o sinal em 59,65 ppm referente ao C19. Vale ressaltar que o sinal dos três hidrogênios $\mathrm{H} 21$ da primaquina deslocam para a mesma região do $\mathrm{H} 19$ do pentaeritritol, aumentando o tamanho do sinal e sua integral. O RMN de ${ }^{1} \mathrm{H}$ mostra, também, que ainda há traços de acetato de etila utilizado na purificação, sendo que os sinais de seus hidrogênios apareceram em 4,08, 1,96 e 1,18 ppm. Este último está na mesma região do $\mathrm{H} 10$, o que pode modificar a sua integral. 


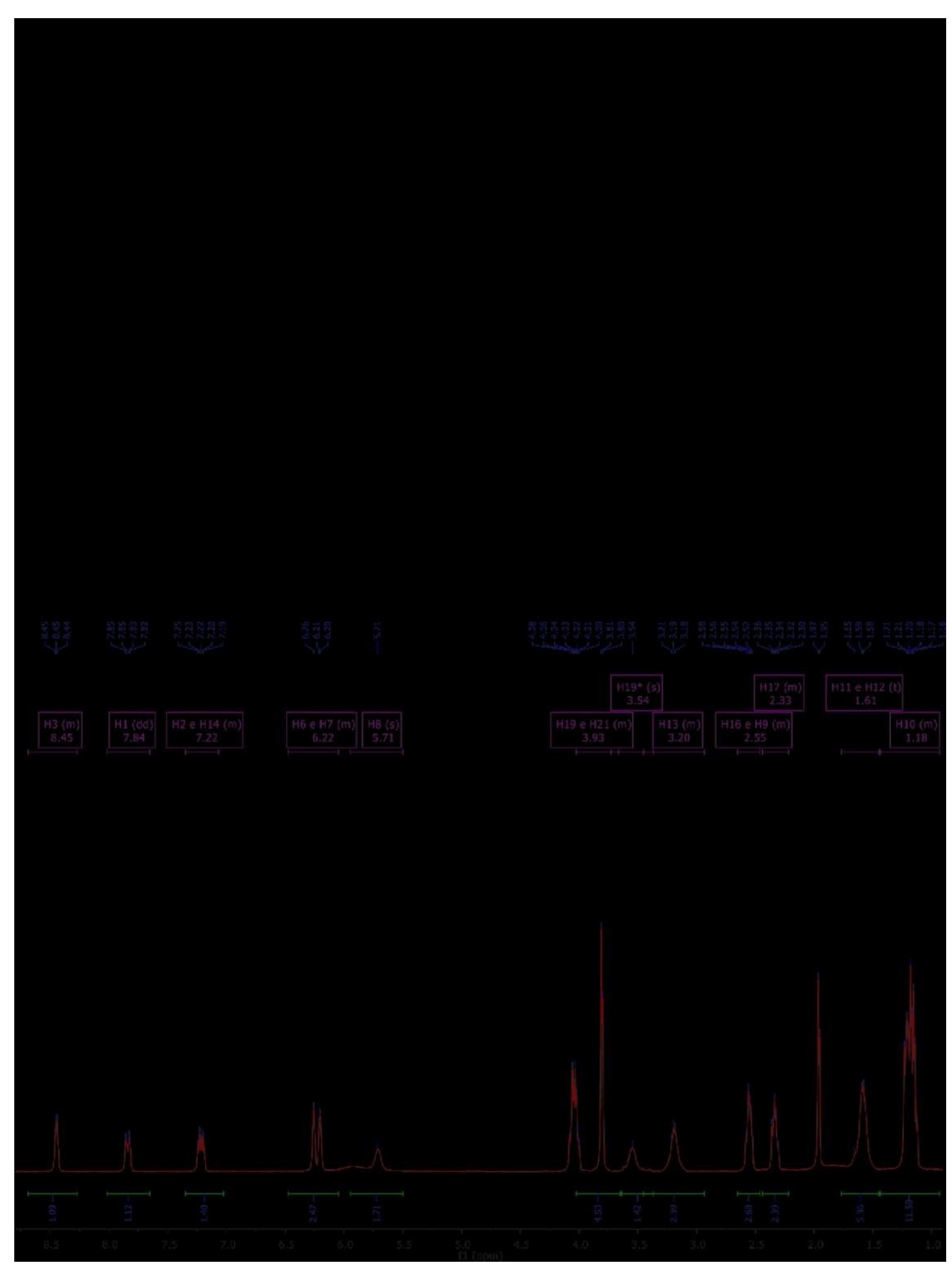

Espectro 7. Espectro de RMN de $1 \mathrm{H}$ do produto G0-Pq.

$$
{ }^{1} \mathrm{H}-\mathrm{RMN}\left(\mathrm{CDCl}_{3}\right), 300 \mathrm{MHz}, \mathrm{\square}=\mathrm{ppm}
$$

H3: $8.69-8.27(\mathrm{~m}, 1 \mathrm{H}), \mathrm{H} 1: 7.84(\mathrm{dd}, J=8.2,2.3 \mathrm{~Hz}, 1 \mathrm{H}), \mathrm{H} 12$ e H14: $7.35-7.07(\mathrm{~m}, 2 \mathrm{H}), \mathrm{H} 6$ e $\mathrm{H} 7: 6.47-6.05(\mathrm{~m}, 2 \mathrm{H}), \mathrm{H} 8: 5.71(\mathrm{~s}, 1 \mathrm{H}), \mathrm{H} 19$ e H21: $4.02-3.66(\mathrm{~m}, 5 \mathrm{H}), \mathrm{H} 19^{*}: 3.54(\mathrm{~s}, 1 \mathrm{H}), \mathrm{H} 13$ : $3.45-2.93(\mathrm{~m}, 2 \mathrm{H}), \mathrm{H} 16$ e H9: $2.65-2.46(\mathrm{~m}, 3 \mathrm{H}), \mathrm{H} 17: 2.44-2.22(\mathrm{~m}, 2 \mathrm{H}), \mathrm{H} 11$ e H12: $1.61(\mathrm{t}, J=11.1 \mathrm{~Hz}, 4 \mathrm{H}), \mathrm{H} 10: 1.45-0.93(\mathrm{~m}, 3 \mathrm{H})$. 


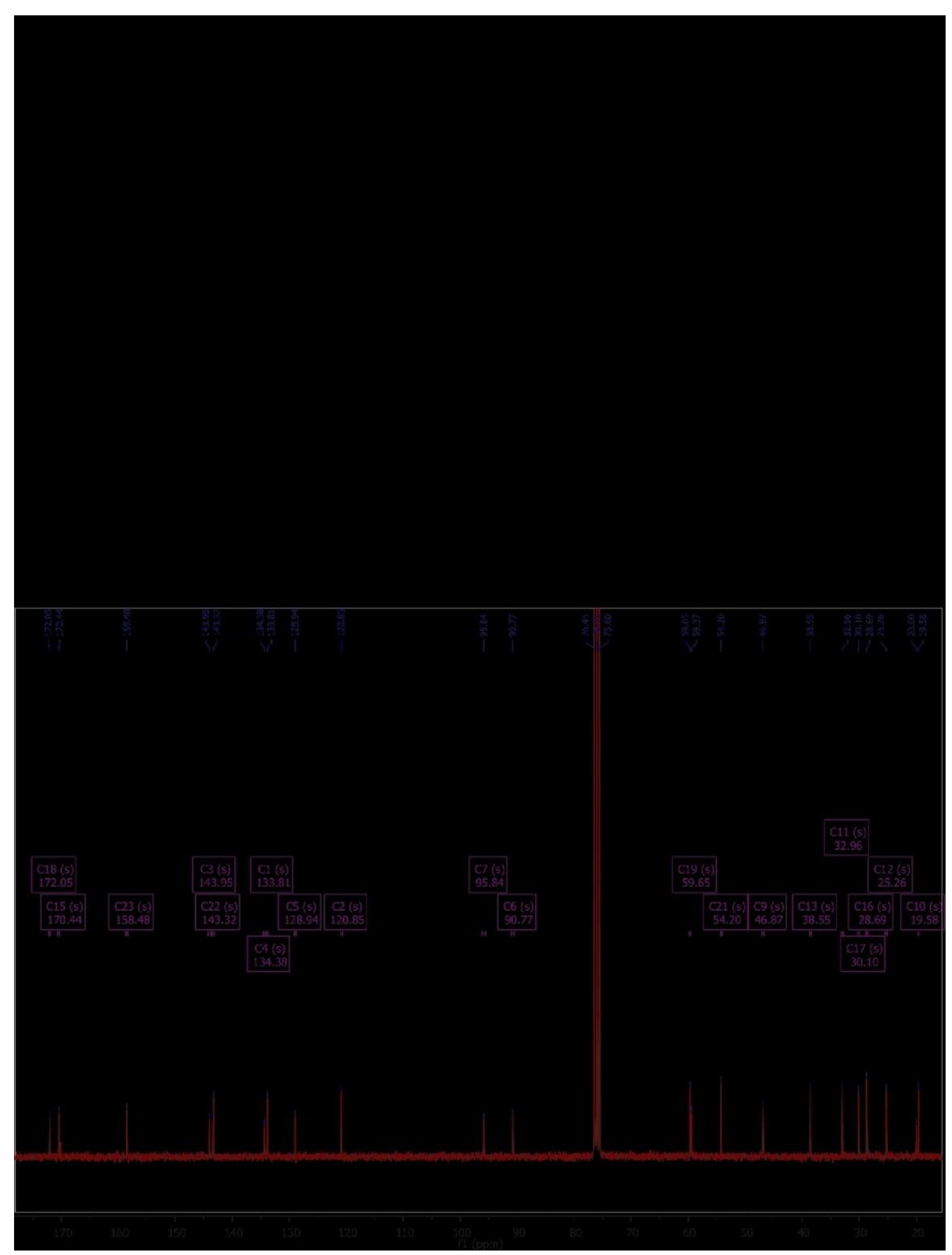

Espectro 8. RMN de $13 \mathrm{C}$ do produto G0-Pq.

${ }^{13} \mathrm{C}-\mathrm{RMN}\left(\mathrm{CDCl}_{3}\right), 75 \mathrm{MHz}, \mathrm{Q}=\mathrm{ppm}$

C18: 172.05, C15: 170.44, C23: 158.48, C3: 143.95, C22: 143.32, C1: 134.38, C4: 133.81, C5: 128.94, C2: 120.85, C7: 95.84, C6: 90.77, C19: 59.65, C21: 54.20, C9: 46.87, C13: 38.55, C11: 32.96, C17: 30.10, C16: 28.69, C12: 25.26, C10: 19.58. 
No IV do produto G0-Pq, assim como no do G0-Iso, destacam-se as bandas 1731 e $1651 \mathrm{~cm}^{-1}$ que correspondem, respectivamente, aos estiramentos de grupos éster e amida. A banda em $2932 \mathrm{~cm}^{-1}$, por sua vez, pode ser da amina secundária presente na estrutura da primaquina. Já a ausência de um sinal muito pronunciado em $3362 \mathrm{~cm}^{-1}$ pode representar a presença de poucas hidroxilas livres. A Espectro 12 ilustra o espectro de IV do G0-Pq.

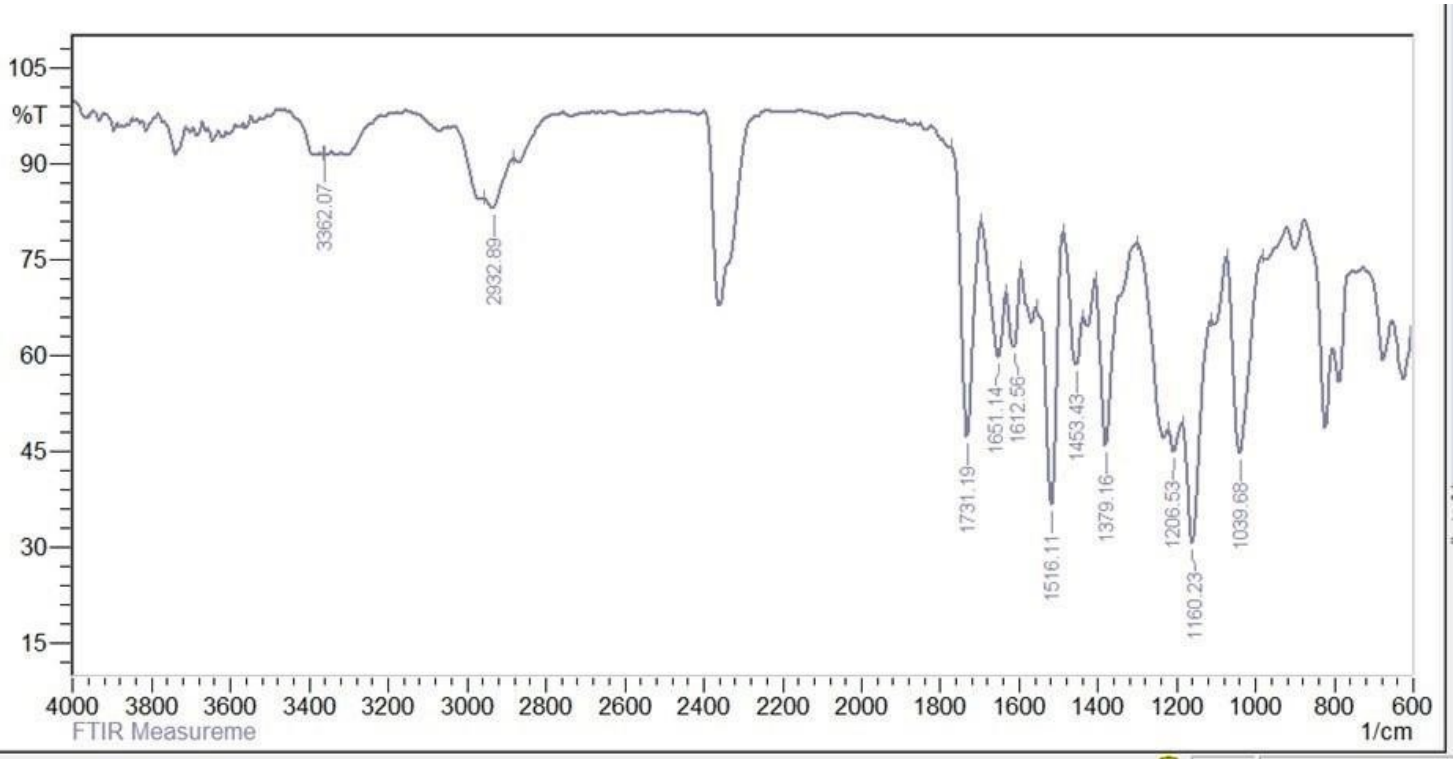

Espectro 9. Espectro no infravermelho do produto G0-Pq.

Nos espectros de RMN de ${ }^{1} \mathrm{H}$ (Espectro 7) e ${ }^{13} \mathrm{C}$ (Espectro 8) do G0-Iso, além dos sinais da Iso-Suc em 8,66 ppm (H1 e H3), 7,75 ppm (H9) e 2,79 ppm (H10), é possível notar a presença dos hidrogênios do pentaeritritol. No G0, há um carbono quaternário (C13) vinculado à quatro grupos hidroximetil (C12). No RMN de ${ }^{1} \mathrm{H}$ do pentaeritritol (Espectos II e III, Anexo I), há, somente, dois sinais: um singleto em 3,39 ppm, correspondendo aos hidrogênios do grupo metila ( $\mathrm{H} 12)$ e um sinal largo em 4,24 ppm, relacionado com os hidrogênios das hidroxilas. No RMN de ${ }^{13} \mathrm{C}$, por sua vez, apareceram dois sinais: um em 63,3 ppm, correspondente aos carbonos do grupo hidroximetil (C12) e outro em 48,2 ppm, relativo ao carbono central (C13). Esse último pode não aparecer em alguns espectros, uma vez que carbonos quaternários demandam mais tempo de análise, ou necessitam de aparelhos com uma frequência de campo maior (SILVERSTEIN, 2006). No Go-Iso, os sinais de H12 do G0 apareceram, no RMN de ${ }^{1} \mathrm{H}$, em 4,70 ppm. Já no RMN de ${ }^{13} \mathrm{C}$, os sinais de $\mathrm{C} 12$ foram vistos em 63,39 ppm. Vale destacar que há a presença de um pequeno sinal em 3,22 ppm 
(espectro de ${ }^{1} \mathrm{H}$ ), que corresponde ao $\mathrm{H} 12$ que não foi substituído, chamado então de $\mathrm{H} 12^{*}$.
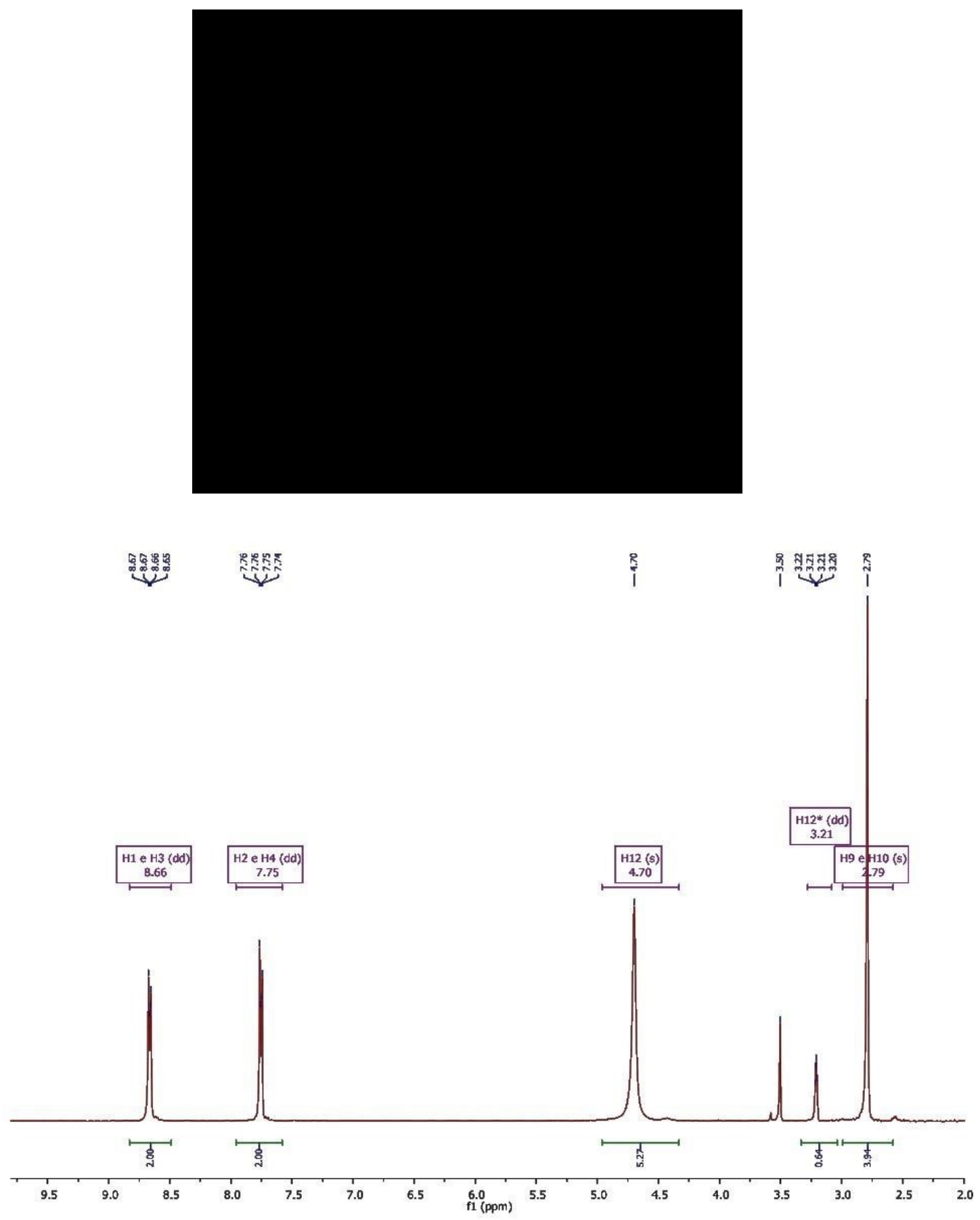

Espectro 10. RMN de $1 \mathrm{H}$ do produto G0-Iso.

$$
{ }^{1} \mathrm{H}-\mathrm{RMN} \text { (MeOD), } 300 \mathrm{MHz}, \mathrm{\square}=\mathrm{ppm}
$$

$\mathrm{H} 1 \mathrm{e} \mathrm{H} 3: 8.64$ (dd, $J=16.8,6.0 \mathrm{~Hz}, 2 \mathrm{H}), \mathrm{H} 2$ e H4: $7.93-7.39(\mathrm{~m}, 2 \mathrm{H}), \mathrm{H} 12: 4.70(\mathrm{~s}, 2 \mathrm{H})$, H12*: $4.14(\mathrm{~s}, 1 \mathrm{H}), \mathrm{H} 12: 3.77$ - $3.34(\mathrm{~m}, 2 \mathrm{H})$, H9 e H10: 2.89 - $2.31(\mathrm{~m}, 4 \mathrm{H})$. 


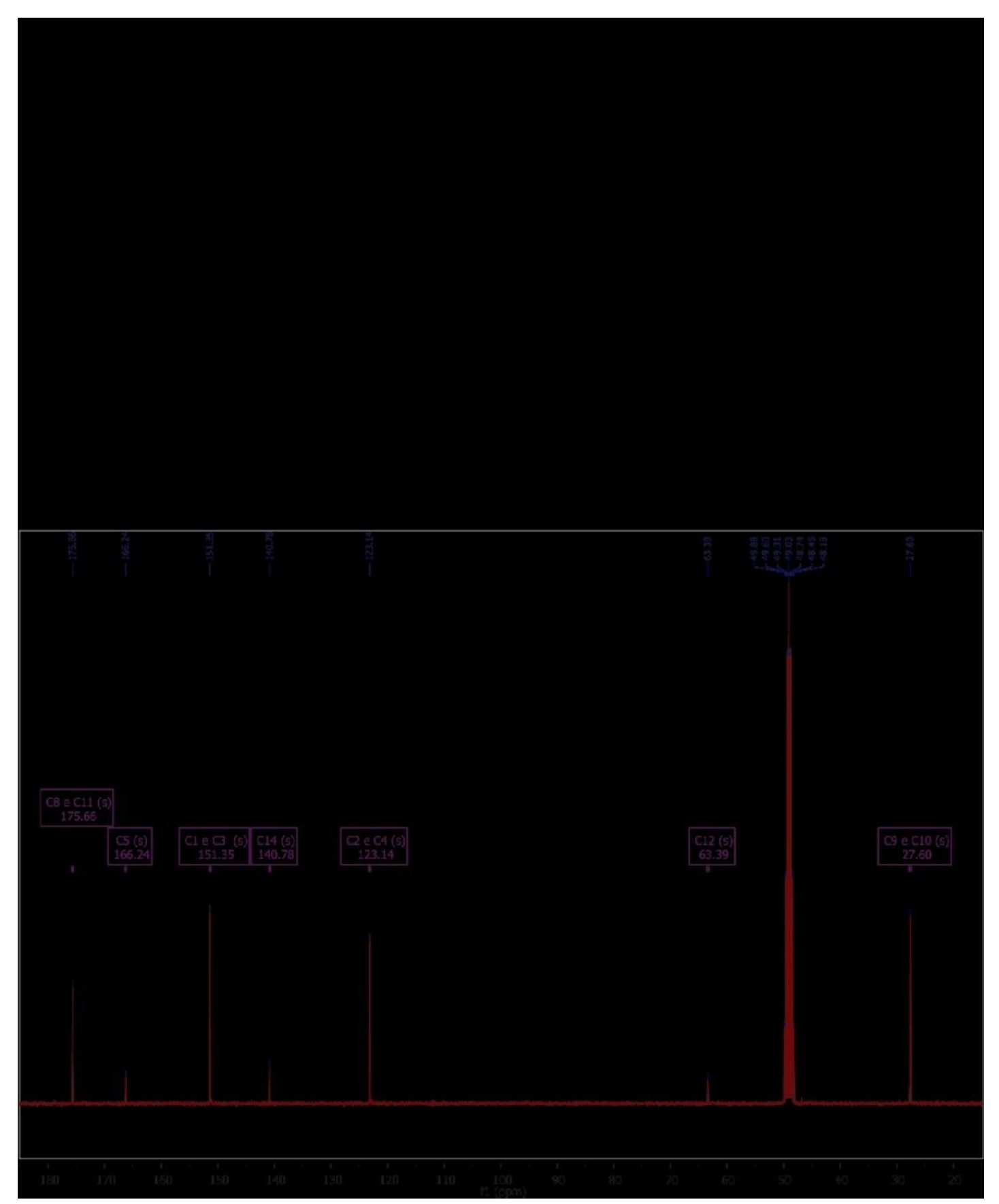

Espectro 11. RMN de $13 \mathrm{C}$ do produto G0-Iso.

${ }^{13} \mathrm{C}-\mathrm{RMN}(\mathrm{MeOD}), 75 \mathrm{MHz}, \mathrm{Q}=\mathrm{ppm}$

C8 e C11: 175.66, C5: 166.24, C1 e C3: 151.35, C14: 140.78, C2 e C4: 123.14, C12: 63.39, C9 e C10: 27.60 (s).

No IV do G0-iso (Espectro 9), destacam-se as bandas em 1723 e 1685 $\mathrm{cm}^{-1}$ representando os estiramentos de carbonila de éster e de amida, respectivamente. É importante destacar que a banda em $3279 \mathrm{~cm}^{-1}$, que 
representa as hidroxilas livres, foi bem pequena, indicando que a maioria destes grupos funcionais foi substituída.

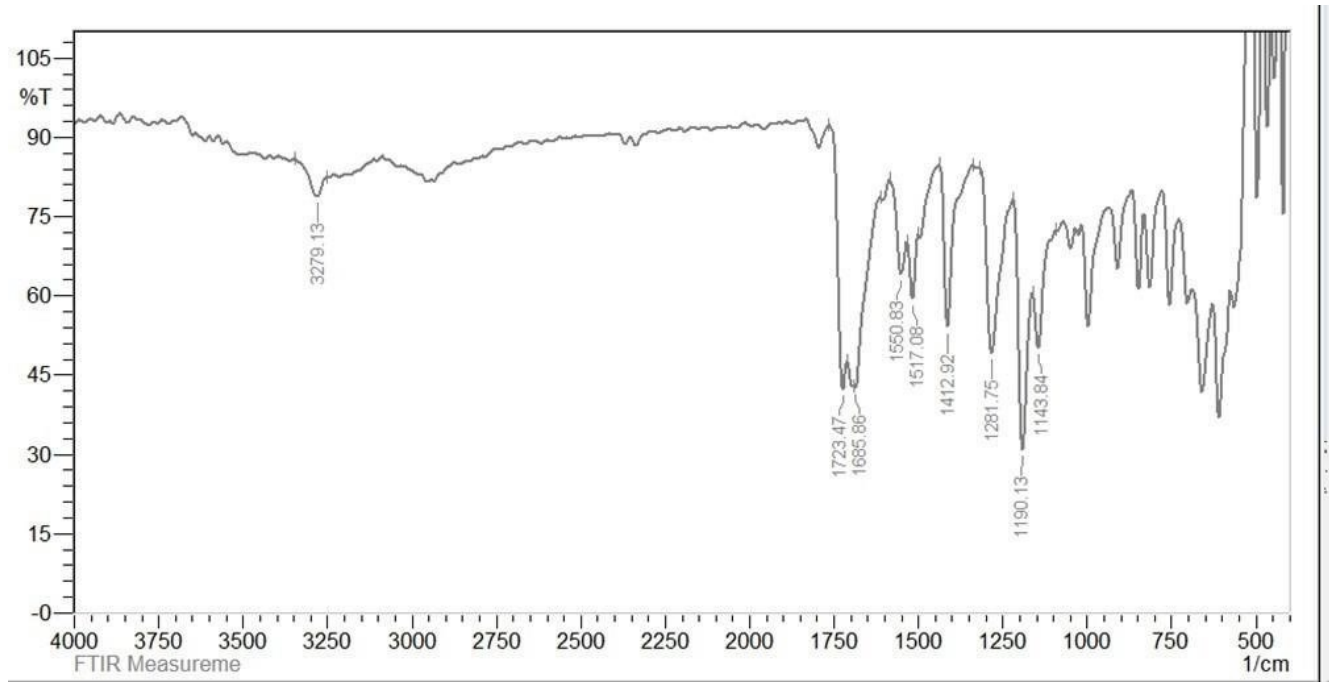

Espectro 12. Espectro no infravermelho do produto G0-Iso.

$\mathrm{Na}$ análise do resultado proveniente da Cromatografia Líquida acoplada à espectrometria de massas (LC-MS) do G0-Iso mostrou que, no picos de menor intensidade entre 4,5 minutos e 4,8 minutos e no de 8,1 minutos, houve a formação majoritariamente do produto monosubstituído $\left(\mathrm{M}+\mathrm{H}^{+}=238,5\right)$, ou seja, das quatro hidroxilas livres presentes no pentaeritritol, uma foi substituída. Há alguns sinais das outras substituições, porém com muito menos intensidade do que a monosubstituída. 


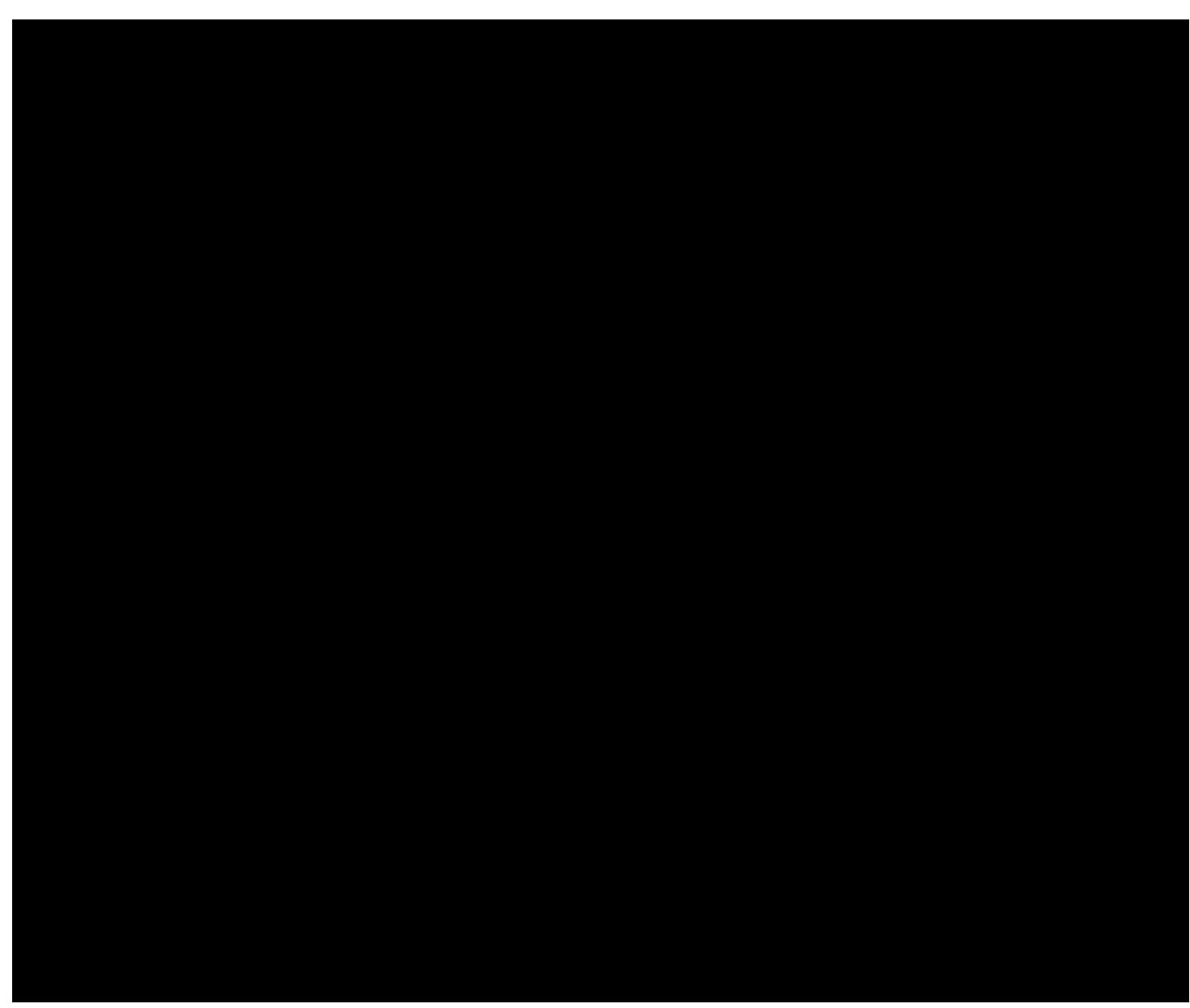

Figura 17. LC-MS de G0-Iso impuro. Condições de análise: Condições de análise no LC: solvente A (0,1\% Ácido Fórmico/Tampão fosfato pH 6,9, v/v); solvente B (Metanol). Proporção de solvente $95 \%$ de A e $5 \%$ de B. Gradiente de fluxo de 0,6 a $1,3 \mathrm{~mL} / \mathrm{min}$ por 10 minutos. Condições de análise no MS: voltagem no capilar (4500 V) e temperatura $\left(325^{\circ} \mathrm{C}\right), 20$ Dde amostra.

Importante mencionar, ainda, que o o resultado de LC-MS revelou um componente importante $[\mathrm{M}+\mathrm{H}+]=220,02$, eluído em 12,8 minutos , que não é compatível com nenhum reagente ou dendrímero substituído. 
Figura 18. Composto do pico majoritário do LC-MS .Condições de análise: Condições de análise no LC: solvente A (0,1\% Ácido Fórmico/Tampão fosfato pH 6,9, v/v); solvente B (Metanol). Proporção de solvente $95 \%$ de A e $5 \%$ de B. Gradiente de fluxo de 0,6 a $1,3 \mathrm{~mL} / \mathrm{min}$ por 10 minutos. Condições de análise no MS: voltagem no capilar (4500 V) e temperatura $\left(325^{\circ} \mathrm{C}\right), 20 \mathrm{D}$ de amostra.

Ademais, o Rf deste produto em CCD (valor de 0,65 em fase móvel Acetato de Etila:Metanol (8:2), v/v) indicava a formação de um sub-produto. Considerando a estrutura química da Iso-Suc, possivelmente, ocorreu um ataque nucleofílico intramolecular dos nitrogênios da hidrazona ao ácido carboxílico livre. Esse ataque resultaria em um subproduto ciclizado de 5 ou 6 membros (Figura 22). Tanto o subproduto de 5 membros, quanto o de 6 , tem uma $[\mathrm{M}+\mathrm{H}+]$ de 220 $\mathrm{g} / \mathrm{mol}$ e o $\log \mathrm{P}$, quando comparado aos reagentes, corroboram com os dados encontrados na CCD. Todas estas informações estão descritas na Figura 23, que mostra o valor de logP muito similar das duas moléculas, o que indica dificuldade de separa-las na cromatografia.
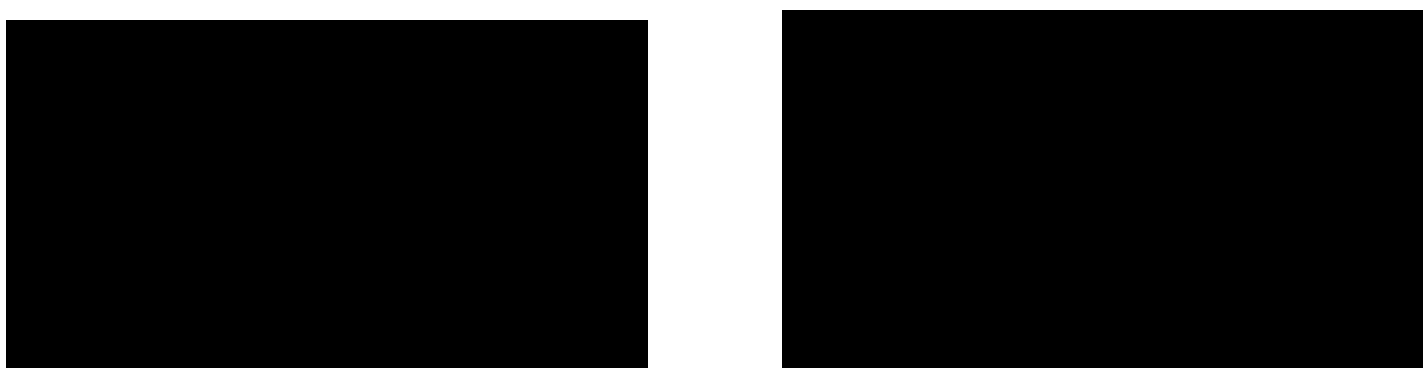

Figura 19. Estruturas químicas e algumas das propriedades da Clso-Suc de 6 e 5 membros.

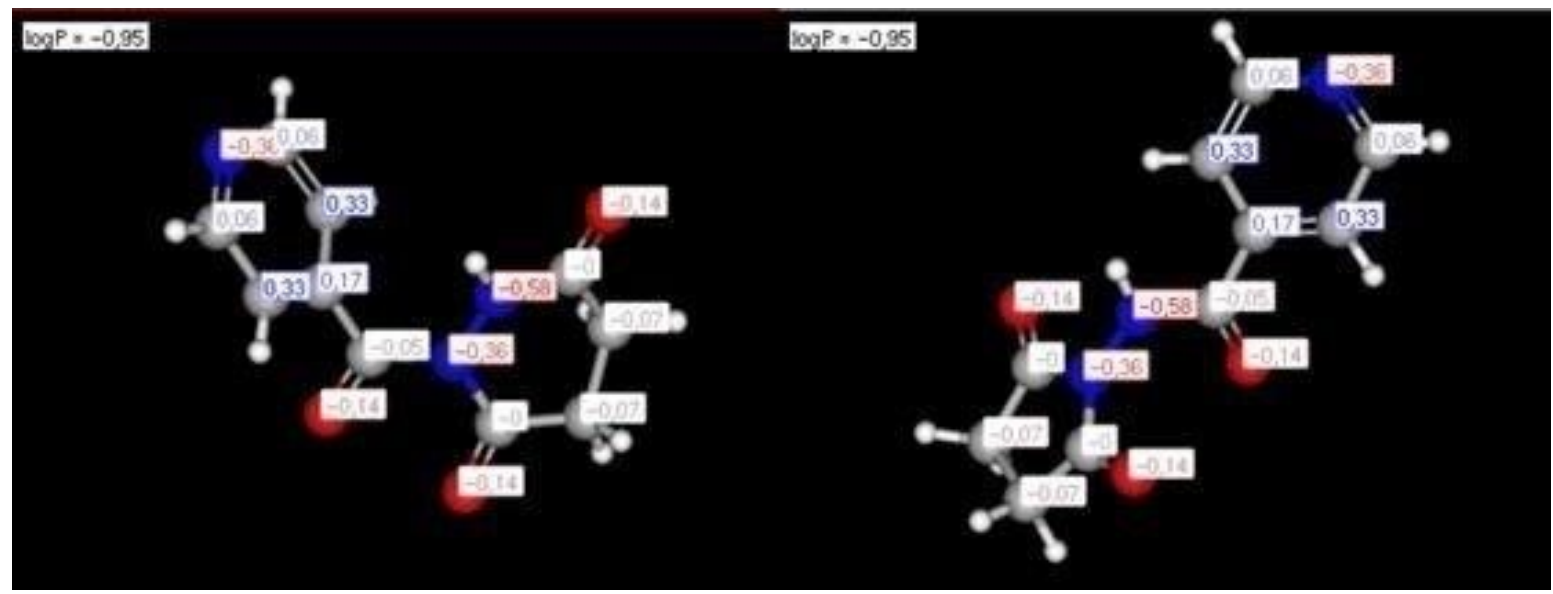

Figura 20. LogP da Clso-Suc de 6 membros (esqueda) e 5 membros (direita).

Afim de tentar entender o mecanismo de reação relacionad com a formação desses subprodutos, foram feitos experimentos trocando as condições 
reacionais. Devido ao fato de serem nitrogênios provenientes de amidas, o ataque intramolecular do nitrogênio na carbonila so poderia ser favorecido frente ao ataque das hidroxilas livres do pentaritritol, caso os nitrogênios da hidrazona fossem desprotonados, ganhando assim uma carga negativa. Assim, esses nitrogênios seriam mais eletronegativos do que as hidroxilas, favorecendo o seu ataque. Essa carga então poderia reagir com o ácido carboxílico. Ao retirar o próton o ataque poderia ocorrer vindo do nitrogênio mais próximo ao anel aromático, formando o ciclizado de 6 membros. Esse ataque também pode ocorrer vindo do nitrogênio mais próximo ao ácido succínico, formando assim o derivado de 5 membros. O mecanismo proposto está exposto na Figura 24. (CLAYDEN, et al, 2012)

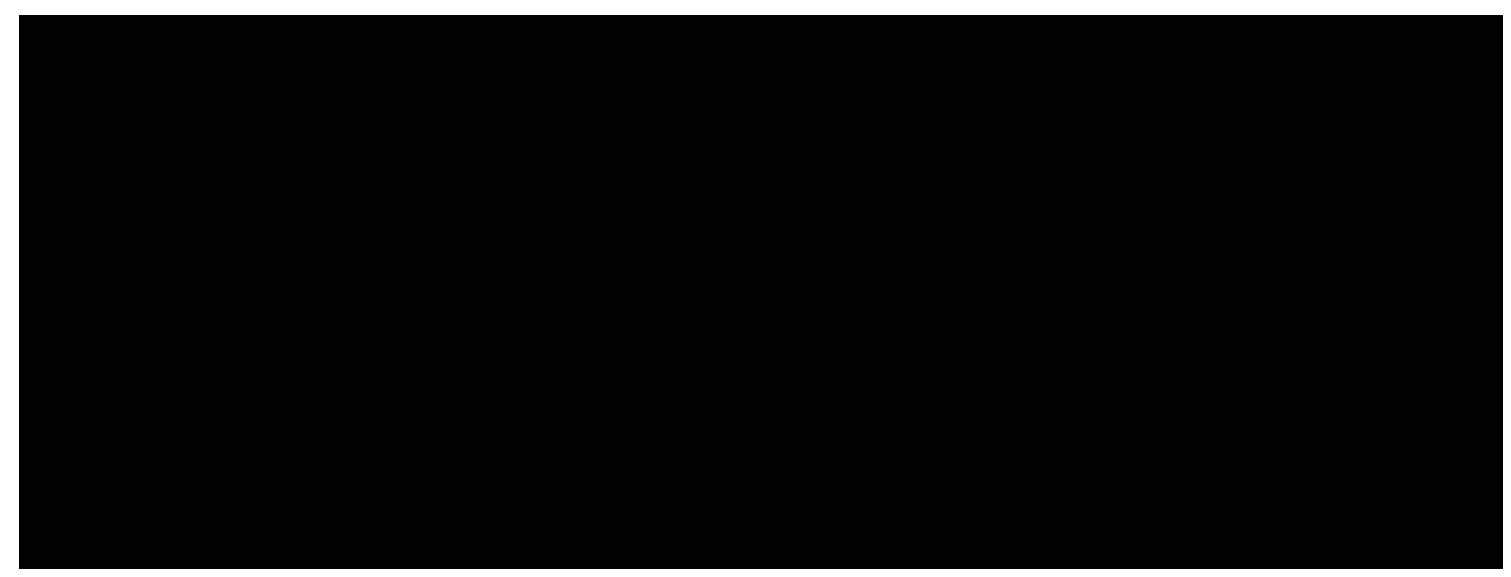

Figura 21. Mecanismo proposto de formação da Clso-Suc.

O valor de pKa dos hidrogênios acoplados aos nitrogênios da Iso-Suc são de 9,04 e 11,46, assim, na presença de EDC com a sua amina terciária e o DMAP que é uma base orgânica, seria possível a desprotonação de algum desses nitrogênios. Com isso, foi testado uma reação utilizando DCC e hidroxibenzotrazol (HOBT), ambos não contém nenhum grupo que seja capaz de retirar os prótons, e não houve sinal de formação de Clso-Suc, o que é um indicativo de que o mecanismo proposto está correto.

Os RMN's de ${ }^{1} \mathrm{H}$ e ${ }^{13} \mathrm{C}$ das formas cilcizadas são muito similares aos encontrados para a Iso-Suc, havendo sinais nas mesmas regiões, com os iguais valores das integrais. Ademais, por técnicas de RMN, é muito difícil diferenciar qual dos produtos ciclizados foi formado, ou seja, com 5 ou o de 6 membros (SILVERSTEIN, 2006). Como apresentado no Espectro 13 (RMN de ${ }^{1} \mathrm{H}$ ), foram observados sinais dos hidrogênios do anel aromático entre 7 e 9 ppm, bem como 
os hidrogênios ligados aos carbonos do ácido succínico estão entre 2,5 e 3 ppm. Do mesmo modo, o RMN de ${ }^{13} \mathrm{C}$ (Espectro 14) é bem semelhante ao da IsoSuc. Importante ressaltar que para Clso-Suc, de 5 ou 6 membros, verificaramse que os carbonos 11 e 14 apareceream em um único sinal com deslocamento químico de 174,01 ppm. Por ser uma banda só, ela pode indicar que a ligação formada é simétrica, situação que ocorre no no anel de 5 membros (CLAYDEN et al, 2012).

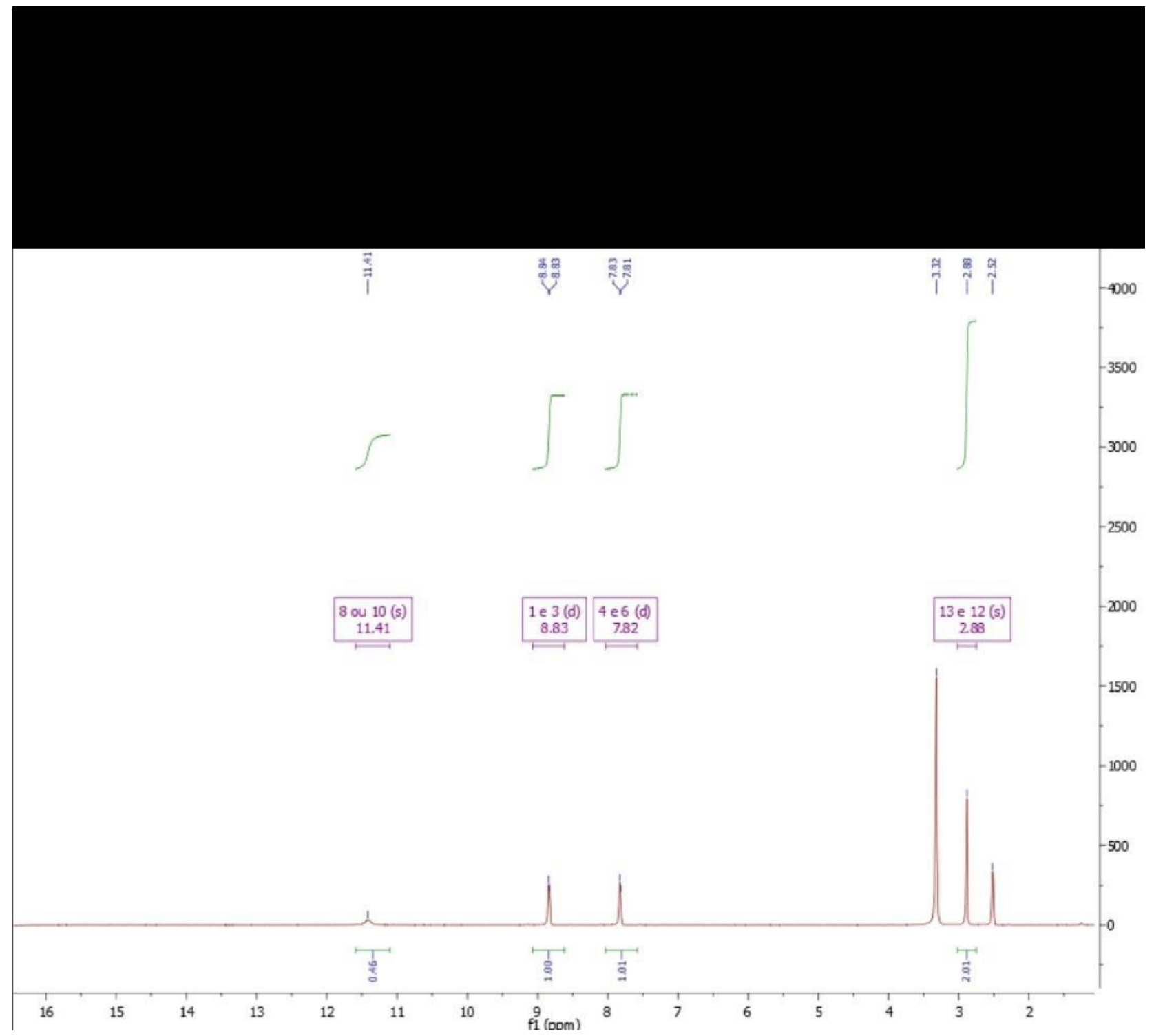

Espectro 13. Espectro de 1H RMN do produto Clso-Suc

${ }^{1} \mathrm{H}-\mathrm{RMN}$ (DMSO-D6), $300 \mathrm{MHz}, \mathrm{Q}=\mathrm{ppm}$

H8 ou 10: 11.41 (s, 1H); H1 e H3 8.83 (d, J = 4.3 Hz, 2H); H4 e H6: 7.82 (d, J = $4.3 \mathrm{~Hz}, 2 \mathrm{H}$ ); H13 e H14: 2.88 (s, 4H). 


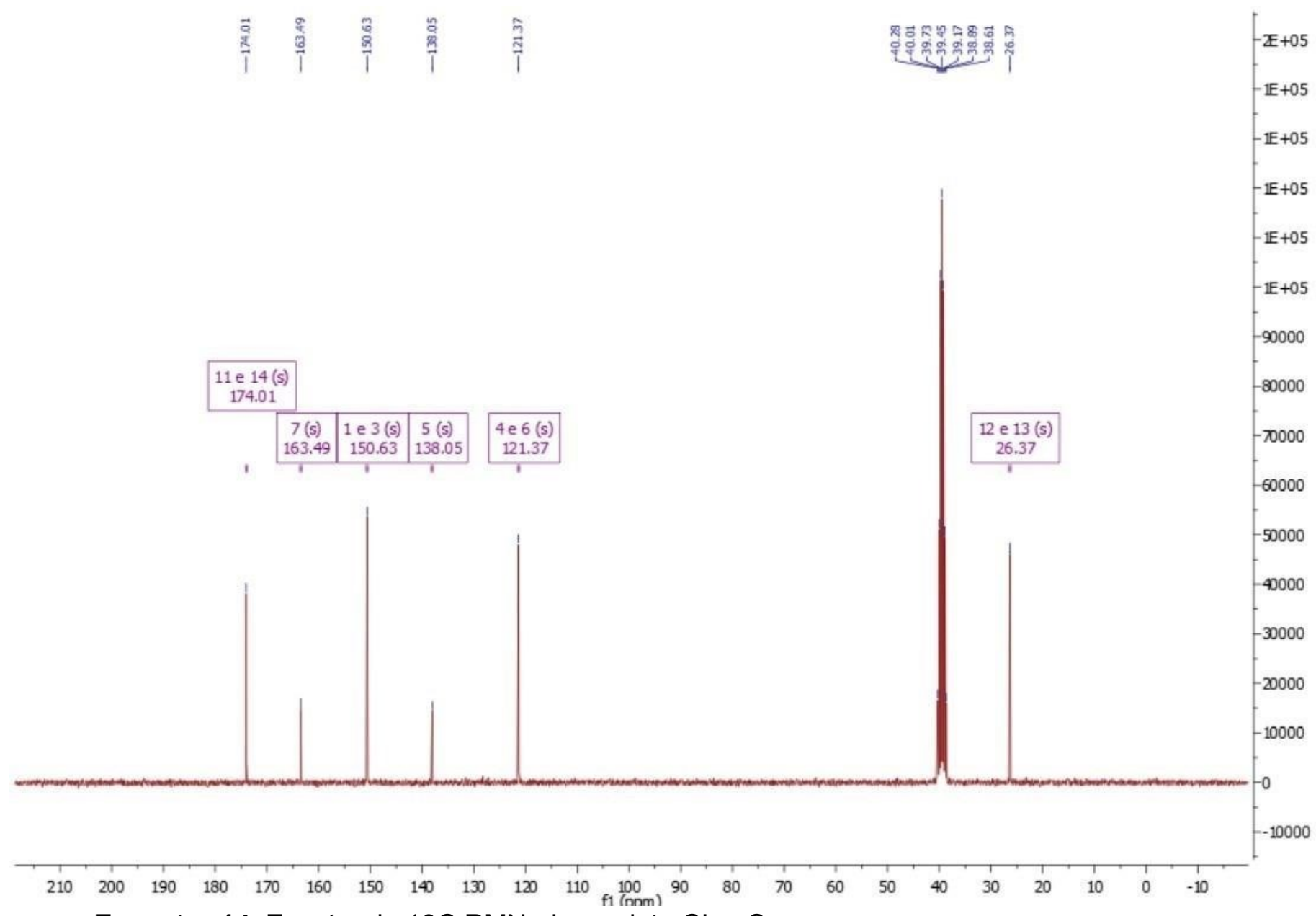

Espectro 14. Espetro de 13C RMN do produto Clso-Suc.

${ }^{13} \mathrm{C}-\mathrm{RMN}$ (DMSO), $75 \mathrm{MHz}, \mathrm{Q}=\mathrm{ppm}$

C11 e C14:174.01, C7: 167.49, C3 e C1: 150.63, C5: 138.05, C4 e C6: 121.37, C12 e C13: 26.37.

4.1.3. Síntese dos pró-fármacos dendriméricos de geração 1 (G1Iso e G1-Pq) 
O dendrímero de geração $1(\mathrm{G} 1)$ é o pentaeritritol esterificado nas hidroxilas por quatro moléculas de Bis-MPA, totalizando 8 hidroxilas livres (Figura 25).

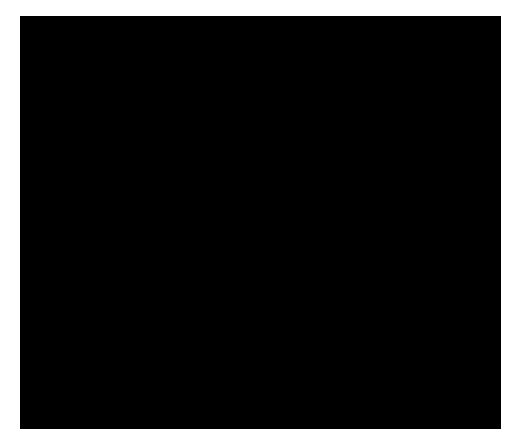

Figura 22. Dendrímero de Bis-MPA de geração 1.

Os experimentos com os dendrímeros de primeira geração utilizaram a mesma metodologia dos com geração 0 , ou seja, reações de acoplamentos com o agente condensante EDC e a base DMAP. Estes seguem, portanto, o mesmo mecanismo reacional, ilustrado na Figura 17. Importante mencionar, entretanto, que as diferenças principais entre as metodologias envolvendo $\mathrm{G} 0$ e G1 foram a proporção estequiométrica dos reagentes e o tempo de reação. Os métodos com geração 0 duravam, no máximo 3 dias. $O$ aumento do número de hidroxilas do G0 para o G1 justifica a necessidade de aumentar o tempo de reação.

No RMN de ${ }^{1} \mathrm{H}$ do material de partida (G1) (Espectro IV, anexo I), além dos sinais em 3,87 ppm do pentaeritritol $(\mathrm{H} 12)$, há o sinal em 3,12 ppm (H11), o qual está relacionado com os H11. Existe, também, um em 1,19 ppm (H10) correspondente à metila do Bis-MPA. Já no RMN de ${ }^{13} \mathrm{C}$, o principal carbono é o ligado a hidroxila (C11), que apareceu em 63,77 ppm (Espectro V, Anexo I). Em G1-Iso, por sua vez, observou-se um sinal em 4,70 ppm (H11), o qual teve um deslocamento de quase $0,8 \mathrm{ppm}$, quando comparado ao mesmo átomo do material de partida. Em 4,12 ppm apareceu um sinal que pode corresponder aos hidrogênios do derivado não substituído $\left(\mathrm{H} 11^{*}\right)$. Já no No $\mathrm{RMN}$ de ${ }^{13} \mathrm{C}$ não foi possível notar a diferença entre substituído e não substituído, sendo que o C11 apareceu em 66,01 ppm. 


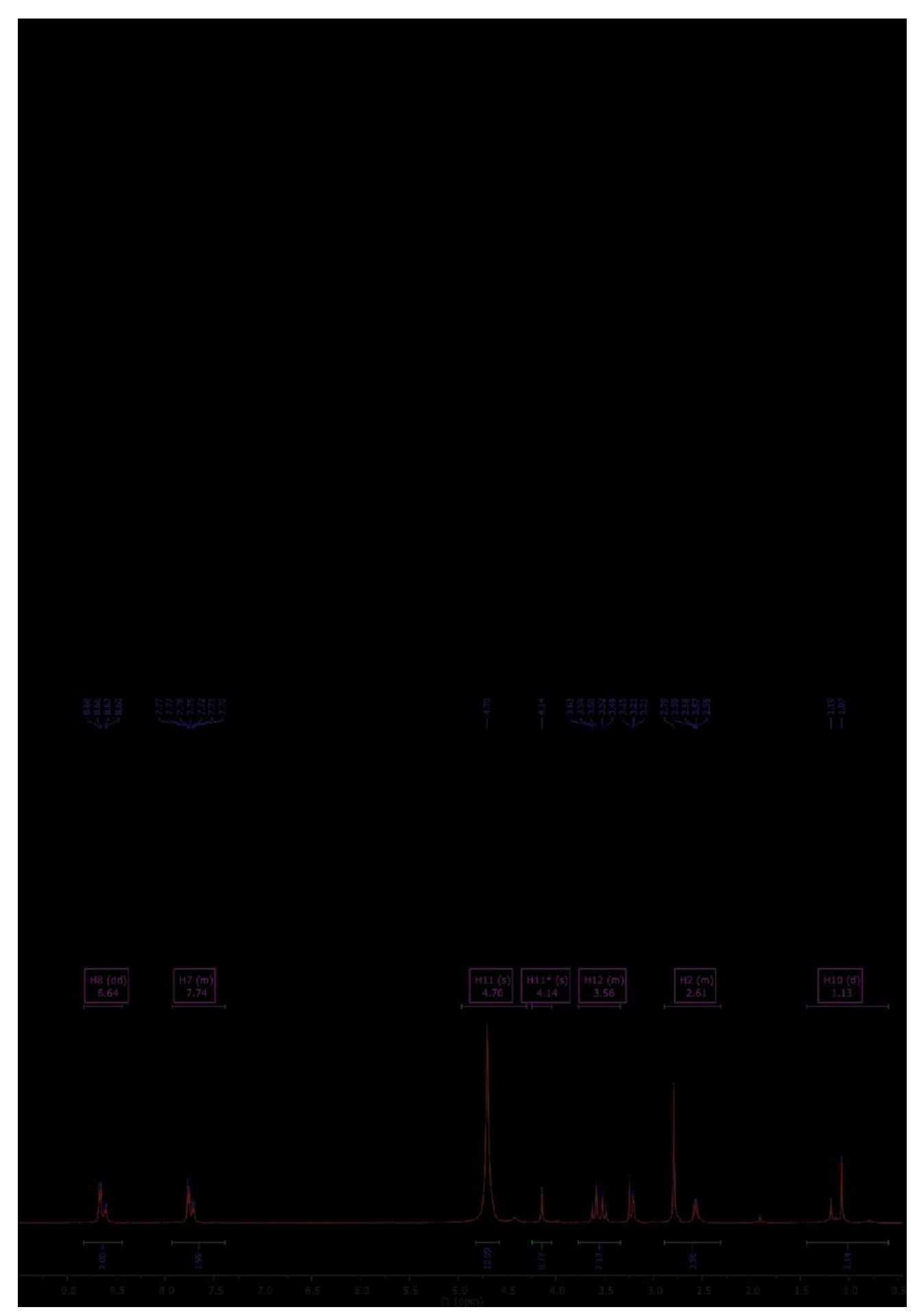

Espectro 15. RMN de $1 \mathrm{H}$ do produto G1-Iso.

${ }^{1} \mathrm{H}-\mathrm{RMN}(\mathrm{MeOD}), 300 \mathrm{MHz}, \mathrm{Q}=\mathrm{ppm}$

H8: 8.64 (dd, $J=16.8,6.0 \mathrm{~Hz}, 2 \mathrm{H}), \mathrm{H} 7: 7.93-7.39(\mathrm{~m}, 2 \mathrm{H}), \mathrm{H} 11: 4.70$ (s, 12H), H11*: $4.14(\mathrm{~s}, 1 \mathrm{H}), \mathrm{H} 12: 3.77-3.34(\mathrm{~m}, 2 \mathrm{H}), \mathrm{H} 2: 2.89-2.31(\mathrm{~m}, 4 \mathrm{H}), \mathrm{H} 10: 1.13(\mathrm{~d}, J=33.3 \mathrm{~Hz}$, $2 \mathrm{H})$. 


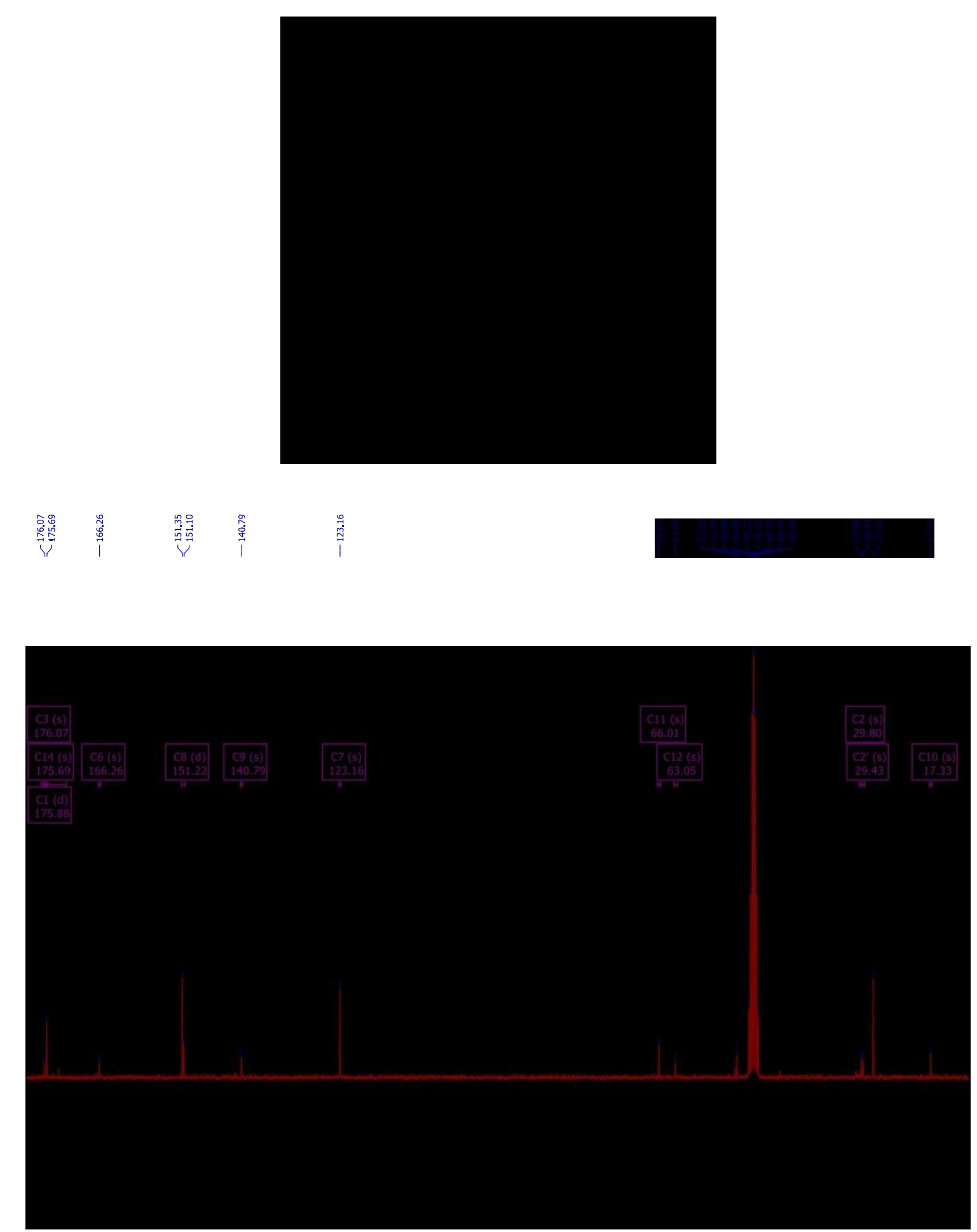

${ }^{13} \mathrm{C}-\mathrm{RMN}(\mathrm{MeOD}), 75 \mathrm{MHz}, \mathrm{Q}=\mathrm{ppm}$

C3: 176.07, C1: 175.88, C14: 175.69, C6: 166.26, C8: 151.22, C9: 140.79, C7: 123.16, C11: 66.01, C12: 63.05, C2: 29.80, C2': 29.43, C10: 17.33.

No pró-fármaco dendrimérico de G1 funcionalizado com primaquina (G1Pq), foi possível visualizar os sinais do dendrímero (H26 e H29) em 4,07 e 3,92 ppm, respectivamente, porém esse último apareceu com mesmo 
deslocamento químico do $\mathrm{H} 18$ da primaquina, em 3,92 ppm (Espectro 17). Esta região ficou, então, de difícil interpretação e as integrais não se mostraram como esperado. O sinal em 3,55 ppm é do derivado não substituído, por isso, recebeu a denominação de $\mathrm{H}_{2} 6^{*}$ para esta diferenciação. Todos os outros sinais, tanto da primaquina, quanto do espaçante, estão de acordo com o que já foi discutido anteriormente. Além disso, vale destacar que há traços de de acetato de etila utilizado na purificação, com os sinais em 1,18, 1,96 e 4,07 ppm. O primeiro e o último foram vistos nas mesmas regiões do produto desejado, o que pode explicar a variação no valor da integral. No RMN de ${ }^{13} \mathrm{C}$ é possível destacar o sinal em 59,65 ppm e 59,37 ppm referente ao C26 e C29 do dendrímero, além dos sinais 170,46 ppm e 172,06 ppm referentes aos carbonos de éster (C26 e C29) e de amida (C19). 


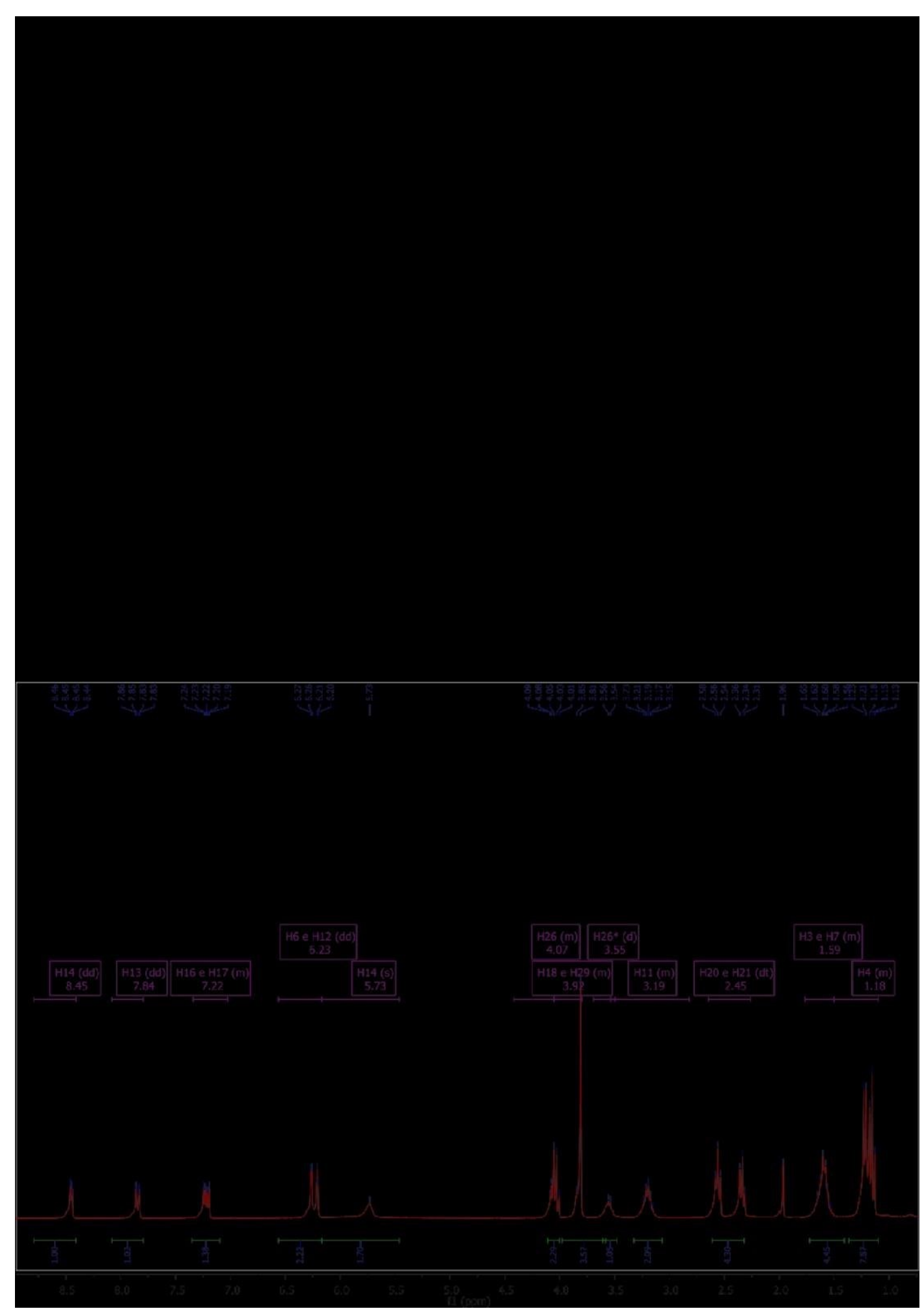

Espectro 17. RMN de $1 \mathrm{H}$ do produto G1-Pq.

${ }^{1} \mathrm{H}-\mathrm{RMN}\left(\mathrm{CDCl}_{3}\right), 300 \mathrm{MHz}, \mathrm{\square}=\mathrm{ppm}$

$\mathrm{H} 14: 8.45$ (dd, $J=4.2,1.6 \mathrm{~Hz}, 1 \mathrm{H}), \mathrm{H} 13: 7.84$ (dd, $J=8.3,1.5 \mathrm{~Hz}, 1 \mathrm{H}), \mathrm{H} 16$ e H17: $7.34-7.03(\mathrm{~m}, 2 \mathrm{H}), \mathrm{H} 6$ e H12: 6.23 (dd, J = 16.2, $2.4 \mathrm{~Hz}, 2 \mathrm{H}), \mathrm{H} 14: 5.73(\mathrm{~s}, 1 \mathrm{H}), \mathrm{H} 26$ $4.42-4.05(\mathrm{~m}, 2 \mathrm{H}), \mathrm{H} 18$ e H29 : $4.05-3.80(\mathrm{~m}, 5 \mathrm{H}), \mathrm{H} 26^{*}: 3.55$ (d, J=6.0 Hz, 1H), H11: $3.54-2.82(\mathrm{~m}, 2 \mathrm{H}), \mathrm{H} 20$ e H21: $2.45(\mathrm{dt}, J=66.3,6.8 \mathrm{~Hz}, 4 \mathrm{H}), \mathrm{H} 3$ e H7: $1.77-$ $1.50(\mathrm{~m}, 4 \mathrm{H}), \mathrm{H} 4: 1.50-1.10(\mathrm{~m}, 3 \mathrm{H})$. 


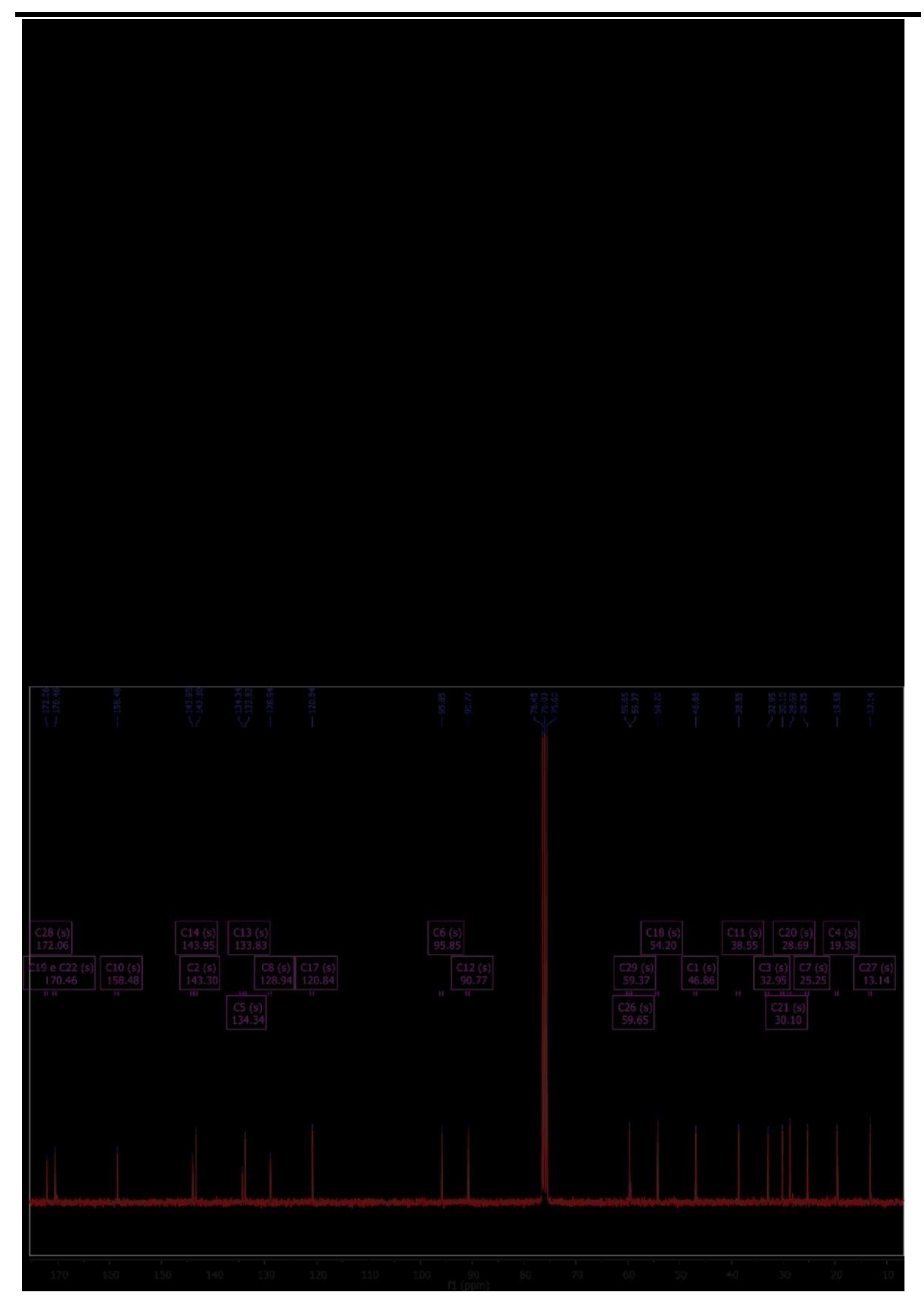

Espectro 18. RMN de $13 \mathrm{C}$ do produto G1-Pq.

${ }^{13} \mathrm{C}-\mathrm{RMN}\left(\mathrm{CDCl}_{3}\right), 75 \mathrm{MHz}, \mathrm{Q}=\mathrm{ppm}$ 
C28: 172.06, C19 e C22: 170.46, C10: 158.48, C14: 143.95, C2: 143.30, C5: 134.34, C13: 133.83, C8: 128.94, C17: 120.84, C6: 95.85, C12: 90.77, C29: 59.65, C26: 59.37, C18: 54.20, C1 46.86, C11: 38.55, C3: 32.95, C21: 30.10, C20: 28.69, C7: 25.25, C4: 19.58, C27: 13.14 .

\subsection{ESTUDOS IN SILICO}

Os estudos computacionais foram feitos em colaboração com aluna de Iniciação Científica Sophia Mikiko.

\subsubsection{Simulações de docking molecular entre os pró-fármacos dendriméricos e esterase inespecífica}

Nesta etapa do projeto, pretendeu-se avaliar, com a estratégia de docking molecular, as interações entre os dendrímeros G0-Iso e G0-Pq, bem como G1Iso e $\mathrm{G} 1-\mathrm{Pq}$ e a butirilcolinesterase, esterase inespecífica capaz de clivar ligações ésteres/amidas no organismo humano (STOK et al., 2004). Estes resultados serão úteis, portanto, para a previsão da hidrólise destes compostos in vitro. Ressaltam-se que as carbonilas de interesse foram nomeadas como $\mathrm{C} 1$ (do dendrímero G1 ou próxima ao dendrímero G0) e C2 (próximas aos fármacos no dendrímero G0) e C3 (próximas aos fármacos no dendrímero G1).

(1)<smiles>[R]CC(C[R])(C[R])CO[R]</smiles>

a)

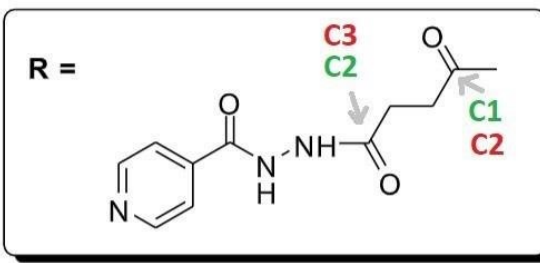

(2)

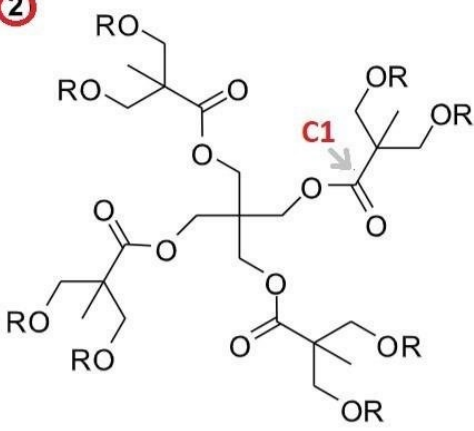

b)

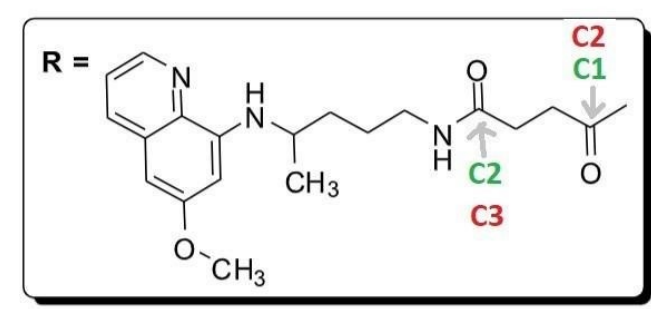

Figura 23. Pró-fármacos dendriméricos potencialmente ativos em malária ou tuberculose. Representaram-se as gerações 0 (esquema 1) e 1 (esquema 2). 
Destacaram-se nos quadrados: a) isoniazida succinoilada e b) primaquina succinoilada. As carbonilas de interesse estão realçadas em vermelho e verde na figura.

\subsubsection{Re-docking no programa GOLD (Verdonk et al, 2003)}

Nas simulações de re-docking, compararam-se as interações do liganteproteína resultantes dos cálculos com as provenientes dos dados de cristalografia. Como resultado, selecionou-se a função ASP devido à maior média de interações entre o ligante e a proteína, quando comparados com o padrão proveniente do PDB. Escolheu-se, então, a pose com maior número destas interações. Mesmo ocupando o quinto lugar no ranking de score, definiuse o confôrmero 4 como melhor resultado (Quadro 1), visualizado na Figura 27.

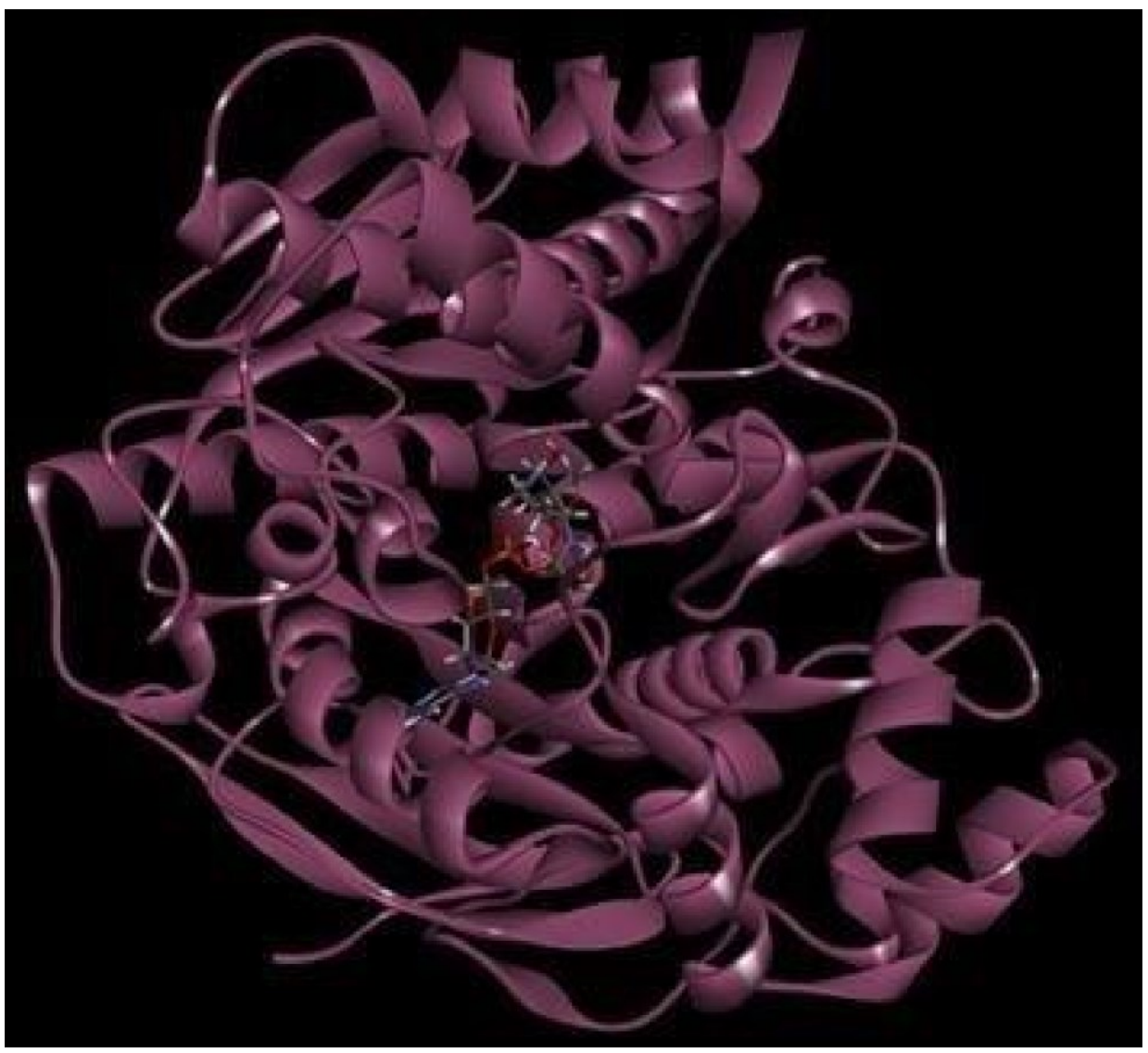

Figura 24. Confôrmero 4 do re-docking do ligante na enzima $2 \mathrm{H} 7 \mathrm{C}$.

Sabe-se que o valor desejável para Root Mean Square Deviation (RMSd),

o qual compara a similaridade entre a disposição dos átomos no espaço do modelo gerado com os da estrutura referência, é em torno de 1,5 $\AA$ (MAIOROV \& CRIPPEN,1994). Não se observou valores próximos a 1,5 $\AA$ nas funções de 
score utilizadas, uma vez que se tratam de ligantes peptídicos, com alta flexibilidade das ligações químicas (YAN, ZHANG \& HUANG, 2017).

Tabela 4. Resultados obtidos no re-docking realizados programa GOLD (Verdonk et al, 2003)

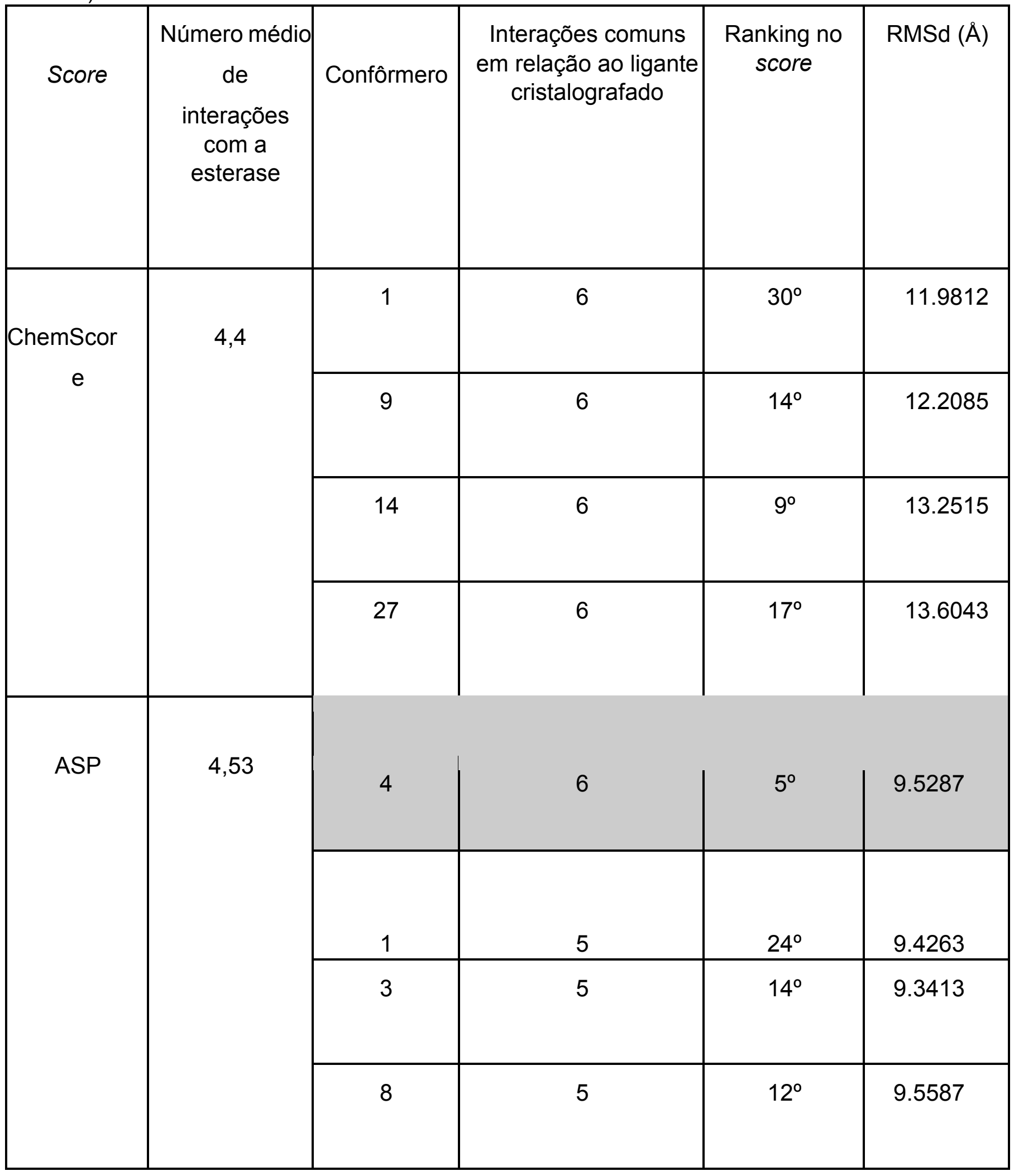


Para a confirmação do RMSd do Dock 4, este desvio foi calculado em três programas diferentes: o Discovery Studio, Chimera e Pymol. Conforme os resultados na tabela $\mathbf{5}$, todos os valores de RMSd estavam fora do desejável por se tratar de um ligante peptídico, uma molécula com elevado grau de flexibilidade.

Tabela 5. Melhor pose obtida no re-docking com o programa GOLD e confirmação do RMSd

\begin{tabular}{|c|c|c|c|c|c|}
\hline $\begin{array}{c}\text { Confôrmer } \\
\text { o }\end{array}$ & ASP & $\begin{array}{c}\text { Interações comuns em relação ao } \\
\text { ligante cristalografado }\end{array}$ & $\begin{array}{c}\text { RMSd } \\
\text { Discovery }\end{array}$ & $\begin{array}{c}\text { RMSd } \\
\text { Chimera }\end{array}$ & $\begin{array}{c}\text { RMSd } \\
\text { Pymol }\end{array}$ \\
\hline 4 & $-923,753$ & 6 & 9.5287 & 9.786 & 4.836 \\
\hline
\end{tabular}

\subsubsection{Resultados de docking no programa GOLD (Verdonk et al,} 2003)

A seleção dos resultados gerados pelo programa GOLD (Verdonk et al, 2003) foi feita com base, principalmente, na distâncias entre os carbonos das carbonilas dos dendrímeros (C1, C2 e C3) e o oxigênio da hidroxila da Serina 221, conforme Quadro 3. Importante mencionar que este valor deve ser inferior a $3 \AA$, possibilitando, assim, o ataque nucleofílico da Serina 221 na carbonila de interesse (ARANTES, 2008).

Como mostrado na Figura 3, o mecanismo geral da catálise da serinoprotease inicia-se pelo ataque nucleofílico na carbonila do substrato pela serina, auxiliado pela histidina que age como catalisador ácido-base, gerando um intermediário tetraédrico. Este último composto é instável e, ao final do processo, há a liberação de ácido carboxílico e a regeneração da enzima (HEDSTROM, 2002). 


\begin{tabular}{|c|c|c|c|c|c|c|c|c|c|c|c|c|c|c|c|c|c|}
\hline \multicolumn{4}{|c|}{ G0 - isoniazida } & \multicolumn{5}{|c|}{ G1 - isoniazida } & \multicolumn{4}{|c|}{ G0 - primaquina } & \multicolumn{5}{|c|}{ G1 - primaquina } \\
\hline Dock & ASP & C1 & C2 & Dock & ASP & C1 & C2 & C3 & Dock & ASP & C1 & C2 & Dock & ASP & C1 & C2 & C3 \\
\hline 1 & -284.644 & 6.197 & 3.959 & 1 & -1200.100 & 3.138 & 3.739 & 6.610 & 1 & -482.581 & 2.186 & 2.786 & 1 & -1843.230 & 2.159 & 3.499 & 7.075 \\
\hline 2 & -237.664 & 546 & 1.905 & 2 & -1174.380 & 1.706 & 4.025 & 6.166 & 2 & -523.834 & 6.626 & 6.146 & 2 & -2037.290 & 2.319 & 4.944 & 7.642 \\
\hline 3 & -216.762 & 5.075 & 3.945 & 3 & -945.340 & 4.642 & 3.116 & 3.401 & 3 & -358.235 & 6.240 & 6.522 & 3 & -2312.700 & 1.052 & 3.749 & 3.731 \\
\hline 4 & -243.083 & 4.423 & 3.789 & 4 & -1138.710 & 2.640 & 5.394 & 7.730 & 4 & -540.484 & 4.222 & 1.259 & 4 & -2106.440 & 2.454 & 3.382 & 5.154 \\
\hline 5 & -181.293 & 5.104 & 4.347 & 5 & -902.605 & 3.516 & 2.518 & 5.636 & 5 & -717.754 & 1.832 & 3.389 & 5 & -1827.760 & 6.449 & 4.157 & 3.048 \\
\hline 6 & -179.357 & 3.635 & 5.663 & 6 & -1129.310 & 3.095 & 3.751 & 5.800 & 6 & -483.843 & 3.572 & 2.599 & 6 & -1912.980 & 2.862 & 3.719 & 6.389 \\
\hline 7 & -255.653 & 3.641 & 4.972 & 7 & -1200.560 & 4.298 & 1.292 & 2.964 & 7 & -388.070 & 2.593 & 3.591 & 7 & -1949.330 & 2.827 & 3.114 & 5.070 \\
\hline 8 & -232.717 & 4.094 & 4.985 & 8 & -922.408 & 7.687 & 4.669 & 1.674 & 8 & -490.344 & 3.679 & 5.857 & 8 & -1875.270 & 2.835 & 3.958 & 5.970 \\
\hline 9 & -274.989 & 5.297 & 4.262 & 9 & -1005.250 & 4.770 & 3.742 & 6.839 & 9 & -560.853 & 2.614 & 5.948 & 9 & -2056.360 & 2.904 & 2.195 & 5.542 \\
\hline 10 & -297.450 & 3.791 & 2.482 & 10 & -1074.690 & 1.793 & 4.719 & 4.402 & 10 & -575.206 & 3.715 & 1.490 & 10 & -1679.360 & 2.666 & 3.925 & 6.400 \\
\hline 11 & -176.970 & 5.244 & 5.395 & 11 & -904.774 & 6.508 & 3.842 & 4.491 & 11 & -528.367 & 2.478 & 2.068 & 11 & -2062.430 & 3.800 & 1.590 & 4.430 \\
\hline 12 & -266.264 & 4.830 & 5.677 & 12 & -1201.040 & 2.230 & 3.912 & 4.891 & 12 & -436.813 & 3.716 & 2.839 & 12 & -2117.130 & 5.071 & 1.114 & 2.932 \\
\hline 13 & -258.054 & 4.187 & 5.736 & 13 & -1127.850 & 2.337 & 3.981 & 6.675 & 13 & -561.054 & 5.960 & 3.332 & 13 & -2362.290 & 3.892 & 2.822 & 4.842 \\
\hline 14 & -239.157 & 3.321 & 2.859 & 14 & -1138.140 & 4.029 & 2.458 & 5.308 & 14 & -388.619 & 3.292 & 5.414 & 14 & -1722.670 & 3.115 & 4.109 & 5.780 \\
\hline 15 & -214.434 & 2.734 & 3.766 & 15 & -1043.000 & 3.639 & 4.097 & 3.229 & 15 & -430.298 & 4.835 & 5.993 & 15 & -1706.700 & 3.823 & 2.880 & 4.553 \\
\hline 16 & -183.583 & 5.631 & 6.452 & 16 & -1165.760 & 8.213 & 5.513 & 3.772 & 16 & -522.498 & 3.378 & 3.134 & 16 & -1828.390 & 1.834 & 0.848 & 4.267 \\
\hline 17 & -257.173 & 5.580 & 7.271 & 17 & -1255.790 & 1.355 & 4.396 & 6.159 & 17 & -591.451 & 4.232 & 4.630 & 17 & -1846.460 & 2.909 & 3.267 & 4.979 \\
\hline 18 & -221.738 & 3.710 & 4.497 & 18 & -1063.800 & 6.119 & 3.643 & 3.638 & 18 & -385.259 & 5.533 & 3.572 & 18 & -1666.520 & 4.156 & 3.549 & 2.897 \\
\hline 19 & -365.229 & 2.792 & 3.999 & 19 & -1133.700 & 2955 & 4.433 & 3.682 & 19 & -514.784 & 2.925 & 4.516 & 19 & -1861.160 & 2.828 & 4.405 & 4.643 \\
\hline 20 & -284270 & 3.885 & 4.677 & 20 & -1102.530 & 4.189 & 6.804 & 4.622 & 20 & -487.103 & 3.237 & 3.272 & 20 & -1722.310 & 3.045 & 3.208 & 5.280 \\
\hline 21 & -223.911 & 4.122 & 6.704 & 21 & -1246.940 & 3.332 & 3.103 & 4.230 & 21 & -513.189 & 4.360 & 3.671 & 21 & -2369.560 & 3.319 & 1.666 & 4.699 \\
\hline 22 & -269.695 & 4.332 & 5.298 & 22 & -1203.710 & 4.306 & 3.614 & 3.731 & 22 & -473.154 & 6.342 & 3.762 & 22 & -2147.720 & 2.345 & 2.801 & 5.480 \\
\hline 23 & -228.590 & 5.052 & 7.226 & 23 & -1374.320 & 3.135 & 1.785 & 3.044 & 23 & -656.394 & 3.202 & 5.379 & 23 & -1730.780 & 6.118 & 5.865 & 5.392 \\
\hline 24 & -310.080 & 4.581 & 1.943 & 24 & -1088.220 & 5.027 & 1.479 & 3.098 & 24 & -463.230 & 4.409 & 5.307 & 24 & -2041.710 & 0.960 & 3.005 & 6.359 \\
\hline 25 & -202.919 & 4.506 & 3.612 & 25 & -1019.890 & 4.048 & 3.147 & 4.338 & 25 & -491.914 & 3.616 & 5.194 & 25 & -1751.230 & 5.304 & 5.022 & 6.776 \\
\hline 26 & -165.941 & 2.434 & 4.179 & 26 & -894.609 & 7.065 & 4.125 & 4.253 & 26 & -576.134 & 2.750 & 4.482 & 26 & -1854.610 & 2.994 & 3.661 & 4.477 \\
\hline 27 & -175.044 & 3.850 & 2.053 & 27 & -1056.690 & 6.292 & 5.867 & 7.192 & 27 & -477.626 & 4.034 & 2.903 & 27 & -1636.810 & 3.142 & 3.405 & 6.038 \\
\hline 28 & -259.336 & 3.075 & 3.553 & 28 & -1080.170 & 3.406 & 3.899 & 4.776 & 28 & -557.000 & 2.806 & 2.905 & 28 & -1683.120 & 1.336 & 4.121 & 6.950 \\
\hline 29 & -220.121 & 4.385 & 5.459 & 29 & -941.284 & 8.544 & 4.861 & 1.869 & 29 & -503.420 & 4.409 & 6.449 & 29 & -1685.020 & 6.010 & 7.773 & 9.566 \\
\hline 30 & -256.945 & 3.160 & 4.065 & 30 & -1107.930 & 1.766 & 4.282 & 7.719 & 30 & -491.015 & 3.21 & 3.347 & 30 & -2001.570 & 6.635 & 2.391 & 3.972 \\
\hline
\end{tabular}

\section{tetrabedral}

tetrabedral
intermediate

Ser195 Gyr193

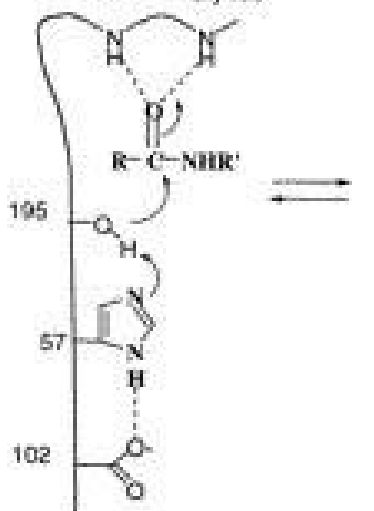

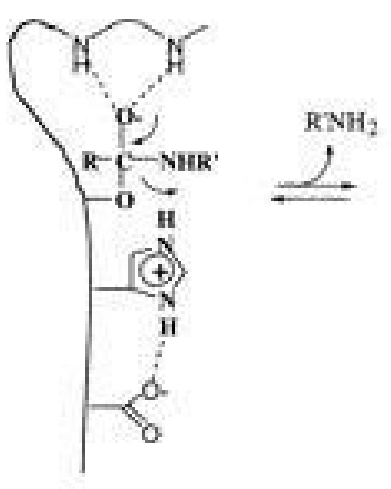

acylenzyme

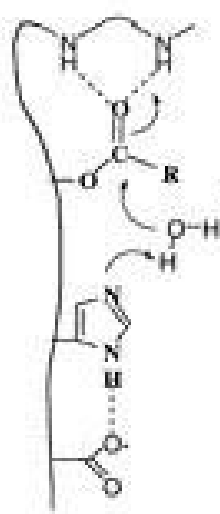

tetrahedral intermediate

Figura 25. Mecanismo geral da catálise da serinoprotease (HEDSTROM, 2002).

Tabela 6. Resultados dos 30 confôrmeros obtidos pelo docking da G0-Iso, G1-Iso, GOPq e G1-Pq no programa GOLD (Verdonk et al, 2003). 


\subsubsection{G0-Iso}

Obtiveram-se menores distâncias para a C2 quando analisado o dendrímero de geração 0 contendo isoniazida (Tabela 7). Indicam-se, assim, que as chances do derivado sofrer hidrólise enzimática na periferia podem ser maiores em relação à C1 (carbonila próxima ao dendrímero). Os confôrmeros 24 e 10 (Figura 29) ficaram entre os cinco melhores em relação ao score (valores de -310.080 e -297.450 , respectivamente), corroborando com a hipótese de que a hidrólise enzimática pode acontecer em C2. As distâncias da Serina 221 e C2 foram de 1,943 $\AA$ e 2,482 A, para os Dock 24 e 10, respectivamente.
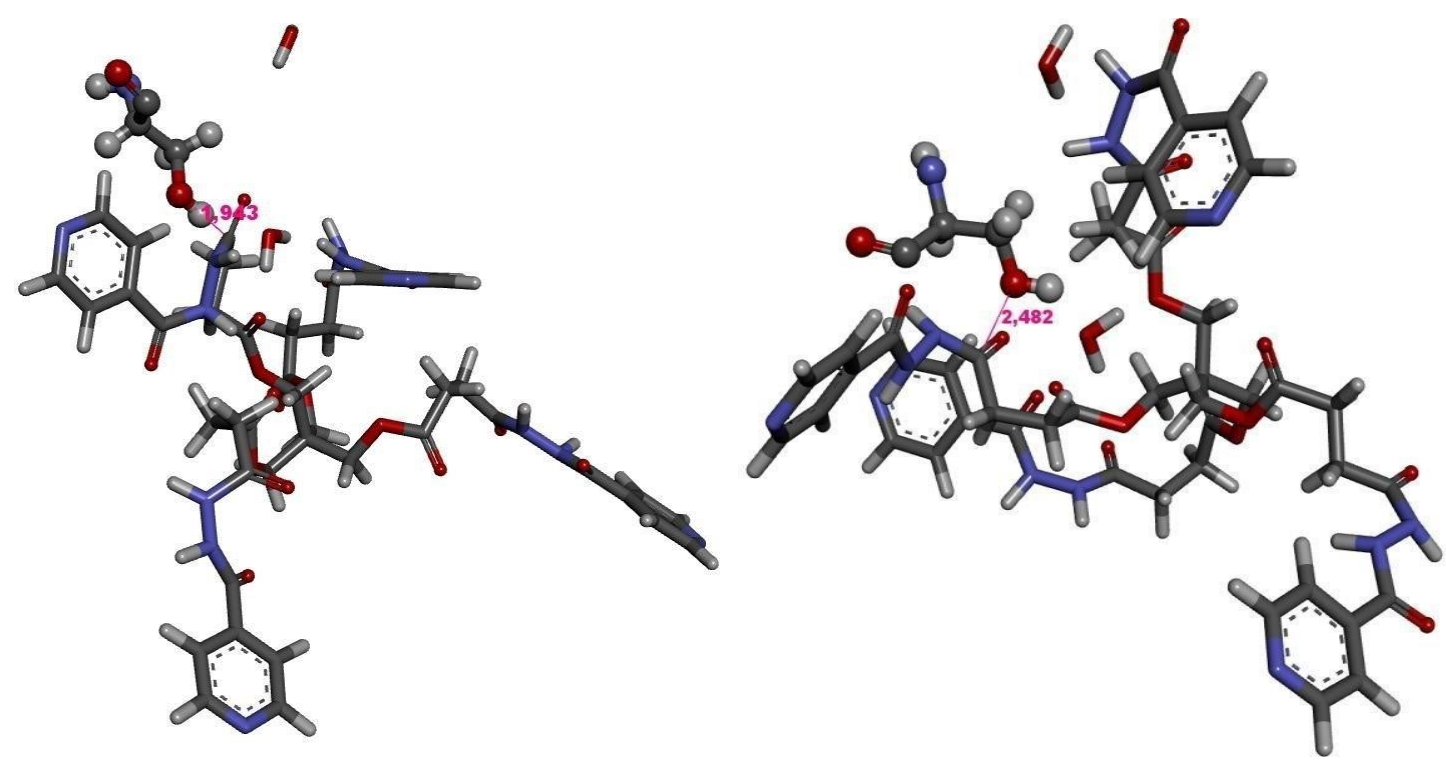

Figura 26. Confôrmeros 24 (esquerda) e 10 (direita) resultantes das simulações de docking da G0-Iso na enzima 2H7C. As distâncias entre a Serina 221 e as carbonilas C2 estão destacadas em vermelho.

Tabela 7. Melhores resultados de docking da G0-Iso na enzima 2H7C. C1 e C2 estão destacadas em vermelho na estrutura. 


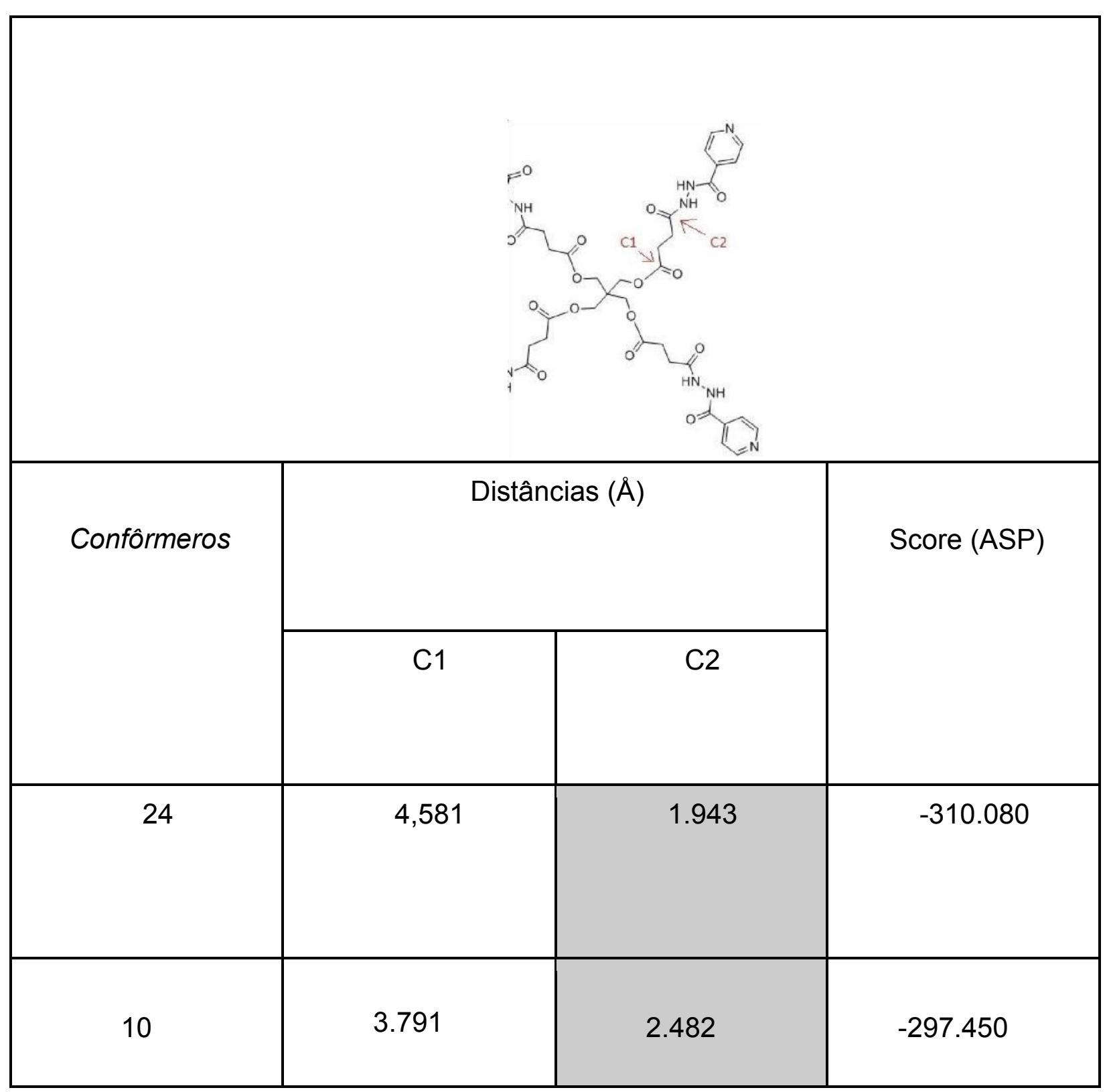

\subsubsection{G1-Iso}

$\mathrm{Na}$ análise do pró-fármaco G1-Iso, observa-se, na tabela 6, que os resultados dos 30 confôrmeros apresentaram certa tendência à ação enzimática ocorrer em C1, uma vez que esta região apresentou maior número de resultados inferiores a 3 A. Assim, conforme dados apresentados na tabela 8, o confôrmero 17 (Figura 30), está entre os cinco melhores em relação ao score (valor de 1255,790), cuja carbonila com menor distância foi a C1 (1,355 Å). Já os confôrmeros 7 e 2 (Figura 31) estavam entre os dez melhores (score iguais a 1200,560 e -1174,380, respectivamente). Nestes dois últimos confôrmeros, as distâncias observadas para C1 foram de $4.298 \AA$ e $1.706 \AA$, respectivamente. 
Estimam-se, então, maiores chances da hidrólise enzimática ocorrer em C1.

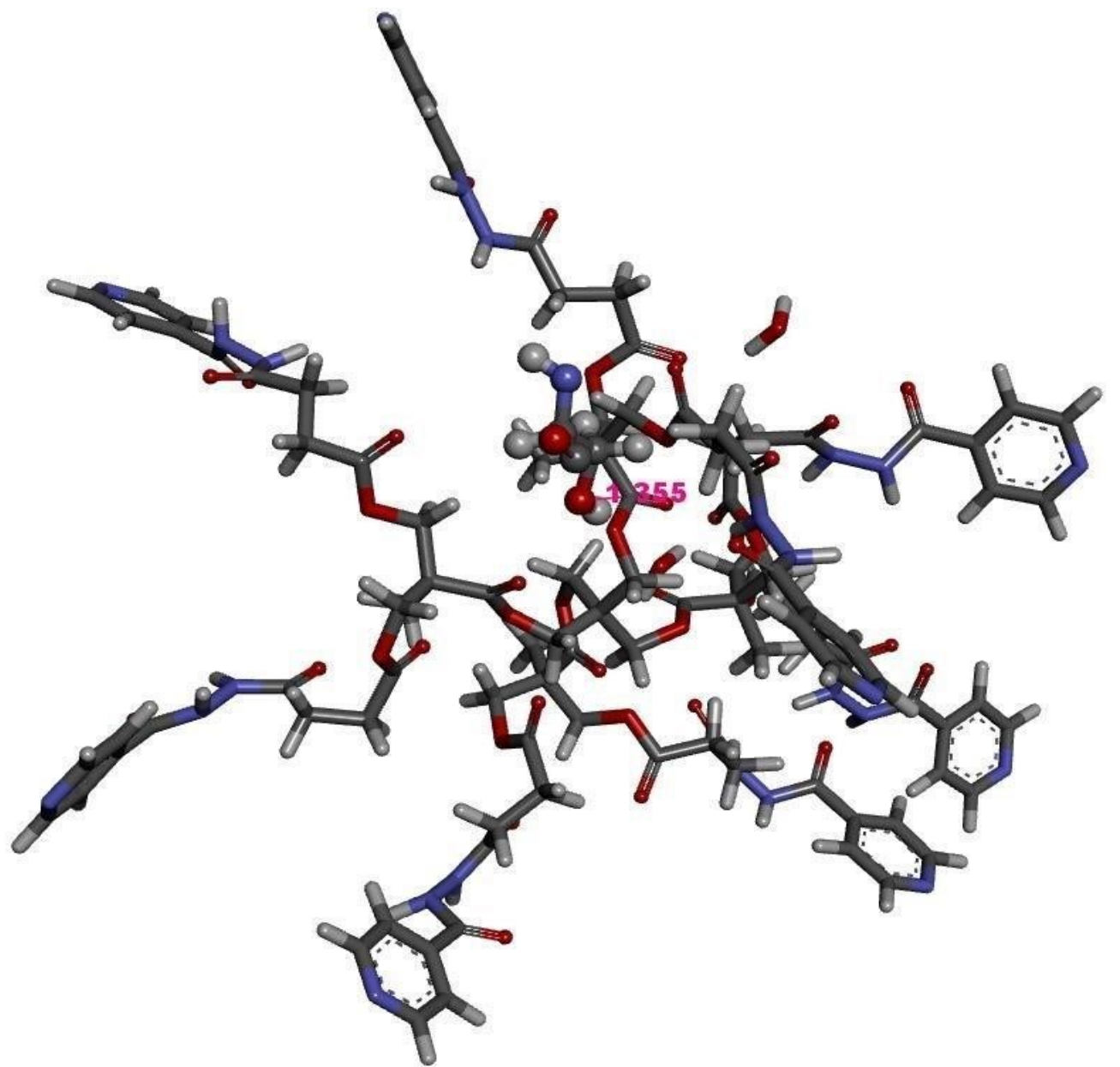

Figura 27. Confôrmero 17 resultante das simulações de docking da G1-Iso na enzima 2H7C.A distância entre a Serina 221 e C1 está destacada em vermelho.
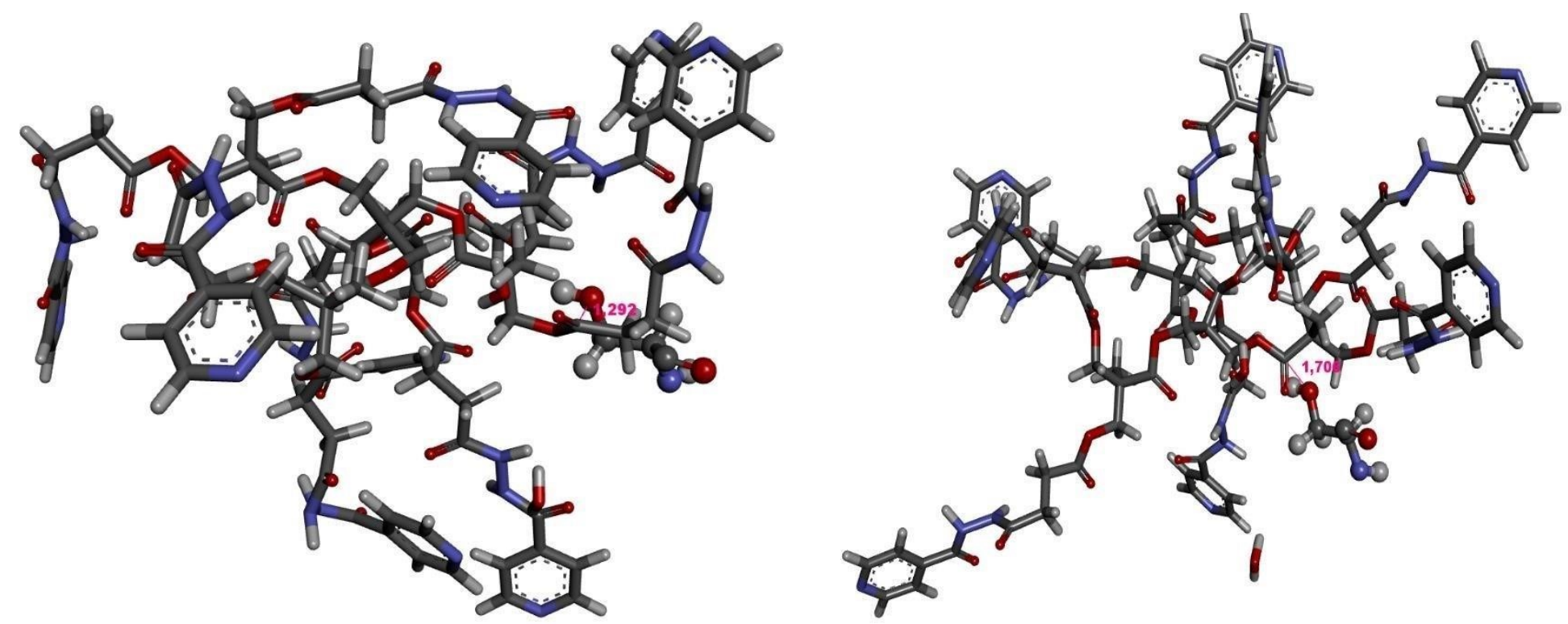

Figura 28. Confôrmeros 7 (esquerda) e 2 resultantes das simulações de docking da G1lso na enzima 2H7C. As distâncias entre a Serina 221 e C1 estão destacadas em vermelho. 
Tabela 8. Resultados obtidos pelo docking da G1-Iso no programa GOLD (Verdonk et al, 2003). As carbonilas C1 e C2 estão destacadas em vermelho.

\begin{tabular}{|c|c|c|c|c|}
\hline \multirow[b]{2}{*}{ Confôrmeros } & \multicolumn{3}{|c|}{ Distâncias (Å) } & \multirow[b]{2}{*}{ Score (ASP) } \\
\hline & $\mathrm{C} 1$ & $\mathrm{C} 2$ & C3 & \\
\hline 7 & 4.298 & 1.292 & 2.964 & -1200.560 \\
\hline 17 & 1.355 & 4.396 & 6.159 & -1255.790 \\
\hline 2 & 1.706 & 4.025 & 6.166 & -1174.380 \\
\hline
\end{tabular}

\subsection{6. $\mathrm{GO}-\mathrm{Pq}$}

De forma geral, observaram-se 8 resultados menores que $3 \AA$ tanto para C1, quanto para C2 (Tabela 6). Porém, entre os cinco melhores confôrmeros obtidos, a carbonila $\mathrm{C} 2$ apresentou resultados ligeiramente melhores, como verificado no Quadro 6.

Os confôrmeros 5 e 10 estão entre os cinco melhores em relação ao score (-717.754 e -575.206, respectivamente) e os confôrmeros 4 e 11 ficaram entre os dez melhores neste ranking (scores de -540.484 e -575.206 , respectivamente). Com base somente nestes achados, existe, portanto, maior possibilidade de $\mathrm{C} 2$ periférica sofrer hidrólise enzimática em comparação com a c1.

Tabela 9. Resultados obtidos pelo docking da G0-primaquina no programa GOLD (Verdonk et al, 2003) 


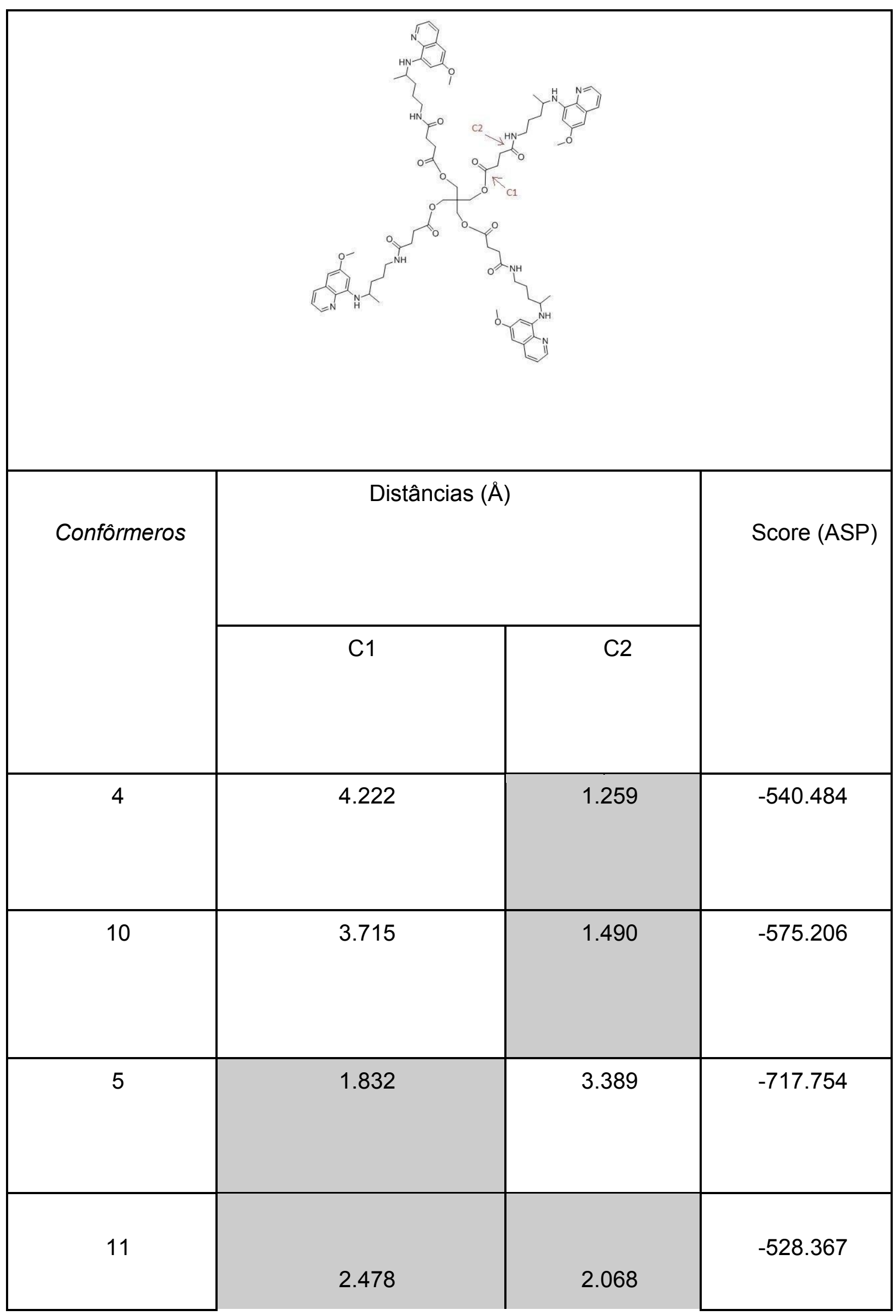




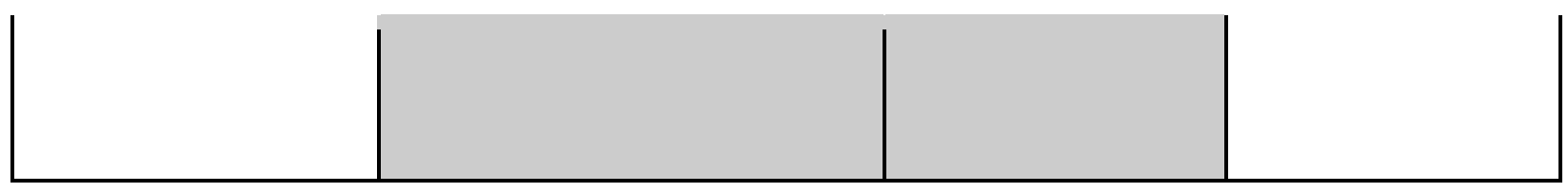

\subsection{7. $\mathrm{G} 1-\mathrm{Pq}$}

Observando-se os resultados gerados para o pró-fármaco G1-Pq na Tabela 6, é possível notar a relevante diferença entre C1, C2 e C3. Para C1 obteve-se 16 resultados desejáveis, sendo o maior valor o do confôrmero 26 (2,994 Å) e menor o do confôrmero 24 (0,960 Å). Enquanto para C2, entre os 9 resultados mais interessantes, houve variação entre $0,848 \AA$ (confôrmero 16) a $2,880 \AA$ (confôrmero 15). Apenas dois resultados de C3 mostraram-se satisfatórios, o do confôrmero $12(2,932 \AA)$ e do confôrmero $18(2,897 \AA)$. Importante mencionar que essa proporção foi mantida na Tabela 10, no qual foram selecionadas as quatro melhores poses. Os confôrmeros 3 e 12, cujas distâncias foram de 1,052 $\AA$ e 1,114 $\AA$, respectivamente, ficaram entre os cinco melhores no ranking do score (valores calculados iguais a -2312,700 e 2117,130, respectivamente) e o 24 , de distância $0,960 \AA$, entre as dez melhores (valor de score calculado foi de -2041,710). Dessa forma, acredita-se que a hidrólise enzimática, possivelmente, ocorrerá em C1.

Tabela 10. Resultados obtidos pelo docking da G1-Pq no programa GOLD (Verdonk et al, 2003)

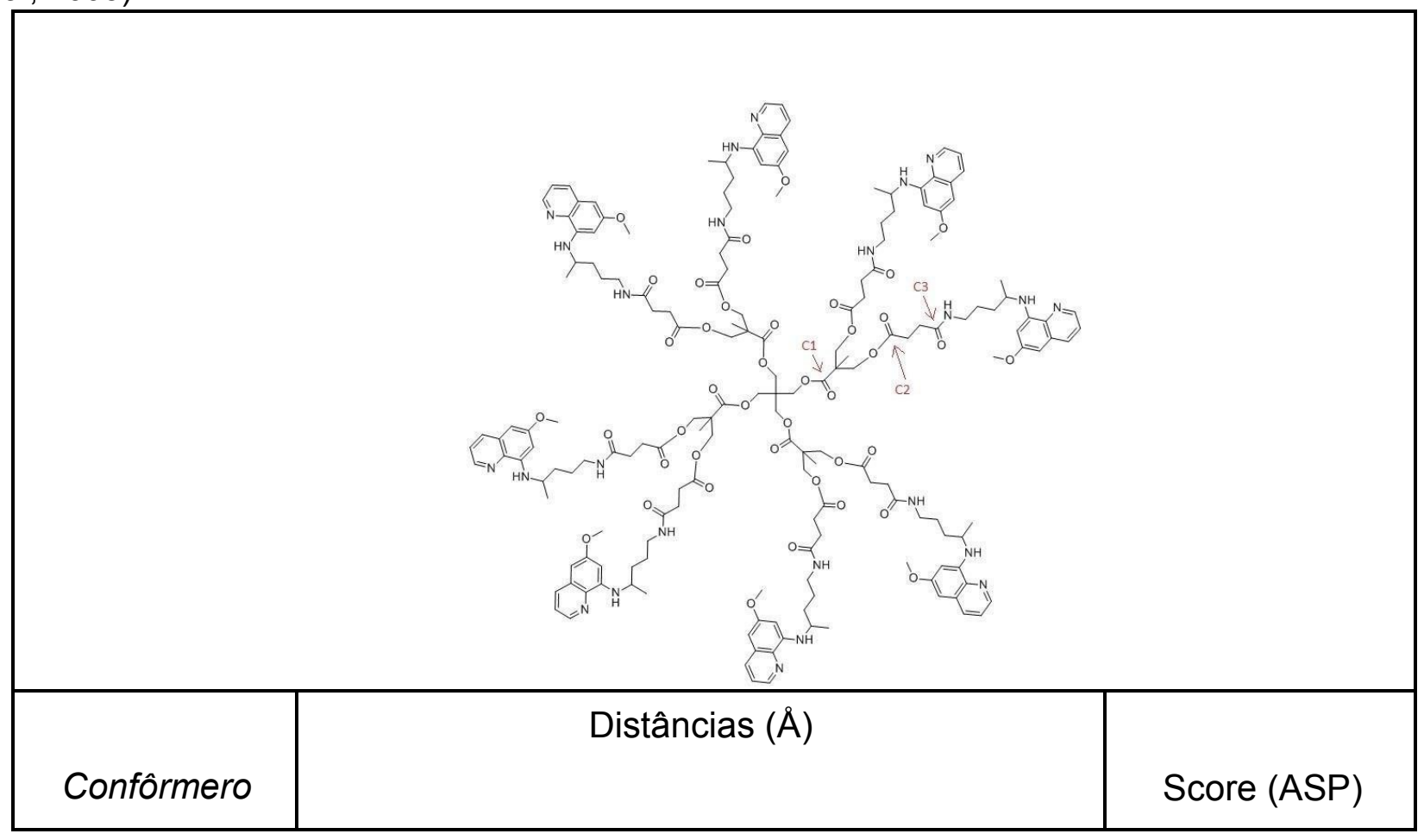




\begin{tabular}{|c|c|c|c|c|}
\cline { 2 - 4 } & C1 & C2 & C3 & \multicolumn{1}{c|}{} \\
\hline 16 & 1.834 & 0.848 & 4.267 & -1828.390 \\
\hline 24 & 0.960 & 3.005 & 6.359 & -2041.710 \\
\hline 3 & 1.052 & 3.749 & 3.731 & -2312.700 \\
\hline 12 & 5.071 & 1.114 & 2.932 & -2117.130 \\
\hline
\end{tabular}

4.2.8. Resultados AutoDock (Trott et al., 2010)

Com o intuito de validar e comparar os dados obtidos no Gold, utilizou-se o programa AutoDock. Conforme ilustra a Tabela 11, observaram-se que nenhum dos resultados das distâncias de $\mathrm{C} 1$ e C2 em relação à Serina 221 foram próximo de $3 \AA$. Todos foram superiores a $12 \AA$. Logo, estes dados mostraram que não houve interação entre qualquer uma das estruturas com o sítio ativo. Provavelmente, não aconteceu a acomodação do ligante na enzima. Posteriores investigações utilizando outros padrões de parametrização serão, portanto, necessárias.

Tabela 11. Resultados das simulações de docking resultantes do programa AutoDock (Trott et al., 2010).

\begin{tabular}{|c|c|c|c|c|}
\hline Estrutura & Confôrmero & $\begin{array}{c}\text { Carbonila mais próxima da Serina } \\
221\end{array}$ & $\begin{array}{c}\text { Distância } \\
(\AA)\end{array}$ & Affinity (kcal/mol) \\
\hline G0-Iso & 19 & $\mathrm{C} 2$ & 12.687 & -5.6 \\
\hline
\end{tabular}




\begin{tabular}{|c|c|c|c|c|}
\hline & 13 & $\mathrm{C} 2$ & 12.847 & -5.8 \\
\hline & 4 & C1 & 14.340 & -6.8 \\
\hline \multirow{4}{*}{ G1-Iso } & 12 & $\mathrm{C} 2$ & 13.643 & -5.8 \\
\hline & 7 & C3 & 14.180 & -5.9 \\
\hline & 10 & C3 & 14.225 & -5.8 \\
\hline & 1 & C2 & 14.335 & -9.1 \\
\hline \multirow[t]{3}{*}{ G0-Pq } & 3 & C2 & 14.555 & -8.5 \\
\hline & 2 & $\mathrm{C} 2$ & 14.370 & -8.6 \\
\hline & 3 & C3 & 13.945 & -5.8 \\
\hline \multirow[t]{2}{*}{$\mathrm{G} 1-\mathrm{Pq}$} & 4 & $\mathrm{C} 3$ & 14.079 & -5.8 \\
\hline & 2 & C3 & 14.165 & -6.0 \\
\hline
\end{tabular}




\subsubsection{Simulações de docking molecular entre a Clso-Suc e a catalase-peroxidase}

O objetivo desta etapa do trabalho foi analisar modo de interação das Clso-Suc, chamadas aqui de Iso_Cic5 para a de 5 membros e Iso_Cic6 para a de 6 membros, em comparação com a isoniazida, na enzima Katg, catalase peroxidade envolvida no mecanismo de ação da isoniazida. Alemjava-se enteder se estes derivados ciclizados poderiam ter ação per se.

Considerando a impossibilidade da realização do re-docking, uma vez que a enzima escolhida não estava cristalografada com um ligante, fizeram-se as avaliações dos resultados computacionais em relação às interações com aminoácidos da proteína, expressos como distâncias médias (em $\AA$ ) (Tabela 12).

Tabela 12. Resultados obtidos no programa Gold (Verdonk et al, 2003) para as funções de scores ChemScore e ASP e as distâncias médias (em $\AA$ ) entre os ligantes e o ferro do grupo heme.

\begin{tabular}{|c|c|c|c|c|c|c|c|c|c|c|c|}
\hline \multicolumn{4}{|c|}{ ISONIAZIDA } & \multicolumn{4}{|c|}{ ISO_CIC5 } & \multicolumn{4}{|c|}{ ISO_CIC6 } \\
\hline Dock & ChemScore & ASP & Dist. média HEME & Dock & ChemScore & ASP & Dist. média HEME & Dock & ChemScore & ASP & Dist. média HEME \\
\hline 1 & 17.087 & 16.895 & 9.914 & 1 & 10.640 & 11.408 & 11.449 & 1 & 6.477 & 4.625 & 10.715 \\
\hline 2 & 13.136 & 14.292 & 10.143 & 2 & 11.285 & 9.366 & 11.709 & 2 & 9.853 & 6.412 & 12.874 \\
\hline 3 & 13.232 & 11.696 & 11.589 & 3 & 11.285 & 9.366 & 11.709 & 3 & 6.782 & 8.564 & 7.027 \\
\hline 4 & 16.713 & 16.762 & 9.680 & 4 & 8.407 & 12.656 & 10.757 & 4 & 6.847 & 5.864 & 12.978 \\
\hline 5 & 17.027 & 17.202 & 9.776 & 5 & 8.193 & 10.419 & 10.305 & 5 & 9.419 & 12.060 & 12.997 \\
\hline 6 & 15.887 & 15.060 & erro & 6 & 9.820 & 13.586 & 9.500 & 6 & 8.670 & 5.524 & 11.012 \\
\hline 7 & 14.764 & 15.334 & 9.111 & 7 & 10.387 & 13.600 & 10.655 & 7 & 8.599 & 10.018 & 13.369 \\
\hline 8 & 17.705 & 14.758 & 9.049 & 8 & 7.010 & 10.444 & 12.358 & 8 & 8.302 & 7.416 & 10.779 \\
\hline 9 & 16.757 & 17.193 & 9.896 & 9 & 10.564 & 13.084 & 9.879 & 9 & 4.238 & 4.339 & 10.390 \\
\hline 10 & 14.459 & 11.118 & 14.442 & 10 & 36.883 & 9.279 & 8.756 & 10 & 8.670 & 5.524 & 11.012 \\
\hline 11 & 17.126 & 16.891 & 9.926 & 11 & 67.109 & 9.874 & 9.220 & 11 & 0.151 & -2.663 & 9.672 \\
\hline 12 & 16.909 & 16.336 & 9.774 & 12 & 10.837 & 10.646 & 12.192 & 12 & 9.293 & 12.060 & 12.998 \\
\hline 13 & 17.843 & 15.191 & 9.137 & 13 & 10.934 & 11.693 & 9.809 & 13 & 6.993 & 1.603 & 10.700 \\
\hline 14 & 13.777 & 15.398 & 9.623 & 14 & 11.629 & 12.870 & 12.579 & 14 & 9.362 & 11.421 & 13.019 \\
\hline 15 & 14.608 & 13.920 & 10.162 & 15 & 8.347 & 10.090 & 12.390 & 15 & 8.670 & 5.524 & 11.012 \\
\hline 16 & 17.800 & 15.068 & 9.074 & 16 & 8.735 & 11.698 & 10.656 & 16 & 7.987 & 6.948 & 13.477 \\
\hline 17 & 12.514 & 14.482 & 8.988 & 17 & 11.771 & 14.870 & 10.561 & 17 & 4.238 & 4.339 & 10.390 \\
\hline 18 & 16.757 & 17.193 & 9.896 & 18 & 8.376 & 12.763 & 10.453 & 18 & -2.490 & -3.427 & 9.866 \\
\hline 19 & 16.875 & 14.604 & 10.341 & 19 & 8.775 & 12.801 & 10.677 & 19 & 7.320 & 11.139 & 12.092 \\
\hline 20 & 14.619 & 12.970 & 11.869 & 20 & 11.164 & 12.728 & 11.949 & 20 & 9.311 & 9.964 & 12.764 \\
\hline 21 & 14.722 & 13.312 & 10.486 & 21 & 8.111 & 12.444 & 9.464 & 21 & 8.670 & 5.524 & 11.012 \\
\hline 22 & 14.207 & 13.774 & 10.771 & 22 & 9.853 & 14.282 & 11.311 & 22 & 9.382 & 11.421 & 13.045 \\
\hline 23 & 16.909 & 16.336 & 9.774 & 23 & 8.703 & 12.486 & 10.639 & 23 & 8.670 & 5.524 & 11.012 \\
\hline 24 & 13.232 & 11.696 & 11.589 & 24 & 14.467 & 6.338 & 12.916 & 24 & 0.026 & -3.825 & 6.728 \\
\hline 25 & 12.897 & 14.560 & 8.096 & 25 & 9.611 & 14.221 & 9.491 & 25 & 6.108 & -14.040 & 9.658 \\
\hline 26 & 12.668 & 10.633 & 11.774 & 26 & 12.376 & 15.100 & 10.505 & 26 & 7.609 & 10.985 & 12.291 \\
\hline 27 & 14.608 & 13.920 & 10.162 & 27 & 7.286 & 11.856 & 11.957 & 27 & 8.257 & 5.686 & 13.145 \\
\hline 28 & 14.592 & 12.372 & 11.654 & 28 & 11.784 & 13.710 & 11.702 & 28 & 4.844 & 8.798 & 8.767 \\
\hline 29 & 13.608 & 13.666 & 9.921 & 29 & 7.406 & 10.506 & 11.766 & 29 & 9.286 & 4.679 & 13.268 \\
\hline 30 & 17.126 & 16.891 & 9.926 & 30 & 10.825 & 10.646 & 12.192 & 30 & 11.128 & 15.404 & 11.513 \\
\hline
\end{tabular}

Pode-se constatar que a distância média em relação ao ferro do grupo heme foi mais próxima entre a isoniazida e a Iso_Cic5 (10,226 e 10,984, 
respectivamente, Tabela 13), apesar de Iso_Cic6 não ter apresentado resultado tão diferente $(11,319$, Tabela 13).

Tabela 13. Distância média das estruturas em relação ao ferro do grupo heme (em $\AA$ ).

\begin{tabular}{|l|c|c|c|}
\hline & Isoniazida & Iso_Cic5 & Iso_Cic6 \\
\hline Distância média $(\AA)$ & 10,226 & 10,984 & 11,319 \\
\hline
\end{tabular}

As análises dos 30 confôrmeros provenientes das simulações de doking molecular com a isoniazida mostrou que o aminoácido ASP137 parece ser interessante para a interação com a Katg. Ademais, de modo geral, a Iso_Cic6 apresentou mais interações em comum com a isoniazida, além de um de seus confôrmeros apresentarem uma interação a mais, com o aminoácido VAL230, em relação à isoniazida (Figura 2).

Foram poucas as interações dos confôrmeros de isoniazida, Iso_Cic5 e Iso_Cic6 com os aminoácidos THR314, ALA139 e ALA281. Ademais, apesar de não se verificar para a isoniazida, com os aminoácidos SER315, GLU233 e ASN231 paracem ser importantes para Iso_Cic5 e Iso_Cic6. Por outro lado, sugerem-se que PR0136 e ARG104 são interessantes para a isoniazida. Já LEU227 teve quantidade de interações com a isoniazida semelhantes à Iso_Cic5 e Iso_Cic6. Todos estes dados estão apresentados na Tabela 14.

Tabela 14. Principais aminoácidos envolvidos nas interação de Iso_Cic5 e Iso_Cic6 com o alvo molecular, comparados com a isoniazida. 


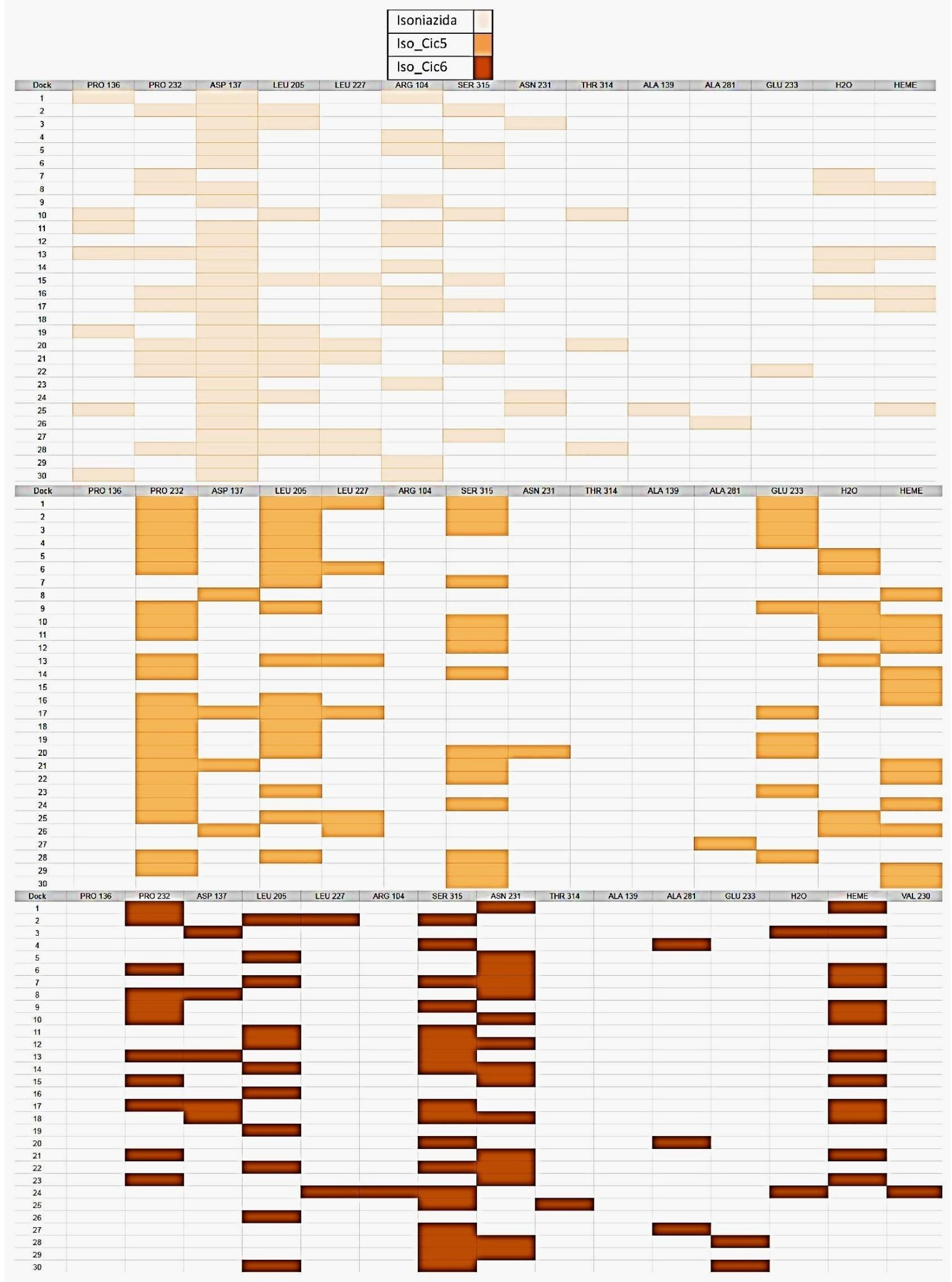

Em destaque na Tabela15, nota-se a importância da PRO232 e da LEU205, tanto para a isoniazida, quanto para Iso_Cic5 e Iso_Cic6. Estes amináciodos parecem, portanto, serem interessantes para a interação ligantereceptor. Os valores encontrados foram de 10, 23 e 11, para PRO232 e 
isoniazida, Iso_Cic5 e Iso_Cic6, respectivamente. Já em relação à LEU205, observaram-se 11, 17 e 11 interações com isoniazida, Iso_Cic5 e Iso_Cic6, respectivamente.

Tabela 15. Comparação entre quantidade de interações das estruturas com os aminoácidos.

\begin{tabular}{|c|c|c|c|}
\hline \multirow{2}{*}{ Aminoácido } & \multicolumn{3}{|c|}{ Quantidade de interações (total $=30$ poses de cada estrutura) } \\
\hline & Isoniazida & Iso_Cic5 & Iso_Cic6 \\
\hline PRO136 & 7 & 0 & 0 \\
\hline PRO232 & 10 & 23 & 11 \\
\hline ASP137 & 28 & 4 & 5 \\
\hline LEU205 & 11 & 17 & 11 \\
\hline LEU227 & 5 & 6 & 2 \\
\hline ARG104 & 13 & 0 & 1 \\
\hline
\end{tabular}




\begin{tabular}{|c|c|c|c|}
\hline SER315 & 8 & 15 & 18 \\
\hline ASN231 & 3 & 1 & 15 \\
\hline THR314 & 3 & 0 & 1 \\
\hline ALA139 & 1 & 0 & 0 \\
\hline ALA281 & 1 & 1 & 3 \\
\hline GLU233 & 1 & 10 & 2 \\
\hline $\mathrm{H}_{2} \mathrm{O}$ & 5 & 8 & 2 \\
\hline HEME & 5 & 13 & 12 \\
\hline VAL230 & 0 & 0 & 1 \\
\hline
\end{tabular}

As melhores poses da isoniazida, Iso_Cic5 e Iso_Cic6 (Figuras 32, 33 e 34, respectivamente) foram escolhidas considerando as os aminoácidos ASP137, PRO232 e LEU205, conforme importância discutida previamente. 


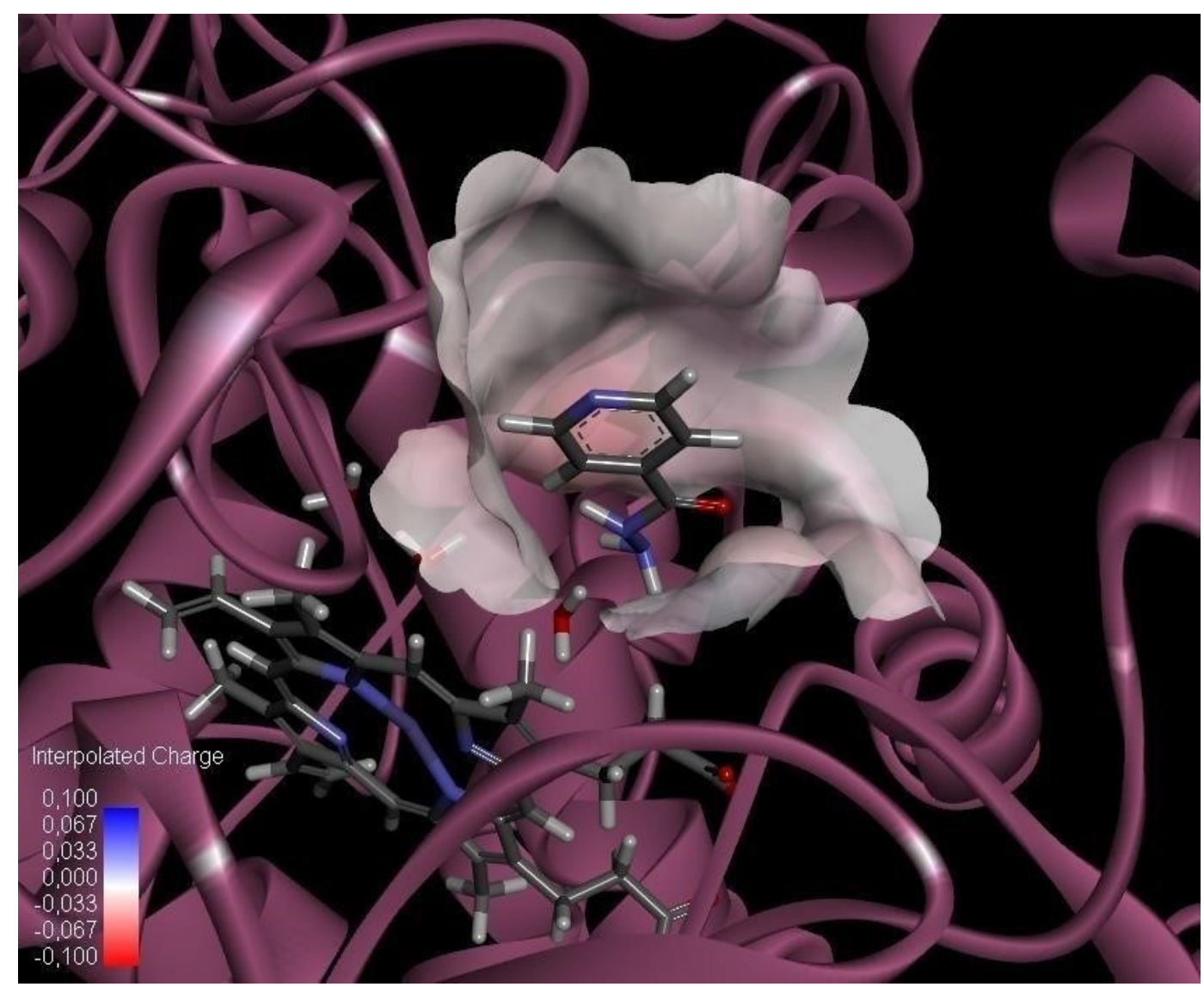

Figura 29. Dock (número 2) da isoniazida na enzima PDB 1 SJ2.

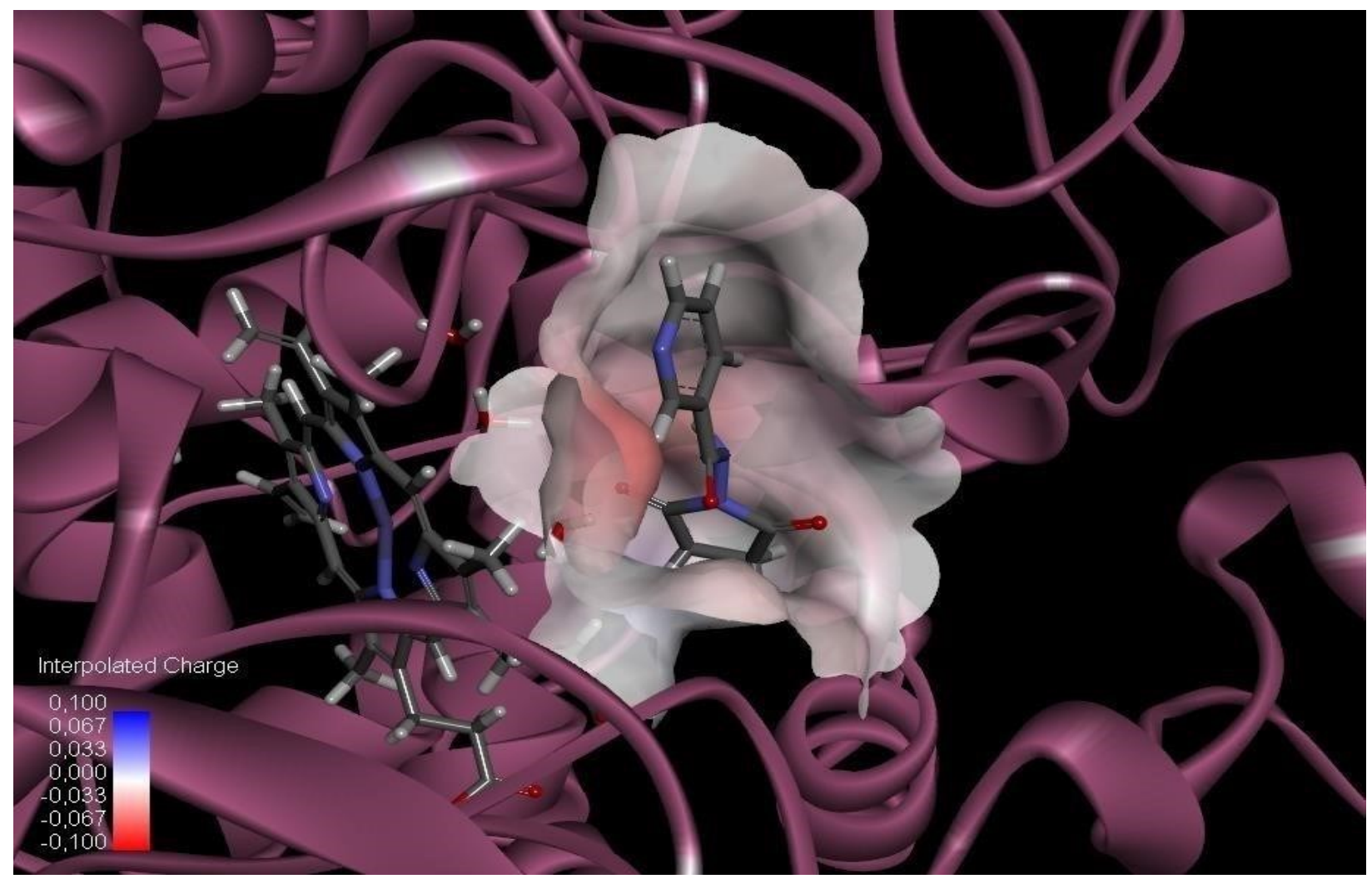

Figura 31. Dock (número 17) da Iso_Cic5 na enzima 1 SJ2. 


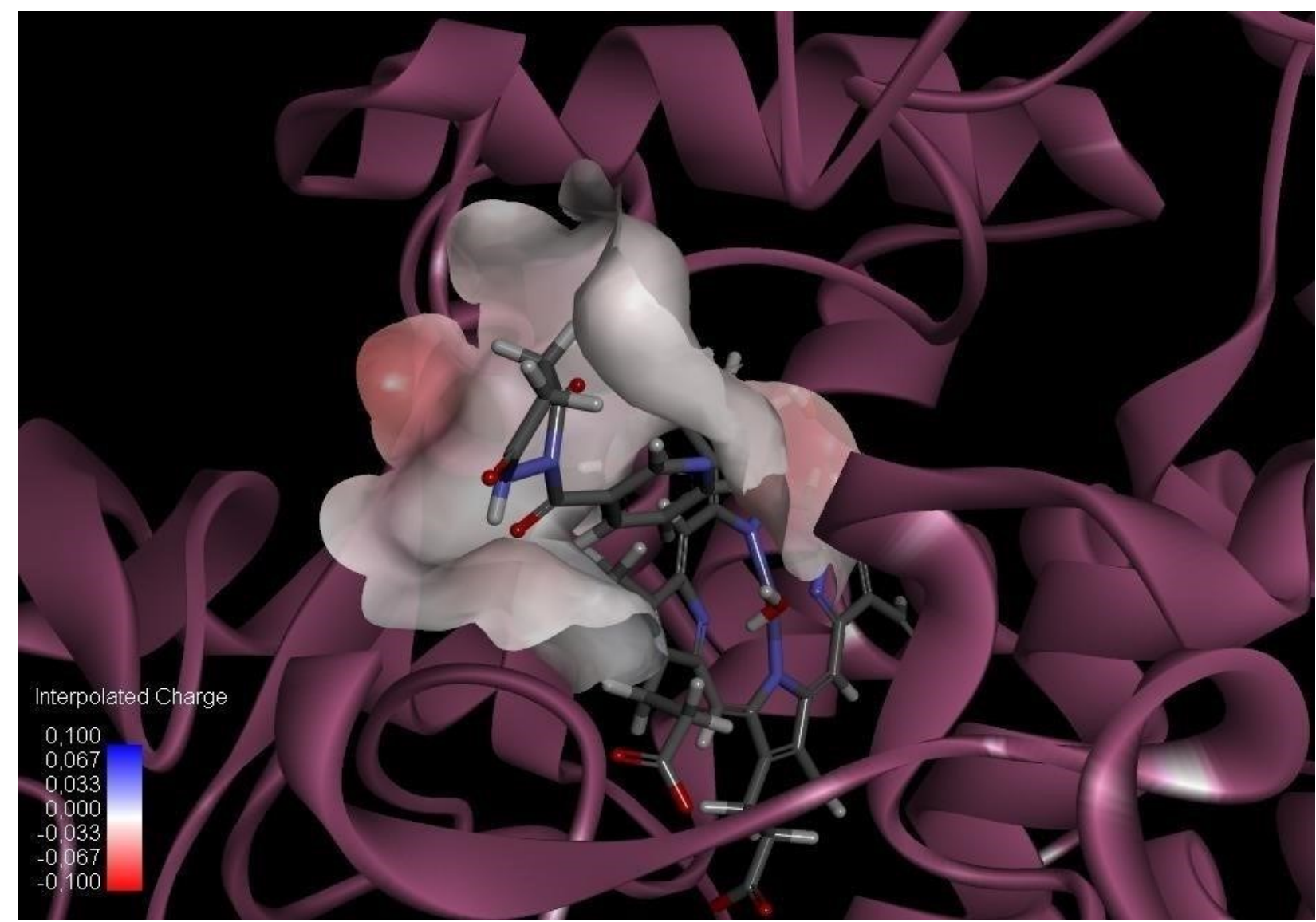

Figura 30. Dock (número 17) da Iso_Cic6 na enzima 1SJ2.

\subsection{ESTUDOS DE ESTABILIDADE QUÍMICA DA Clso-Suc (NAJLAH et al, 2006)}

Esta etapa do projeto teve a colaboração do aluno de Iniciação Científica José Carlos V. L. dos Reis.

\subsubsection{Desenvolvimento do método analítico}

O desenvolvimento do método teve início com a escolha de uma coluna cromatográfica mais próxima daquela descrita pela farmacopeia brasileira. Para tanto, foram selecionadas colunas de Octadecilsilano $(5 \mu \mathrm{m})$, tanto de $250 \mathrm{~mm} x$ 4,6 mm, quanto de $150 \mathrm{~mm} \times$ 4,6 mm de marcas distintas.

Os testes foram realizados com amostras de isoniazida de concentração igual a $1,82 \times 10^{-3} \mathrm{M}$, preparadas em fase móvel conforme descrito na Farmacopeia, tomando como parâmetros de aceitação o Fator de cauda, número de pratos teóricos, pureza dos picos e tempo de retenção. A média das cinco análises, para cada coluna, estão apresentadas na Tabela 16.

Tabela 16. Colunas cromatográficas testadas. 


\begin{tabular}{|c|c|c|c|c|}
\hline Coluna & Fator de Cauda & $\begin{array}{c}\mathbf{N}^{\circ} \text { pratos } \\
\text { teóricos }\end{array}$ & $\begin{array}{c}\text { Pureza do } \\
\text { pico }\end{array}$ & $\begin{array}{c}\text { Tempo de } \\
\text { retenção } \\
\text { (min) }\end{array}$ \\
\hline $\begin{array}{c}\text { C18 - MERK } \\
250 \mathrm{~mm}\end{array}$ & 2,38 & 2289,23 & puro & 3,88 \\
\hline $\begin{array}{c}\text { C18 - } \\
\text { LICHROSPHERE } \\
250 \mathrm{~mm}\end{array}$ & 1,95 & 2283,33 & puro & 7,81 \\
\hline $\begin{array}{c}\text { C18 - ACE } \\
150 \mathrm{~mm}\end{array}$ & 2,48 & 691,47 & puro & 3,59 \\
\hline C18 - XBridge & 1,31 & 4679,87 & puro & 3,37 \\
$150 \mathrm{~mm}$ & & & & \\
\hline
\end{tabular}

Com base nos resultados apresentados na Tabela 16, a coluna C18 Xbridge $(5 \mu \mathrm{m})-150 \mathrm{~mm} \times 4,6 \mathrm{~mm}$ foi escolhida como a mais adequada dentre as verificadas, uma vez que apresentou o menor fator de cauda e maior número de pratos teóricos. Esses dados indicam maior eficiência na separação dos componentes de uma mistura.

A otimização do método prosseguiu com a determinação do $\mathrm{pH}$ da fase móvel a ser empregada. Tal determinação teve como objetivo encontrar um valor onde a maioria das espécies analisadas encontrava-se eletricamente neutra, visando uma melhor interação com a coluna cromatográfica. Para tanto, fora realizada a determinação do pKa das espécies Clso-suc, Iso-suc e isoniazida a partir de simulações com o software MarvinSketch.

Com base nos resultados apresentados acima, tanto a Clso-suc quanto a isoniazida encontram-se, predominantemente, na forma molecular no valor de $\mathrm{pH}$ de 6,9, conforme proposto pela metodologia inicial da Farmacopeia. Entretanto, a Iso-suc mostra-se carregada negativamente e, visando melhorar sua interação com a coluna cromatográfica, foram realizados testes adicionando $0,1 \%$ de trietilamina (TEA) ou $0,1 \%$ de ácido trifluoracético (TFA) à fase móvel.

Embora não tenham sido observadas variações significativas no tempo de retenção médio dos analitos, uma melhor simetria dos picos fora constatada com o emprego de $0,1 \%$ de TFA, sendo este, portanto, o componente acrescido a fase móvel. 
A etapa seguinte de desenvolvimento do método envolveu a determinação da proporção de tampão fosfato e metanol que melhor permitia a separação dos analitos em questão. Como ponto de partida, foram feitas análises na proporção 95:5 (v/v), conforme descrito na farmacopeia. Com o objetivo de melhor separação dos picos de Iso-suc e isoniazida, fora necessário diminuir a proporção de solvente orgânico para 97,5:2,5 (v/v), para que fosse aumentada a interação destes analitos com a coluna. A média das cinco análises dos tempos de retenção obtidos, para cada proporção, estão apresentadas na Tabela 17.

Tabela 17. Determinação da proporção entre os solventes tampão fosfato e metanol.

\begin{tabular}{|c|c|c|}
\hline \multirow[t]{2}{*}{ Analito } & \multicolumn{2}{|c|}{$\begin{array}{c}\text { Tempo de Retenção } \\
\text { (min) }\end{array}$} \\
\hline & $95: 5(v / v)$ & $97,5: 2,5(v / v)$ \\
\hline Clso-suc & 4,952 & 6,610 \\
\hline Iso-suc & 2,413 & 2,685 \\
\hline isoniazida & 3,332 & 3,930 \\
\hline
\end{tabular}

O planejamento do método teve continuidade com o aumento da temperatura do forno de ambiente $\left(\sim 25^{\circ} \mathrm{C}\right)$ para o valor constante de $35^{\circ} \mathrm{C}$, com os propósitos de se padronizar a temperatura de análise e melhorar em 0,76 a simetria dos picos. Sabe-se que o aumento de temperatura, dentro dos limites da coluna, favorece a interação dos analitos com a fase estacionária.

A penúltima etapa do desenvolvimento do método foi o ajuste do fluxo de fase móvel durante a análise. A escolha de se modificar o fluxo surgiu da necessidade em se aumentar os parâmetros de fator de cauda e número de pratos teóricos. Pretendeu-se, então, assegurar a manutenção destes valores acima dos mínimos ao longo de todo o estudo de estabilidade, uma vez que as numerosas análises poderiam desgastar a coluna e inviabilizar sua utilização durante o ensaio.

Para esta finalidade, foi escolhido trabalhar com um gradiente de fluxo de fase móvel, entretanto, por não se tratar de uma prática frequente, poucas referências foram encontradas acerca deste assunto, de modo que os testes foram realizados empiricamente e os ajustes foram sendo feitos a partir dos resultados gerados. Após serem realizados ensaios testando diversos gradientes 
de fluxo, achou-se a melhor condição (relatada na Tabela 18). Esse gradiente de fluxo apresentou, quando comparado aos fluxos constantes de $0,8 \mathrm{~mL} / \mathrm{min}$ e 1 $\mathrm{mL} / \mathrm{min}$, a melhor resolução dentre os gradientes testados (aumento médio de 0,53 em relação aos demais). Essa comparação pode ser observada na Tabela 19.

Tabela 18. Gradiente de fluxo escolhido.

\begin{tabular}{|c|c|}
\hline $\begin{array}{c}\text { Tempo } \\
(\mathbf{m i n})\end{array}$ & $\begin{array}{c}\text { Fluxo } \\
(\mathbf{m L} / \mathbf{m i n})\end{array}$ \\
\hline 0,01 & 0,6 \\
\hline 2,0 & 0,8 \\
\hline 5,0 & 1,0 \\
\hline 6,0 & 1,3 \\
\hline
\end{tabular}

Tabela 19. Comparação entre o fluxo constante e o gradiente de fluxo.

\begin{tabular}{|c|c|c|c|c|}
\hline \multirow[t]{2}{*}{ Analito } & \multirow[t]{2}{*}{ Parâmetro } & \multicolumn{3}{|c|}{ Fluxo } \\
\hline & & $0,8 \mathrm{~mL} / \mathrm{min}$ & $1,0 \mathrm{~mL} / \mathrm{min}$ & Gradiente \\
\hline \multirow[t]{3}{*}{ Clso-suc } & $\begin{array}{l}\text { Tempo de } \\
\text { retenção }\end{array}$ & 7,639 & 6,234 & 5,828 \\
\hline & Fator de cauda & 1,701 & 1,203 & 1,197 \\
\hline & $\begin{array}{l}\text { Número de } \\
\text { pratos teóricos }\end{array}$ & 4681,051 & 6690,351 & 13489,695 \\
\hline \multirow[t]{3}{*}{ Iso-suc } & $\begin{array}{l}\text { Tempo de } \\
\text { retenção }\end{array}$ & 3,175 & 2,612 & 3,190 \\
\hline & Fator de cauda & 1,380 & 1,278 & 1,315 \\
\hline & $\begin{array}{l}\text { Número de } \\
\text { pratos teóricos }\end{array}$ & 3206,873 & 3683,531 & 4330,149 \\
\hline \multirow[t]{2}{*}{ Isoniazida } & $\begin{array}{l}\text { Tempo de } \\
\text { retenção }\end{array}$ & 4,711 & 3,760 & 4,237 \\
\hline & Fator de cauda & 1,589 & 1,362 & 1,364 \\
\hline
\end{tabular}




\begin{tabular}{|l|c|c|c|c|}
\hline $\begin{array}{c}\text { Número de } \\
\text { pratos teóricos }\end{array}$ & 4762,223 & 5609,857 & 6612,388 \\
\hline
\end{tabular}

Por fim, a última etapa de desenvolvimento do método envolveu o ajuste dos volumes de amostra e de injeção, com o propósito de se adequar a quantidade de analito que chega ao detector dentro limites de detecção. Para tanto, fora necessário, primeiramente, determinar qual a concentração de Clsosuc a ser empregada no ensaio de estabilidade.

Por uma questão de praticidade e de redução da incerteza atrelada a pesagem, a massa inicial de Clso-suc fora estabelecida como $6 \mathrm{mg}$, os quais foram dissolvidos em $15 \mathrm{~mL}$ de fase móvel, resultando em uma concentração molar de $1,82 \times 10^{-3} \mathrm{~mol} / \mathrm{L}$. Uma vez determinada a concentração inicial e, conhecendo-se o comportamento do detector disponível, foi estabelecido $1 \mathrm{~mL}$ como volume de amostra no interior do vial $(\sim 2 \mathrm{~mL})$ e $60 \mu \mathrm{L}$ como volume de injeção para respeitar o limite de detecção do equipamento.

\subsubsection{Estudos de estabilidade química}

As informações principais dos resultados dos estudos de estabilidade química de Clso-Suc mostraram que Clso-Suc pode se converter Iso-Suc. Por outro lado, a quebra da ligação entre o ácido succínico e a isoniazida praticamente não foi observada, uma vez que praticamente não há sinais correspontes desta nos crimatogramas. Isso pode ser explicado pelo anel heterocíclico pirrolidiona da Clso-suc, o qual é menos estável, quando comparado à cetohidrazona da Iso-suc (CLAYDEN et al, 2012).

Soluções tampão pH 1,2 e 6,0

Os experimentos demonstraram que o anel cilcizado da Clso-Suc de manteve realtivamente manteve estável nas faixas de soluções tampões de $\mathrm{pH}$ de 1,2 e 6,0 durante 24 horas, mesmo sob agitação e aquecimento a $37^{\circ} \mathrm{C}$, uma vez que o sinal da Clso-Suc foi menor do que os outros dois $\mathrm{pH}$. Tal constatação pode ser vantajosa pensando na administração oral do pró-fármaco, uma vez que não haverá hidrólise durante o trânsito gastrointestinal. 
Ademais, observa-se uma variação irregular da área de Iso-suc na primeira hora de ensaio, o que reflete a dificuldade de se quantificar analitos em concentrações muito próximas do limite de detecção do equipamento utilizado. As Figuras $\mathbf{3 5}$ e $\mathbf{3 6}$ foram feitas com base nos dados das Tabelas 20 e 21.

Tabela 20. Média das áreas de Clso-suc e Iso-suc ao longo do ensaio em solução tampão $\mathrm{pH}$ 1,2.

\begin{tabular}{|c|c|c|}
\hline Número da Amostra & $\begin{array}{l}\text { Área média de Clso-suc } \\
\text { (unidades de área) }\end{array}$ & $\begin{array}{l}\text { Área média de Iso-suc } \\
\text { (unidades de área) }\end{array}$ \\
\hline T0 & 24282334 & 0 \\
\hline T1 & 25210251 & 7258 \\
\hline $\mathrm{T} 2$ & 23261969 & 0 \\
\hline T3 & 25494918 & 316070 \\
\hline T4 & 22601230 & 280079 \\
\hline T5 & 14103048 & 0 \\
\hline T6 & 18649172 & 128193 \\
\hline $\mathrm{T7}$ & 17647228 & 167130 \\
\hline T8 & 19940223 & 612957 \\
\hline T9 & 19144319 & 710516 \\
\hline T10 & 18768167 & 837559 \\
\hline T11 & 15489071 & 4173326 \\
\hline $\mathrm{T} 12$ & 13917164 & 4293758 \\
\hline
\end{tabular}




\section{Perfil de estabilidade em solução tampão pH 1,2}

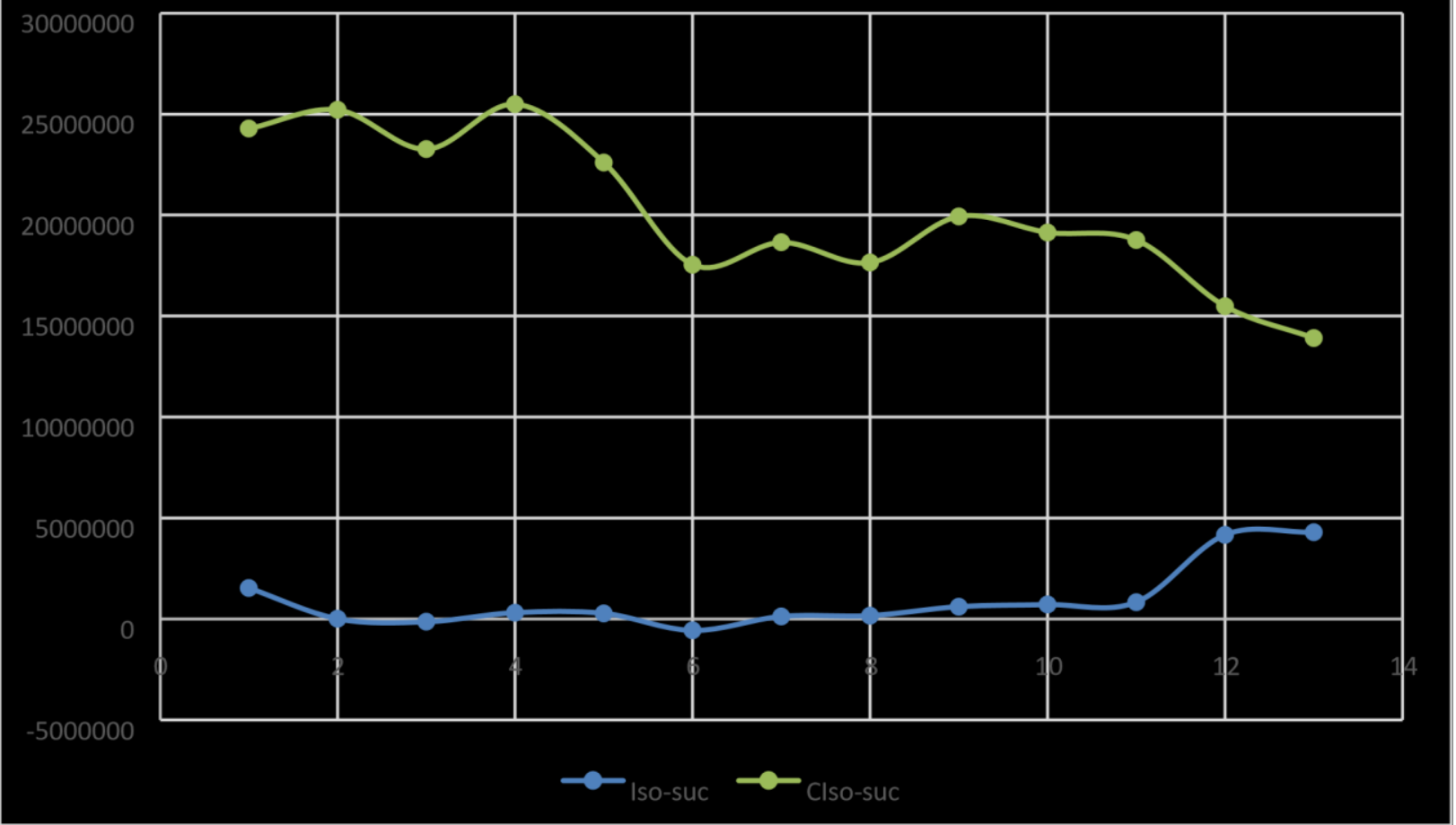

Figura 32. Gráfico da variação da área do pró-fármaco ao longo de 24 horas em solução tampão $\mathrm{pH} 1,2$.

Tabela 21. Média das áreas de Clso-suc e Iso-suc ao longo do ensaio em solução tampão pH 6,0.

\begin{tabular}{|c|c|c|}
\hline Número da Amostra & $\begin{array}{c}\text { Área média de Clso-suc } \\
\text { (unidades de área) }\end{array}$ & $\begin{array}{c}\text { Área média de Iso-suc } \\
\text { (unidades de área) }\end{array}$ \\
\hline T0 & 14668571 & 1830878 \\
\hline T1 & 12821106 & 231857 \\
\hline T2 & 15975284 & 12028 \\
\hline T3 & 15467310 & 272838 \\
\hline T4 & 15566218 & 526685 \\
\hline T5 & 15819410 & 143555 \\
\hline T6 & 13181978 & 867150 \\
\hline T7 & 15204397 & 767540 \\
\hline T8 & 13394802 & 1458216 \\
\hline T9 & 14973192 & \\
\hline & & \\
\hline
\end{tabular}




\begin{tabular}{|c|c|c|}
\hline T10 & 14872890 & 1191123 \\
\hline T11 & 10765658 & 8254535 \\
\hline T12 & 9746752 & 8831036 \\
\hline
\end{tabular}

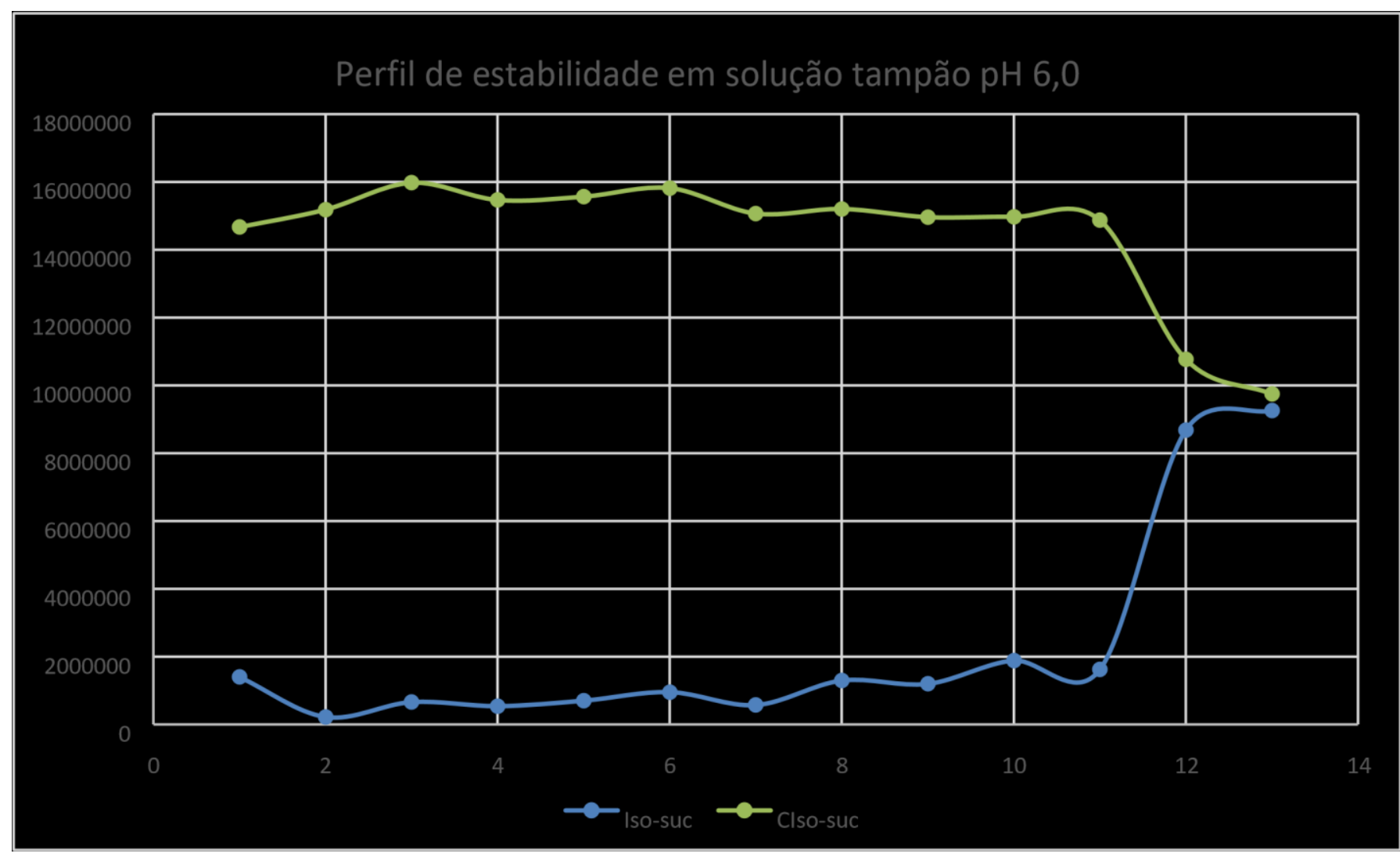

Figura 33. Gráfico da variação da área do pró-fármaco ao longo de 24 horas em solução tampão pH 6,0.

Considerando os ensaios com Clso-Suc em solução tampão pH 1,2, ao se comparar os cromatogramas do tempo 0 (T0) com o tempo 24 horas (T13), é possível notar o aumento da amplitude do sinal da Iso-Suc (tempo de retenção próximo de 3,371 minutos, área sob a curva inicial de 0 e final de 4293758), a diminuição de Clso-Suc (tempo de retenção próximo de 6,525 minutos, área sob a curva inicial de 24282334 e final de 13917164) (Cromatogramas 1 e 2). 


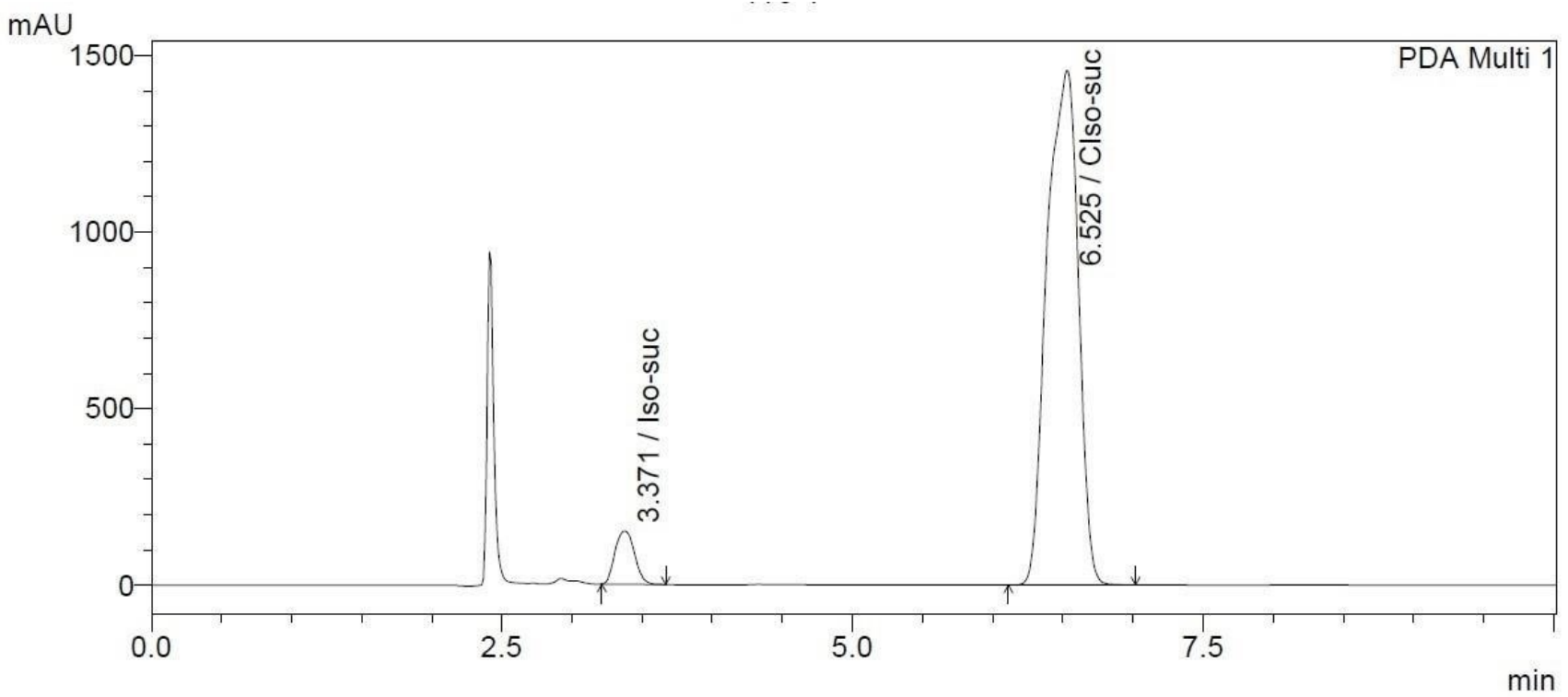

Cromatograma 1. Cromatograma resultante do estudo de estabilidade em pH 1,2 (T0). Condições cromatográficas: Solvente A (0,1\% TFA/Tampão fosfato pH 6,9, v/v); solvente B (Metanol). Proporção de solvente $95 \%$ de A e $5 \%$ de B. Gradiente de fluxo de 0,6 a 1,3 $\mathrm{mL} / \mathrm{min}$ por 10 minutos. Comprimento de onda: $261 \mathrm{~nm}$.

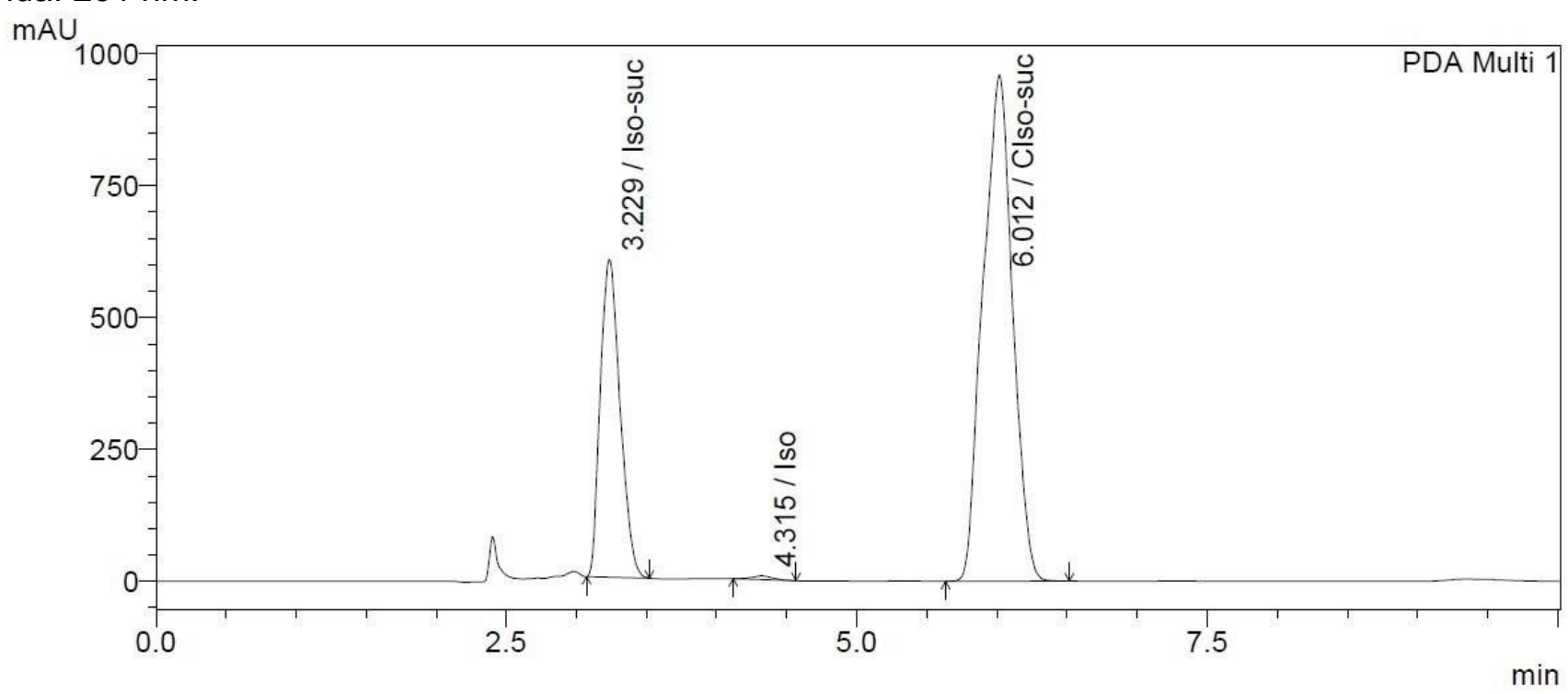

Cromatograma 3. Cromatograma resultante do estudo de estabilidade em pH 1,2 (T13). Condições cromatográficas: Solvente A (0,1\% TFA/Tampão fosfato $\mathrm{pH} 6,9, \mathrm{v} / \mathrm{v})$; solvente $\mathrm{B}$ (Metanol). Proporção de solvente $95 \%$ de $A$ e $5 \%$ de $B$. Gradiente de fluxo de 0,6 a $1,3 \mathrm{~mL} / \mathrm{min}$ por 10 minutos. Comprimento de onda: $261 \mathrm{~nm}$.

Em relação à solução tampão pH 6,0, do mesmo modo que em pH 1,2, ao se comparar os cromatogramas do tempo 0 (T0) com o tempo 24 horas (T12), verifica-se o aumento da amplitude do sinal da Iso-Suc (tempo de retenção de próximo de 3,345 minutos, área sob a curva inicial de 1830878 e final de 8831036), a diminuição de Clso-Suc (tempo de retenção de 6,525 minutos, área sob a curva inicial de 14668571 e final de 9746752) (Cromatogramas 3 e 4). 


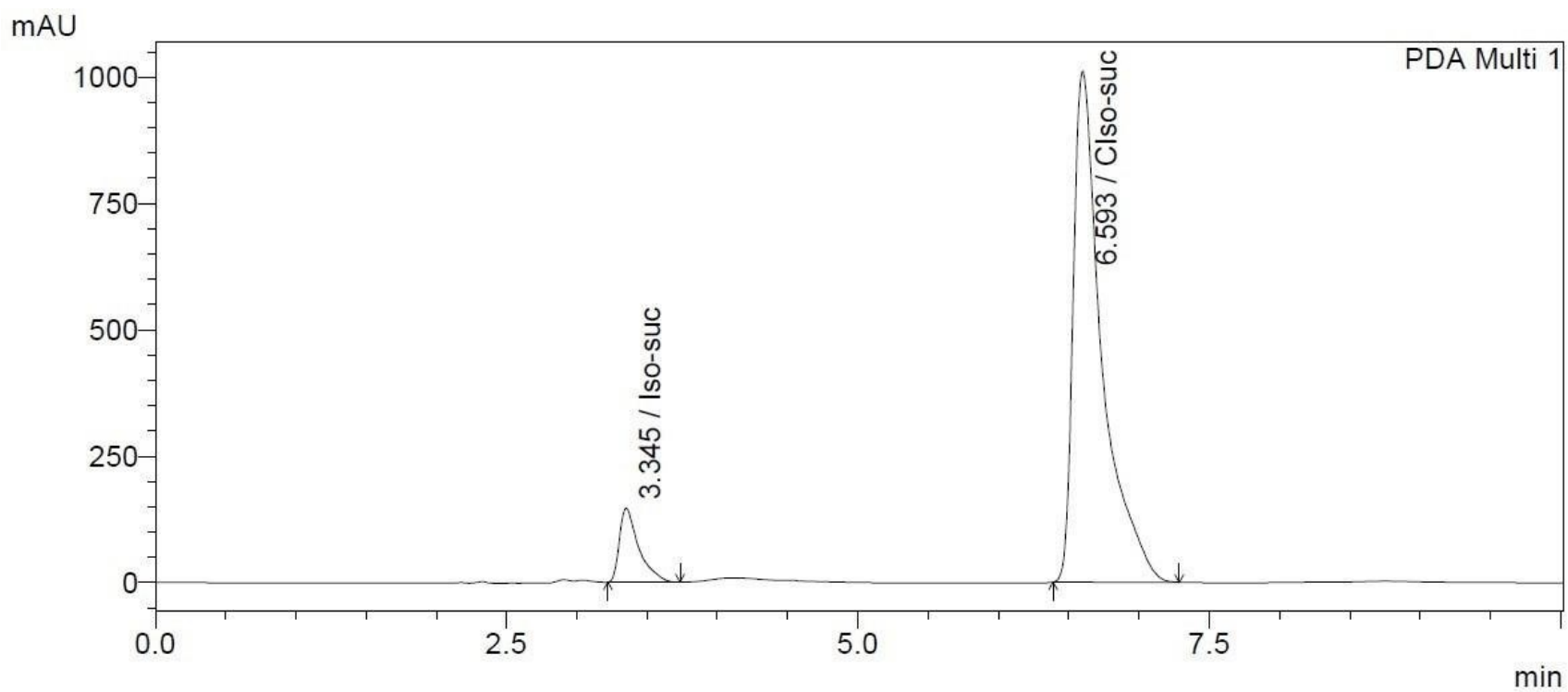

Cromatograma 2. Cromatograma resultante do estudo de estabilidade em $\mathrm{pH} \mathrm{6,0} \mathrm{(T0).} \mathrm{Condições}$ cromatográficas: Solvente A (0,1\% TFA/Tampão fosfato $\mathrm{pH} 6,9, \mathrm{v} / \mathrm{v})$; solvente $\mathrm{B}$ (Metanol). Proporção de solvente $95 \%$ de $A$ e $5 \%$ de $B$. Gradiente de fluxo de 0,6 a $1,3 \mathrm{~mL} / \mathrm{min}$ por 10 minutos. Comprimento de onda: $261 \mathrm{~nm}$. mAU

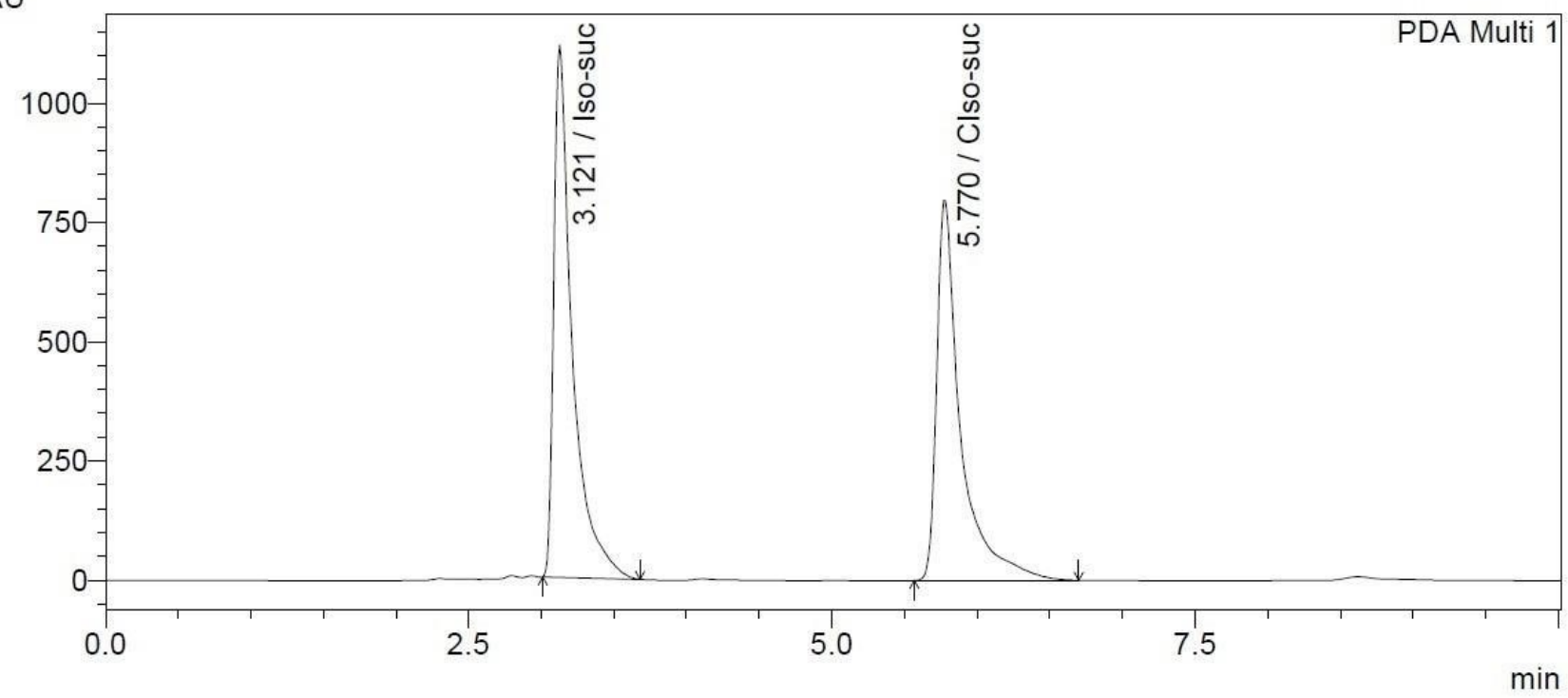

Cromatograma 4. Cromatograma resultante do estudo de estabilidade em pH 6,0 (T13). Condições cromatográficas: Solvente A (0,1\% TFA/Tampão fosfato $\mathrm{pH} 6,9, \mathrm{v} / \mathrm{v})$; solvente B (Metanol). Proporção de solvente $95 \%$ de $A$ e $5 \%$ de $B$. Gradiente de fluxo de 0,6 a $1,3 \mathrm{~mL} / \mathrm{min}$ por 10 minutos. Comprimento de onda: $261 \mathrm{~nm}$.

$\mathrm{pH} 7,4$ e 8,5

Assim como nos experimentos com soluções $\mathrm{pH} 1,2$ e 6,0 , os experimentos em $\mathrm{pH}$ 7,4 e 8,5 demonstraram que a ligação entre a isoniazida e o transportador se manteve estável em 24 horas, uma vez que não fora observado sinal de isoniazida dentro do limite de detecção do equipamento. Por 
outro lado, é possível observar que, tanto em $\mathrm{pH} 7,4$, quanto 8,5 ocorre a conversão de Clso-Suc para Iso-Suc, evidenciado pela queda na média das áreas sob a curva de Clso-suc e aumento de Iso-suc (Figura 34 e Figura 35). Importante mencionar que os $\mathrm{pH} 7,4$ e 8,5 representam, respectivamente, o sangue e as partes distais do intestino.

Tabela 22. Média das áreas de Clso-suc e Iso-Suc ao longo do ensaio em pH 7,4.

\begin{tabular}{|c|c|c|}
\hline Número da Amostra & $\begin{array}{l}\text { Área média de Clso-suc } \\
\text { (unidades de área) }\end{array}$ & $\begin{array}{l}\text { Área média de Iso-suc } \\
\text { (unidades de área) }\end{array}$ \\
\hline T0 & 26200865 & 1793247 \\
\hline T1 & 25900463 & 615393 \\
\hline T2 & 26433645 & 1071884 \\
\hline T3 & 24442601 & 973887 \\
\hline T4 & 24934870 & 1780307 \\
\hline T5 & 24953983 & 2141859 \\
\hline T6 & 24345718 & 2386693 \\
\hline $\mathrm{T} 7$ & 22158901 & 2798471 \\
\hline T8 & 20529808 & 3221222 \\
\hline T9 & 19915539 & 3843329 \\
\hline T10 & 16727201 & 3448101 \\
\hline $\mathrm{T} 11$ & 9543599 & 14317749 \\
\hline $\mathrm{T} 12$ & 9099986 & 14608956 \\
\hline $\mathrm{T} 13$ & 7523524 & 15993041 \\
\hline
\end{tabular}




\section{Perfil de estabilidade no pH 7,4}

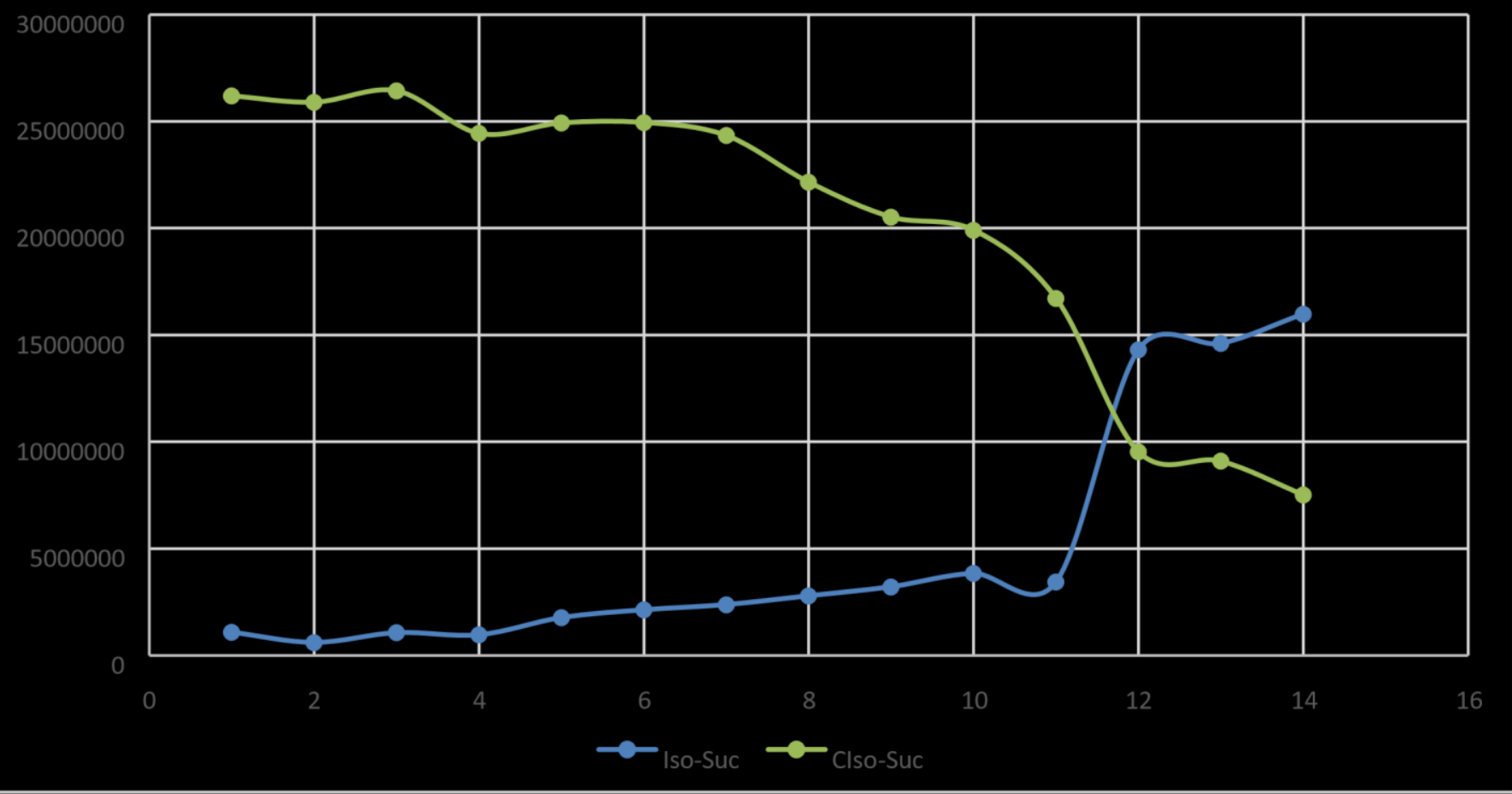

Figura 34. Gráfico da variação da área do pró-fármaco ao longo de 24 horas em solução tampão pH 7,4.

Tabela 23. Média das áreas de Clso-suc e Iso-Suc ao longo do ensaio em pH 8,5.

\begin{tabular}{|c|c|c|}
\hline $\begin{array}{c}\text { Tempo de coleta da } \\
\text { mostra }\end{array}$ & $\begin{array}{c}\text { Área média de } \\
\text { Clsosuc } \\
\text { (unidades de área) }\end{array}$ & $\begin{array}{c}\text { Área média de Iso-suc } \\
\text { (unidades de área) }\end{array}$ \\
\hline T0 & 16604510 & 1366383 \\
\hline T1 & 17345057 & 714749 \\
\hline T2 & 16210976 & 1046567 \\
\hline T3 & 16149613 & 1720601 \\
\hline T4 & 18118573 & 2304926 \\
\hline T5 & 17704015 & 2601910 \\
\hline T6 & 15529743 & 3028890 \\
\hline T7 & 14601338 & 3664896 \\
\hline T8 & 14144228 & 4614864 \\
\hline T9 & & \\
\hline & & \\
\hline
\end{tabular}




\begin{tabular}{|c|c|c|}
\hline T10 & 14361243 & 5490075 \\
\hline T11 & 5816111 & 19335696 \\
\hline T12 & 5047512 & 18611643 \\
\hline T13 & 3223828 & 7523524 \\
\hline
\end{tabular}

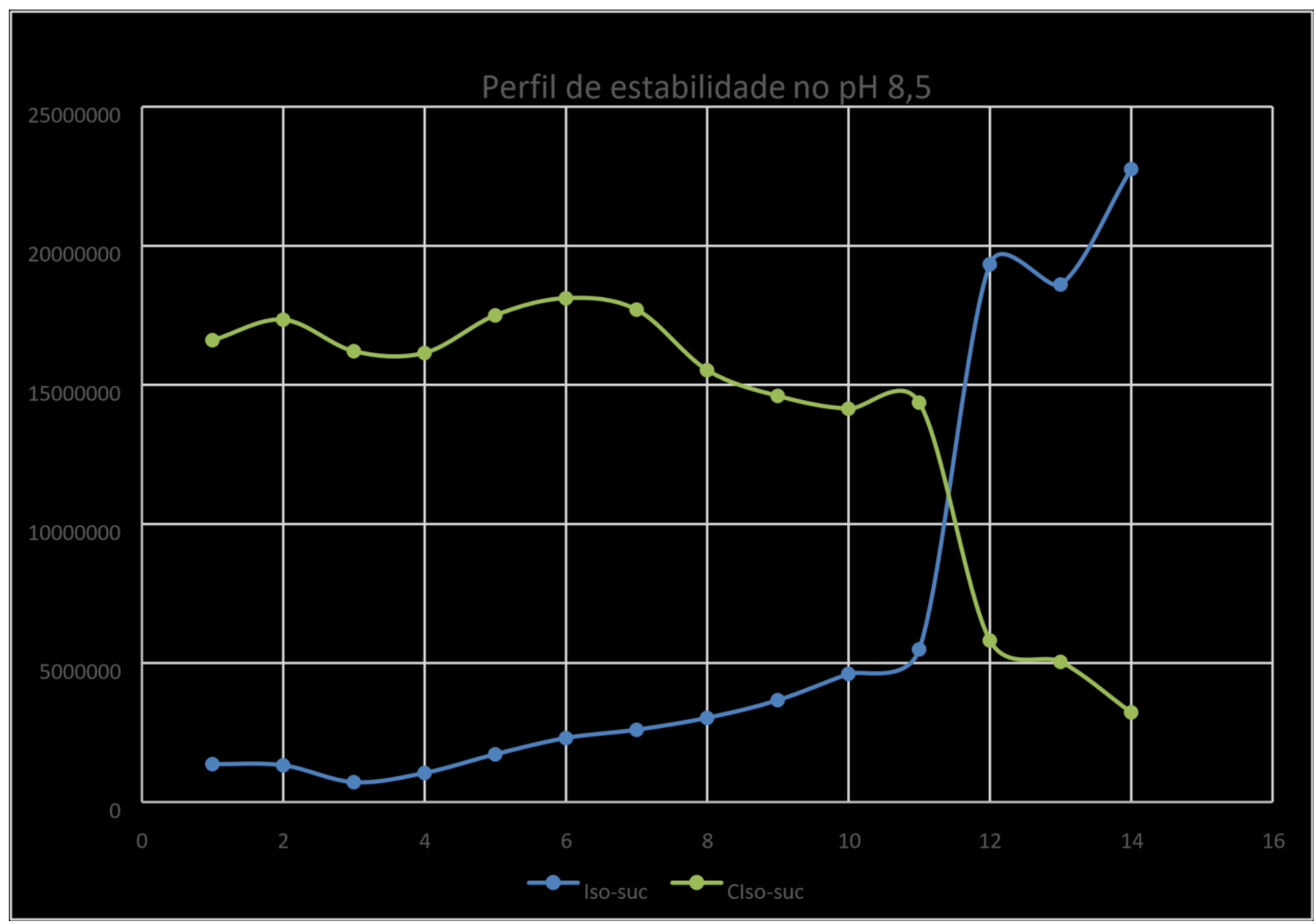

Figura 35. Gráfico da variação da área do pró-fármaco ao longo de 24 horas em solução tampão pH 8,5.

A liberação mais eficientes nesses meios podem ser demonstradas através do coeficiente linear da curva da Iso-Suc que para o $\mathrm{pH} 7,4$ é de $1 \times 10^{6}$ e para o $\mathrm{pH} 8,5$ é de $2 \times 10^{6}$. Esses valores são 2 vezes e 4 vezes maior que o $\mathrm{pH} 6$. Os cromatogramas 5 e 6 referentes ao $\mathrm{pH}$ 7,4 e os cromatogramas 7 e 8 referente ao pH 8,5 mostram que após 24 horas o pico que representa a ClsoSuc já tem a sua porcentagem em área muito menor quando comparado ao T0, antes do início da incubação. No pH 7,4 a média da área correspondente ao IsoSuc (tempo de retenção 3,116 minutos) sobe de 1793247 no T0 para 15993041 no útimo tempo 
de coleta (T13). A média da área da Clso-Suc (tempo de retenção 5,704 minutos) cai de 26200865 no T0 para 7523524 no T13. Já no pH 8,5, o a média da área da Iso-Suc sobe de 1366383 para 7523524 (T0 e T13) e a média da área de Clso-Suc cai de 16604510 para 3223828$)$.

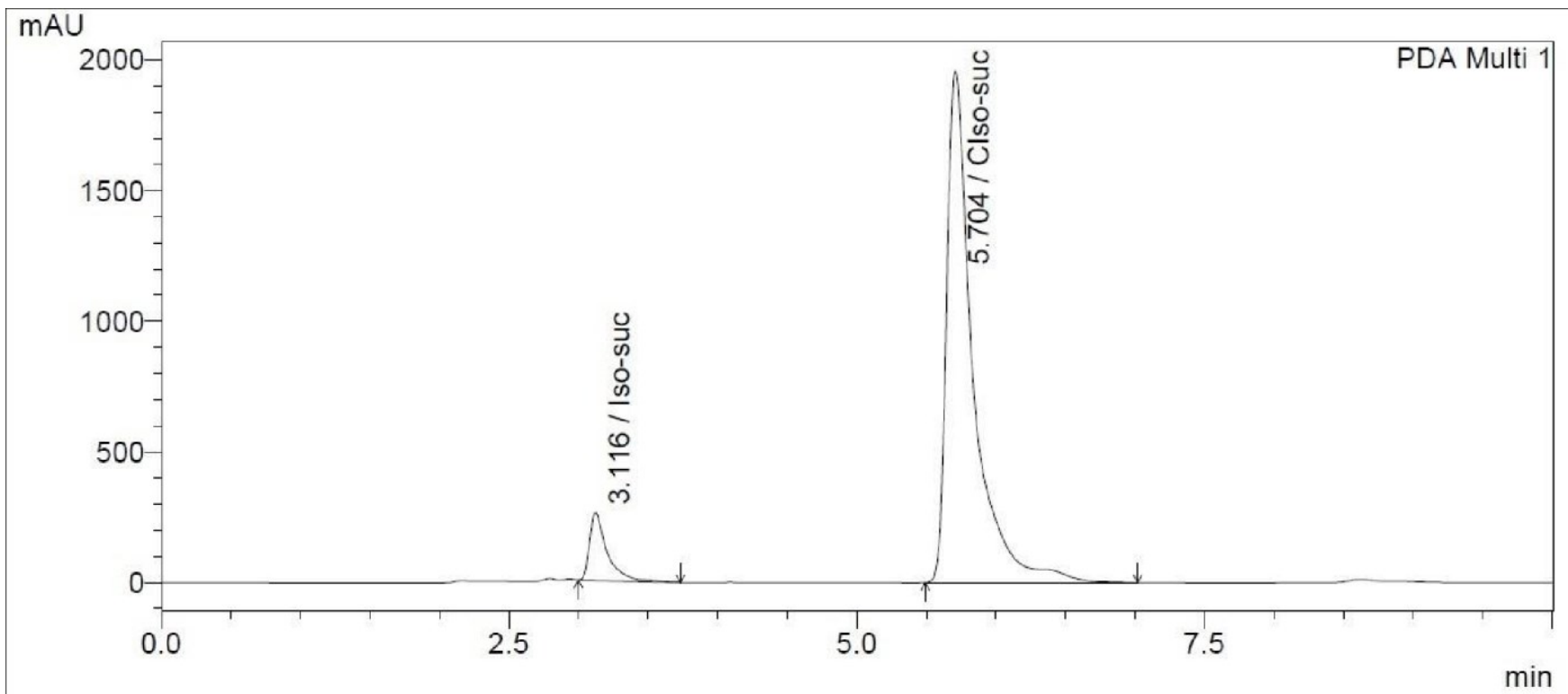

Cromatograma 5. Cromatograma resultante do estudo de estabilidade em pH 7,4 (T0). Condições cromatográficas: Solvente A (0,1\% TFA/Tampão fosfato $\mathrm{pH} 6,9, \mathrm{v} / \mathrm{v})$; solvente B (Metanol). Proporção de solvente $95 \%$ de A e $5 \%$ de B. Gradiente de fluxo de 0,6 a $1,3 \mathrm{~mL} / \mathrm{min}$ por 10 minutos. Comprimento de onda: $261 \mathrm{~nm}$.

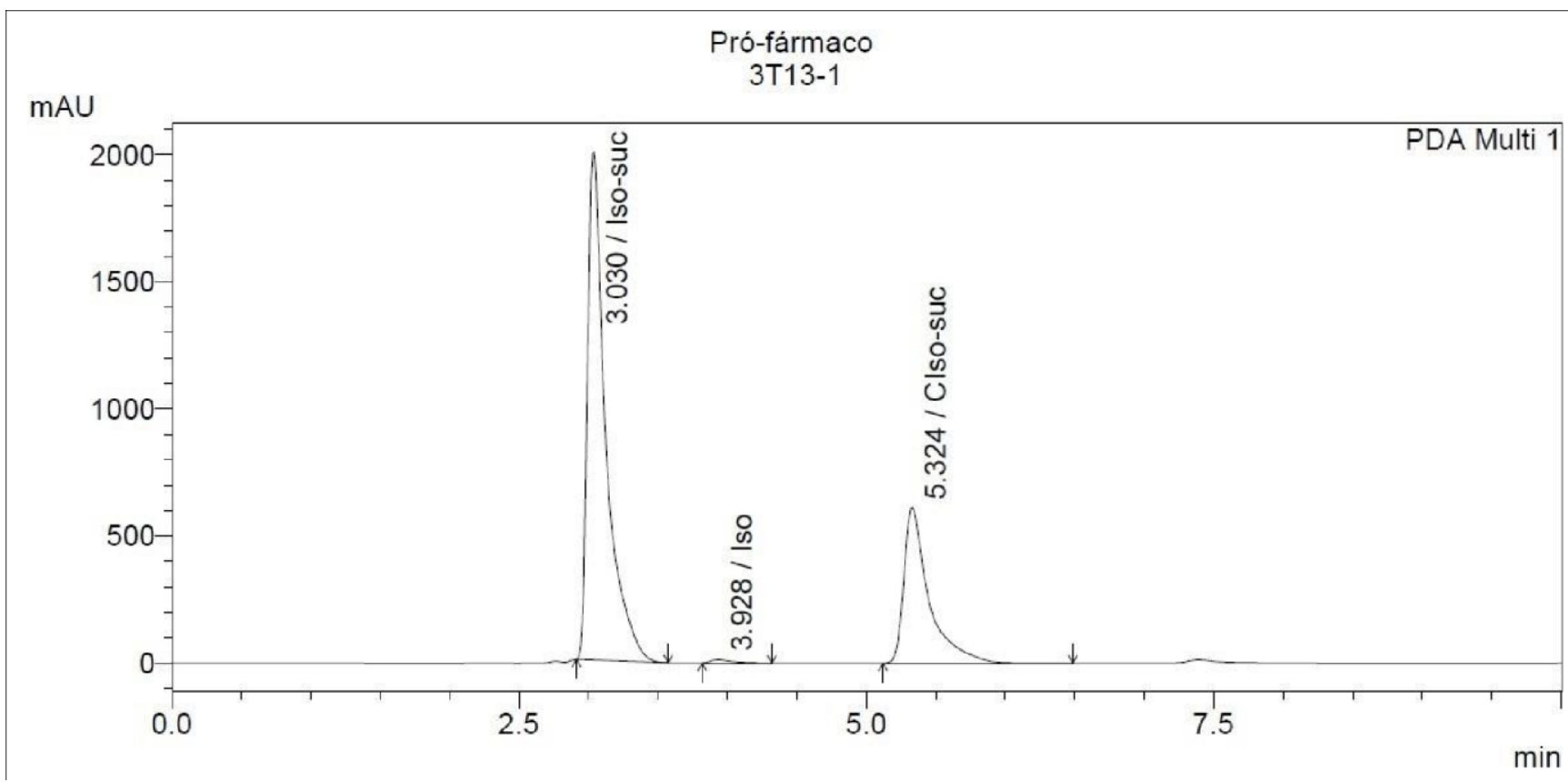

Cromatograma 6. Cromatograma resultante do estudo de estabilidade em pH 7,4 (T13). Condições cromatográficas: Solvente A (0,1\% TFA/Tampão fosfato $\mathrm{pH} 6,9, \mathrm{v} / \mathrm{v})$; solvente $\mathrm{B}$ (Metanol). Proporção de solvente $95 \%$ de A e $5 \%$ de B. Gradiente de fluxo de 0,6 a $1,3 \mathrm{~mL} / \mathrm{min}$ por 10 minutos. Comprimento de onda: $261 \mathrm{~nm}$. 


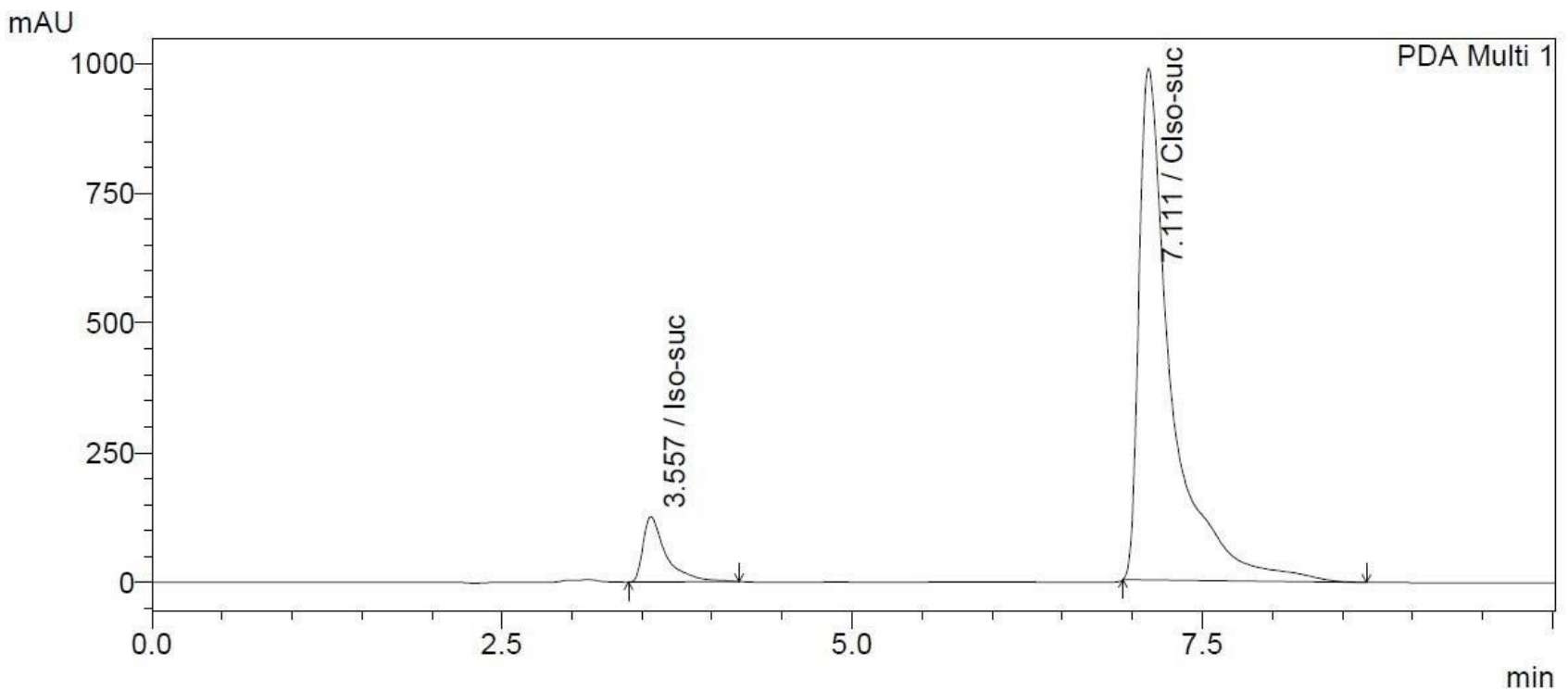

Cromatograma 7. Cromatograma resultante do estudo de estabilidade em $\mathrm{pH} 8,5$ (T0). Condições cromatográficas: Solvente A (0,1\% TFA/Tampão fosfato $\mathrm{pH} 6,9, \mathrm{v} / \mathrm{v})$; solvente B (Metanol). Proporção de solvente $95 \%$ de $A$ e $5 \%$ de $B$. Gradiente de fluxo de 0,6 a $1,3 \mathrm{~mL} / \mathrm{min}$ por 10 minutos. Comprimento de onda: $261 \mathrm{~nm}$.

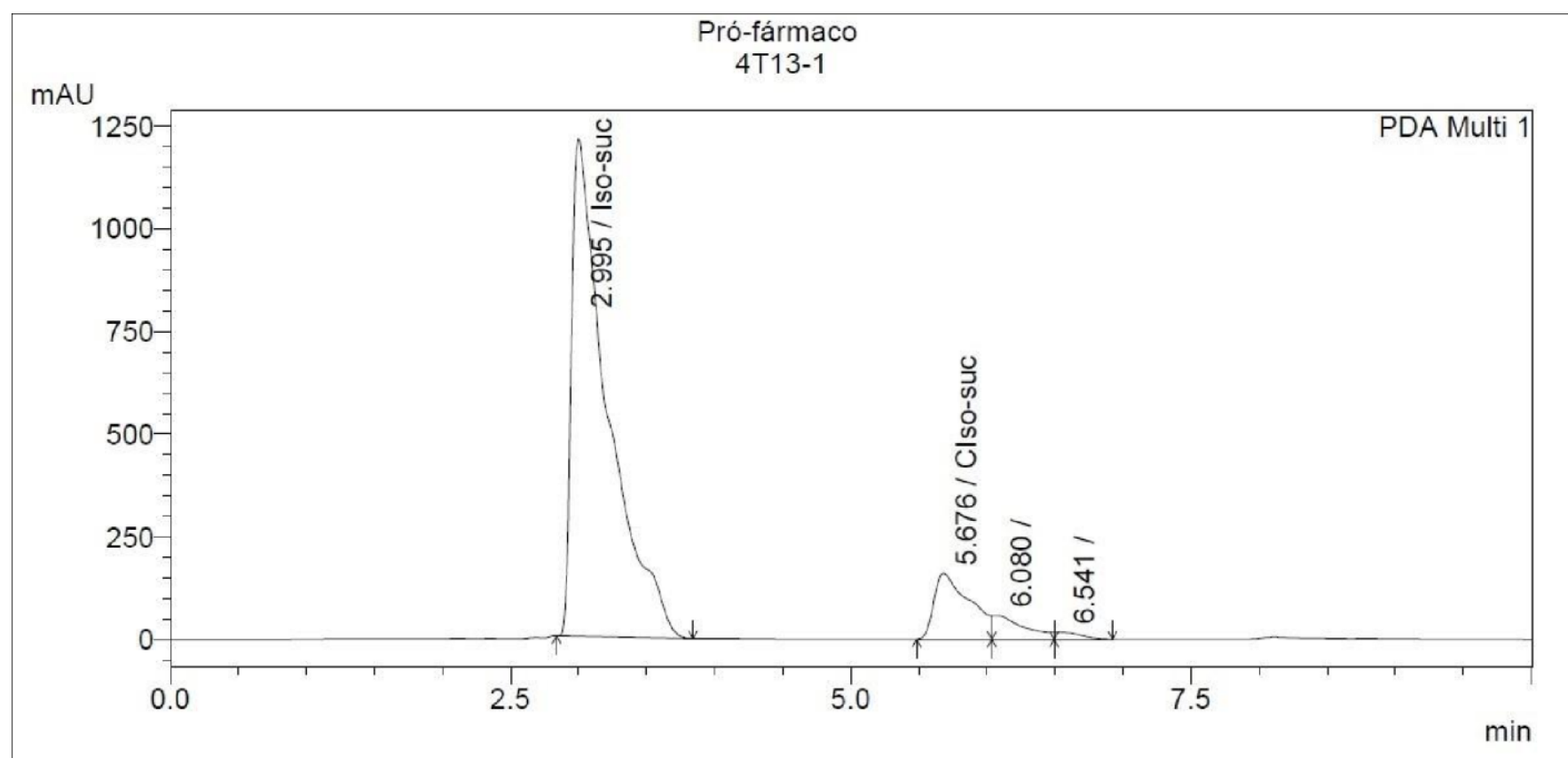

Cromatograma 8. Cromatograma resultante do estudo de estabilidade em pH 8,5 (T13). Condições cromatográficas: Solvente A (0,1\% TFA/Tampão fosfato $\mathrm{pH} 6,9, \mathrm{v} / \mathrm{v})$; solvente B (Metanol). Proporção de solvente $95 \%$ de $A$ e $5 \%$ de B. Gradiente de fluxo de 0,6 a $1,3 \mathrm{~mL} / \mathrm{min}$ por 10 minutos. Comprimento de onda: $261 \mathrm{~nm}$.

É importante destacar que, na condição com solução tampão pH 7,4, apareceu um pequeno pico referente á isoniazida (tempo de retenção de 3,928) 
indicando uma pequena liberação do ativo, mesmo que pequena quando comparada à Iso-Suc (tempo de retenção 5,324). Já em solução tampão de pH 8,5 , os picos mostraram-se mais assimétricos, característica relacionada com os valores de pKa dos hidrogênios ligados ao nitrogênio das moléculas, os quais são de 8,6 (nitrogênio 8, Figura 36, a esquerda) na Clso-Suc, considerando a de 5 membros e 9,0 para a Iso-Suc (nitrogênio 5, Figura 36, a direita). Assim, estas moléculas encontram-se nas formas ionizadas e não ionizadas, aumentando o fator de cauda, distorcendo o pico.
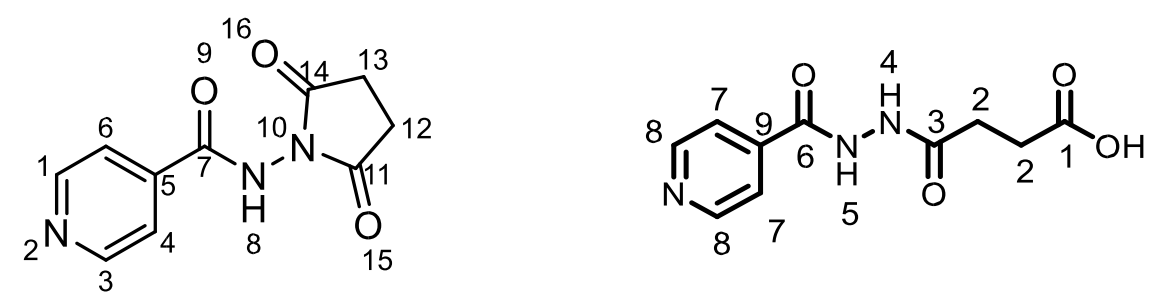

Figura 36. Estruturas da Clso-Suc (esquerda) e Iso-Suc (direita).

\section{CONCLUSÃO E PERSPECTIVAS}

Pelos resultados de infravermelho, RMN de ${ }^{1} \mathrm{H}$ e ${ }^{13} \mathrm{C}$, possivelmente, sintetizaram-se os intermediários Iso-Suc, Pq-suc, bem como os pró-fármacos dendriméricos de G0 (G0-Iso e G0-Pq) e de G1 (G1-Iso e G1-Pq). A análise da espectroscopia de massas revelou a presença de um intermediário de síntese Clso-Suc que pode estar ligada ao uso do EDC e DMAP para as sínteses EDC e DMAP. Foi identificado o potencial como pró-fármaco desse intermediário e usou-se então a metodologia analítica desenvolvida para os estudos de liberação. Esses ensaios revelaram que o pró-fármaco é consideravelmente mais estável em meio ácido ( $\mathrm{pH}$ 's 1,2 e 6,0) e libera com uma taxa maior em meios neutros/básicos ( $\mathrm{pH} 7,4$ e 8,5). Esses dados foram importantes para indicar uma possível estabilidade oral dessa molécula. Por fim, foram analisados via estudos in sílico a sua inibição direta no alvo da isonizida que revelou que é possível prever a sua ligação, mas não a sua atividade biológica. Para comprovar a atividade biológica per si da Clso-Suc serão necessários estudos da sua atividade biológica que já estão em processo de execução. Ainda com relação 
aos estudos computacionais, a carbonila $\mathrm{C} 2$ do dendrímero G0-Iso e G0-Pq, parece ser a mais interessante para a ação enzimática. Já para o pró-fármaco G1-Iso e G1-Pq, a carbonila C1 foi a mais promissora.

\section{REFERÊNCIAS}

ABDULLA, M. H.; RUELAS, D. S.; WOLFF, B.; SNEDECOR, J.; LIM, K.; XU, F.; RENSLO, A.R.; WILLIAMS, J.; CAFFREY, C.R. Drug discovery for schistosomiasis: Hit and lead compounds identified in a library of known drugs by medium-throughput phenotypic screening. PLoS Neglected Tropical Diseases, v.3, n.7, p. 1-14, 2009.

ANVISA. AGENCIA NACIONAL DE VIGILÂNCIA SANITÁRIA. Farmacopeia Brasileira, volume 2. $5^{\mathrm{a}}$ Ed. Brasília, 2010.

ARANTES, G.M. Uma perspectiva computacional sobre catálise enzimática.

Química Nova, v. 31, n. 2, p. 377-383, 2008.

ARAUJO, R.V.V.; SANTOS, S.S.; FERREIRA, E.I.; GIARROLA, J. New Advances in General Biomedical Applications of PAMAM Dendrimers.

Molecules, v. 23, p. 1, 2018.

BAIRD, J.K; LACY, M.D; BASRI, H; BARCUS, M.J; MAGUIRE, J.D; BANGS, M.J; GRAMZINSKI, R; SISMADI, P; KRISIN-LING, J; WIADY, I; KUSUMANINGSIH, M; JONES, T.R; FRYAUFF, D.J; HOFFMAN, S.L. Randomized, parallel placebocontrolled trial of primaquine for malaria prophylaxis in Papua, Indonesia. Clinical Infectious Diseases, v.33, p.1990-1997, 2001.

BENCHARIT, S.; EDWARDS, C.C.; MORTON, C.L.; HOWARD-WILLIAMS, E.L.; KUHN, P.; POTTER, P.M.; REDINBO, M.R. Multisite promiscuity in the processing of endogenous substrates by human carboxylesterase 1 . Journal of molecular biology, v. 363, n. 1, p. 201-214, 2006.

BERTRAND, T.; EADY, N.A.J.; JONES, J.N.; JESMIN.; NAGY, J.M.; GREGOIRE, B.J.; RAVEN, E.L.; BROWN, K.A. Crystal Structure of Mycobacterium tuberculosis Catalase-Peroxidase. Journal of Biological Chemistry, v. 279, p. 38991-38999, 2004. 
BIRD, I. M. High performance liquid chromatography: principles and clinical applications. Department of Biochemistry, University of Edinburgh, v. 299, p. 783-787, 1989.

BOAS, U.; HEEGAARD, P.M.H. Dendrimers in drug research. Chemical Society Reviews, v. 33, n. 1, p. 43-63, 2004.

BOECHAT, N., MAGALHÃES, J. Era uma vez... Doenças Negligenciadas.

Revista Virtual de Química, v. 4, n. 3, p. 195-196, 2012.

BRASIL. Ministério da Saúde. Malária: o que é, causas, sintomas, tratamento, diagnóstico e prevenção. Brasília, DF, 2019.

CATTAMANCHI, A.; DANTES, R.B.; METCALFE, J.Z.; JARLSBERG, L.G.; GRINSDALE, J.; KAWAMURA, L.M.; OSMOND, D.; HOPEWELL, P.C.; NAHID, P. Tuberculosis: clinical characteristics and treatment outcomes of patients with isoniazid-monoresistant tuberculosis. Clinical Infectious Diseases, v. 48, p.179-185, 2009.

CHAUDHARI, S.S.; AKAMANCHI, K.G. Thionyl Chloride-Benzotriazole in Methylene Chloride: A Convenient Solution for Conversion of Alcohols and Carboxylic Acids Expeditiously into Alkyl Chlorides and Acid Chlorides by Simple Titration. Synlett, v.11, p.1763-1765, 1999.

CHENG, Y.; XU, Z.; MA, M.; XU, T.; Dendrimers as Drug Carriers: Applications in Different Routes of Drug Administration. Journal of Pharmaceutical Sciences, v.97, p.123-143, 2008.

CHUNG, M.; SILVA, A.; CASTRO, L.F.; GUILDO, R.; NASSUTE, J.C. Advances in prodrug design. Mini Reviews in Medicinal Chemistry, v.5, p.893-914, 2005.

CLAYDEN, J., GREEVES, N., WARREN, S. Organic Chemistry, $2^{\text {nd }}$ Edition, Ed. Oxford University Press, 2012.

CROFT, S. L. Neglected tropical diseases in the genomics era: re-evaluating the impact of new drugs and mass drug administration. Genome Biology, v.17, p.46, 2016. 
DA SILVA SANTOS, S.; FERREIRA, E. I.; GIAROLLA, J. Dendrimer prodrugs. Molecules, v. 21, n. 6, p. 686, 2016.

Das GUPTA, R.; KRAUSE-IHLE, T.; BERGMANN, B.; MÜLLER, I.B.; KHOMUTOV, A.R.; MÜLLER, S.; WALTER, R.D.; LÜERSEN, K. 3Aminooxy1aminopropane and derivatives have an antiproliferative effect on cultured Plasmodium falciparum by decreasing intracellular polyamine concentrations. Antimicrobial Agents and Chemotherapy, v.29, p. 2857-2864, 2005.

De ASSIS, J.V.; TEIXEIRA, M.G.; SOARES, C.G.P.; LOPES, J.F.; CARVALHO, G.S.L.; LOURENÇO, M.C.S.; ALMEIDA, M.V.; ALMEIDA, W.B.; FERNANDES, S.A. Experimental and theoretical NMR determination of isoniazid and sodium psulfonatocalix[n]arenes inclusion complexes. European Journal of Pharmaceutical Sciences, v.47, p. 539-548, 2012.

DIAS, A.P.; SANTOS, S.S; SILVA, J.V.; PARISE-FILHO, R.; FERREIRA, E.I.; SEOUD, O.E.; GIAROLLA, J. Dendrimers in the context of nanomedicine. International Journal of Pharmaceutics, v. 573, 2020.

ENGELS, D. Neglected tropical diseases in the Sustainable Development Goals. The Lancet, v. 387, n. 10015, p. 223-224, 2016.

FAKUNLE, E. S.; LORING, J. F. Ethnically diverse pluripotent stem cells for drug development. Trends in Molecular Medicine, v. 18, p. 709-716, 2012.

FENG, X.; YUAN, Y.J.; WU, J.C. Synthesis and Evaluation of Water-Soluble Paclitaxel Prodrugs. Bioorganic \& Medicinal Chemistry Letters, v.12, p.33013303, 2002.

FERREIRA, E.I. Latenciação e formas avançadas de transporte de fármacos. Revista Brasileira de Ciências Farmacêuticas, v. 41, p.155-179, 2005. FERREIRA, L.G.; SANTOS, R. N.; OLIVA, G.; ANDRICOPULO, A. D. Molecular docking and structure-based drug design strategies. Molecules, v. 20, n. 7, p. 13384-13421, 2015.

FRECHET, J. M. J.; TOMALIA, D. A. Dendrimers and other dendritic polymers. John Wiley and Sons Inc., 2001. 
GIAROLLA, J.; FERREIRA, E.I. Drug Design for Neglected Disease in Brazil.

Mini-Reviews in Medicinal Chemistry, v. 15, p. 219-241, 2015.

Global tuberculosis report 2018. Geneva: World Health Organization; 2018.

Licence: CC BY-NC-SA 3.0 IGO p. 7. Disponível em: <http://apps.who.int/iris/bitstream/handle/10665/274453/9789241565646eng.pdf> Acesso em: 24 jan 2019.

GRAYSON, S. M.; FRECHET, J. M. J. Convergent dendrons and dendrimers: from synthesis to applications. Chemical Reviews, v. 101, n. 12, p. 3819-3868, 2001.

GREENALL, M.; KUNII, O.; THOMSON, K.; BANGERTA, R.; NATHANA, O. Reaching vulnerable populations: lessons from the Global Fund to fight AIDS, tuberculosis and malaria. Bull World Health Organization, v. 95, p. 159-161, 2017.

GRAYSON, S.M.; FRÉCHET, J.M.J. Convergent dendrons and dendrimers: from synthesis to application. Chemical Reviews, v. 101, p. 3819-3867, 2001.

Guidelines for the treatment of malaria 2015. Geneva: World Health Organization; 2015. p 96 e 97, 250 - 253. Disponível em: <http://apps.who.int/iris/bitstream/handle/10665/162441/9789241549127 eng.p df? sequence=1> Acesso em: 18 jan 2019.

GUIDO, R. V. C.; ANDRICOPULO, A. D.; OLIVA, G. Drug design, biotechnology and medicinal chemistry: applications to infectious diseases. Estudos Avançados, v. 24, p. 81-98, 2010.

HAMADA, Y. Recent progress in prodrug design strategies based on generally applicable modifications. Bioorganic and Medicinal Chemistry Letters, v. 27, p.1627-1632, 2017.

HEDSTROM, L. Serine protease mechanism and specificity. Chemical reviews, v. 102, n. 12, p. 4501-4524, 2002.

HERNÁNDEZ-SANTOYO, A.; TENORIO-BARAJAS, A. Y.; ALTUZAR, V.; VIVANCO-CID, H.; MENDOZA-BARRERA, C. Protein-protein and protein-ligand docking. In: OGAWA, T. Protein engineering - technology and application. 
Croácia: InTech, cap. 3, p. 63-81, 2013.

HORSBURGH R., C. Robert; BARRY III, C. E.; LANGE, C. Treatment of tuberculosis. New England Journal of Medicine, v. 373, n. 22, p. 2149-2160, 2015.

HOTEZ, P. J.; MOLYNEUX, D. H.; FENWICK, A.; KUMARESAN, M. B.; SACHS, S. E.; SACHS, J. D.; SAVIOLI, L. Control of neglected tropical diseases. The New England Journal of Medicine, v. 357, n. 10, p. 1018-1027, 2007.

HOTEZ, P. J.; FUJIWARA, R. T. Brazil's neglected tropical diseases: an overview and a report card. Microbes and Infection, v. 16, p. 601-606, 2014.

JIANG, L.; LAl, L. CH $\cdots$ O hydrogen bonds at protein-protein interfaces. Journal of Biological Chemistry, v. 277, n. 40, p. 37732-37740, 2002.

KEALEY, A.; SMITH, R. Neglected tropical disease: Infection, modeling and control. Journal of Health Care for the Poor and Underserved, v. 21, p. 53-69, 2010.

KESHARWANI, P.; JAIN, K.; JAIN, N. K. Dendrimer as nanocarrier for drug delivery. Progress in Polymer Science, v. 39, p. 268-307, 2014.

KETATA, W.; REKIK, W. K.; AYADI, H.; KAMMOUN, S. Les tuberculoses extrapulmonaires. Revue de Pneumologie Clinique, v. 71, p. 83-92, 2015. KIM, Y.; PARK, E.J.; NA, D.H. Recent progress in dendrimer-based nanomedicine development. Archives of Pharmacal Research, v. 41, p. 571582, 2018.

La-SCALEA, M. A.; MENEZES, C. M. S.; MATSUTAMI, G.C. ; POLLI, M.C. ; SERRANO, H.P. ; FERREIRA, E.I. Molecular modeling of the voltammetric oxidation at a glassy carbon electrode of the antimalarial drug primaquine and its prodrugs succinylprimaquine and maleylprimaquine. Electrochimica Acta, v. 51, p. 5103-5111, 2006.

LIM, L. E.; VILCHĖZE, C.; NG, C.; JACOBS, W. R.; RAMÓN-GARCIA, S.; THOMPSON, C. J. Anthelmintic avermectins kill Mycobacterium tuberculosis, including multidrug-resistant clinical strains. Antimicrobial agents and chemotherapy, v. 57, n. 2, p. 1040-1046, 2013. 
MAIOROV, V. N.; CRIPPEN, G. M. Significance of root-mean-square deviation in comparing three-dimensional structures of globular proteins. Journal of Molecular Biology, v. 235, n. 2, p. 625-634, 1994.

MARTINS-MELO, F. R. ; ROGERLANDIO, F.; RAMOS-JR, A.N. ; ALENCAR, C.H.; HEUKELBACH, J. Trends and spatial patterns of mortality related to neglected tropical diseases in Brazil. Parasite Epidemiology and Control, v.1, n. 2, p. 56-65, 2016.

MOLYNEUX, D. H.; SAVIOLI, L.; ENGELS, D. Neglected tropical diseases: progress towards addressing the chronic pandemic. The Lancet, v. 389, n. 10066, p. 312-325, 2017.

MOONEY, A.; CORRY, A. J.; CLIODHNA, N. R.; MAHGOUB, T,. SULLIVAN, D. O.; DONOVAM, N. O.; CROWN, J.; VARUGHESE, S.; DRAPER, S. M.; RAI, D. K.; KENNY, P. T. M. Synthesis, characterisation and biological evaluation of $\mathrm{N}$ (ferrocenyl)naphthoyl amino acid esters as anticancer agents. Dalton Transections, v. 35, p. 8228-8239, 2010.

MORAN, M.; GUZMAN, J.; ROPARS, A. L.; MCDONALD, A.; JAMESON, N.; OMUNE, B.; RYAN, S.; WU, L. Neglected disease research and development: How much are we really spending? PLoS Medicine, v. 6, n. 2, p. 0137-0146, 2009.

MORI, G.; CHIARELLI, L. R.; RICCARDI, G.; PASCA, M. R. New prodrugs against tuberculosis. Drug Discovery Today, v. 22, p. 519-525, 2017.

MÜLLER, I. B.; WU; F.; BERGMANN, B.; KNÖCKEL, J.; WALTER, R. D.; GEHRING, H.; WRENGER, C. Poisoning pyridoxal 5-phosphate-dependent enzymes: a new strategy to target the malaria parasite Plasmodium falciparum.

PLoS One, v. 4, p.1-9, 2009.

NAJLAH, M.; FREEMAN, S.; ATTWOOD, D.; D'EMANUELE, A. Synthesis, characterization and stability of dendrimer prodrugs. International Journal of Pharmaceutics, v.308, p.175-182, 2006.

NEISES, B.; STEGLICH, W. Simple Method for the Esterification of Carboxylic Acids. Angewandte Chemie International, v. 553, n. 7, p. 12-14, 1978. 
NDJONKA, D.; BERGMANN, B.; AGYARE, C.; ZIMBRES, F.M.; LÜERSEN, K.; HENSEL, A.; WRENGER, C.; LIEBAU, E. In vitro activity of extracts and isolated polyphenols from West African medicinal plants against Plasmodium falciparum. Parasitology Research, v.111, p.827-834, 2002.

OMANSEN, T. F.; PORTER, J. L.; JOHNSON, P. D. R.; VAN DER WERF, T. S.; STIENSTRA, Y.; STINEAR, T. P. In-vitro activity of avermectins against Mycobacterium ulcerans. PLoS neglected tropical diseases, v. 9, n. 3, p. e0003549, 2015.

PANDA, S.; SWAMINATHAN, S.; HYDER, K. A.; CRISTOPHEL, E.; PENDSE, R. N.; SREENIVAS, A. N.; LAKSONO, S. J.; SRIVASTAVA, R.; NAIR, G. B.; ADITAMA, T.Y.; SINGHASIVANON, P.; THAPA, A. B.; SARKAR, S. K. Drug resistance in malaria, tuberculosis, and HIV in South East Asia: biology, programme, and policy considerations. BMJ, v. 358, p. 67-70, 2017.

PALOMINO, J. C.; MARTIN, A.; CAMACHO, M.; GUERRA, H.; SWINGS, J.; PORTAELS, F. Resazurin microtiter assay plate: simple and inexpensive method for detection of drug resistance in Mycobacterium tuberculosis.

Antimicrobial Agents and Chemotherapy, v. 46, p. 2720-2722, 2002.

PETTERSEN, E. F.; GODDARD, T. D.; HUANG, C. C.; COUCH, G. S.; GREENBLATT, D. M.; MENG, E. C.; FERRIN, T. E. UCSF Chimera--a visualization system for exploratory research and analysis. Journal of Computational Chemistry, v. 25, p. 1605-1612, 2004.

PRIETO, D. C. Planejamento e síntese de pró-fármacos dendriméricos potencialmente ativos em doenças negligenciadas. Trabalho de Conclusão de Curso, 31p. Faculdade de Ciências Farmacêuticas, Universidade de São Paulo [apresentação em 19 de junho de 2017].

RANDO, D. G.; BRANDT, C. A.; FERREIRA, E.I. Use of $N$-methylene phosphonic chitosan to obtain an isoniazid prodrug. Revista Brasileira de Ciências Farmacêuticas, v. 40, p. 334-344, 2004.

RAUTIO, J.; KUMPULAINEN, H.; HEIMBACH, T.; OLIYAI, R.; OH, D.; JARVINEN, T.; SAVOLAINEN, J. Prodrugs: Design and clinical applications.

Nature Reviews Drug Discovery 7, p. 255-270, 2008. 
RENSLO, A. R.; MCKERROW, J. H. Drug discovery and development for neglected parasitic diseases. Nature chemical biology, v. 2, n. 12, p. 701-710, 2006.

SADEKAR, S.; THIAGARAJAN, G.; BARTLETT, K.; HUBBARD, D.; RAY, A.; MCGILL, L.D.; GHANDEHARI, H. Poly(amido amine) dendrimers as absorption enhancers for oral delivery of camptothecin. International Journal of Pharmaceutics, v. 456, p. 175-85, 2013.

SATIJA, J.; SAIB, V. V. R.; MUKHERJI, S. Dendrimers in biosensors: Concept and applications. Journal of Materials Chemistry, v. 21, p. 1467-1486, 2011.

SCALACCI, N.; BROWN, A. K.; PAVAN, F. R.; RIBEIRO, C. M.; MANETTI, F.; BHAKTA, S.; MAITRA, A.; SMITH, D. L.; PETRICCI, E.; CASTAGNOLO, D. Synthesis and SAR evaluation of novel thioridazine derivatives active against drug-resistant tuberculosis. European Journal of Medicinal Chemistry, v. 127, p.147-158, 2017.

SCHLESINGER, P. H.; KROGSTAD, D.J.; HERWALDT, B. L. Antimalarial agents: mechanisms of action. Antimicrobial Agents and Chemotherapy, v. 32, p. 793-798, 1988.

SELIN, M.; PELTONEN, L.; HIRVONEN, J.; BIMBO, L. M. Dendrimers and their supramolecular nanostructures for biomedical applications. Journal of Drug Delivery Science and Technology, v. 34, p. 10-20, 2016.

SILVA, A. T. A.; CASTRO, L. F.; GUIDO, R. V.C.; CHUNG, M. C.; FERREIRA, E. I. Advances in prodrug design. Mini Reviews in Medicinal Chemistry, v. 5 , p. 893-914, 2005.

SILVERSTEIN, R.; WEBSTER, F. X.; KIEMLE, D. L. Identificação Espectrométrica de Compostos Orgânicos. 7 ed. LTC, 2006.

STOK, J. E.; GOLOSHCHAPOV, A.; SONG, C.; WHEELOCK, C. E.; DERBEL, M. B. H.; MORISSEAU, C.; HAMMOCK, B. D. Investigation of the role of a second conserved serine in carboxylesterases via site-directed mutagenesis. Archives of Biochemistry and Biophysics, v. 430, p. 247-255, 2004. 
TRAGER, W.; JENSEN, J. D. Human malaria parasites in continuous culture. Science, v. 193, p. 673-675, 1976.

TROTT, O.; OLSON, A. J. AutoDock Vina: improving the speed and accuracy of docking with a new scoring function, efficient optimization and multithreading. Journal of Computational Chemistry, v. 31, p. 455-461, 2010.

TOMALIA, D. A.; BAKER, H.; DEWALD, J.; HALL, M.; KALLOS, G.; MARTIN, S.; ROECK, J.; RYDER, J.; SMITH, P. A new class of polymers: starburst dendritic macromolecules. Polymer Journal, v. 17, p. 117-132, 1985.

TWIBANIRE, J. A. K.; GRINDLEY, T. B. Polyester dendrimers: smart carriers for drug delivery. Polymers, v. 6, p. 179-213, 2014.

VERDONK, M. L.; COLE, J. C.; HARTSHORN, M. J.; MURRAY, C. W.; TAYLOR, R. D. Improved protein-ligand docking using GOLD. Proteins, v. 52, p. 609-623, 2003.

WHITE, N. J.; PUKRITTAYAKAMEE, S.; HIEN T. T.; FAIZ, M. A.; MOKUOLU, O. A.; DONDORP, A. M. Malaria. The Lancet Jornal, v. 383, n. 9918, p. 723-735, 2014.

WORLD HEALTH ORGANIZATION. World Malaria Report 2018. Geneva, Switzerland, $2018 . \quad$ Disponível em: < http://apps.who.int/iris/bitstream/handle/10665/275867/9789241565653eng.pdf? ua=1> Acesso em: 16 jan 2019.

WHO (World Health Organization). HIVIAIDS, TB, Malaria and Neglected Tropical Diseases (HTM). Disponível em: <http://www.who.int/about/structure/organigram/htm/en/> Acesso em: 31 mai 2017.

YAN, Y.; ZHANG, D.; HUANG, S. Efficient conformational ensemble generation of protein-bound peptides. Journal of cheminformatics, v. 9, n. 1, p. 59, 2017. YEOH, K. K.; CHAN, M. C.; THALHAMMER, A.; DEMETRIADES, M.; CHOWDHURY, R.; TIAN, Y.; STOLZE, I.; MCNEIL, L. A.; LEE, M. K.; WOON, E. 
C. Y.; MACKEEN, M. M.; KAWAMURA, A.; RATCLIFFE, P. J.; MECINOVIC, J.; SCHOFIELD, C. J. Dual-Action Inhibitors of HIF Prolyl Hydroxylases That Induce Binding of a Second Iron lon. Organic and Biomolecular Chemistry, v.11, n. 5, p. 732-745, 2013.

YOUNG, J. Y; WESTBROOK, J. D.; FENG, Z.; PEISACH, E.; PERSIKOVA, I.; SALA, R.; SEN, S.; BERRISFORD, J. M.; SWAMINATHAN, G. J.; OLDFIELD, T. J.; GUTMANAS, A.; IGARASHI, R.; ARMSTRONG, D. R.; BASKARAN, K.; CHEN, L.; CHEN, M.; CLARK, A. R.; CONSTANZO, L. D.; DIMITROPOULOS, D.; GAO, G.; GHOSH, S.; GORE, S.; GURANOVIC, V.; HENDRICKX, P. M. S.; HUDSON, B. P.; IKEGAWA, Y.; KENGAKU, Y.; LAWSON, C. L.; LIANG, Y.; MAK, L.; MUKHOPADHYAY, A.; NARAYANAN, B.; NISHIYAMA, K.; PATWARDHAN, A.; SAHNI, G.; SANZ-GARCIA, E.; SATO, J.; SEKHARAN, M.

R.; SHAO, C.; SMART, O. S.; TAN, L.; VAN GINKEL, G.; YANG, H.; ZHURAVLEVA, M. A.; MARKLEY, J. L.; NAKAMURA, H.; KURISU, G.; KLEYWEGT, G. J.; VELANKAR, S.; BERMAN, H. M.; BURLEY, S. K. Worldwide Protein Data Bank biocuration supporting open access to high-quality 3D structural biology data. Database, v. 2018, p. 1-17, 2018.

ZAWILSKA, J. B.; WOJCIESZAK, J.; OLEJNICZAK, A. B. Prodrugs: a challenge for the drug development. Pharmacological Reports, v. 65, p.1-14, 2013. 


\section{ANEXOS}

\section{Anexo I}

RMN de ${ }^{1} \mathrm{H}$ e ${ }^{13} \mathrm{C}$ dos materiais de partida
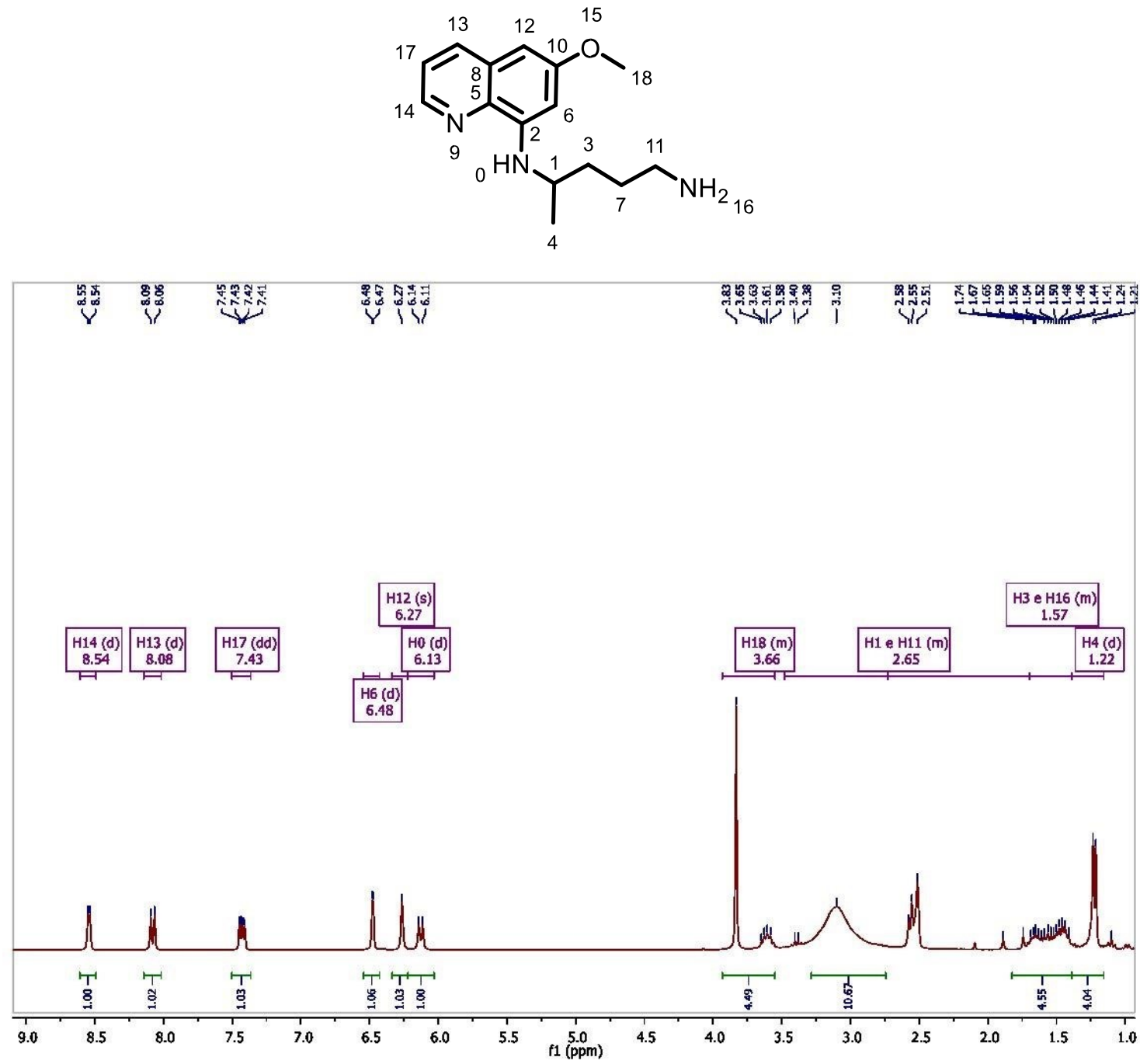
Espectro I: RMN de ${ }^{1} \mathrm{H}$ da primaquina.

${ }^{1} \mathrm{H}-\mathrm{RMN}$ (DMSO), $300 \mathrm{MHz}, \mathrm{Q}=\mathrm{ppm}$

$\mathrm{H} 14: 8.54(\mathrm{~d}, J=4.0 \mathrm{~Hz}, 1 \mathrm{H}), \mathrm{H} 13: 8.08(\mathrm{~d}, J=8.2 \mathrm{~Hz}, 1 \mathrm{H}), \mathrm{H} 17: 7.43(\mathrm{dd}, J=8.2,4.1 \mathrm{~Hz}, 1 \mathrm{H}), \mathrm{H} 6:$ $6.48(\mathrm{~d}, J=1.6 \mathrm{~Hz}, 1 \mathrm{H}), \mathrm{H} 12: 6.27(\mathrm{~s}, 1 \mathrm{H}), \mathrm{H} 06.13(\mathrm{~d}, J=8.5 \mathrm{~Hz}, 1 \mathrm{H}), \mathrm{H} 18: 3.93-3.55(\mathrm{~m}$,

$3 \mathrm{H}), \mathrm{H} 1$ e H11: $3.48-1.70$ (m, 3H), H3 e H16: $2.73-1.39$ (m, 4H), H4: 1.22 (d, J = 6.2 Hz, 3H).
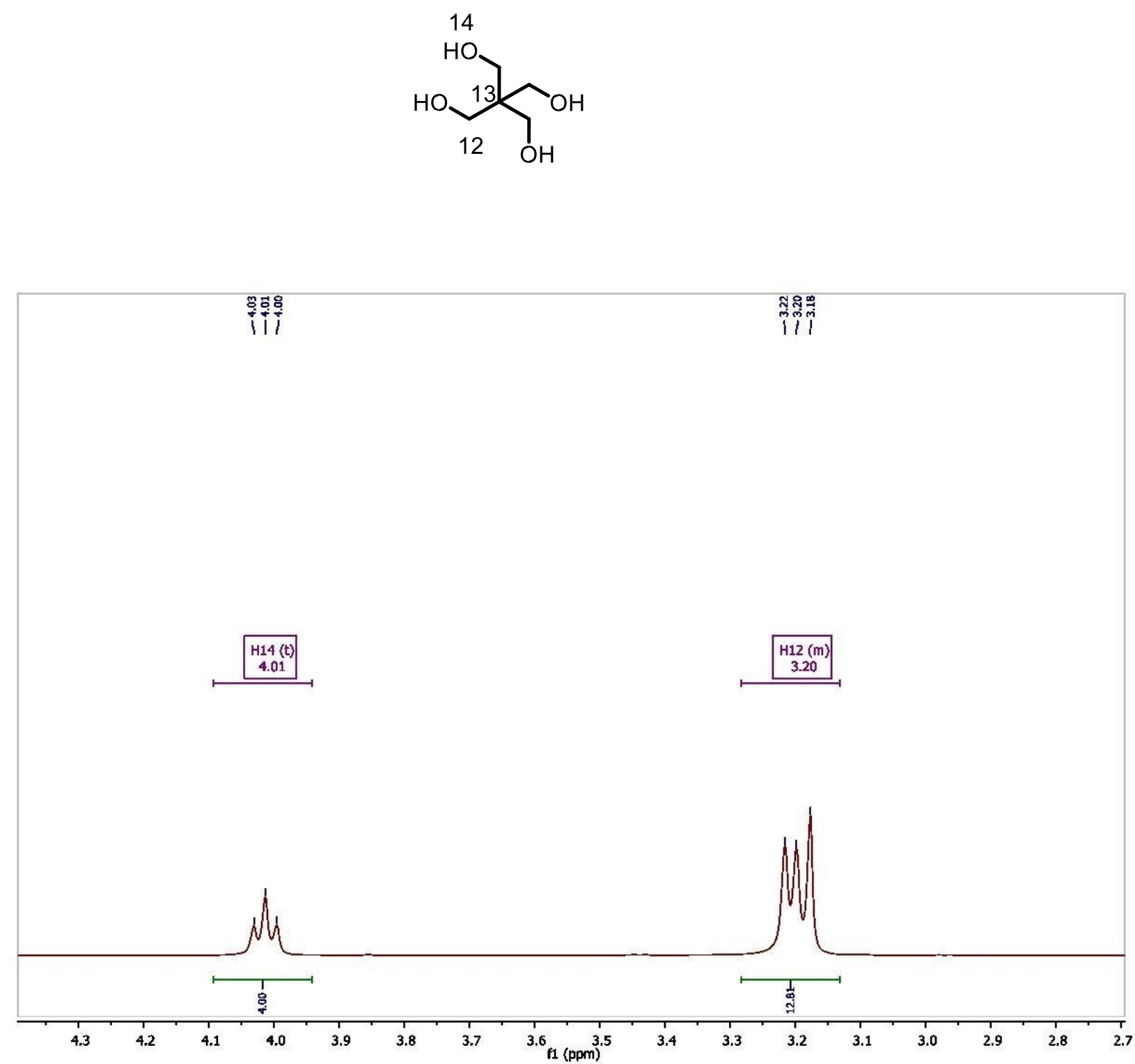
Espectro II: RMN de ${ }^{1} \mathrm{H}$ do pentaeritritol.

${ }^{1} \mathrm{H}-\mathrm{RMN}$ (DMSO), $300 \mathrm{MHz}, \mathrm{Q}=\mathrm{ppm}$

$\mathrm{H} 14$ :

$4.01(\mathrm{t}, J=5.3 \mathrm{~Hz}, 4 \mathrm{H}), \mathrm{H} 12 ; 3.28-3.13(\mathrm{~m}, 12 \mathrm{H})$.
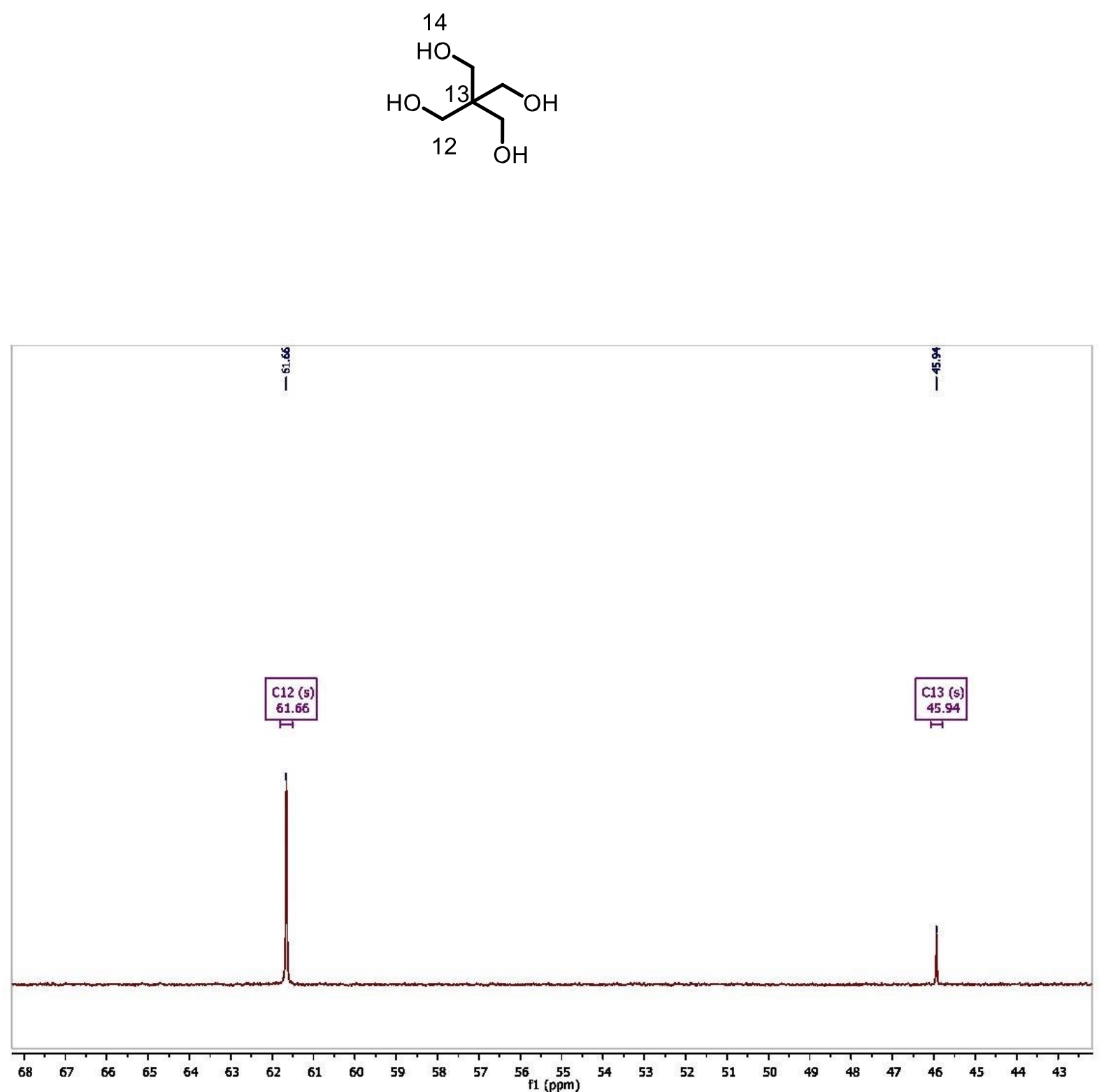
Espectro III: RMN de ${ }^{13} \mathrm{C}$ do pentaeritritol.

${ }^{1} \mathrm{H}-\mathrm{RMN}$ (DMSO), $75 \mathrm{MHz}, \mathrm{\square}=\mathrm{ppm}$

C12: 61.66, C13: 45.94. 
4.41 (s,

$8 \mathrm{H})$,

H12:

3.87 (s,

$8 \mathrm{H})$,

H11:

$3.33-$

$2.92(\mathrm{~m}$, $16 \mathrm{H}$ ),

H10:

0.82 (s, $12 \mathrm{H}$ ).

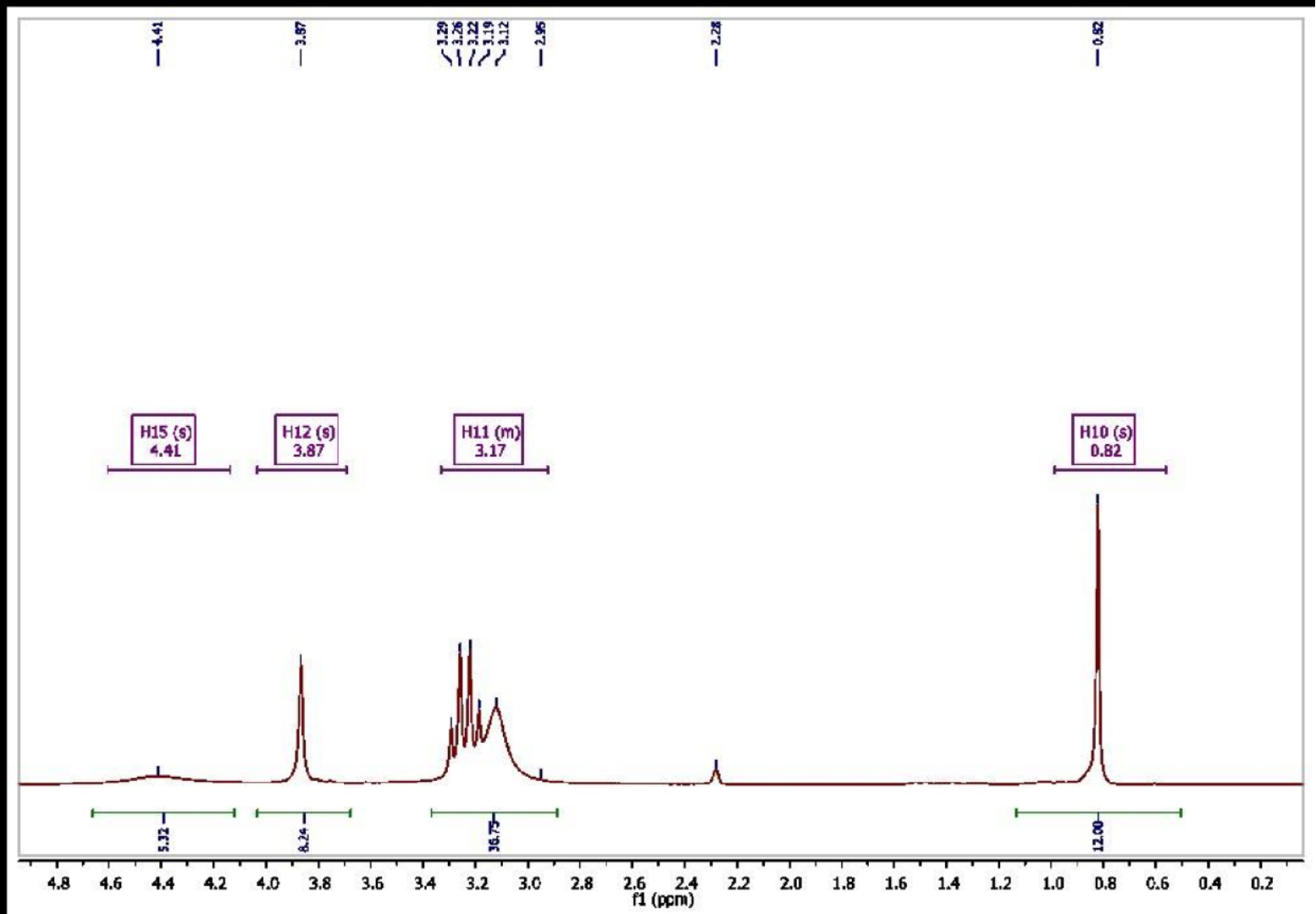

ㅁ= 

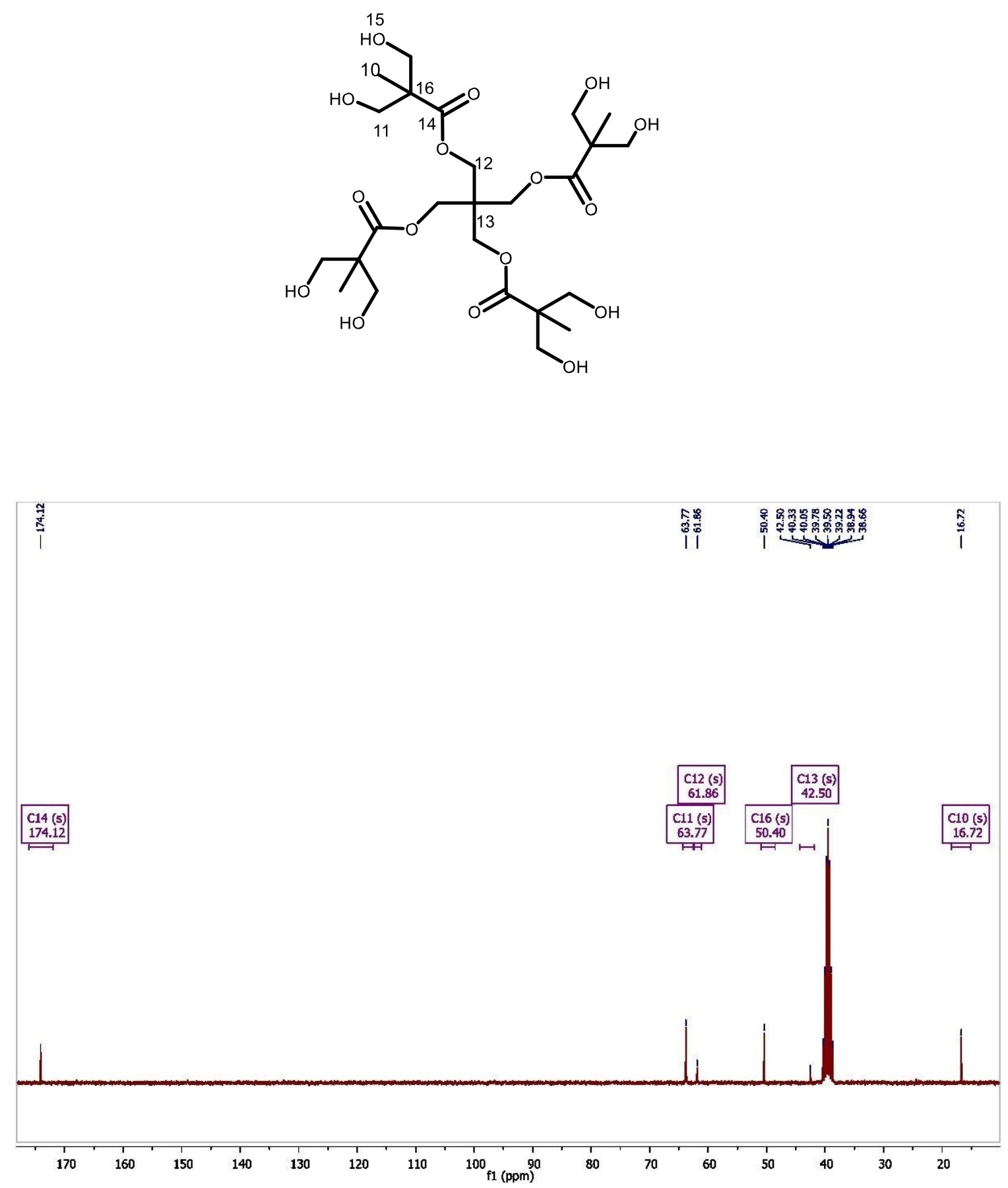

Espectro V: RMN de ${ }^{13} \mathrm{C}$ do $\mathrm{G} 1$.

${ }^{1} \mathrm{H}-\mathrm{RMN}$ (DMSO), $75 \mathrm{MHz}, \mathrm{\square}=\mathrm{ppm}$

C14: 174.12, C11: 63.77, C12: 61.86, C16: 50.40, C13: 42.50, C10: 16.72. 


\section{EXPRESSÃO, PURIFICAÇÃO E COCRISTALIZAÇÃO DE ANÁLOGOS COM POSSÍVEL INIBIÇÃO DE MtPtpA E MtPtpB PARA O TRATAMENTO DE TUBERCULOSE}

\section{Introdução}

A tuberculose é uma doença infecciosa causada pela bactéria Mycobacterium tuberculosis, uma bactéria flexível e que tem como principal vantagem frente ao sistema imune do hospedeiro a capacidade de se adaptar a ambientes desfavoráveis criados pelas células de defesa humana. Esse patógeno é transmitido por gotículas de saliva humana, o que torna lugares com grande concentração de pessoas locais de alto risco de transmissão (KNECHEL, 2009).

Segundo dados dos relatórios anuais da Organização Mundial da Saúde (OMS) a prevalência de tuberculose em 2017 foi de 10,4 milhões de pessoas no mundo, com uma incidência média de 140/100 mil habitantes. Apesar de ter casos relatados na Europa e América do Norte, a maioria foi reportada no sudeste asiático (45\%) e África $(25 \%)$, o a que aproxima, epidemiologicamente, das doenças negligenciadas. A Figura 1 ilustra a incidência global de tuberculose no ano de 2017. No mesmo ano, a OMS registrou mortalidade de 1,3 milhões de pessoas em pacientes HIV-negativo. Desse número de mortes, $82 \%$ aconteceram nas mesmas regiões onde a incidência é maior: o sudeste asiático e a África (WHO, 2018). 


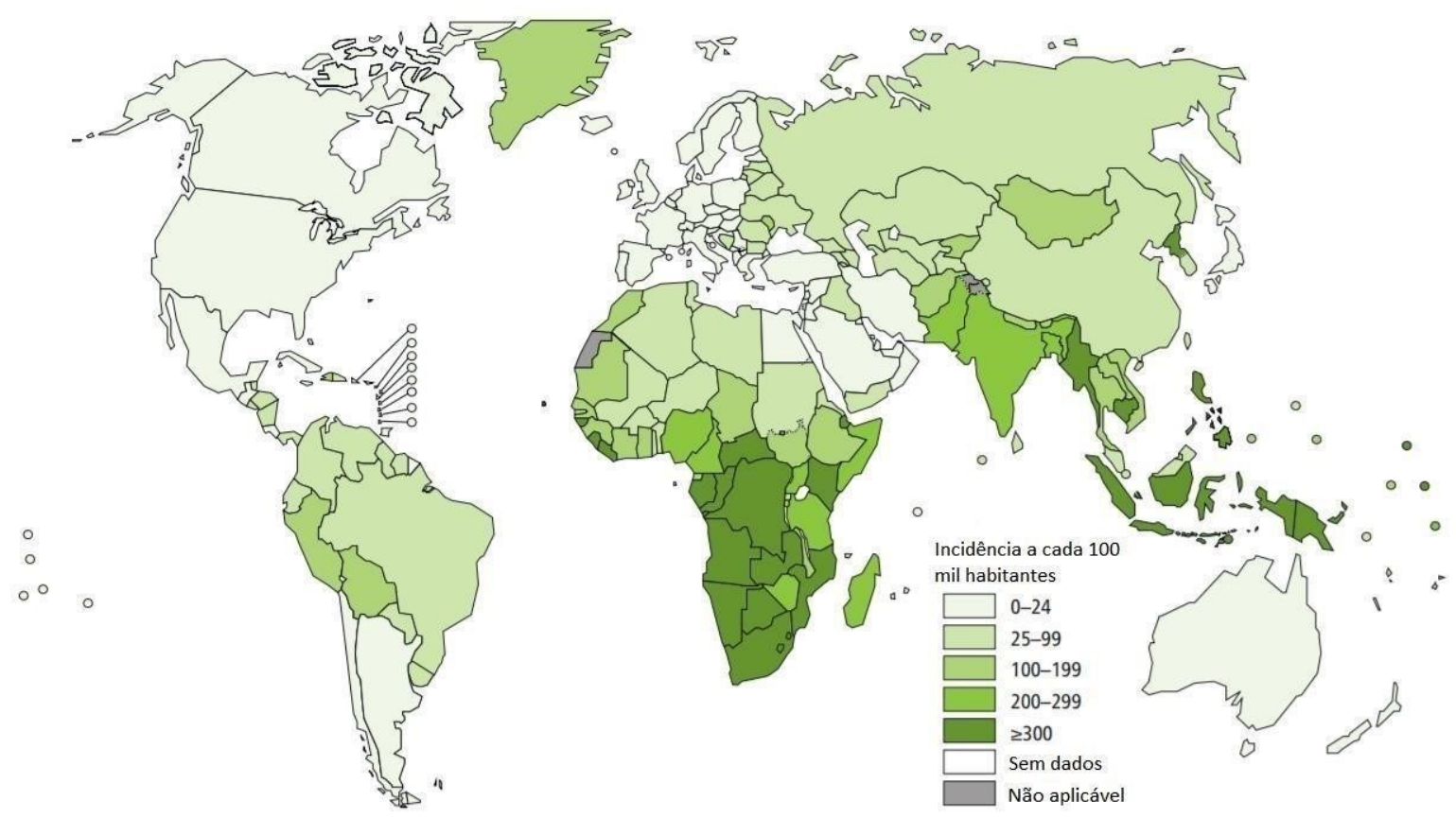

Figura 1. Incidência global de tuberculose para cada 100 mil habitantes em 2017.

Ao entrar nos alvéolos do hospedeiro, a micobactéria é rapidamente capturada por macrófagos que, posteriormente, induzem a migração de células T para o local da infecção. Mesmo dentro dos macrófagos, essas bactérias conseguem se multiplicar, aumentando a quantidade de macrófagos e células T, criando, assim, um granuloma entorno do local infeccionado. Esse granuloma gera um ambiente na tentativa de limitar o crescimento bacteriano, causando a lise dos macrófagos e necrose tecidual. Mesmo com um baixo $\mathrm{pH}$, hipóxia e com uma quantidade limitada de nutrientes, a micobactéria consegue mudar o seu fenótipo e sobreviver, ainda que em período de latência (KNECHEL, 2009).

Os tratamentos de primeira escolha consistem em combinações de quatro fármacos: rifampicina, pirazinamida, etambutol e isoniazida. O tratamento é demorado, entorno de 6 meses, resultando em baixa de adesão do paciente. Outro problema grave que tem colocado, novamente, a tuberculose como um dos problemas de saúde mais monitorados no mundo é a resistência aos antibióticos de primeira escolha. Já há relatos de multirresistência contra os quatro fármacos ao mesmo tempo, o que expõe a falta de opção de medicamentos disponíveis, bem como a a falta de investimento no desenvolvimento de novos compostos (RABAHI et al, 2017).

O desenvolvimento de novos fármacos é um processo extremamente complexo e caro. A busca de um líder, ou seja, uma molécula com potencialidade para se tornar um fármaco, é demorada. Primeiramente, é necessário determinar o tipo de estratégia 
de planejamento a ser utilizada, a baseada no alvo, chamada de Structure Based Drug Design (SBDD), ou no ligante Ligand Based Drug Design (LBDD) (GUIDO; ANDRICOPULO; OLIVA, 2010). Aproximadamente $70 \%$ de compostos líderes falham nas primeiras etapas de ensaios pré-clínicos, devido, principalmente, a toxicidade e problemas farmacocinéticos (FAKUNLE; LORING, 2012). O SBDD, por sua vez, é uma importante ferramenta baseada na estrutura química cristalografada de um alvo, enzima ou receptor para entender, principalmente, quais são e quais as características dos aminoácidos presentes nos bolsões de ligação. A partir dessas informações é possível fazer estudos computacionais como o docking, técnica que simula o encaixe de uma molécula no sítio de ligação do alvo, podendo inferir como seria essa interação, auxiliando, assim, no desenvolvimento de novos ligantes (KALYAANAMOORTHY, CHEN, 2011).

Dentre os novos alvos estudados para a tuberculose, destacam-se duas tirosinas fosfatases de micobactéria: a mtPtpA e a mtPtpB. A primeira impede a ligação entre o fagossomo e o lisossomo, bem como na modulação da indução de apoptose por células de defesa. Já a segunda está relacionada com a sobrevivência dentro dos macrófagos. Nos últimos anos, foram relatadas as primeiras moléculas com potencial inibição dessas enzimas, entre elas estão os derivados de ácido salicílico, as chalconas e os derivados de isoxazois (CHATTERJEE et al, 2015).

Tendo em vista ao exposto, fica clara a necessidade de alternativas de tratamento para a tuberculose. Com isso, o desenvolvimento de inibidores de mtPtpA e mtPtpB são ótimas alternativas para se chegar a novas moléculas bioativas que tenham potencial de se tornarem medicamentos.

\section{Objetivos}

No laboratório do Professor Matthew Groves, da University of Groningen, pretende-se, primeiramente, expressar as enzimas mtPtpA e mtPtpB e, posteriormente, fazer a cocristalização dessas enzimas com as moléculas sintetizadas pelo Professor Alexander Domling, também da University of Groningen. Estes compostos apresentaram, em estudos prévios, resultados promissores em simulações de docking molecular. Pretende-se, ainda, analisar os cristais para o planejamento de análogos com estruturas químicas otimizadas. 


\section{Metodologia}

\subsection{Expressão das enzimas mtPtpA e mtPtpB (WAUGH et al, 2005)}

A expressão de mtPtpA foi feita em células de Escherichia coli Rosetta 2 (DE3), próprias para a produção de proteínas, utilizando o vetor pETM carregando o gene RV2234 que consiste em um promotor T7-lac, 6-His tag e o sítio de clivagem do TEV

(vírus do mosaico do tabaco). Foi adicionado ao meio de cultura IPTG (isopropil $\beta D 1$ tiogalactopiranosídeo) que serve de indutor da expressão de genes, os quais não são característicos da bactéria utilizada. As bactérias foram mantidas em meio de cultura suplementadas por $0,5 \%$ de glicose, por 16 a 18 horas. A extração da proteína foi feita, primeiramente, centrifugando as bactérias a $5000 \mathrm{rpm}$ a $4{ }^{\circ} \mathrm{C}$ por 30 minutos. O precipitado é ressuspendido usando o tampão de lise $(50 \mathrm{mM}$ de Tris- $\mathrm{HCl}, 300 \mathrm{mM}$ de $\mathrm{NaCl}, \mathrm{pH}$ 8.0) e na presença de lisozima e um inibidor de protease. Essa mistura foi suspendida utilizando sonicamento em ultrassom. O lizado de células foi, então, centrifugado a $18000 \mathrm{rpm}$ por 45 minutos e em uma temperatura de $4{ }^{\circ} \mathrm{C}$. O sobrenadante foi separado para a purificação. Essa purificação foi feita usando uma coluna de purificação com um tampão A (50 mM de Tris- $\mathrm{HCl}, 300$ mM de $\mathrm{NaCl}, \mathrm{pH}$ 8,0) e um tampão B (50 mM de Tris-HCl, 300 de mM NaCl, 500 mM de imidazol) e a corrida foi feita usando um gradiente de imidazol. Após essa primeira etapa, os eluentes com pico único no cromatograma foram injetados em uma coluna cromatográfica de troca aniônica usando um tampão $\mathrm{A}(50 \mathrm{mM}$ de Tris- $\mathrm{HCl}$, pH 8,5) e um tampão $\mathrm{B}$ (50 mM de Tris- $\mathrm{HCl}, 1 \mathrm{M}$ de $\mathrm{NaCl}, \mathrm{pH}$ 8,0). Após a coluna de troca aniônica os produtos eluidos foram injetados em uma coluna por exclusão de tamanho usando uma coluna HiLoad 16/60 Superdex 75 pré equilibrada com um tampão SEC (10 mM de Tris- $\mathrm{HCl}, 100$ mM de $\mathrm{NaCl}, \mathrm{pH}$ 8,0). A expressão e purificação do MtPtpB foi feita do mesmo modo, porém, utilizando o plasmídeo contendo o gene RV0163.

\subsection{Cocristalização dos ligantes com as enzimas mtPtpA e mtPtpB e análise computacional (GRUDNER et al, 2007)}

As enzimas mtPtpA e mtPtpB foram, primeiramente, adicionadas às soluções de 5 $\mathrm{mM}$ dos análogos selecionados. Após o tempo necessário para a ligação, as enzimas são separadas e diluídas a $16 \mathrm{mg} / \mathrm{mL}$ no caso da MtPtpB e 6,6 mg/mL para a MtPtpA. Em cada uma foram utilizados kits de cristalização como MIDAS, MORPHEUS, PACT, JCSG+ e HT-INDEX e a purificação foi feita utilizando $10 \mathrm{mM}$ de Tris-base com $\mathrm{pH}$ 7,5 e $\mathrm{NaCl}$.

As análises dos cocristais foi feita através do programa Scorpion onde foram estudadas as ligações de cada um dos análogos com as enzimas para elucidar o mecanismo de inibição de cada um e planejar melhorias estruturais das moléculas para o planejamento de novos ligantes. 


\section{Resultados e discussão}

A biblioteca FS contendo inibidores covalentes à base de acrilamida foi a primeira testada contra PtPA. Os resultados mostraram alguns acertos como FS185, FS137 e FSGOI, este último já mostrou atividade contra o PtPB. A Figura 2 mostra as curvas de cada composto e a Figura 3 mostra a porcentagem de ativação do PNPP dos melhores compostos. Alguns compostos como FS217 e FS155 parecem ativar a enzima, provavelmente isso está acontecendo porque eles alteram $\mathrm{opH}$, aumentando a atividade de PtPA e não por ativação direta.

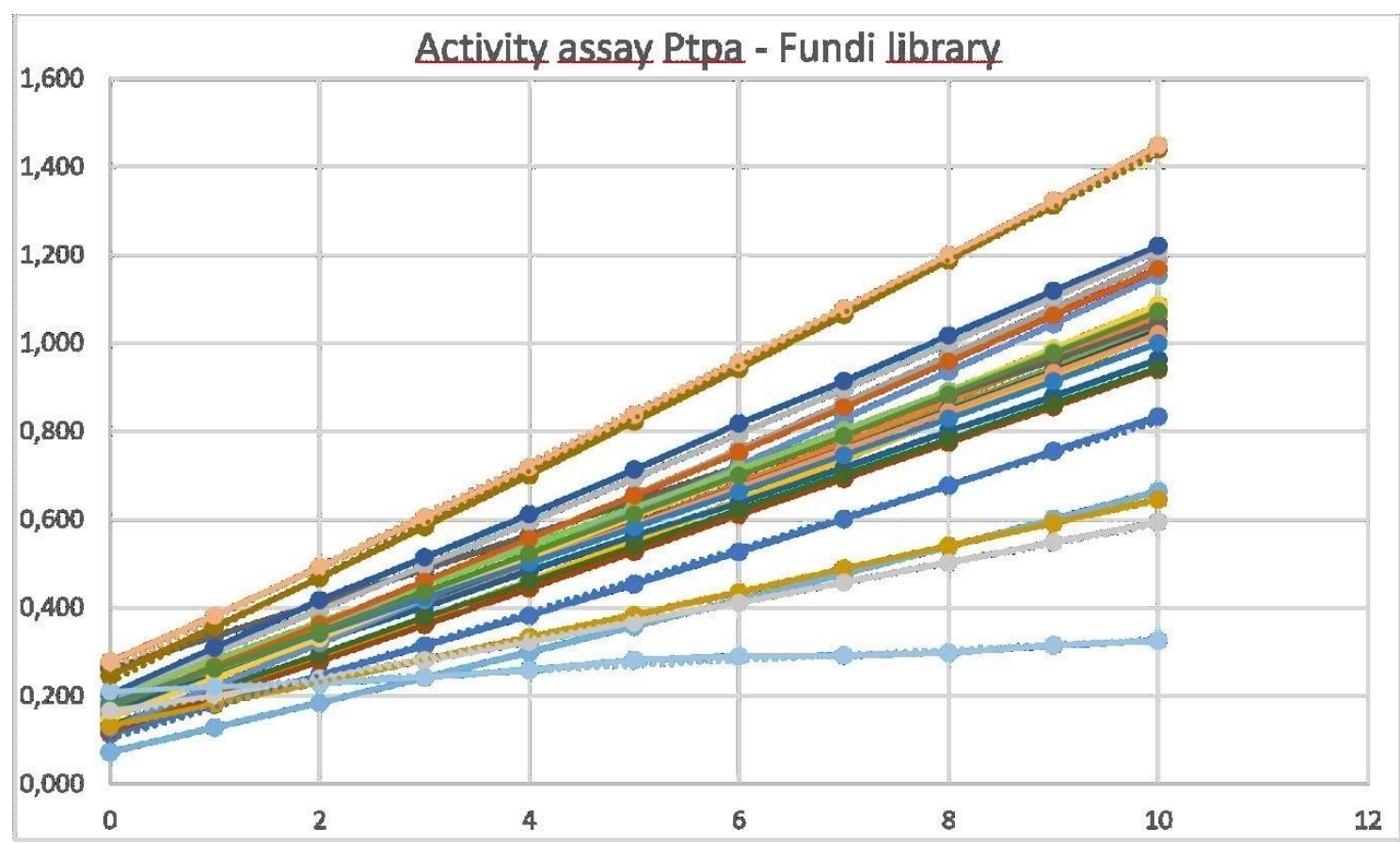

Figura 2: Curva de atividade para cada inibidor testado.

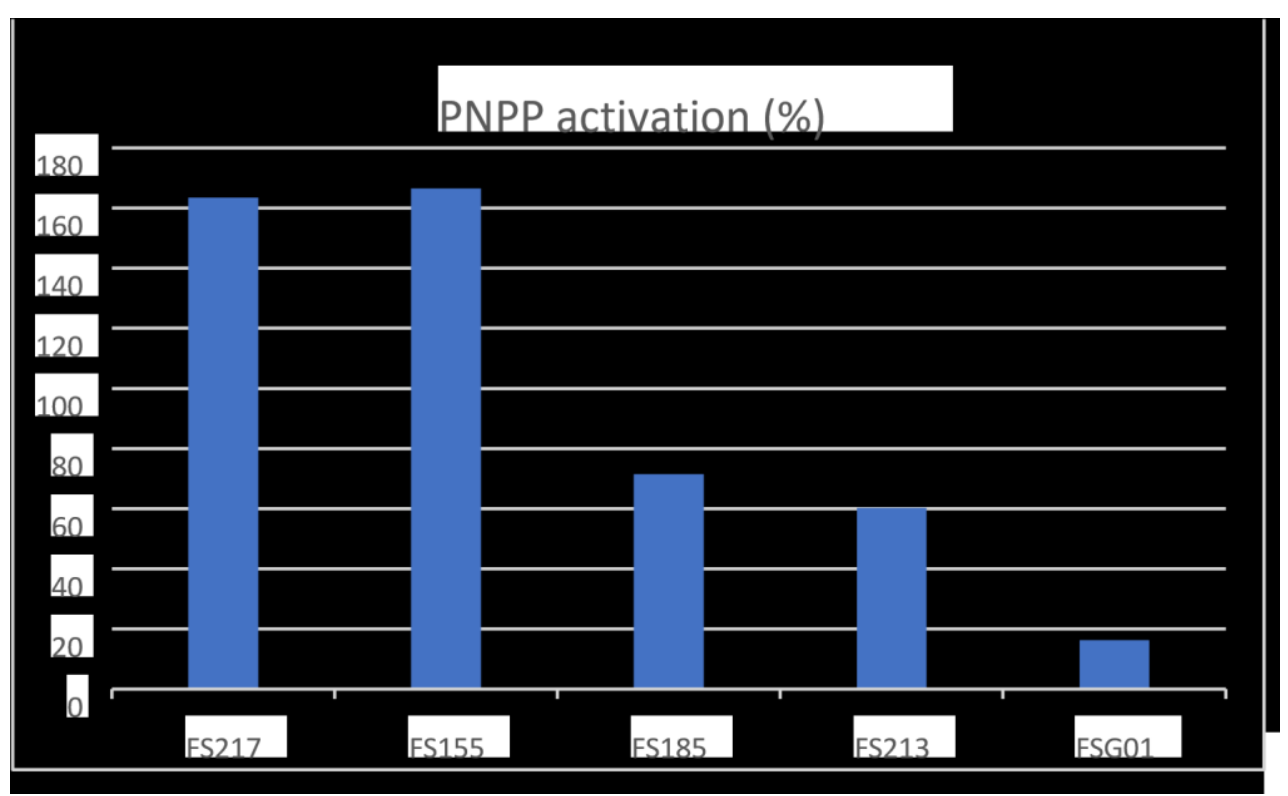


Figura 3: Porcentagem de ativação de PNPP pelos principais inibidores encontrados

Também foram rastreados os compostos à base de ácido borônico que foram planejados para serem inibidores competitivos, uma vez que há uma indicação de que essa fração possa imitar o fosfato e, portanto, se ligar à enzima. A triagem mostrou três ocorrências: TAT106, DMNT10 e MIS55. As Figura 4 e Figura 5 mostram as curvas para cada composto e a porcentagem de ativação desses compostos.

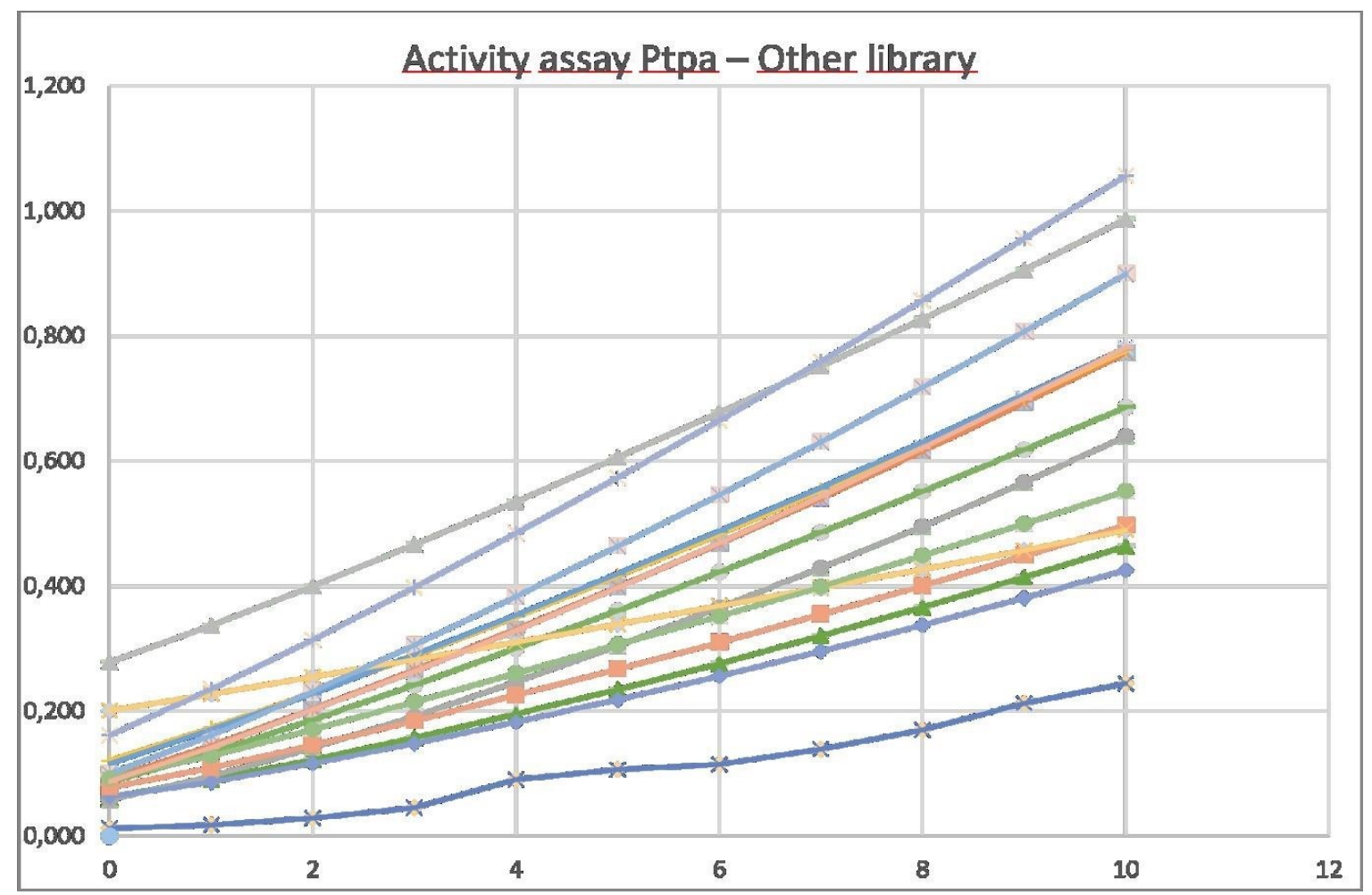

Figura 4: Curva de atividade para cada inibidor competitivo testado. 


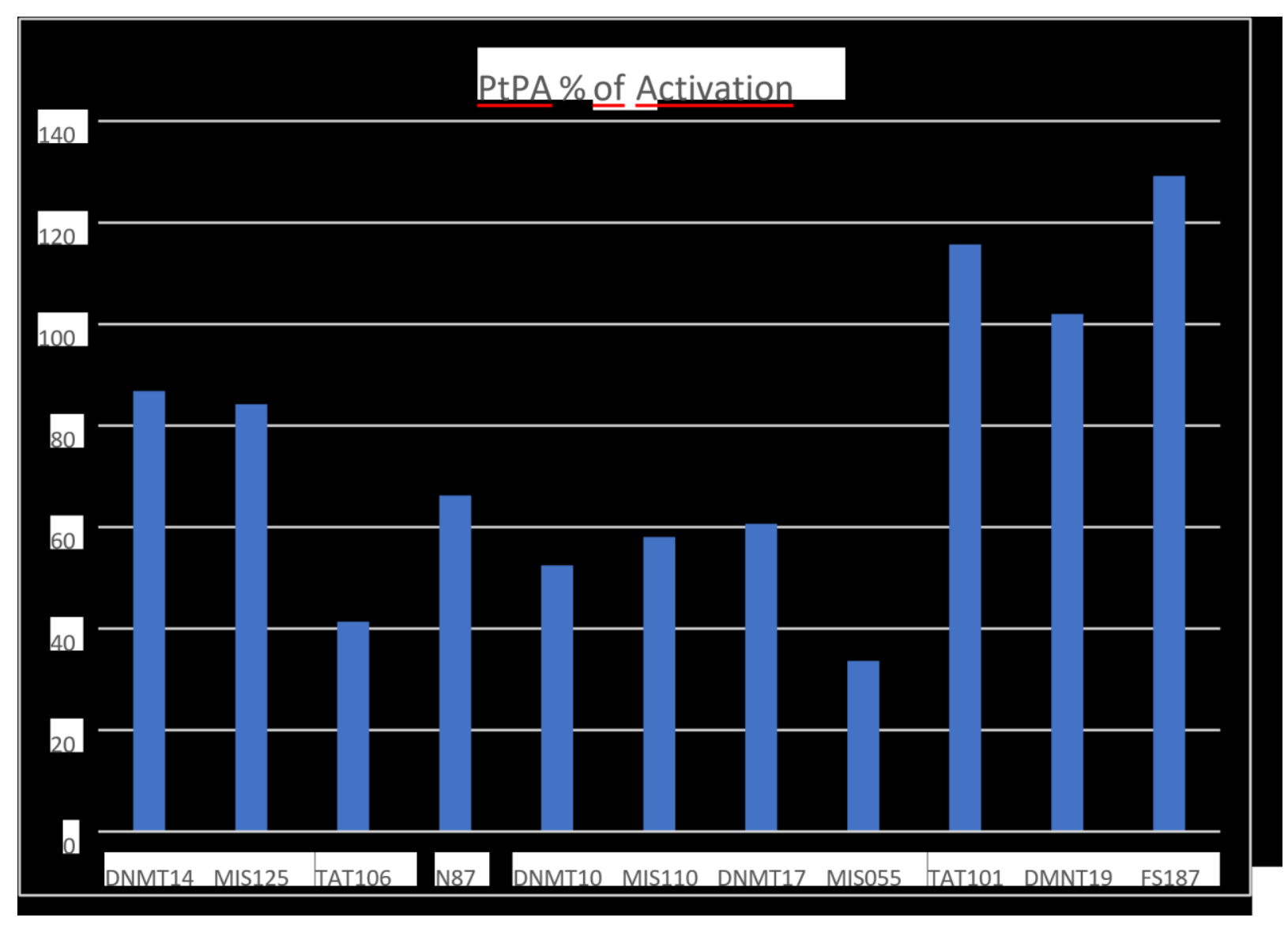

Figura 5: Porcentagem de ativação de PNPP para os melhores análogos encontrados. Após encontrar os hits em cada biblioteca, eles foram testados novamente em triplicado para confirmar sua atividade. Após o teste, o composto 4 foi escolhido para medir o IC50: TAT106, FS213, DMNT10 e FS137. As Figura 6 e Figura 7 ilustram as curvas para cada composto testado em triplicado e a porcentagem de ativação de PNPP para as melhores moléculas. 


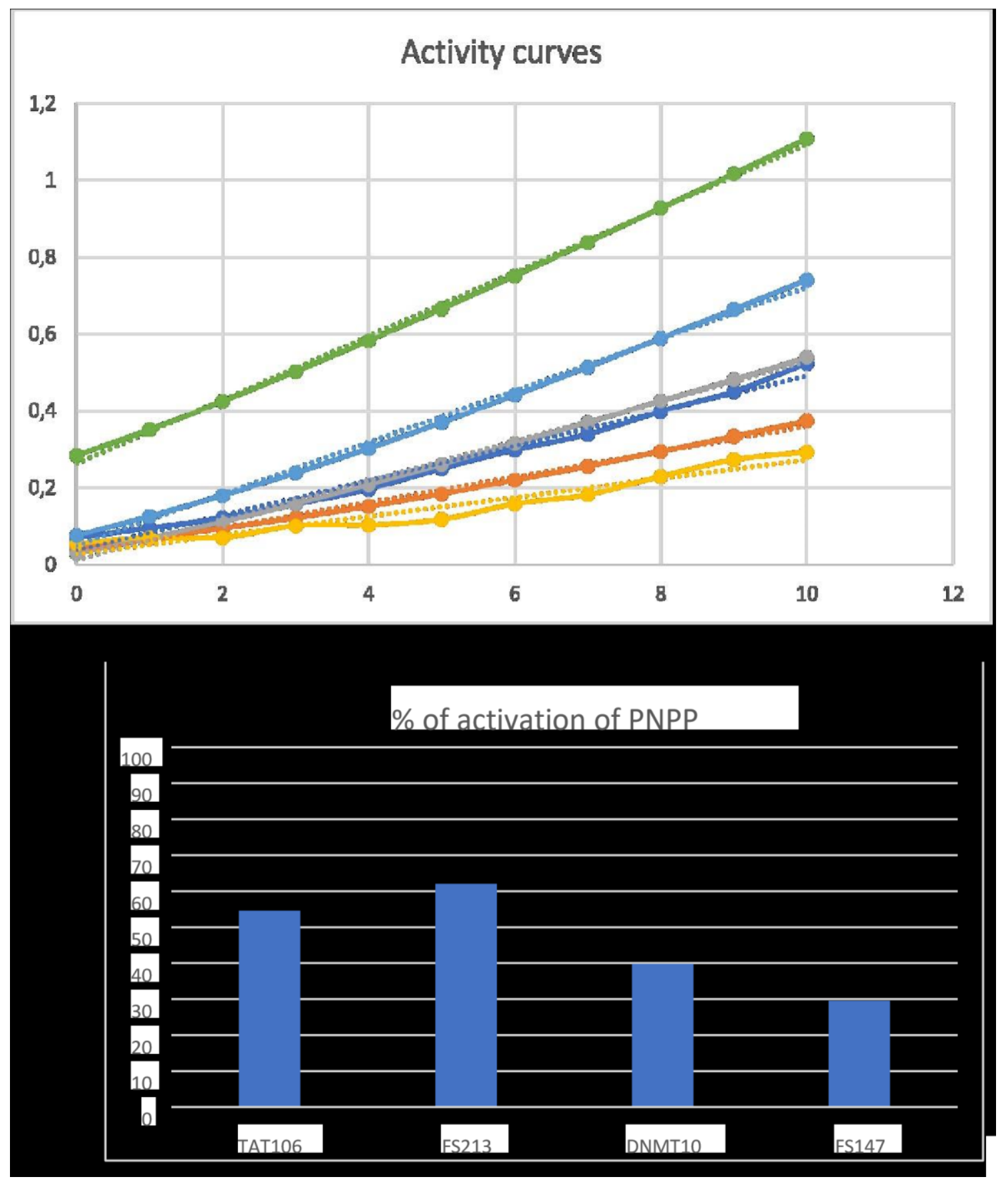

Figura 7: Porcentagem de ativação dos melhores análogos testados em triplicata. A medição de IC50 em PtPA e PtPB não mostrou bons resultados, como pode ser visto na Figura 8. A dose inicial de $1 \mathrm{mM}$ parece inibir a proteína, mas em 0,5 $\mathrm{mM}$ já é possível notar alguma atividade e, portanto, o valor calculado de IC50 é alto $(0,415 \mathrm{mM})$. Estes dados e a baixa solubilidade na água de todos esses análogos podem indicar que a proteína está sendo morta por outros 


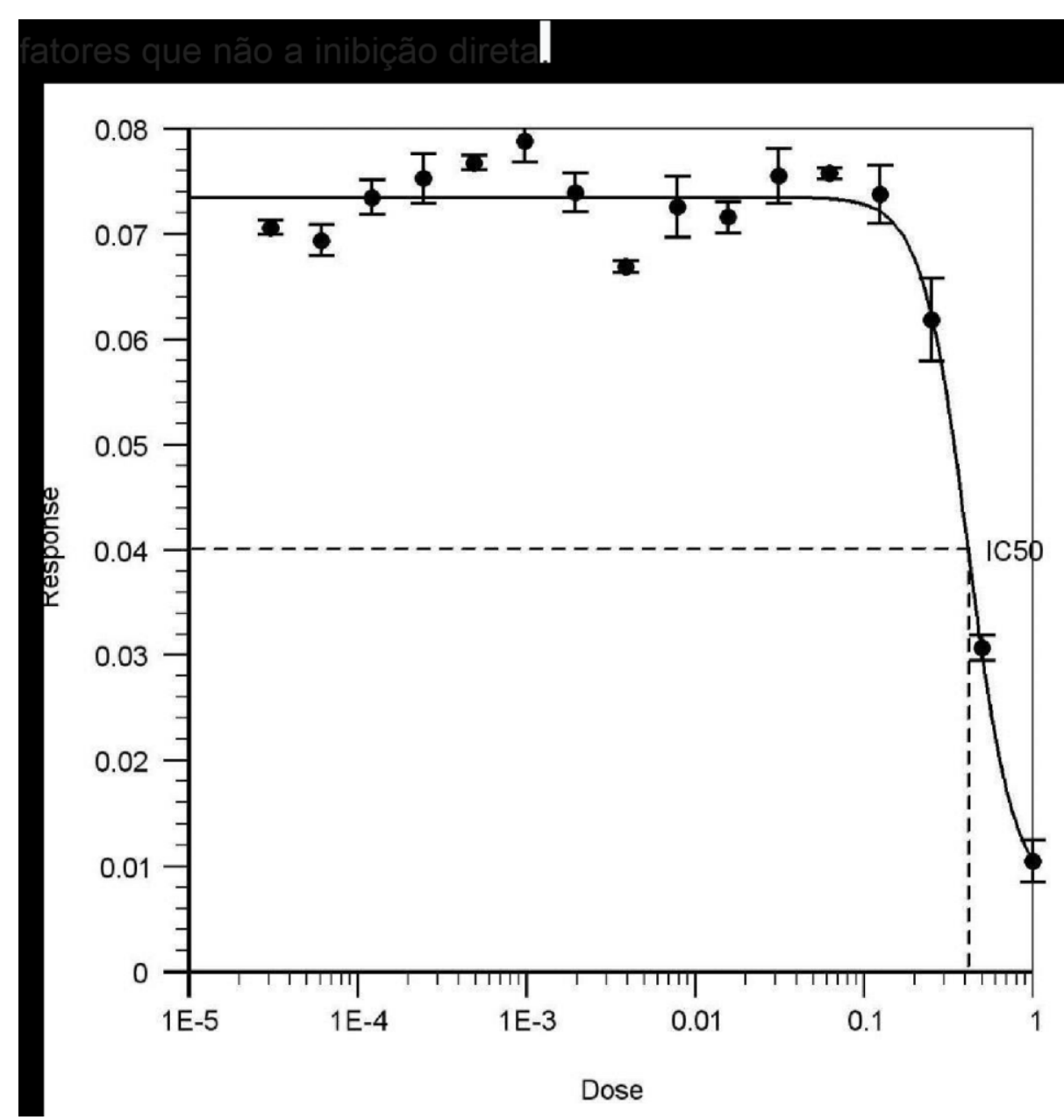

Figura 8: Curva de IC50 do análogo TAT106.

Os outros compostos mostraram o mesmo padrão de curva, por isso era necessário verificar se as porções básicas que foram projetadas para se ligarem às proteínas podem de fato se ligar aos alvos. Assim, foi testada a afinidade de ligação da acrilamida, o componente básico dos inibidores covalentes (FS BB), ácido bórico e citrato (esses dois últimos funcionariam como inibidores competitivos). Todos os compostos são mostrados na Figura 9. 
<smiles>C=CC(N)=O</smiles>

Acrylamide<smiles>O=C([O-])CC(O)(CC(=O)[O-])C(=O)[O-]</smiles>

Citrate<smiles>C=CC(=O)NCCN</smiles>

FS BB<smiles>OB(O)O</smiles>

\section{Boric acid}

Figura 9: Estruturas base testadas contra PtPA e PtPB.

Os resultados em PtPB não mostraram atividade de nenhuma das moléculas como pode ser observado na Figura 10. No entanto, para o PtPA, tanto a acrilamida quanto o FS BB apresentaram uma boa atividade, principalmente o FS BB (curva cinza). A Figura 11 mostra as curvas de atividade para cada composto contra PtPA.

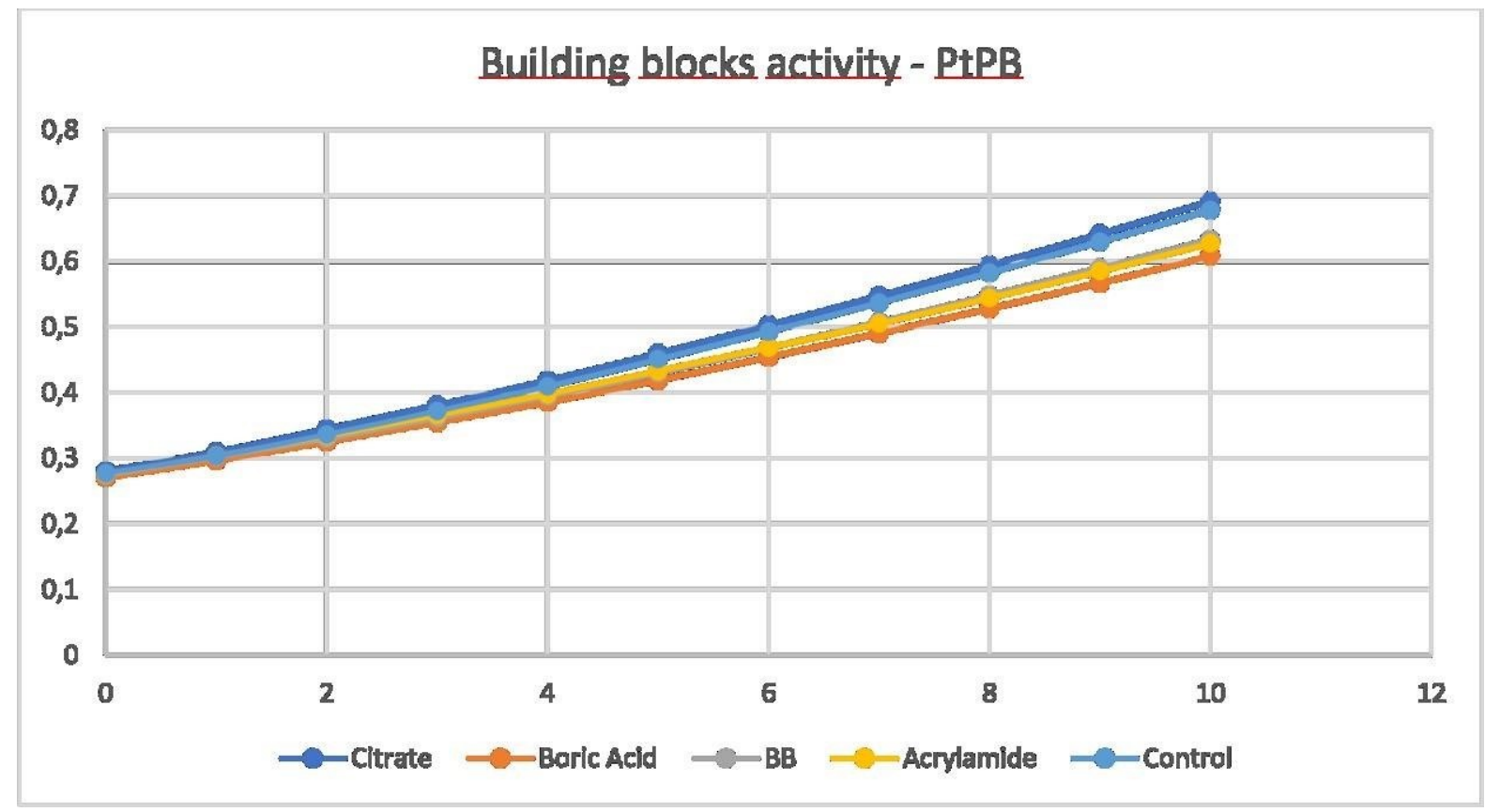

Figura 10: Atividade dos compostos precursores contra PtPB 


\section{Building blocks activity - PtPA}

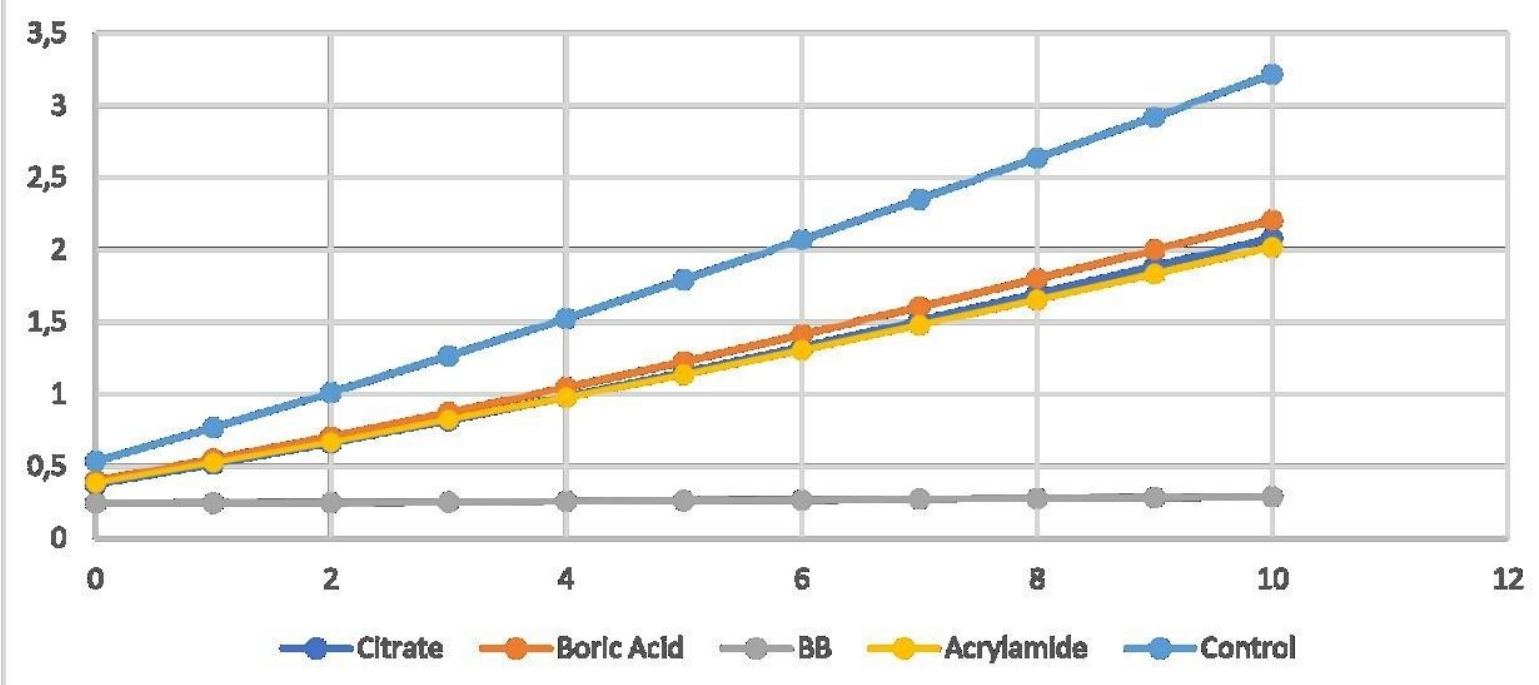

Figura 11: Atividade dos compostos precursores contra PtPA.

Este resultado indica que a acrilamida pode se ligar à cisteína do local ativo de PtPA. Para confirmar o teste de ligação, foi feita uma medida de IC50. A Figura 12 mostra que a curva, diferente dos hits das bibliotecas, tem um perfil de inibição direta. Ademais, o valor IC50 $(0,163$ $\mathrm{mM}$ ) é um bom ponto de partida para um building block. 


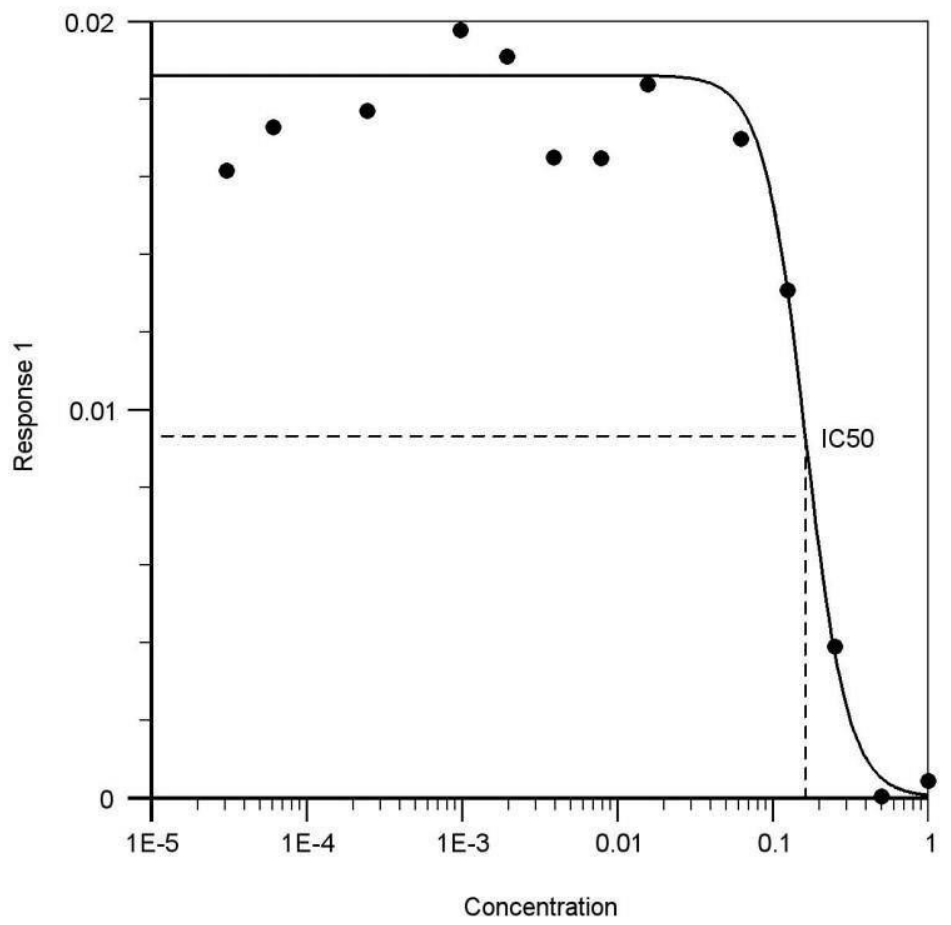

Figura 12: Curva de IC50 do FSBB.

Após estabelecer que a acrilamida poderia se ligar à proteína, uma nova série de análogos foi planejada com base na estrutura da tirosina. Utilizando o anel aromático ligado diretamente à acrilamida, esperava-se aumentar a afinidade com as fosfatases. Os dois primeiros análogos FS440 e FS441 foram sintetizados seguindo essa estratégia. A Figura 13 ilustra a lógica por trás da nova série de análogos.

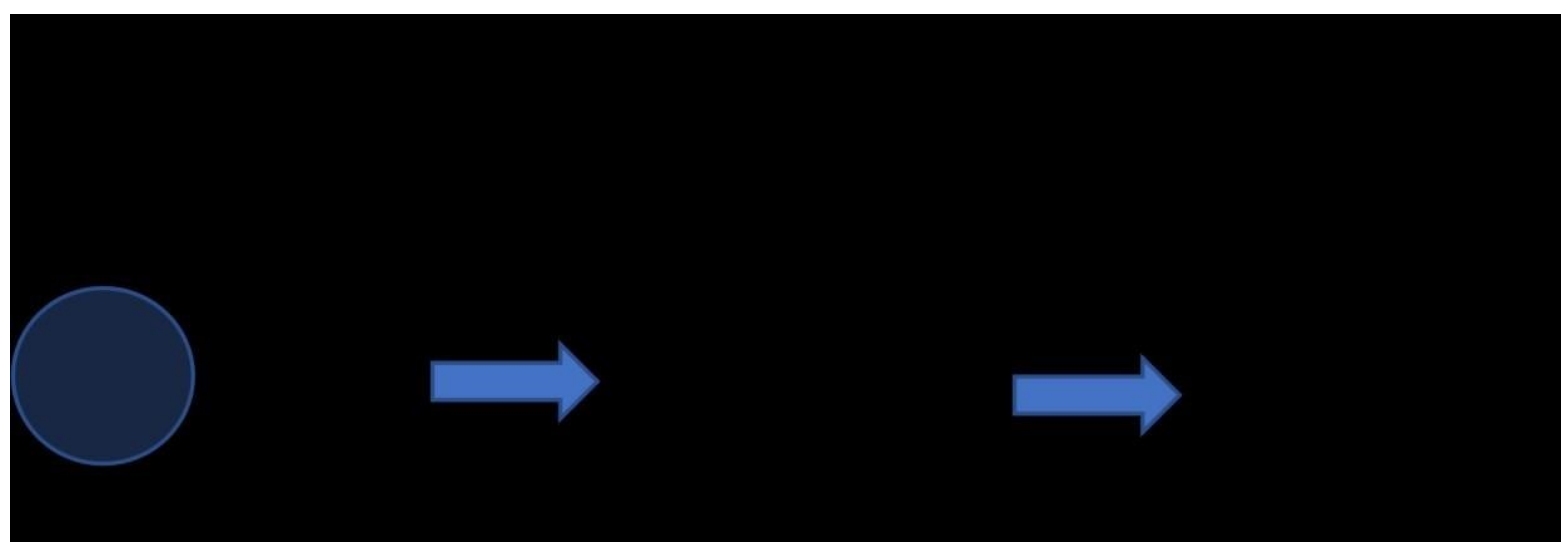

Figura 13: Planejamento dos análogos FS440 e FS441 baseado na estrutura da tirosina. 
Os novos análogos foram então testados para verificar sua afinidade com o PtPA. Os resultados mostraram que ambos, como esperado, inibiram a enzima em uma concentração de $250 \mu \mathrm{M}$, como pode ser visto na Figura 14.

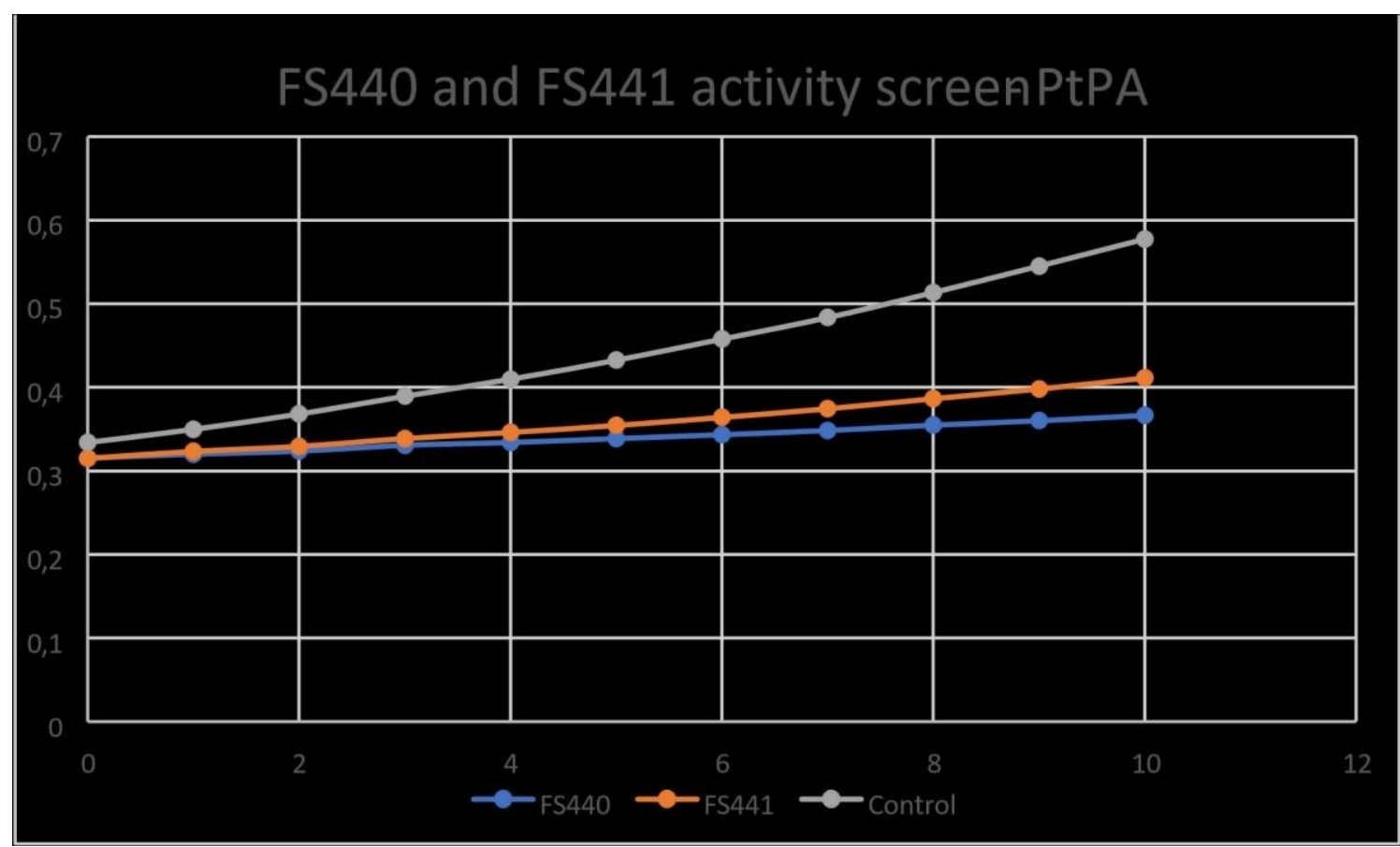

Figura 14: Curva de atividade dos compostos FS440 e FS441 contra PtPA.

Após confirmar que o FS440 e o FS441 podem se ligar ao PtPA, foram calculadso os seus respectivos IC50. Para o FS440, a curva (Figura 15) a curva saiu dentro do esperado e o valor diminuiu substancialmente $(0,065 \mathrm{mM})$. Isso pode indicar que os novos análogos podem se ligar melhor à enzima do que o building block, o que indica um ganho de especificidade. Novos análogos serão desenvolvidos para diminuir ainda mais o valor do IC50. 


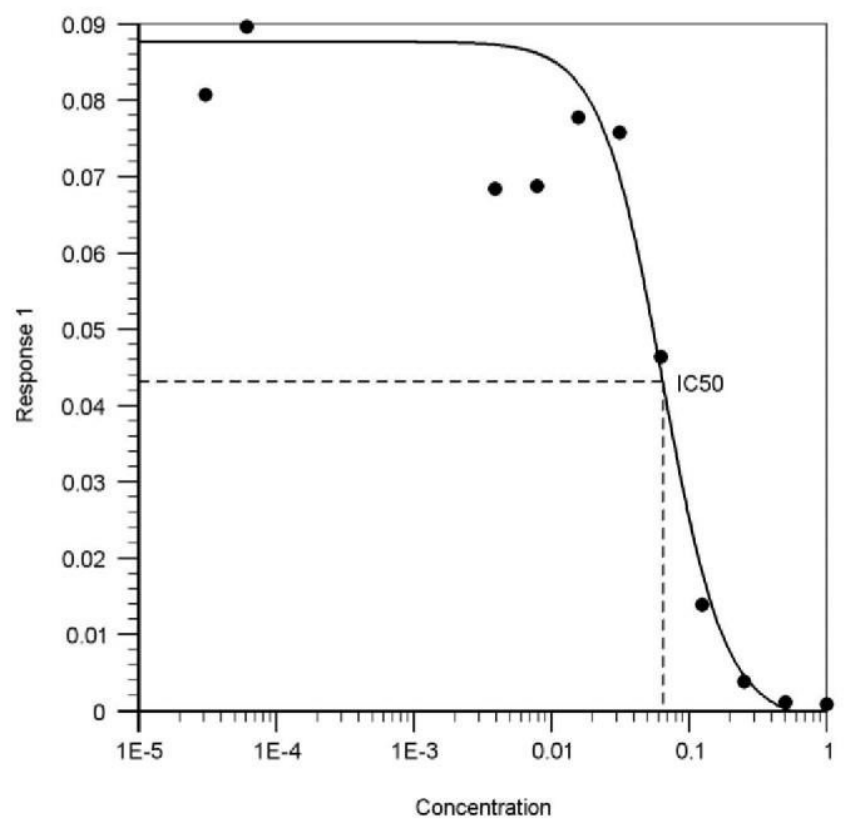

Figura 15: Curva de IC50 para o análogo FS440.

Os ensaios de cristalização não ocorreram como esperado. Os primeiros ensaios usando os kits de cristalização formaram alguns cristais no C12 do kit JCSG. No entanto, após a refração de Raio-X, descobriu-se que eram cristais de zinco e não proteínas. Mesmo as triagens usando o método dos artigos não resultaram na formação de cristais. No entanto, os exames mostraram que as proteínas não sobreviveram em altas concentrações de PEG (acima de 12\% de PEG 6000) e baixo $\mathrm{pH}$ (abaixo de 6,5). Os próximos passos estão tentando cristalizar a proteína e absorver os análogos projetados recentemente (FS440 e FS441) para ajudar a orientar o planejamento das próximas moléculas.

\section{Conclusão e perspectivas}

As bibliotecas de compostos testadas inicialmente indicaram alguns hits que poderiam inibir as enzimas PtPA e PtPB, porém não foi possível indicar que qualquer delas tinham a capacidade de inibir diretamente as fosfatases. Com isso, foi necessário testar se a hipótese de que os compostos derivado de acrilamida podiam reagir covalentemente com a cisteína presente no bolsão catalítico das fosfatases. Assim, testou-se a acrilamida e o building block utilizado na síntese da biblioteca original, além de borato e citrato como possíveis inibidores competitivos. Os resultados mostraram que tanto a acrilamida quanto o building block eram 
capazes de inibir PtPA, porém não PtPB. A partir disso, foram desenhados dois outros compostos utilizando a acrilamida e a estrutura geral da tirosina (FS440 e FS441). Ambos compostos mostraram uma capacidade de inibição de PtPA, e o composto FS440 teve um IC50 abaixo de 0,1 mM, o que é um importante ponto de partida para o planejamento de compostos ainda mais específicos e com uma atividade melhor. Como perspectiva, além do planejamento de melhores análogos está a critalização do PtPA e posteriormente cocristalização dos compostos para auxiliar no desenvolvimento de novas moléculas.

\section{Referências}

CAHTTERJEE, A.; PANDEY, S.; SINGH, P.K.; PATHAK, N.P; RAI, N.; RAMACHANDRAN, R.; TRIPATHI, R.P.; SRIVASTAVA, K.K. Biochemical and functional characterizations of tyrosine phosphatases from pathogenic and nonpathogenic mycobacteria: indication of phenyl cyclopropyl methyl-/phenyl butenyl azoles as tyrosine phosphatase inhibitors. Apllied Microbiology and Biotechnology, v.99, p.7539-7548, 2015.

FAKUNLE, E. S.; LORING, J. F. Ethnically diverse pluripotent stem cells for drug development. Trends in Molecular Medicine, v18, p.709-716, 2012.

GUIDO, R. V. C.; ANDRICOPULO, A. D.; OLIVA, G. Drug design, biotechnology and medicinal chemistry: applications to infectious diseases. Estudos Avançados, v.24, p.81- 98, 2010.

GRUDNER, C.; PERRIN, D.; HUIJSDUIJNEN, H.; SWINNEN, D.; GONZALEZ, J.; GEE, C.L.; WELLS, T.N.; ALBER, T. Structural basis for selective inhibition of Mycobacterium tuberculosis protein tyrosine phosphatase PtpB. Structure, v.15, p.499-509, 2007.

KNECHEL, N.A. Tuberculosis: Pathophysiology, Clinical Features, and Diagnosis. Critical Care Nurse, v.29, p.34-43, 2009

RABAHI, M.F.; JUNIOR, J.L.; FERREIRA, A.C.; TANNUS-SILVA, D.G.; CONDE, M.B. Tratamento da tuberculose. Jornal Brasileiro de Pneumologia, v.43, p.472-486, 2017.

KALYAANAMOORTHY, S.; CHEN Y,P. Structure-based drug design to augment hit discovery. Drug Discovery Today, v.16, p.831-839, 2011.

WAUGH, D.S. Making the most of affinity tags. Trends biotechnology, v. 23, p.316-320, 2005. WHO (World Health Organization). Global tuberculosis report. Switzerland, 2018. 


\section{Anexo III}

Ficha do

Aluno e Cúrriculo Lattes

Fanus - Sistema Administrativo da Pós-Graduação

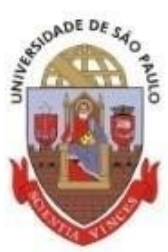

\section{Universidade de São Paulo \\ Faculdade de Ciências Farmacêuticas \\ Documento sem validade oficial \\ FICHA DO ALUNO}

9138 - 7705197/1 - Diego Campos Prieto

\begin{tabular}{|c|c|c|c|c|c|c|c|c|c|}
\hline Sigla & Nome da Disciplina & Inicio & Término & $\begin{array}{l}\text { Carga } \\
\text { Horária }\end{array}$ & Cred. & Freq. & Conc. & Exc. & Situação \\
\hline $\begin{array}{l}\text { FBF5777- } \\
3 / 9\end{array}$ & Tópicos Gerais de Fármaco e Medicamentos I & 03/08/2017 & $15 / 11 / 2017$ & 45 & 3 & 100 & A & N & Concluida \\
\hline $\begin{array}{l}\mathrm{FBF} 5724- \\
8 / 1\end{array}$ & Latenciação & $11 / 09 / 2017$ & 19/11/2017 & 90 & 6 & 100 & A & $\mathrm{N}$ & Concluida \\
\hline $\begin{array}{l}\text { FBF5734- } \\
\quad 8 / 1\end{array}$ & $\begin{array}{l}\text { Mecanismos de Ação dos Fármacos aos Niveis Molecular e } \\
\text { Eletrônico }\end{array}$ & $20 / 02 / 2018$ & $05 / 06 / 2018$ & 90 & 6 & 100 & A & N & Concluida \\
\hline $\begin{array}{l}\text { FBA5728- } \\
4 / 6\end{array}$ & Aprimoramento Pedagógico & $03 / 04 / 2018$ & $30 / 04 / 2018$ & 60 & 4 & 90 & A & N & Concluída \\
\hline$\underset{3 / 1}{\text { BMF } 5871}$ & $\begin{array}{l}\text { Neurobiologia do Envelhecimento \& Hormese e as Doenças } \\
\text { Neurodegenerativas (Instituto de Ciências Biomédicas - } \\
\text { Universidade de São Paulo) }\end{array}$ & 06/08/2019 & $09 / 09 / 2019$ & 120 & 8 & 100 & A & N & Concluída \\
\hline
\end{tabular}

\begin{tabular}{|l|ccc|}
\hline & \multicolumn{2}{|c|}{ Créditos mínimos exigidos } & Créditos obtidos \\
\hline & Para exame de qualificação Para depósito da dissertaçäo & \\
\hline Disciplinas: & 0 & 25 & 27 \\
\hline Estágios: & & 25 & 27 \\
\hline Total: & 0 & 25 & \\
\hline
\end{tabular}

Créditos Atribuidos à Dissertação: 71 

Diego Campos Prieto

ndereco para acessar este CV: http://lattes.cnpq.br/146535968387001

Última atualização do currículo em 18/08/2019

Resumo informado pelo autor

Cursou Farmácia e Bioquímica na Universidade de São Paulo, periodo noturno. Tem experiência na área de química farmacêutica, sendo que de fevereiro de 2013 a Julho de 2014 frequentou o Laboratório de Síntese de Fármacos, com orientaçáo do professor Dr. Roberto Parise Filho. Nesse período,aprimorou sua prática em síntese orgânica aplicada a fármacos, mais especificamente aminação redutiva e alquilação de aminas, realizando experimentos como recristalização, cromatografia em coluna e em camad delgada, leitura de espectros de $13 \mathrm{C} / 1 \mathrm{H}$ RMN. Além disso realizou projetos na área de atenção farmacêutica, mais precisamente em seguimento farmacoterapêutico. Dé janiero a junho de 2019 fez um estágio no laboratório de biologia estrutural da Faculty of Science and Engineering da University of Groningen sob orientação do Prof. Dr. Matthew Groves. Atualmente realiza um projeto na área de Química Farmacêutica com síntese de pró-fármacos dendriméricos para doenças negligenciadas no LAPEN sol orientação da professora doutora Jeanine Giarolla Vargas.

(Texto informado pelo autor)

Nome civil

Nome Diego Campos Prieto

\section{Dados pessoais}

Nascimento 07/03/1993 - São paulo/SP - Bras

CPF $418.601 .518-09$

\section{Formação acadêmica/titulação}

2017 Mestrado em Fármacos e Medicamento

ruiversidade de Sao Paulo, USP, Sao Paulo, Bras

ETICOS POTENIALMENTE ATIVOS EM MALARIA

Orientador: Elizabeth lgne Ferreira (9.)

2011 - 2017 Graduaçào em Farmácia e Bioquimica

Universidade do săo Paul uso sao Paulo Brast

Titulo: PLANEJAMENTO E SINTESE DE PRÓ-FARMACOS DENDRIMERICOS POTENCIALMENTE

ATIVOS EM DOENCCAS NEGLIGENCIADAS

Orientador: Jeanine Giarolla Vargas

2008 - 2010 Ensino Médio (2o grau)

Colegio Stockler, STO, Brasil, Ano de obtençằo: 2010

\section{Atuação profissional}

1. Universidade de São Paulo - USP

\section{Vinculo}

instituciona

2014 - 2015 Vinculo: Bolsista , Enquadramento funcional: Iniciação Cientifica , Carga horária: 6, Regime: Parcial

2013 - 2014 Vinculo: Bolsista , Enquadramento funcional: Iniciação Cientifica , Carga horária: 20, Regime: Dedicaçăo exclusiva

Atividades

08/2014 - 07/2015 Pesquisa e Desenvolvimento, Faculdade de Ciências Farmacềuticas

Linhas de pesquisa:

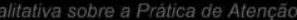

Farmacéutica no Brasil, no periodo de 2002-2014, com foco nos desfechos terapéuticos

01/2013 - 07/2014 Pesquisa e Desenvolvimento, Faculdade de Ciências Farmacêuticas

Linhas de pesquisa:
SINTESEDE ANALOGOS DA QUELERITRINA PLANEJADOS POR SIMPLIFICACÃO MOLECULAR

COMPOTENCIAL INIBICAO DEPROTEINAS DA FAMILA BCL-2

2. University of Groningen - RUG 


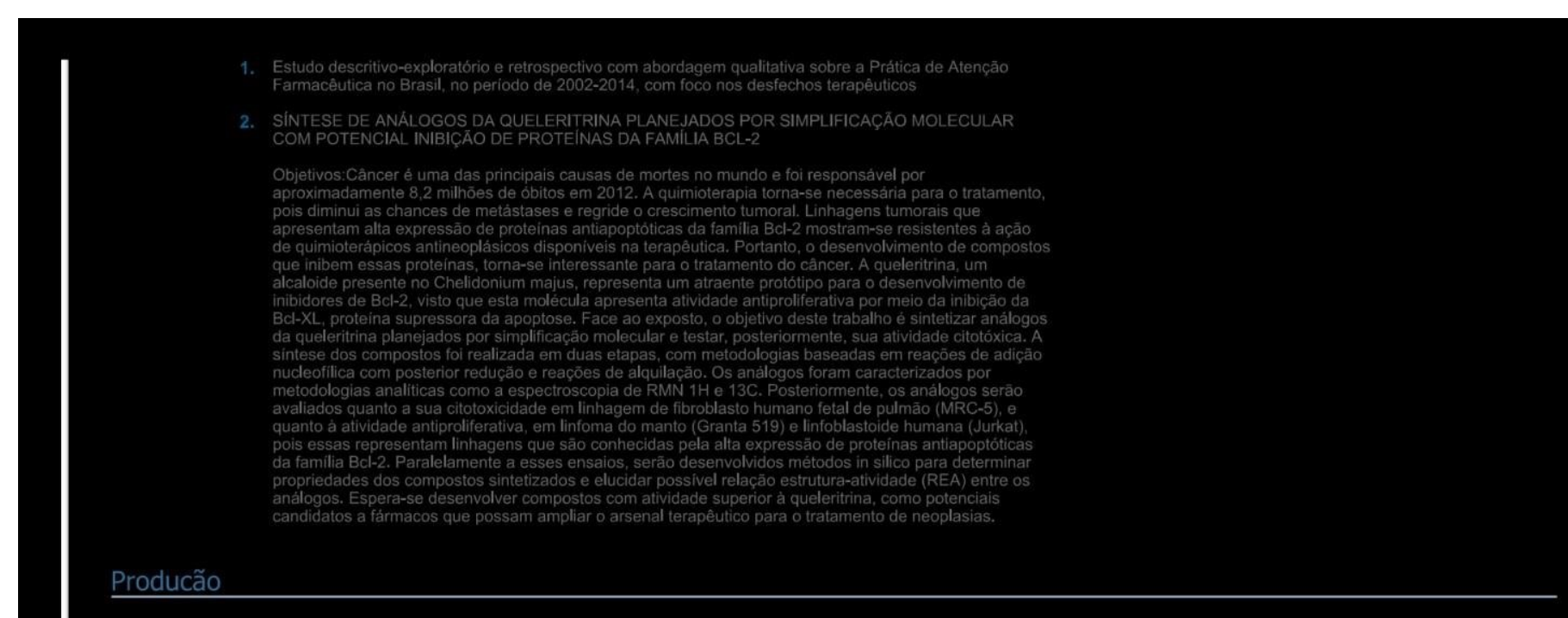

Produção bibliográfica

Artigos completos publicados em periódicos

DOI

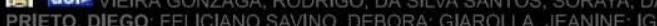

Targeting Groups Employed in Selective Dendrons and Dendrimers. PHARMACEUTICS. JICR

đđII SANTOS, SORAYA SILVA; GONZAGA, RODRIGO VIEIRA: SILVA, JOĀO VITOR; SAVINO

DEBORA FELICIANO PRIETO, DIEGO CAMPOS. SHIKAY IENNIFER MIDORI. SILVA RENAN SOUSA PAULO, LUCAS HENRIQUE DE ALMEIDA; FERREIRA, ELIZABETH IGNE; VARGAS, JEANINE

(ane delivery and other approaches, CANADIAN JOURNAL OF CHEMISTRY Pepi v. 00, p. $1-10,2017$

3. doì TAVARES, MAURICIO T.; TEIXEIRA, SARAH F.; AZEVEDO, RICARDO A.; C. PIETRO, DIEGO C. PIETRO, DIEGO; FERREIRA, ADILSON K.; TROSSINI, GUSTAVO H.G.; BARBUTO, JOSÉ A.M. Toward chelerytinne optimization: Analogues designed by molecular simplification exhibit selective growt inhibition in non-small-cell lung cancer cells. BIOORGANIC \& MEDICINAL CHEMISTRY. JCR V.2
p. $4600-4610,2016$.

Página gerada pelo sistema Curriculo Lattes em 23/01/2020 às 18:34:27 